\title{
Statistical Analysis of Earthquake Ground Motion Parameters
}

Shannon \& Wilson, Inc. and Agbabian Associates

\section{Prepared for}

U. S. Nuclear Regulatory

Commission 


\section{DISCLAIMER}

This report was prepared as an account of work sponsored by an agency of the United States Government. Neither the United States Government nor any agency Thereof, nor any of their employees, makes any warranty, express or implied, or assumes any legal liability or responsibility for the accuracy, completeness, or usefulness of any information, apparatus, product, or process disclosed, or represents that its use would not infringe privately owned rights. Reference herein to any specific commercial product, process, or service by trade name, trademark, manufacturer, or otherwise does not necessarily constitute or imply its endorsement, recommendation, or favoring by the United States Government or any agency thereof. The views and opinions of authors expressed herein do not necessarily state or reflect those of the United States Government or any agency thereof. 


\section{DISCLAIMER}

Portions of this document may be illegible in electronic image products. Images are produced from the best available original document. 


\section{NOTICE}

This report was prepared as an account of work sponsored by an agency of the United States Government. Neither the United States Government nor any agency thereof, or any of their employees, makes any warranty, expressed or implied, or assumes any legal liability or responsibility for any third party's use, or the results of such use, of any information, apparatus product or process disclosed in this report, or represents that its use by such third party would not infringe privately owned rights.

\section{Available from}

GPO Sales Program

Division of Technical Information and Document Control

U. S. Nuclear Regulatory Commission

Washington, D. C. 20555

and

National Technical Information Service

Springfield, Virginia 22161 


\section{Statistical Analysis of Earthquake Ground Motion Parameters}

Manuscript Completed: October 1979

Date Published: December 1979

Shannon \& Wilson, Inc. and

Agbabian Associates

Prepared for

Division of Reactor Safety Research

Office of Nuclear Regulatory Research

U.S. Nuclear Regulatory Commission

Washington, D.C. 20555

NRC FIN No. B3015 
-

- 


\section{PREFACE}

This report describes a statistical investigation of ground motion parameters that has been carried out by the Shannon \& Wilson/Agbabian Associates (SW/AA) joint venture under Contract No. NRC-04-76-200 with the United States Nuclear Regulatory Commission. The work was performed during the time period extending from September 1978 through October 1979.

The project manager for the SW/AA joint venture is R.P. Miller of Shannon \& Wilson, Inc. Project engineer for Agbabian Associates is S.D. Werner. Principal investigator for this study was H.S. Ts'ao of Agbabian Associates. The statistical analyses were performed by D. Rothman of Agbabian Associates. J. Harbour of the United States Nuclear Regulatory Commission has served as technical monitor to the joint venture. 
○

(1) 
Several earthquake ground response parameters that define the strength, duration, and frequency content of the motions are investigated using regression analyses techniques; these techniques incorporate statistical significance testing to establish the terms in the regression equations. The parameters investigated are the peak acceleration, velocity, and displacement; Arias intensity; spectrum intensity; bracketed duration; Trifunac-Brady duration; and response spectral amplitudes. The study provides insight into how these parameters are affected by magnitude, epicentral distance, local site conditions, direction of motion ( $1 . e$. , whether horlzontal or vertical), and earthquake event type. The results are presented in a form so as to facilitate their use in the development of seismic input criteria for nuclear plants and other major structures. They are also compared with results from prior investigations that have been used in the past in the criteria development for such facilities. 
-

- 
SUMMARY

This study uses regression analysis procedures to investigate how ground response parameters are influenced by variations in magnitude, epicentral distance, local site conditions, direction of motion (i.e., whether horizontal or vertical) and earthquake event type. The several ground response parameters investigated define the strength of the shaking (peak acceleration, velocity, and displacement; Arias intensity; and spectrum intensity), the duration of strong shaking (bracketed duration and TrifunacBrady duration), and the frequency content (response spectral amplitudes at 32 frequencies between $0.067 \mathrm{~Hz}$ and $25 \mathrm{~Hz}$ ). For each parameter, statistical significance testing techniques are used to establish each term in the regression equation. Results from each regression equation are presented in three parts: (1) comparisons with recorded data, (2) parametric effects, and (3) comparisons with results from prior studies.

The most important results and conclusions from this study are as follows :

1. The shapes of the response spectra developed from this study are not fixed as per the currently common assumption in the development of seismic input criteria. Rather, they vary with magnitude, epicentral distance, site conditions, and earthquake event type. Such variations are important and should be considered in design applications.

2. At frequencies of interest for nuclear plant design $(>1.5 \mathrm{~Hz})$, the Regulatory Guide ( $R G) 1.60$ spectra for vertical motion are typically very conservative when compared to the 84 th percentile spectra from this study. This conservatism is most pronounced for rock sites and is small or nonexistent only for certain deep soil site results. Therefore, since many nuclear plants are constructed on rock or intermediate soil sites, the current RG 1.60 provisions for developing vertical 
ground response spectra should be reassessed. Similar comparisons between RG 1.60 and this study for horizontal motion are dependent on the particular magnitude, distance, and site conditions being considered; typically, the RG 1.60 results fall between the 50 th and 84 th percentile results for horizontal motion at frequencies above $1.5 \mathrm{~Hz}$.

3. The effects of local soil conditions are significant for all parameters investigated except peak acceleration and bracketed duration. Deep soil sites exhibit the largest values of the parameters, followed in order by intermediate and rock sites. This suggests that, to minimize applied ground motions, it is most advantageous to construct nuclear plants and other major structures on rock sites.

4. The rate of attenuation with distance of the ground motion strength parameters is dependent on the type of earthquake event being considered. The San Fernando earthquake parameters exhibit a faster attenuation rate than do the composite parameters from all other earthquake events. Also, the response spectra results indicate that low frequency spectral amplitudes attenuate more slowly with distance than do intermediate and high frequency amplitudes.

5. There are significant differences in the trends exhibited by the bracketed duration and the Trifunac-Brady duration, because of their differing interpretations of the duration of strong shaking. For example, the bracketed duration increases with magnitude, decreases with distance, is influenced by the earthquake event type, and is independent of local site conditions. The Trifunac-Brady duration, on the other hand, is independent of magnitude, increases with distance, is independent of earthquake event type, and is dependent on local site conditions. 


\section{CONTENTS}

Chapter

$\underline{\text { Page }}$

1

INTRODUCTION AND DETAILED SUMMARY . . . . . . . 1-1

1.1 Background Information ......... 1-1

1.2 Purpose and Scope .. . . . . . . . . 1-2

1.3 Report Organization ........ . . 1-4

1.4 Detailed Summary ........... 1-4

1.5 Recommendations for Future Work..... . 1-11

2 DATA BASE, CLASSIFICATION, AND ANALYSIS

PROCEDURES ................ 2- 2

2.1 CIT Data Base............. 2-1

2.2 Accelerograph Site Classifications . . . 2-2

2.3 Statistical Analysis Procedure . . . . 2-7

3 STRENGTH PARAMETERS ............. 3-1

3.1 General Discussion . . . . . . . 3-1

3.2 Regression Analysis . . . . . . . 3-3

3.3 Comparisons with Recorded Data . . . . 3-5

3.4 Parametric Effects . . . . . . . . 3-6

3.5 Comparisons with Results from other Studies 3-7

4 DURATION OF STRONG SHAKING ......... 4-1

4.1 General Discussion ......... 4-1

4.2 Regression Analysis......... . 4-2

4.3 Comparisons with Recorded Data . . . . 4-3

4.4 Parametric Effects ......... 4-5

4.5 Comparisons with Results from other Studies 4-8

5 RESPONSE SPECTRA .............. . 5-1

5.1 General Discussion ......... 5-1

5.2 Regression Analysis . . . . . . . . 5-2

5.3 Comparisons with Recorded Data . . . . 5-3

5.4 Parametric Effects . . . . . . . . 5-6

5.5 Comparisons with Current Design Practice . 5-10 
CONTENTS (CONTINUED)

Chapter
6 REFERENCES .................. $6-1$

Appendix

A MULTIPLE LINEAR REgRESSION ANALYSIS . . . . . . A-1

B USE OF THEORETICAL SOURCE MECHANISM STUDIES IN DEFINING DISTANCE-ATTENIUATION RELATIONSHIPS . . . B-1

TABLES

Table

2-1 Summary of Site Classifications........ 2-10

3-1 Regression Coefficients for Strength Parameters . 3-12

3-2 Outliers from Regression Analyses of Strength

Parameters ............. 3-13

3-3 Data-Fit Parameters--Strength of Ground Shaking . 3-14

4-1 Regression Coefficients for Duration Parameters . 4-10

4-2 Data-Fit Parameters--Duration of Strong

Shaking................ 4-11

4-4 Relative Effects of Magnitude on Trifunac-Brady

Duration (TBD) ............. . . 4-13

5-1 Regression Coefficients for Response Spectral

Amplitudes .............. 5-16

5-2 Outliers from Regression Analyses of Spectral

Amplitudes at Frequencies of $0.067 \mathrm{~Hz}, 1.18 \mathrm{~Hz}$,

and $25.0 \mathrm{~Hz}$................ 5-17

5-3 Data-Fit Parameters--Spectral Amplitudes at
Frequencies of $0.067 \mathrm{~Hz}, 1.18 \mathrm{~Hz}$, and $25.0 \mathrm{~Hz}$. 5-18 


\section{ILLUSTRATIONS}

Figure

Page

2-1 Site Classification Procedure Used in this Study 2-11

2-2 Probability Distributions for Sites with Undefined and Defined Classifications... . 2-12

3-1 Comparison between Computed and Recorded Peak Accelerations--Type 1 Earthquake Events . . . 3-15

3-2 Comparison between Computed and Recorded Peak Accelerations--Type 2 Earthquake Events with Magnitude 5.4............. 3-16

3-3 Comparison between Computed and Recorded Peak Accelerations--Type 2 Earthquake Events with Magnitude 6.4.............. 3-17

3-4 Comparison between Computed and Recorded Peak Accelerations--Type 2 Earthquake Events with Magnitude 7.7 ............... 3-18

3-5 Comparison between Computed and Recorded Peak Velocities for Various Site Conditions--Type 1 Earthquake Events............ 3-19

3-6 Comparison between Computed and Recorded Peak Velocities for Various Site Conditions--Type 2 Earthquake Events with Magnitude 5.4... . 3-20

3-7 Comparison between Computed and Recorded Peak Velocities for Various Site Conditions--Type 2 Earthquake Events with Magnitude 6.4 . . . . 3-21

3-8 Comparison between Computed and Recorded Peak Velocities for Various Site Conditions--Type 2 Earthquake Events with Magnitude 7.7 . . . . 3-22

3-9 Comparison between Computed and Recorded Peak Displacements for Various Site Conditions--Type 1 Earthquake Events ... . . . . . . . 3-23

3-10 Comparison between Computed and Recorded Peak Displacements for Various Site Conditions--Type 2 Earthquake Events with Magnitude 5.4 . . . . . 3-24

3-11 Comparison between Computed and Recorded Peak Displacements for Various Site Conditions--Type 2 Earthquake Events with Magnitude 6.4... . . 3-25 


\section{ILLUSTRATIONS (CONTINUED)}

Figure

Page

3-12 Comparison between Computed and Recorded Peak Displacements for Various Site Conditions--Type 2 Earthquake Events with Magnitude 7.7 . . . . 3-26

3-13 Comparison between Computed and Recorded Arias Intensities for Various Site Conditions--Type 1 Earthquake Events . . . . . . . . . . 3-27

3-14 Comparison between Computed and Recorded Arias Intensities for Various Site Conditions--Type 2 Earthquake Events with Magnitude 5.4 . . . . 3-28

3-15 Comparison between Computed and Recorded Arias Intensities for Various Site Conditions--Type 2 Earthquake Events with Magnitude 6.4 . . . . 3-29

3-16 Comparison between. Computed and Recorded Arias Intensities for Various Site Conditions--Type 2 Earthquake Events with Magnitude 7.7 . . . . 3-30

3-17 Comparison between Computed and Recorded Spectrum Intensities for Various Site Conditions--Type 1

Earthquake Events............ 3-31

3-18 Comparison between Computed and Recorded Spectrum Intensities for Various Site Conditions--Type 2

Earthquake Events with Magnitude 5.4. . . . 3-32

3-19 Comparison between Computed and Recorded Spectrum Intensities for Various Site Conditions--Type 2

Earthquake Events with Magnitude 6.4... . 3-33

3-20 Comparison between Computed and Recorded Spectrum Intensities for Various Site Conditions--Type 2

Earthquake Events with Magnitude 7.7 . . . . 3-34

3-21 Effect of Earthquake Event Type on Peak Accelerations . . . . . . . . . . 3-35

3-22 Effect of Earthquake Event Type on Peak Velocities . . . . . . . . . . . 3-36

3-23 Effect of Earthquake Event Type on Peak Displacements... . . . . . . . . . . 3-37 


\section{ILLUSTRATIONS (CONTINUED)}

Figure

Page

3-24 Effect of Earthquake Event Type on Arias Intensities............ . . 3-38

3-25 Effect of Earthquake Event Type on Spectrum Intensities............ . . 3-39

3-26 Effect of Magnitude on Peak Accelerations . . . 3-40

3-27 Effect of Magnitude on Peak Velocities . . . . 3-41

3-28 Effect of Magnitude on Peak Displacements . . . 3-42

3-29 Effect of Magnitude on Arias Intensities . . 3-43

3-30 Effect of Magnitude on Spectrum Intensities . . 3-44

3-31 Comparison between Horizontal and Vertical Peak

Accelerations............ 3-.. 35

3-32 Comparison between Horizontal and Vertical Peak Velocities............ 3-46

3-33 Comparison between Horizontal and Vertical Peak

Displacements.......... . . . 3-47

3-34 Comparison between Horizontal and Vertical Arias

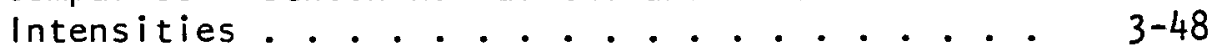

3-35 Comparison between Horizontal and Vertical

Spectrum Intensities .......... . 3-49

3-36 Comparison between Peak Horizontal Acceleration

Results from This Study and from Prior

Investigations for Magnitude 6.5 Earthquakes . . 3-50

3-37 Comparison of Peak Acceleration Results from This Study with Those of Trifunac (1976). . . . . 3-51

3-38 Comparison of Peak Horizontal Acceleration Results from This Study with Those of McGuire (1978) ................ 3-... 32

3-39 Comparison of Peak Horizontal Velocity Results from This Study with Those of Duke et al. (1976) for San Fernando Earthquake... . . . . . 3-53 


\section{ILLUSTRATIONS (CONTINUED)}

Figure

Page

3-40 Comparison of Peak Horizontal Velocity Results

from This Study with Those of Seed et al. (1976)--

Magnitude 6.5, 50th Percentile ....... 3-54

3-41 Comparison of Peak Velocity Results from This

Study with Those of Trifunac (1976) . . . . . 3-55

3-42 Comparison of Peak Horizontal Velocity Results

from This Study with Those of McGuire (1978) . 3-56

3-43 Comparison of Peak Displacement Results from This Study with Those of Trifunac (1976) . . . . . 3-57

3-44 Comparison of Peak Horizontal Displacement Results from This Study with Those of McGuire (1978)

3-45 Comparison of Arias Intensity Results from This Study with Those of Trifunac and Brady (1975b) . 3-59

4-1 Definitions of Duration of Strong Shaking Considered in This Study ........... 4-14

4-2 Comparison between Computed and Recorded Bracketed Durations--Type 1 Earthquake Events . 4-15

4-3 Comparison between Computed and Recorded Bracketed Durations--Type 2 Earthquake Events with Magnitude 5.4........... 4-16

4-4 Comparison between Computed and Recorded

Bracketed Durations--Type 2 Earthquake Events with Magnitude 6.4.......... . . 4-17

4-5 Comparison between Computed and Recorded Bracketed Durations--Type 2 Earthquake Events with Magnitude 7.7 ............. 4-18

4-6 Comparison between Computed and Recorded TrifunacBrady Durations for Various Site Conditions . . 4-19

4-7 Effects of Magnitude and Distance on Bracketed Duration ................ 4-..20 


\section{ILLUSTRATIONS (CONTINUED)}

Figure

Page

4-8 Effects of Earthquake Event Type on Bracketed

Duration . . . . . . . . . . . . . .

4-9 Comparison of Bracketed Durations of Horizontal

and Vertical Motions .......... . 4-22

4-10 Effects of Local Site Conditions on Trifunac-

Brady Duration . . . . . . . . . . .

4-11 Comparison of Trifunac-Brady Durations for Horizontal and Vertical Motions....... 4-24

4-12 Effects of Magnitude on Trifunac-Brady Duration - 4-25

4-13 Comparison of Trifunac-Brady Durations from This Study and from Trifunac-Brady (1975b).... . 4-26

5-1 Comparison between Computed and Recorded Ground Response Spectra for Type 1 Earthquake Event

(111 N. Hope, 1971) . . . . . . . . . . .

5-2 Comparison between Computed and Recorded Ground Response Spectra for Type 1 Earthquake Event

(15250 Ventura Blvd., 1971) ........ 5-20

5-3 Comparison between Computed and Recorded Ground Response Spectra for Type 1 Earthquake Event

(3345 Wilshire Blvd., 1971) .........

5-4 Comparison between Computed and Recorded Ground Response Spectra for Type 1 Earthquake Event

(Castaic, 1971) . . . . . . . . . . . .

5-5 Comparison between Computed and Recorded Ground Response Spectra for Type 1 Earthquake Event (Lake Hughes No. 4, 1971) . . . . . . . . . .

5-6 Comparison between Computed and Recorded Ground Response Spectra for Type 1 Earthquake Event (Pacoima Dam, 1971) . . . . . . . . . .

5-7 Comparison between Computed and Recorded Ground Response Spectra for Type 1 Earthquake Event (Millikan Library, 1971) 


\section{ILLUSTRATIONS (CONTINUED)}

Figure

Page

5-8 Comparison between Computed and Recorded Ground Response Spectra for Type 2 Earthquake Event

(Taft Lincoln School, 1952) ......... 5-26

5-9 Comparison between Computed and Recorded Ground Response Spectra for Type 2 Earthquake Event

(0lympia Highway Test Laboratory, 1949). . . . 5-27

5-10 Comparison between Computed and Recorded Ground Response Spectra for Type 2 Earthquake Event (Golden Gate Park, 1957) .......... 5-28

5-11 Comparison between Computed and Recorded Ground Response Spectra for Type 2 Earthquake Event

(El Centro Terminal Substation, 1940) . . . . .

5-12 Comparison between Computed and Recorded Ground Response Spectra for Type 2 Earthquake Event (Jet Propulsion Laboratory, 1968) . . . . . . 5-30

5-13 Comparison between Computed and Recorded Ground Response Spectra for Type 2 Earthquake Event (Ferndale, 1941) ............ 5-31

5-14 Effect of Earthquake Event Type on Horizontal Ground Response Spectra . . . . . . . . . .

5-15 Effect of Earthquake Event Type on Vertical Ground Response Spectra . . . . . . . . . .

5-16 Distance Attenuation of Horizontal and Vertical Ground Response Spectra for Types 1, 2, and 3 Earthquake Events............. 5-34

5-17 Effect of Magnitude on Horizontal Ground Response Spectra............... . . 5-35

5-18 Effect of Magnitude on Vertical Ground Response Spectra................. 5-36

5-19 Distance Attenuation of Horizontal and Vertical Ground Response Spectra for Type 3 Earthquakes with Various Magnitude Levels . . . . . . . . . 


\section{ILLUSTRATIONS (CONCLUDED)}

Figure

$\underline{\text { Page }}$

5-20 Effect of Site Conditions on Ground Response

Spectra ............ . . 5-38

5-21 Comparison between Horizontal and Vertical Ground Response Spectra ........... 5-39

5-22 Comparison of Spectra from RG 1.60 and from This Study for Magnitude 5.0 Earthquakes...... 5-40

5-23 Comparison of Spectra from RG 1.60 and from This Study for Magnitude 6.5 Earthquakes... . . . 5-41

5-24 Comparison of Spectra from RG 1.60 and from This Study for Magnitude 8.0 Earthquakes... . . 5-42

5-25 Comparison of Spectra from RG 1.60 and from This Study for Various Site Conditions--Horizontal Motions............... . 5-43

5-26 Comparison of Spectra from RG 1.60 and from This Study for Various Site Conditions--Vertical Motions............... . . 5-44

5-27 Comparison of Seed-Ugas-Lysmer (SUL) Spectra to Spectra from This Study--Deep Soil Sites . . . 5-45

5-28 Comparison of Seed-Ugas-Lysmer (SUL) Spectra to Spectra from This Study--Intermediate Sites... 5-46

5-29 Comparison of Seed-Ugas-Lysmer (SUL) Spectra to Spectra from This Study--Rock Sites....... 
CHAPTER 1

INTRODUCTION AND DETAILED SUMMARY

\subsection{BACKGROUND INFORMATION}

An important aspect of the seismic design of any major facility is the definition of the seismic input criteria. Such criteria, most typically in the form of peak motions and ground response spectra, can be defined using either site-independent or site-dependent techniques. As defined in SW/AA (1975), site-independent techniques correspond to the use of ground motion parameters from records at a variety of sites whose regional and local geologic environment does not necessarily correspond in any way to that of the site under investigation. The Regulatory Guide (RG) 1.60 spectrum shapes that are widely used in nuclear plant applications have been developed from such an ensemble of records and therefore correspond to a site-independent technique (USAEC, 1973). Site-dependent techniques, on the other hand, utilize information that corresponds in some way to the geologic characteristics of the site. Such techniques may include the use of analytical models (e.g., Schnabel et al, 1972), site-matched records (e.g., Guzman and Jennings, 1976) or results from regression analyses of ensembles of strong motion records (e.g., McGuire, 1978)

of the various site-dependent techniques, the particular method that has received the greatest developmental emphasis in recent years has been the regression analysis approach. The approach involves the following three steps:

1. Definition of a particular set of dependent parameters (e.g., peak motion) from an ensemble of strong motion records

2. Formulation of a regression equation that relates the dependent parameter to a set of independent variables (e.g., magnitude, distance, site conditions, etc.)

3. Use of least-squares techniques to fit this equation to the data. The advantage of this approach is that it utilizes existing recorded motions to provide a means for estimating how ground response parameters are influenced 
by a set of variables that are related to the geologic environment for a site. Such information is valuable for use in the development of seismic input criteria for the site of a major facility.

There has been a multitude of different regression analyses of earthquake motion parameters in recent years (see summary by Idriss, 1978). The majority of the analyses have dealt with peak motion (i.e., acceleration, velocity, and displacement) and how it has been affected by such parameters as magnitude, distance, site conditions, intensity, and direction of shaking (e.g., Esteva, 1970; Donovan, 1973; Trifunac and Brady, 1975a; Duke et al, 1976; Seed et al, 1976; Trifunac, 1976; and McGuire, 1978). However, studies have also been made of the duration of strong shaking (e.g., Bolt, 1973; Trifunac and Brady, 1975b; Dobry, Idriss, and $\mathrm{Ng}, 1978$ ) and the spectral content of ground shaking (Seed, Ugas, and Lysmer, 1976; Trifunac, 1977; Werner and Ts'ao, 1978; McGuire, 1978). These studies have yielded estimates of ground motion parameters that agree fairly well within the range of independent variables encompassed by the currently existing strong motion data; however, beyond this range, these estimates vary widely because of differences in the data base, regression equation form, parameter definitions, analysis procedures, and site classifications used in the various investigations.

\subsection{PURPOSE AND SCOPE}

The purpose of this study is to carry out regression analyses of a multitude of different ground response parameters, including peak acceleration, velocity, and displacement; Arias intensity; spectrum intensity; duration of strong shaking; and response spectral amplitudes. Multiple linear regression analyses are carried out to determine how each of these parameters is affected by magnitude, epicentral distance, site conditions, direction of motion (i.e., whether horizontal or vertical), and earthquake event type. Results from this study are intended to provide guidance and information for use in developing seismic input criteria for use in the design of major facilities. 
This study differs in the following important ways from the prior investigations noted in Section 1.1 .

a. A large number of ground response parameters is analyzed using a common large data base in a consistent way, so as to permit comparison of their relative characteristics (e.g., their magnitude dependence, distance attenuation rates, etc.)

b. The site classifications of the various records are based on actual geotechnical investigations carried out at the strong motion accelerograph sites by the Shannon $\&$ Wilson/Agbabian Associates joint venture (SW/AA). The information from these investigations was developed only over the past few years and was therefore not available when many of the prior investigations of local site effects was carried out (SW/AA, 1976; $1977 a, b ; 1978 a, b, c)$.

c. In addition to considering magnitude, distance, site, and directional effects, the study also identifies different types of earthquake events from the data and investigates distinguishing features of their ground response characteristics. The earthquake events considered are

Type 1: San Fernando earthquake

Type 2: All earthquakes except San Fernando

Type 3: All earthquakes including San Fernando

The consideration of this variable in this way illustrates how the large amount of data from the San Fernando earthquake has influenced the composite ground response characteristics now being used to develop seismic input criteria for nuclear plants and other major structures.

d. The analysis procedure used to carry out the study incorporates statistical significance testing techniques to establish each term in the regression equation. 


\subsection{REPORT ORGANIZATION}

This report is organized into five main chapters and two appendices. The remainder of this first chapter contains a detailed summary of the results of the study, and recommendations for future work along these lines. Chapter 2 describes the data base, accelerograph site classifications, and statistical analysis procedures used to carry out the study. Chapters 3 through 5 contain the regression analysis results for the strength parameters (i.e., peak motions, spectrum intensity, and Arias intensity), the duration of strong shaking, and the response spectral amplitudes, respectively. Appendices A and B provide background information regarding the regression analysis procedures used in this study and source mechanism studies used in the development of distanceattenuation relationships.

\subsection{DETAILED SUMMARY}

This section contains a detailed summary of the procedures and results from this study. A more concise summary is provided at the beginning of this report.

\subsubsection{REGRESSION ANALYSIS PROCEDURES. (CHAP. 2 AND APP. A)}

The study uses multiple linear regression analysis techniques to study how various strength and duration parameters and response spectral amplitudes are affected by magnitude, distance, site conditions, direction of shaking and earthquake event type. The techniques consist of the following steps: (1) form the basic regression equation; (2) determine the regression coefficients using least-squares fitting techniques; (3) use a step-down algorithm to assure that only statistically-significant terms are retained in the regression equation; (4) further investigate particularly significant variables by adding cross products and higher order terms to the regression equation and repeating Steps 1 to 3; and (5) when the final regression equation is defined, compute data-fit parameters and identify outliers. It is noted that the step-down algorithm in Step 3 uses an F-test to eliminate statistically insignificant terms--which are terms whose F-value falls below the 95 th percentile on the F-distribution. 


\subsubsection{STRENGTH PARAMETERS (CHAP. 3)}

\subsubsection{Comparisons with Measured Data}

The peak acceleration, velocity, and displacement; spectrum intensity; and Arias intensity have all been investigated using multiple linear regression equations with the same basic form. For each parameter, visual comparisons with data points from measured records have been made, and data-fit parameters (standard deviation, coefficient of variation, and correlation coefficient) have been obtained to quantitatively show the scatter in the data and how well the regression equations fit the data. These results show that, of the various strength parameters, the Arias intensity regression exhibits the most favorable fit, and the peak displacement regression shows the poorest fit.

\subsubsection{Parametric Effects}

\section{a. Site Conditions}

The effects of local site conditions are statistically insignificant for peak acceleration. For the remaining strength parameters, site effects are significant; the largest values of the strength parameters are exhibited by deep soil sites, followed in order by intermediate sites and rock sites.

\section{b. Magnitude}

The values of all strength parameters increase with increasing magnitude at a successively decreasing rate. 
c. Earthquake Event Type

The rate of attenuation with distance for each of the strength parameters is much faster for Type 1 (San Fernando earthquake) events than for Type 2 (other than San Fernando earthquake) events. Also, at distances less than $80 \mathrm{~km}$, the Type 1 events result in higher values of the varlous strength parameters than do the Type 2 events; at longer distances, the opposite is true. In all cases, the Type 3 (all earthquake) events represent a condition that is intermediate between that of Type 1 and Type 2.

d. Horizontal vs. Vertical Motion

For all of the strength parameters, the horizontal motion exceeds the vertical motion. The common assumption that the vertical motion is two-thirds of the horizontal motion (which is used primarily for peak acceleration) is conservative in all cases.

\subsubsection{Comparison with Other Results}

Results from these regression analyses have been compared with several other sets of results by other investigators. As expected, it is seen that at those magnitude-distance ranges for which substantial data exist, all of the various results agree reasonably well; outside of this range, agreement is poor. Of particular significance is that peak acceleration results by Trifunac (1976) and MeGuire (1978) show only very small effects of local site conditions. This supports the results from the present study which show that local site effects on peak acceleration are statistically insignificant and therefore can be neglected.

\subsubsection{DURATION OF STRONG SHAKING (CHAP. 4)}

There are several definitions of duration of strong shaking currently in existence. All of the definitions involve markedly different interpretations of this duration quantity and therefore lead to different 
results and trends from regression analyses. Two of the more widely used definitions are considered in this study - the bracketed duration (based on a threshold acceleration of $0.05 \mathrm{~g}$ ) and the Trifunac-Brady (1975b) duration.

\subsubsection{Comparisons with Measured Data}

Both the bracketed duration (BD) and the Trifunac-Brady duration (TBD) have been analyzed using multiple linear regression analysis techniques. The regression equations developed for the $B D$ and $T B D$ are seen to differ markedly because of their differing interpretations of the duration of strong shaking. Visual comparisons with measured data and datafit parameters both indicate that the $B D$ data are much more scattered.

\subsubsection{Parametric Effects}

\section{a. Site Conditions}

The effects of local site conditions on the $B D$ are statistically insignificant. For the TBD, however, local site effects are significant, with deep soil sites having the largest TBD's, followed by intermediate and rock sites.

\section{b. Magnitude}

The BD's increase with Increasing magnitude; these magnitude effects are seen to increase with decreasing epicentral distance. The effects of magnitude on the TBD are statistically insignificant and can be neglected.

\section{c. Epicentral Distance}

Significant BD's occur only at epicentral distances less than 60 to $70 \mathrm{~km}$; within this distance range, the $B D$ 's decrease with increasing distance. For the TBD's, however, the opposite trend occurs whereby a increase in TBD with increasing epicentral distance is observed. These differing trends are related to the differing phenomena represented by the $B D$ and $T B D$. The $T B D$ is particularly sensitive to dispersion effects 
which tend to spread the strong motion segment of the ground shaking as the epicentral distance increases. The BD, on the other hand is related to the strength of the ground shaking, which decreases with increasing distance.

\section{d. Earthquake Event Type}

Within the distance range at which significant BD's occur, the Type 1 earthquake events exhibit larger BD's and decay faster with distance than do the Type 2 events. The BD's for the Type 3 events are intermedlate between Type 1 and Type 2. For the TBD, the effects of earthquake event type are statistically insignificant.

\section{e. Horizontal vs. Vertical Motion}

The BD's for horizontal motion exceed those for vertical motion by an amount that increases as the magnitude increases; only at small magnitudes $(\approx 5.0)$ is the BD for vertical motion larger. However, the TBD for vertical motion always exceeds that for horizontal motion.

\subsubsection{Comparisons with Other Results}

The TBD's from the present study are seen to compare well to those from the original study by Trifunac and Brady (1975b). No suitable $B D$ results by other investigators are now available for comparison with the results of the present study.

\subsubsection{RESPONSE SPECTRAL AMPLITUDES (CHAP. 5)}

This study of response spectral amplitudes has consisted of separate regression analyses of 5\%-damped pseudovelocities at 32 freguencies between $0.067 \mathrm{~Hz}$ and $25.0 \mathrm{~Hz}$. Response spectra corresponding to appropriate percentiles have been formed from the results of this analysis. The direct determination of response spectra in this way has several important advantages over the present design practice, which involves the scaling of a fixed spectrum shape according to some peak acceleration level. 


\subsubsection{Comparisons with Measured Data}

To indicate the adequacy of the regression analysis model, response spectrum results are computed for combinations of magnitudes, distances, site conditions, and earthquake event types for which recorded data exist. The computed results are then compared to spectra from the measured records; this comparison is carried out for 7 sets of spectra from the San Fernando earthquake (Type 1 event) and 6 sets of spectra from other earthquakes besides San Fernando (Type 2 events). The comparisons are, on the whole, quite satisfactory and are somewhat better for the Type 1 than the Type 2 events. This is because the Type 1 event represents a single earthquake whereas the Type 2 results are developed using data from a multitude of different earthquakes, each with its own unique source mechanism and propagating wave characteristics; therefore, there is more scatter in the Type 2 results than in the Type 1 results. Also of interest is the fact that the poorest comparisons involving the Type 1 results are those involving the low frequency components of the Castaic and Lake Hughes No. 4 spectra. These spectra are from data recorded north of the causative fault for the San Fernando earthquake, whereas the regression analysis results are most heavily influenced by the predominant amount of San Fernando data recorded south of the fault, or in the direction of its thrusting action. Conceivably, differing characteristics of the seismic waves propagating north and south of the fault could account for the differences in spectra noted above.

\subsubsection{Parametric Effects}

\section{a. General}

The shapes of the response spectra developed from this study are seen to be not fixed as per the currently common assumption in the development of seismic imput criteria. Rather, they vary with magnitude, epicentral distance, site conditions and earthquake event type. Such variations are important and should be considered in design applications. 


\section{b. Site Conditions}

At low and intermediate frequencies, deep soil sites exhibit the largest spectral amplitudes, followed in order by the intermediate and rock sites. At high frequencies, deep soil sites still have greater spectral amplitudes, and there are no statistically significant differences between the spectra for intermediate and rock sites. These site-dependent effects become more prominent with increasing epicentral distance, particularly at high frequencies.

\section{c. Magnitude}

The response spectral amplitudes at all frequencies increase with increasing magnitude at a successively decreasing rate.

\section{d. Earthquake Event Type}

The effects of earthquake event type on the spectral amplitudes are dependent on epicentral distance. At short distances, spectra from the Type 1 earthquakes exhibit larger spectral amplitudes than those of Type 2 , and have a markedly different shape. At long distances, the effects of the earthquake event type are negligible. The Type 3 results are intermediate between those of Types 1 and 2 .

\section{e. Epicentral Distance}

The rate of attenuation of the response spectral amplitudes with increasing epicentral distance is seen to be dependent on frequency and on earthquake event type. For Type 2 earthquakes, the low-frequency spectral amplitudes attenuate slowest, and the rate of attenuation increases with increasing frequency. For the Type 1 earthquake, the lower frequency spectral amplitudes also attenuate slowest; however, there is no marked difference in the distance attenuation rate at intermediate and high frequencies.

\section{f. Horizontal vs. Vertical Motion}

For all frequencies, the horizontal response spectral amplitudes exceed the vertical response spectral amplitudes. The common assumption that vertical response spectra can be represented as two-thirds of the horizontal spectra is seen to be conservative.

$$
1-10
$$




\subsubsection{Comparisons with Other Results}

Two sets of comparisons of results from this study and from prior investigations are presented. This first comparison involves the Regulatory Guide (RG) 1.60 spectra, which are widely used in the design of nuclear plants and other major structures. The comparisons show that, at frequencies of interest for nuclear plant design $(>1.5 \mathrm{~Hz})$, the Regulatory Guide (RG) 1.60 spectra for vertical motion are typically very conservative when compared to the 84 th percentile spectra from this study. This conservatism is most pronounced for rock sites and is small or nonexistent only for certain deep soil site results. Therefore, since many nuclear plants are constructed on rock or intermediate soil sites, the current RG 1.60 provisions for developing vertical ground response spectra should be reassessed. Similar comparisons between RG 1.60 and this study for horizontal motion are dependent on the particular magnitude, distance, and site conditions being considered; typically, the RG 1.60 horizontal response spectra fall between the 50 th and 84 th percentile spectra from this study at frequencies above $1.5 \mathrm{~Hz}$.

The second comparison involves the widely-used spectra developed by Seed, Ugas, and Lysmer (SUL, 1976) for various site soil classifications. The comparisons were made for Magnitude 6.5, Type 3 earthquake events and epicentral distances of $10 \mathrm{~km}$ and $50 \mathrm{~km}$. They showed that the mean and 84 th percentile SUL spectra generally fell between the 50 th and 84 th percentile results from this study. The only exception to this trend is for deep soil sites and a distance of $50 \mathrm{~km}$, where the SUL spectra at frequencies above $1 \mathrm{~Hz}$ fall below the 50 th percentile spectra from this study.

\subsection{RECOMMENDATIONS FOR FUTURE WORK}

There are several areas where additional work is recommended along the lines described in this report. These areas pertain to: (1) the data base used to carry out the study; (2) a more extensive study of earthquake event type effects; and (3) soil/structure interaction effects on motions recorded in basements of buildings. They are summarized below. 


\subsubsection{EXTENDED DATA BASE}

This study, as well as most other statistical studies of strong motion parameters, has been based on data up to and including the San Fernando earthquake that have been processed under the CIT(1969-1975) program (see Sec. 2.1). However, since that program was completed, additional data from more recent earthquakes in California, Alaska, Peru, Nicaragua, Chile, and Japan have been made available in magnetic tape forms by USGS/NOAA and other agencies. These data should be used to supplement the CIT data and to thereby provide an improved data base for carrying out future statistical analyses of the type described herein.

\subsubsection{EFFECTS OF EARTHQUAKE EVENT TYPE}

The present study has shown that ground motion parameters from the San Fernando earthquake exhibited trends that were significantly different from those of the other earthquake events. The techniques employed to develop these trends can be used to study such effects further, in order to determine if other earthquake events besides San Fernando exhibit statistically significant differences. For example, from the new data described in Section 1.5.1, the possible existence of systematic differences between earthquakes in Japan and in various regions of the Western Hemisphere should be evaluated.

\section{5 .3 SOIL/STRUCTURE INTERACTION EFFECTS}

Many of the strong motion records used to represent free-field ground motions in this and other studies of earthquake motions have been measured in basements of buildings. However, under certain conditions, these basement motions may differ substantially from those of the free field because of soil/ structure interaction effects. (See, for example, a recent study of such effects at the El Centro Terminal Substation Building, SW/AA, 1979.) In view of this, it is recommended that parametric analyses of the dynamic response of buildings typical of the type that house strong motion accelerographs be carried 
out. The purpose of these analyses would be to identify conditions related to the properties of the'soil medium, the structure, and the incident wave motions for which basement motions differ substantially from the free field. Results from such analysis would guide the inclusion or rejection of certain records in future studies of earthquake ground motions for purposes of developing seismic input criteria for nuclear plants and other major structures. 
CHAPTER 2

DATA BASE, CLASSIFICATION, AND ANALYSIS PROCEDURES

The purpose of this chapter is to describe the basic data used in this investigation, and how it is classified according to site conditions and analyzed. The chapter is divided into three main sections. The first describes the strong motion data base developed at the California Institute of Technology (CIT, 1969-1975) from which the data used in this investigation has been extracted. The second section describes the site classification procedures and the data associated with each classification. The final section summarizes the statistical analysis procedures used in this investigation.

\subsection{CIT DATA BASE}

The strong motion data used in the present investigation was developed during a long term data processing program carried out by the California Institute of Technology (CIT). This program was initiated in 1969, with an objective to provide earthquake engineers and scientists with strong motion data that is processed in a uniform manner and as accurately as possible, within the current technology. The program is described in considerable detail in several reports containing the data (CIT, 1969-1975) and in various papers currently available in the technical literature (e.g., Trifunac, Udwadia, and Brady, 1973). A brief summary of the program is contained in the paragraphs that follow.

The procedure followed by CIT in processing the data first involves a digitization of the field accelerograph records using semiautomatic or completely automatic image scanning processes (Hudson, 1974). Two basic sets of numerical corrections are then applied to the digitized data--an instrument correction and a baseline correction. The instrument correction first consists of a low-pass filtering of the original data to eliminate high-frequency digitization errors and aliasing; then, a differential equation of motion for 
a damped single-degree-of-freedom system with a high natural frequency is applied to the data to recover higher frequency components of motion that have been filtered by the transducer (Trifunac, 1972a). The baseline correction consists of the use of a high-pass filter that filters out periods longer than $16 \mathrm{sec}$ and eliminates the long period errors introduced by recording, digitization, and record processing (Trifunac, 1971). The final result is a corrected accelerogram that represents the acceleration of the instrument base within a frequency range of $0.06 \mathrm{~Hz}$ to $25 \mathrm{~Hz}$. These accelerograms are then integrated to produce ground velocity and displacement records, and response spectra and Fourier spectra in various forms are also calculated.

CIT applied the above procedure to records from 128 accelerograph sites and 57 earthquakes centered in the western United States and predominantly in California, with nearly half of these records originating from a single event--the 1971 San Fernando earthquake. The resulting data are available to the general public in the form of digitized printouts and plots in the CIT reports, and are also provided on magnetic tapes or punched cards that can be purchased from CIT or from various government agencies. In the CIT program, such data were developed for nearly 400 sets of strong motion records, each consisting of three accelerogram components. Of these, 186 sets of records correspond to measurements on thr ground surface or on lower floors and the basements of buildings, and can therefore be considered representative of free-field ground shaking. The remaining records represent measurements in the mid-to-upper floors of buildings; these records are influenced by the dynamic response characteristics of the structures, as well as by the ground motions themselves.

\subsection{ACCELEROGRAPH SITE CLASSIFICATIONS}

\subsubsection{CLASSIFICATION DEFINITIONS AND PROCEDURES}

The manner in which accelerograph sites are classified in order to study local site effects on strong motion records is an area of some uncertainty. Not only are several classification approaches currently in existence but, for any one approach, there can exist differences of opinion among 
experienced engineers as to which site classification to place a particular accelerograph station (Trifunac and Brady, 1975a). Furthermore, the buildings in which the "free field" instruments are housed can influence the ground motion measurements; these range from simple corrugated instrument sheds to basements of power stations with thick foundation mats (e.g., El Centro) to basements of high rise buildings that are as deep as $70-\mathrm{ft}$ below grade (e.g., along Wilshire Boulevard).

With this as background, there are two main types of site classifications that have been used in prior statistical studies of local site effects on strong motion records. The first is based on the premise that the subsurface soil and rock materials within a few hundred feet of the ground surface has a significant influence on the strong motion records. This type of classification is generally most widely used and has been employed by Seed, Ugas, and Lysmer (1976) and by Mohraz (1976), among others. The second type of site classification considers that the recorded ground motions have been influenced by subsurface materials that extend to depths comparable to the wavelengths associated with significant frequencies of the motions; this second approach ordinarily considers materials at depths much greater than those associated with the first type of site classification mentioned above. This latter type of site classification has been employed in studies by Trifunac and Brady $(1975 a, 1975 b)$. It is important to be aware of the fundamental differences between these two site classification procedures when using results from the above studies or from the present investigation.

The present investigation uses a site classification procedure that falls in the first category denoted above--i.e,, it is based on the subsurface material properties within a few hundred feet of the ground surface. From a detailed review of the results of the SW/AA geotechnical investigations at strong motion accelerograph sites, it was decided to use the three site soil classifications depicted in Figure $2-1$ and listed below:

- Rock Sites--20 ft or less of overburden that overlies rocklike materials 
- Intermediate Sites--consisting of stiff clays and/or dense sands whose depth to rock-like materials range from about $20 \mathrm{ft}$ to $200 \mathrm{ft}$

- Deep Soil Sites--consisting of stiff clays and/or dense sands whose depth to rock-like materials is approximately $300 \mathrm{ft}$ or greater

In this, rock-like materials correspond to either (a) materials where shear wave velocity is approximately $2500 \mathrm{fps}$ or greater (when shear wave velocities have been measured); or (b) fresh, sound, competent rock, as established by borings or by rock outcropping at the site (when shear wave velocities have not been measured).

In general, the strong motion accelerograph sites are classified from one or more of the following types of information:

a. Deep Borings and Dynamic Testing: Used to develop a complete set of dynamic properties of soil deposits down to rock-like materials; incorporates both field and laboratory test procedures.

b. Site Reconnaissance and Evaluation of Geologic Environment: Used predominantly at sites with significant rock outcropping, in order to evaluate whether site can be classified as rock; uses no laboratory or field tests of dynamic properties.

c. Borings to Rock: Used to establish depth to rock-like material; uses no laboratory or field tests of dynamic properties.

d. Seismic Refraction Surveys to Rock: Used to estimate shear wave velocities of soil deposits down to rock-like material or to substantial depths; uses no borings or laboratory tests.

e. Shallow Borings and/or Seismic Refraction Surveys: Not used to develop site classifications, because depths to which data are obtained are too shallow to establish location of rock-like materials; uses no laboratory tests. 
Procedures (a) to (d) provide an adequate basis for classifying the accelerograph sites into one of the three broad classifications--deep soil, intermediate, or rock--given above. Of these, procedure (a) is, of course, the most comprehensive and provides the most complete soil properties for use in site response analysis or site classifications. Such procedures have been applied at numerous sites by SW/AA $(1976$; 1977a, 1978b, c). Data from procedures (b) through (d) have also been either collected or developed by SW/AA; such data, while not sufficiently detailed for site response analyses, are adequate for site classifications of the type considered here (SW/AA, 1977b; 1978a).

Of the above procedures for developing geotechnical data at accelerograph sites, only procedure (e) is insufficient for site classification purposes. Unfortunately, at 75 of the 128 accelerograph sites, either no geotechnical data have been developed or, alternately, data from procedure (e) are all that are available. Such sites are denoted herein as having an "undefined" site classification, since the available information is not adequate for grouping the site into either the deep soil, intermediate, or rock classifications defined above. The manner in which such sites are included in the statistical analyses is described in the following subsection.

\subsubsection{CLASSIFICATION OF ACCELEROGRAPH SITES}

The classifications of each of the 128 accelerograph sites represented by the CIT data base are given in Table 2-1. Of these, 14 sites fall in the rock category, 26 in the intermediate category, 13 in the deep soil category, and 75 in the undefined category. In terms of records (in which each record comprises two horizontal components and one vertical component of motion) a total of 82 of the 186 records could be site classified on the basis of available geotechnical data. Of these 82 records, 14 (or 17\%) fell in the rock category; $36(44 \%)$ were considered to be intermediate sites; and 32 (39\%) were classified as deep soil sites. A total of 98 records were from sites with undefined classification, and 6 additional records (of the ensemble of 186) were not included in the analysis because they were associated with earthquakes of unknown magnitude. 
Because the records from sites with unknown classification represented a substantial portion of the total ensemble, considerable thought was directed toward how or whether they should be included in the statistical analysis. One possibllity considered was to delete all such records and to base the statistical analysis only on records from sites with known classification. However, this possibility was rejected since site conditions were only one of the independent varlables to be considered--the others being magnitude, distance, direction of motion, and earthquake event type (Sec 1.2). Therefore, to provide a much improved basis for considering the effects of these other variables, all records in the ensemble were included, regardless of whether they were from sites with defined or undefined classification. This, however, necessitated the development of the following approximate procedure for considering the records with undefined site classification.

The procedure for considering such records was based on the assumption that the relative proportion of records with defined classification (already assigned into the deep soil, intermediate, and rock site categories) could be considered representative of the entire population. On this basis, it was considered that $3 / 8$ of the records with undefined classification fell in the deep soil site category, $4 / 8$ were intermediate soil sites, and 1/8 were rock sites. " This assumption corresponds to considering each record with undefined site classification to be represented by the probability distribution shown in Figure 2-2a; in this, a discrete probability ordinate of $3 / 8$ is associated with deep soil sites, $4 / 8$ with intermediate sites, and $1 / 8$ with rock sites. This can be contrasted with the probability distribution for a site with defined classification (Figure 2-2b) in which a single discrete probability ordinate of unit value is assigned to the appropriate classification.

"These proportions are slightly different from the actual proportions of records with defined site conditions, which are: rock sites--17\%; intermediate sites--44\%; and deep soil sites--39\%. One reason for these slight differences was that, in our judgment, more of the undefined sites would fall either in the deep soil or intermediate category than was observed in the defined sites; therefore, the proportion of such sites to be considered as rock was reduced. 
To illustrate how these assumed probability distributions have been implemented, consider an example in which it is desired to relate peak velocity to site conditions. Furthermore, consider that a single record with undefined site classification has a peak velocity of, say, 8 ips. The probability distribution of Figure 2-2a would lead to a peak velocity of 8 ips for $3 / 8$ of a deep soil data point, $4 / 8$ of an intermediate site data point, and $1 / 8$ of a rock data point. Repeating this process for each record, ensembles of peak velocity values for each site classification are thereby formed using the fractional data points from each record with undefined site conditions, together with the complete data points from the records with defined site classification. These ensembles, in turn, form the basis for carrying out the required statistical analysis relating peak velocity to site conditions using records with undefined as well as defined site classification. It is important to emphasize that this procedure, although approximate with regard to site effects, represents an intuitively reasonable vehicle for incorporating the records with undefined site classification. It also provides a much larger data base for considering effects of the other variables (e.g., magnitude, distance, etc.) than would be possible if such records were deleted from consideration.

\subsection{STATISTICAL ANALYSIS PROCEDURE}

The statistical analysis carried out during this study has been based on multiple linear regression analysis techniques. This section summarizes the step-by-step procedures used in carrying out the analysis for each ground motion parameter. More detailed background information is contained in Appendix A, including basic assumptions, procedures for computing regression coefficients, the step-down algorithm, computation of data-fit parameters, and basic features of the MAC/STAT program used to carry out the study. 


\subsubsection{STEP 1: FORM THE BASIC REGRESSION EQUATION}

This step involves the identification of the independent variables to be considered in the regression analysis and the incorporation of these variables into the following multiple regression equation

$$
y=f\left(x_{1}, x_{2}, \ldots x_{m}\right)=a_{1} x_{1}+a_{2} x_{2}+\ldots+a_{m} x_{m}
$$

where $y$ is the dependent variable $(e . g .$, peak acceleration $), x_{i}(i=1, \ldots m)$ are functions of the independent variables (e.g., magnitude, distance, etc., or combinations thereof) and $a_{i}(i=1, \ldots m)$ are the unknown regression coefficients. The identification of the $x_{i}$ is based on engineering judgment and on guidance from appropriate theoretical results that interrelate $x_{i}$ and $y$.

\subsubsection{STEP 2: DETERMINE THE REGRESSION COEFFICIENTS}

The regression coefficients, $a_{i}(i=1, \ldots \mathrm{m})$ in Equations 2-1, are determined using a standard least-squares technique for fitting Equation 2-1 to the ground motion data. This technique is described in Section A-2 of Appendix A.

\subsubsection{STEP 3: CARRY OUT STEP-DOWN ALGORITHM}

A step-down algorithm is employed to assure that only statistically significant terms are retained on the right side of Equation 2-1. The first step in this algorithm uses the F-test to eliminate the most statistically insignificant of the original terms, if the F-value for that term falls below the 95th percentile of the F-distribution. Then, a new set of regression coefficients is determined for the remaining terms (Step 2) and the elimination process is repeated. This algorithm is completed when all remaining terms have an F-value that falls above the 95 th percentile. Section A-3 of Appendix A provides a more extensive description of the step-down algorithm.

*y may also be a transformation of the dependent variable. For example, for several of the ground motion parameters studied, $y=\ln Y$ was used, where $Y$ is the dependent variable. 


\subsubsection{STEP 4: FURTHER INVESTIGATE PARTICULARLY SIGNIFICANT VARIABLES}

The effects of variables shown from step 3 to be particularly significant are investigated further by defining cross products, higher order terms, etc., involving these variables and repeating steps 1 to 3 to determine if these additional terms are significant.

\subsubsection{STEP 5: COMPUTE DATA-FIT PARAMETERS AND IDENTIFY OUTLIERS}

Once the final regression equation is determined from Steps 1 to 4 , the standard deviation, coefficient of variation, and multiple correlation coefficient are computed (see Sec. A-4, App. A). In addition, outliers are identified as ground motion records whose residual exceeds 30 (for the strength parameters and response spectral amplitudes) or 2.50 (for the duration parameters), where $\sigma$ is the standard deviation of $y$ (Eq. 2-1). 
TABLE 2-1. SUMMARY OF SITE CLASSIFICATIONS

\begin{tabular}{|c|c|c|c|c|}
\hline Rock & Intermediate & Deep Soil & \multicolumn{2}{|c|}{ Undefined } \\
\hline $\begin{array}{l}\text { Golden Gate Park, SF } \\
\text { Carroll College, Melena, MT } \\
\text { Temblor \#2 } \\
\text { Recreation Bldg., San Luis Obispo } \\
\text { Pacoima Dam } \\
\text { Santa Felicia Dam } \\
\text { CIT Seismological Lab, Pasadena } \\
\text { Lake Hughes \#4 } \\
\text { Lake Hughes \#9 } \\
\text { Lake Hughes } \# 12 \\
\text { Griffith Park, LA } \\
\text { Fairmont Reservoir } \\
\text { Santa Anita Reservoir, Arcadia } \\
\text { Allen Ranch, Cedar Springs }\end{array}$ & $\begin{array}{l}\text { CIT Athenaeum, Pasadena } \\
\text { Lincoln School, Taft } \\
\text { Alexander Bldg., SF } \\
\text { State Bidg., SF } \\
\text { Old Ridge Route, Castaic } \\
3710 \text { Wilshire, LA } \\
4680 \text { Wilshire, LA } \\
3470 \text { Wilshire, LA } \\
3407 \text { Sixth, LA } \\
633 \text { 8roadway, Glendale } \\
2011 \text { Zonal, LA } \\
\text { Ft. Tejon, Tejon } \\
\text { CiT Millikan Library, Pasadena } \\
\text { Jet Propulsion Lab, Pasadena } \\
\text { Fed. Office Bldg., Seattle } \\
616 \text { S. Normandie, LA } \\
3838 \text { Lankershim, LA } \\
2516 \text { Via Tejon, Palos Verdes } \\
2500 \text { Wilshire, LA } \\
4867 \text { Sunset, LA } \\
3345 \text { Wilshire, LA } \\
6200 \text { Wilshire, LA } \\
5900 \text { Wilshire, LA } \\
3411 \text { Wilshire, LA } \\
3550 \text { Wilshire, LA }\end{array}$ & $\begin{array}{l}\text { Terminal Substation, El Centro } \\
\text { city Hall, Ferndale } \\
\text { Courthouse Bldg. Santa Barbara } \\
\text { Federal Bldg. Eureka } \\
\text { Highway Test Lab, Olympia, WA } \\
445 \text { Figueroa, LA } \\
\text { Water and Power } 81 d g ., ~ L A \\
15250 \text { Ventura, LA } \\
4205 \text {. Grand, LA } \\
14724 \text { Ventura, LA } \\
800 \text { W. First, LA } \\
222 \text { Figueroa, LA } \\
234 \text { Figuroa, LA } \\
15910 \text { Ventura, LA }\end{array}$ & 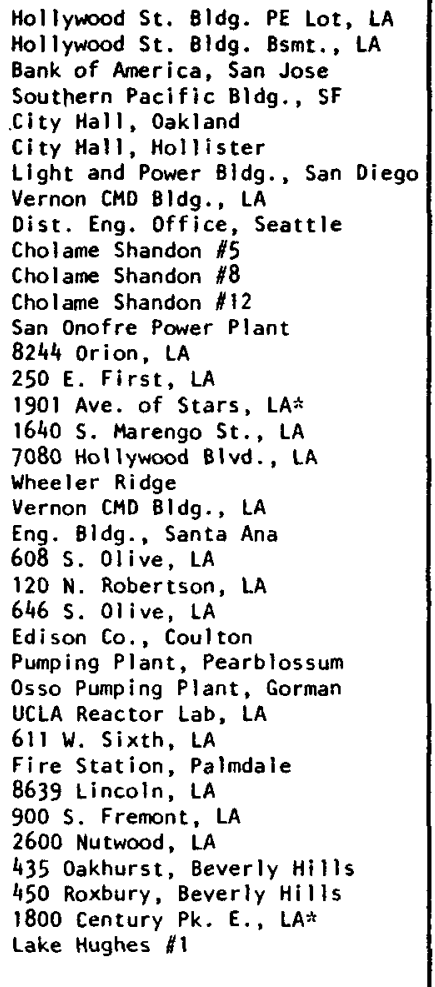 & 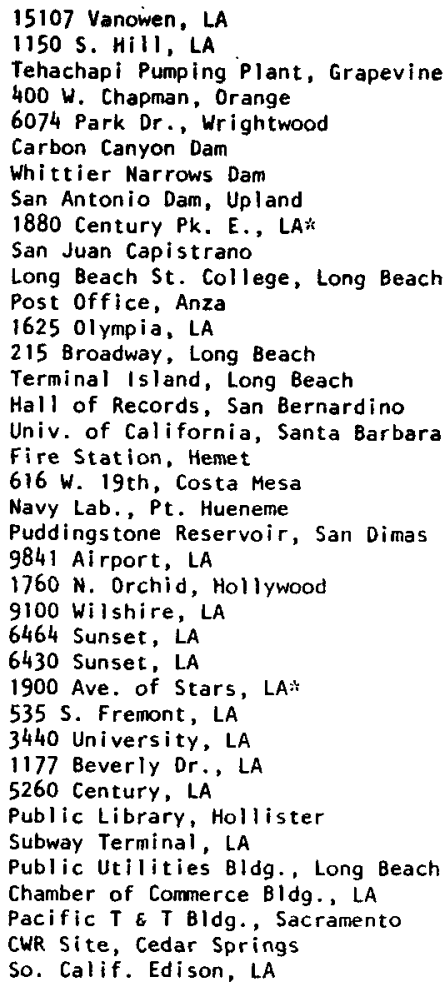 \\
\hline
\end{tabular}

: Sites assigned a weighting factor of 4/8--deep soil; 4/8-- intermediate. These sites, from the Century City, LA, area had site conditions established motion parameters from these sites were weighted equally between these two classifications. Ground motion parameters from all other sites in the undefined classificatlon were weighted as $3 / 8-$-deep soil; 4/8-- intermediate; and $1 / 8-$-rock (Sec. 2.2 .2$)$. 
STIFF CLAYS AND/OR DENSE

SANDS (FIRM SOIL)

$h=$ DEPTH OF FIRM

SOIL MEDIUM

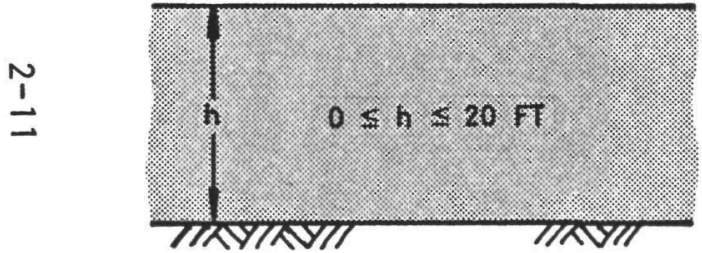

$v_{s} \geq 2500 \mathrm{FT} / \mathrm{s}$

(a) Rock sites

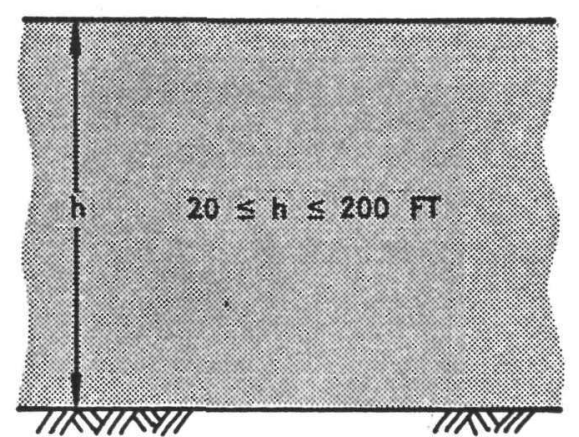

$v_{s} \geq 2500 \mathrm{FT} / \mathrm{S}$

(b) Intermediate soil sites

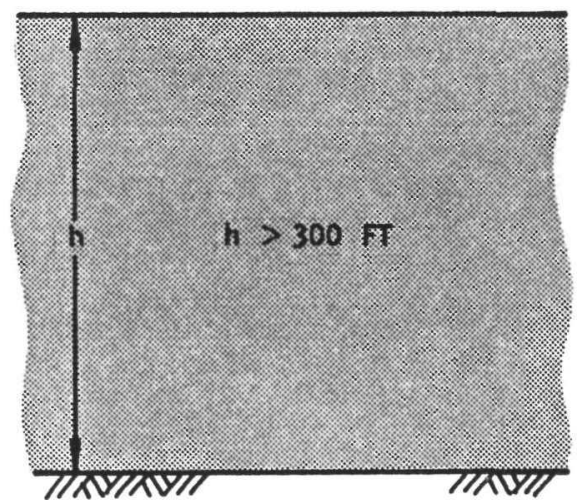

$v_{s} \geq 2500 \mathrm{FT} / \mathrm{S}$

(c) Deep soil sites

FIGURE 2-1. SITE CLASSIFICATION PROCEDURE USED IN THIS STUDY 


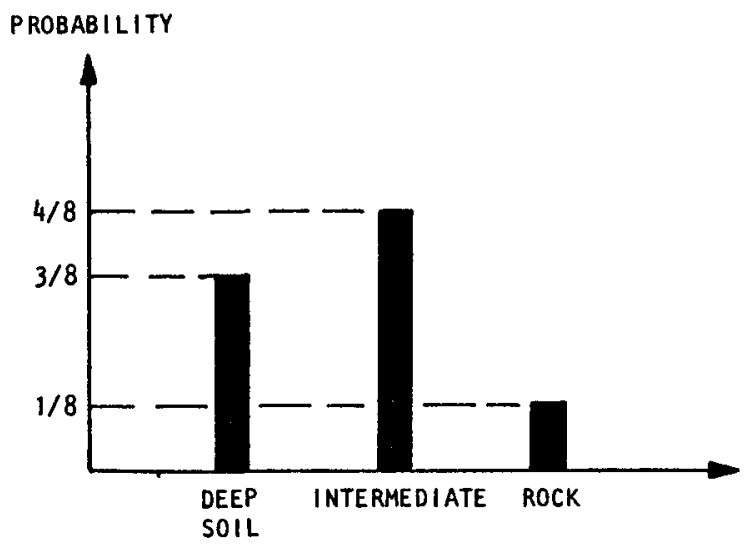

(a) Sites with undefined classification

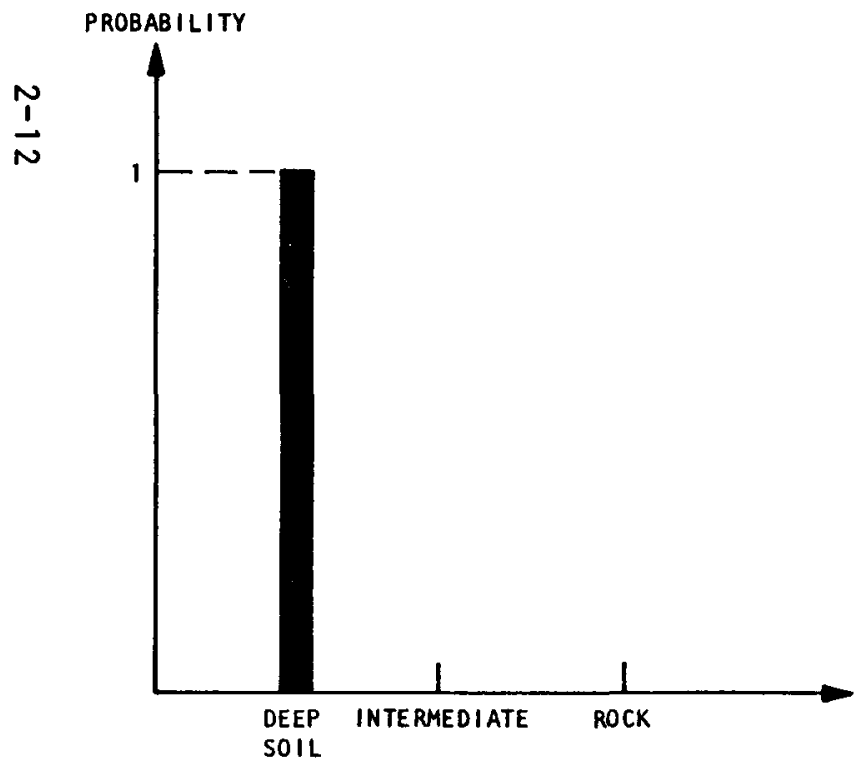

DEEP SOIL SITES

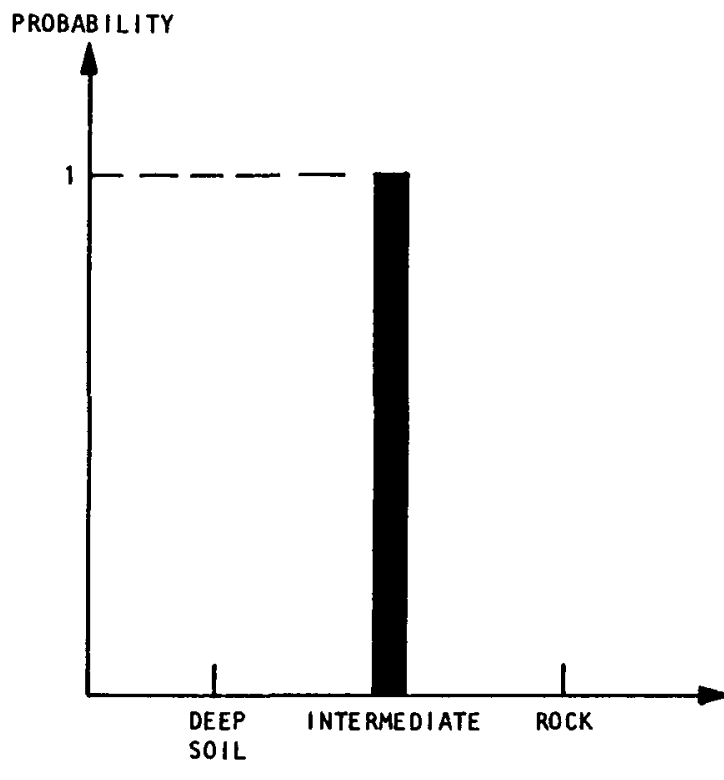

INTERMEDIATE SITES

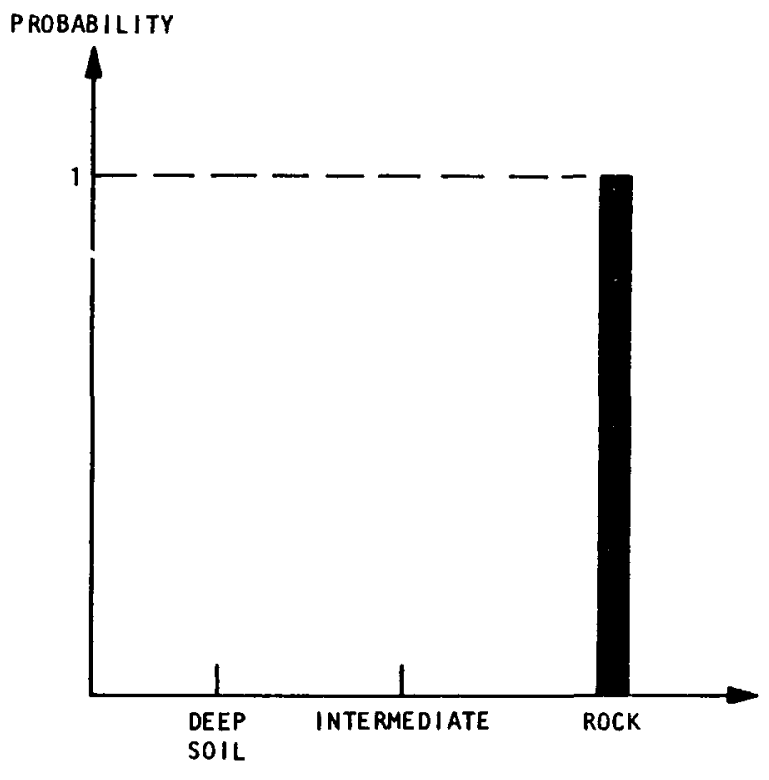

ROCK SITES

(b) Sites with defined classification

FIGURE 2-2. PROBABILITY DISTRIBUTIONS FOR SITES WITH UNDEFINED AND DEFINED CLASSIFICATIONS 


\section{CHAPTER 3}

\section{STRENGTH PARAMETERS}

\subsection{GENERAL DISCUSSION}

For some time, earthquake engineers have wrestled with the problem of defining a single, simple parameter that represents the strength of the ground shaking as represented by an accelerograph record. Such a parameter would be of value for quantitatively comparing different records or for relating measured ground motions to potential structural damage. However, no single parameter has yet been found that is fully satisfactory for this purpose.

This chapter describes results from regression analyses of several strength parameters that have been used, or at least advocated for use, in current engineering practice. The parameters considered herein are the peak acceleration, velocity, and displacement; the spectrum intensity; and the Arias intensity.

Of these parameters, the peak acceleration has been most widely used, probably because of its convenience; i.e., it is a readily identifiable point on the accelerograph record. However, the use of this parameter has several shortcomings. For example, the peak acceleration is closely related to maximum forces applied to high-frequency systems but not to more typical low- or intermediate-frequency structures. Also, the peak acceleration alone does not lead to good correlations between the relative strengths of different earthquake records and, since it is only a single point on the accelerograph trace, it does not account for the duration or frequency content of the motion (SW/AA, 1975).

The strength of the ground shaking can also be depicted by the peak velocity or peak displacement, both of which have a more determinant upper bound than does the peak acceleration (Hudson, 1972). Also, the peak velocity and displacement provide an improved estimate of dynamic forces applied to 
more typical structures with intermediate and low natural frequencies, respectively. of the two, the peak velocity is generally preferred, because: (1) its representation of ground shaking in the intermediate frequency range is most useful for a variety of structures; and (2) although prone to uncertainties associated with numerical integration of the accelerogram, it is less sensitive to such uncertainties than is the peak displacement.

Still another method for representing the strength of the ground shaking is the spectrum intensity (S.I.), which is defined as the area under the pseudovelocity response spectrum curve in a period range extending from $0.1 \mathrm{sec}$ to $2.5 \mathrm{sec}$, i.e.

$$
S .1 .=\int_{0.1}^{2.5} S_{V}(\zeta, T) d T
$$

where $S_{v}$ is the pseudovelocity at a given period $T$ for a response spectrum with a damping ratio $\zeta$. This parameter was first advocated by Housner (1952), following a suggestion originally advanced by Benioff (1934). It has the advantage over peak motions of accounting for the strength of the shaking over a range of periods common to most structures. The spectrum intensity does, however, require the selection of a particular damping ratio, since the spectral amplitudes are strongly dependent on this parameter.

The most recently developed parameter for representing the strength of the ground shaking is the Arias intensity (A.I.), computed as

$$
\text { A.I. }=\frac{\pi}{2 g} \int_{0}^{t_{0}} \ddot{y}(\tau)^{2} d \tau
$$

where $\ddot{y}(\tau)$ is the acceleration at time $\tau, t_{0}$ is the total duration of the ground shaking, and $g$ is the acceleration of gravity. This parameter 
was suggested by Arias (1970) as being represented as the total energy dissipated by damped single-degree-of-freedom structures with various frequencies. It has the advantage over the spectrum intensity of being essentially independent of structural damping over a wide range. Also, the Arias intensity is somewhat similar to the rms acceleration, computed as

$$
r m s=\left[\frac{1}{t_{d}} \int_{0}^{t_{d}} \ddot{y}(\tau)^{2} d \tau\right]^{1 / 2}
$$

and widely advocated by several engineers as a ground motion strength parameter (e.9., McCann and Shah, 1979; Housner, 1975). However, the rms acceleration, as given by Equation $3-3$, is sensitive to the selection of the duration of strong shaking, ' $t_{d}$ ' which can vary widely according to which of several commonly accepted definitions of $t_{d}$ is used (Sec. 4-1). The Arias intensity, on the other hand, is independent of $t_{d}$; i.e., as indicated by Equation 3-2, it is dependent only on the total duration of the record."

\subsection{REGRESSION ANALYSIS}

For each of the strong motion strength parameters discussed in the previous section, the following general regression form was used:

$$
\begin{aligned}
\ln P= & a_{1}+\frac{a_{2}}{M}+a_{3} \ln (R+1)+a_{4} V+a_{5} E+a_{6} \ln (R+1) \cdot E \\
& +a_{7} \ln (R+1) \cdot S_{D}+a_{8} \ln (R+1) \cdot S_{R}
\end{aligned}
$$

where $a_{1}, a_{2}, \ldots, a_{8}$ are the regression coefficients given in Table $3-1$, and

$$
\begin{aligned}
& P=\text { Strength parameter } \\
& M=\text { Local magnitude }
\end{aligned}
$$

\footnotetext{
* The total duration as used in the computation of the Arias intensity need only encompass the strong motion portion of the record since it is that portion that contributes most to the total Arias intensity for that record (Trifunac and Brady, 1975b).
} 


$$
\begin{aligned}
R & =\text { Epicentral distance, } \mathrm{km} \\
V & =1 \text { (if vertical motion) } \\
& =0 \text { (if horizontal motion) } \\
E & =1 \text { (to represent San Fernando earthquake--Type } 1 \text { event) } \\
& =0 \text { (to represent all other earthquakes--Type } 2 \text { event) } \\
& =0.545 \text { (to represent all earthquakes--Type } 3 \text { event) } \\
S_{D} & =1 \text { (if deep soil site) } \\
& =0 \text { (otherwise) } \\
S_{R} & =1 \text { (if rock site) } \\
& =0 \text { (otherwise) }
\end{aligned}
$$

It is noted that Equation 3-4 originally involved terms of the form $\ln (R+\Delta)$, where $\Delta$ was unknown. However, the consideration of this additional variable in the regression optimization would have been time-consuming and difficult; furthermore, $\Delta$ has a significant influence on the strength parameters only in the near field, for which virtually no data exist. For these reasons, separate trial-and-error analyses were carried out in which à value of $\Delta$ was selected based on theoretical source mechanism solutions (see App. B). In this manner, $\Delta=1$ was found to provide the best overall fit to these solutions and was incorporated into Equation 3-4 for all strength parameters. Equation 3-4 was thereby simplified, and all subsequent regression analyses of the strength parameters were carried out using the $\ln (R+1)$ terms as shown above.

Table 3-2 contains outliers for each strength parameter. These outliers correspond to records for which the $\log$ of the measured value of the parameter, $P$, differs by more than $\pm 3 \sigma$ from the mean value of $\ell n P$, as computed using Equation 3-4. This table shows several repeated entries that delineate occurrences of atypical motions arising from such factors as the nature of the earthquake itself or improper functioning of the instrumentation used to record the motions. Most prominent of the repeated entries in Table 3-2 is the 1933 Long Beach Public Utilities Building. 


\subsection{COMPARISONS WITH RECORDED DATA}

The degree of $f i t$ of the regression equations with the recorded values of each parameter can be indicated in two ways. One is visual, in which plotted curves from the regression equation for a given combination of independent variables are compared with data recorded under an identical combination of variables. The second is through the use of data-fit parameters--i.e., the standard deviation, coefficient of variation, and correlation coefficient-that indicate the degree of correlation of the regression equation with the recorded data.

Visual comparisons of the recorded and computed values are presented for each parameter in Figures 3-1 to 3-20. These figures involve two sets of comparisons for each parameter. The first set provides comparisons of recorded and computed results for Type 1 (San Fernando) earthquake events and all three site classifications. The second set also involves all three site classifications but is for Type 2 (other than San Fernando) earthquake events; in this, comparisons are made at three different magnitude levels-5.4, 6.4, and 7.7. Both sets of comparisons show the general trend of the data for each site classification, the degree to which the computed values follow these trends, and scatter in the recorded data.

The data-fit parameters that provide quantitative indications of correlation between recorded and computed parameters are given in Table 3-3. This table shows that of the various strength parameters considered, the Arias intensity regression exhibits the best overall correlation with the recorded data (i.e., it has the highest correlation coefficlent) followed (in order of decreasing correlation coefficient) by the spectrum intensity, peak velocity, peak acceleration, and peak displacement. With the exception of the peak displacement, all of the other parameters have reasonably similar correlation coefficients, with values ranging from about 0.84 to 0.88 ; only the peak displacement is clearly different from the rest, having a correlation coefficient of about 0.77 . 
The coefficient of variation of the various parameters indicates generally similar trends to the correlation coefficient. Only for the Arias Intensity is the trend different; i.e., markedly high values of coefficient of variation are indicated in Table 3-3. This trend, surprising at first in view of the high correlation coefficient of the Arias intensity, can be traced to the fact that this parameter is a function of the square of the acceleration (Eq. 3-2). This tends to artificially increase the coefficient of variation of the Arias intensity relative to the other parameters considered. Of the remaining parameters, the peak displacement exhibits the highest coefficient of variation, followed in order by the peak acceleration, spectrum intensity, and peak velocity.

\subsection{PARAMETRIC EFFECTS}

The effects of magnitude, distance, earthquake event type, direction of shaking, and site conditions of the various strength parameters have been investigated and are summarized in the remainder of this section.

\subsubsection{LOCAL SITE EFFECTS}

The peak acceleration is the only parameter for which no physically consistent trends regarding site conditions could be found from the regression analysis; this parameter can therefore be considered to be independent of site effects. For all other strength parameters, the deep soil sites exhibit the largest values for a given magnitude, distance, and earthquake event type, followed in order by the intermediate sites and the rock sites. (Figs. 3-1 to $3-20$ ).

\subsubsection{EFFECTS OF EARTHQUAKE EVENT TYPE}

The effects of earthquake event type have been evaluated for a given magnitude (6.4), site conditions (intermediate), and probability level (50th percentile). These evaluations show that for all strength parameters, 
the rate of decrease with increasing distance is greater for the Type 1 (San Fernando) earthquake events than for Type 2 (other than San Fernando) earthquakes. At epicentral distances less than 80 to $120 \mathrm{~km}$, the Type 1 strength parameters exhibit the highest values whereas, at distances greater than $120 \mathrm{~km}$, the Type 2 results are greatest. The strength parameters from the Type 3 data (i.e., from all earthquake events) are intermediate between those of Type 1 and Type 2 (Figs. 3-21 to 3-25).

\subsubsection{MAGNITUDE EFFECTS}

As the magnitude increases, the horizontal and vertical values for each strength parameter increases at a decreasing rate (Figs. 3-26 to 3-30).

\subsubsection{EFFECTS OF DIRECTION OF SHAKING}

The horizontal value of each strength parameter exceeds the vertical value for a fixed magnitude, distance, and site condition. The widely used assumption that the vertical value is two-thirds of the horizontal value is seen to be conservative (Figs. 3-31 to 3-35).

\subsection{COMPARISONS WITH RESULTS FROM OTHER STUDIES}

\subsubsection{PEAK ACCELERATION}

Three sets of comparisons of peak acceleration results from this study with those from other investigations are shown in Figures 3-36 to 3-38. The first (Fig. 3-36) utilizes compilations of results from several investigations for a Magnitude 6.5 earthquake. This figure shows that, within the distance range encompassed by most of the currently available data, the results from this study are in reasonable agreement with those from most of the other results shown in Figure 3-36. However, outside of this range, where data are scant, all of the results differ substantially from one another. 
The second set of comparisons involves peak acceleration results developed by Trifunac (1976). These results involve three site classifications--soft, intermediate, and hard--that differ from those of the present study. Also, the Trifunac results feature regression analyses only for magnitude and site conditions; the distance dependence is assumed to correspond to that employed in routine calculations of local magnitude. With these features in mind, the comparisons between the Trifunac results and those of the present study show that (Fig. 3-37):

- At distances between about $10 \mathrm{~km}$ and $80 \mathrm{~km}$, the Trifunac acceleration predictions exceed those of the present study. At all other distances, the accelerations from the present study are greatest.

- The Trifunac acceleration predictions are not very sensitive to site conditions; this supports the results from the present study that show peak acceleration to have statistically insignificant local site effects.

A third set of comparisons involves the results of McGuire (1978), which concerns two, rather than three, site classifications--soil and rock. The McGuire regression analysis differs from that of the present study in that it is based on a linear relationship between the en (peak acceleration) and magnitude, site conditions, and $\ell n$ (distance). The comparisons with peak acceleration results from the present study show that (Fig. 3-38):

- At Magnitude 6.4, the two sets of results compare quite closely. Comparisons at Magnitude 5.0, where somewhat less data exist, are also good but not quite as favorable as at Magnitude 6.4. For Magnitude 8.0, where no recorded data currently exist, the two sets of results compare reasonably well at short distances $(30 \mathrm{~km})$ and more poorly at long distances $(100 \mathrm{~km})$. 
- McGuire's results for his soil and rock classifications are quite similar, which substantiates the results from the present study that show peak accelerations to be insensitive to site conditions.

\subsubsection{PEAK VELOCITY}

Four sets of comparisons of peak velocity results from this study and from other investigations are shown in Figures 3-39 to 3-42. The first of these corresponds to peak horizontal velocity results compiled by Duke et al. (1976) from regression analyses of San Fernando earthquake data. Two sets of results were developed--one for rock sites (Fig. 3-39a) and one for soil sites (Fig. 3-39b). For rock sites, two sets of velocity curves were provided by Duke et al., corresponding to sedimentary rock and basement rock. The rock results from the present study are seen in Figure 3-39a to fall between the two curves of Duke et al. For soil sites, Duke et al. also present two sets of curves, one for a stiff site and one for a softer site. From Figure 3-39b, these are seen to be nearly identical to results from the present study for intermediate and deep soil sites, respectively.

The second set of peak horizontal velocity results to be compared with those of the present study are those of Seed et al. (1976). The Seed et al. results were developed from data from several different earthquake events; however most of the data were from the San Fernando earthquake. Therefore, when results from the present study for Type 3 earthquakes (all events) are compared with those of Seed et al., the comparisons are generally only fair (Figs. 3-40a, b). However, when results from the present study for Type 1 (San Fernando) earthquakes are used instead, the comparisons with Seed et al. are improved, particularly for rock sites (Figs. 3-40c, d).

A third set of comparisons involves 90th percentile results developed by Trifunac (1976) using the same site classifications and regression analysis approach as summarized with regard to peak acceleration in Section 3.5.1. The comparisons with the results from the present study, carried out for a 
Magnitude 6.4 and Type 3 earthquake event, show that except at very short epicentral distances $(<10 \mathrm{~km})$, the Trifunac velocity predictions vary more sharply with distance than do the predictions from the present study (Fig. $3-41$ ). In general, at distances between about $10 \mathrm{~km}$ and $150 \mathrm{~km}$, Trifunac's velocity results are greatest whereas at longer distances, the results from the present study are largest. Also, Trifunac's peak velocity results are less sensitive to site effects than are those of the present study.

The fourth and final comparison involves results of McGuire (1978) from the same regression analysis approach as used for peak accelerations (Sec. 3.5.1). McGuire's peak horizontal velocity results are seen to be less sensitive to site effects than are the results from this study (Fig. $3-42 a$ ). Also, his results for low and moderate earthquake magnitudes are very similar to those from the present study for intermediate site conditions. Only at large magnitudes (i.e., Magnitude 8.0) are there serious discrepancies between the two sets of results, owing to the complete lack of data for such a magnitude level (Fig. 3-42b).

\subsubsection{PEAK DISPLACEMENT}

Two sets of comparisons with the peak displacement results from the present investigation are presented in this section. The first of these involves the 90th percentile results developed by Trifunac (1976) using the same regression analysis approach as described previously with respect to peak accelerations and peak velocities (Fig. 3-43). The comparisons with results from the present study are carried out for a Magnitude 6.4, Type 3 earthquake event and for all three site classifications. Results of the comparisons are as follows:

- Except at very short epicentral distances, the Trifunac displacement comparisons vary more sharply with distance.

- At distances between $10 \mathrm{~km}$ and $80 \mathrm{~km}$, Trifunac's displacement results are higher, whereas at longer distances the results from the present investigation attain the largest values.

- Both sets of results exhibit a comparable sensitivity to site effects. 
The second comparison involves horizontal displacement results from McGuire's (1978) regression analysis. As in the peak velocity comparisons, McGuire's displacement results are much less sensitive to site effects than are the results from the present investigation (Fig. 3-44a). Also, for Magnitude 6.4 earthquakes, McGuire's results compare very closely to those of the present investigation for intermediate site conditions; however, the two sets of results compare less favorably at Magnitudes 5.0 and 8.0 where much less data are available (Fig. 3-44b).

\subsubsection{ARIAS INTENSITY}

To date, only one set of regression analyses of Arias intensity have been carried out that are suitable for comparison with the present investigation--that by Trifunac and Brady (1975b). Comparisons of the Trifunac-Brady results with those of the present study are shown in Figure 3-45 for a Magnitude 6.4, Type 3 earthquake and a 50 th percentile probability level. This figure shows the two sets of results to be quite similar, the only difference being in the somewhat greater sensitivity of the results of the present study to variations in site conditions. This excellent degree of comparison may not hold at higher magnitudes, however, where only scant ground motion motion data currently exist.

\subsubsection{SPECTRUM INTENSITY}

$$
\text { No regression analyses of spectrum intensity are known to have }
$$
been carried out to date; therefore, no comparisons with results from the present study could be made. 


\section{TABLE 3-1. REGRESSION COEFFICIENTS FOR STRENGTH PARAMETERS}

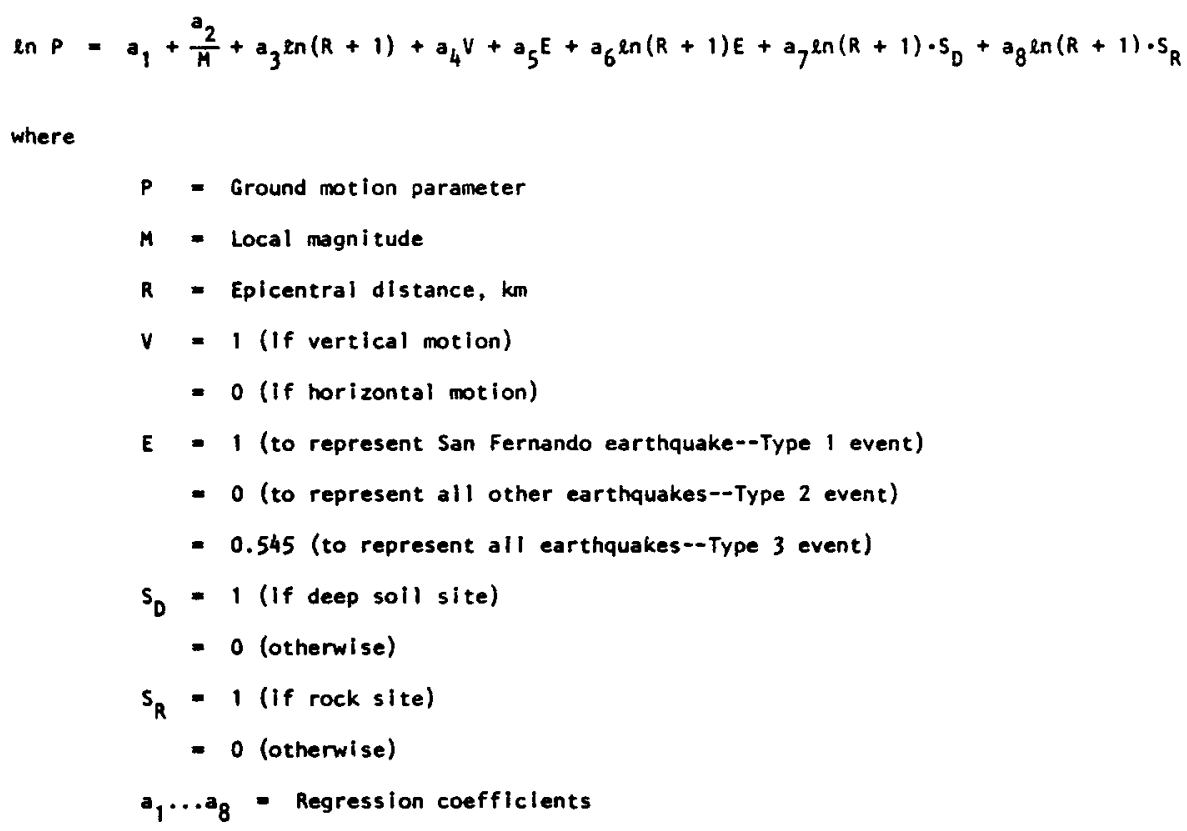

\begin{tabular}{|c|c|c|c|c|c|c|c|c|c|c|}
\hline \multirow{3}{*}{$\begin{array}{l}\text { Regression } \\
\text { Coefficlent } \\
\text { (Eq. 3-4) }\end{array}$} & \multicolumn{10}{|c|}{ Strength Parameter, $P$} \\
\hline & \multicolumn{2}{|c|}{$\begin{array}{l}\text { Peak Acceleration, } \\
\text { in. } / \mathrm{sec}^{2}\end{array}$} & \multicolumn{2}{|c|}{$\begin{array}{l}\text { Peak Velocity, } \\
\text { ips }\end{array}$} & \multicolumn{2}{|c|}{$\begin{array}{c}\text { Peak Displacement, } \\
\text { in. }\end{array}$} & \multicolumn{2}{|c|}{$\begin{array}{l}\text { Arias Intensity, } \\
\text { Ips }\end{array}$} & \multicolumn{2}{|c|}{$\begin{array}{c}\text { Spectrum Intensity, } \\
\text { in. }\end{array}$} \\
\hline & Value & Significance & Value & Signifl cance & Value & Significance & Value & Significance & Value & Significance \\
\hline$a_{1}$ & 12.381 & 1.000 & 8.604 & 1.000 & 5.889 & 1.000 & 17.750 & 1.000 & 9.579 & 1.000 \\
\hline$a_{2}$ & -32.853 & 1.000 & -31.988 & 1.000 & -26.869 & 1.000 & -69.520 & 1.000 & -34.234 & 1.000 \\
\hline$a_{3}$ & -1.010 & 1.000 & -0.663 & 1.000 & -0.363 & 1.000 & -1.528 & 1.000 & -0.648 & 1.000 \\
\hline$a_{4}$ & -0.674 & 1.000 & -0.756 & 1.000 & -0.590 & 1.000 & -1.262 & 1.000 & -0.762 & 1.000 \\
\hline$a_{5}$ & 1.716 & 1.000 & 2.979 & 1.000 & 3.106 & 1.000 & 4.171 & 1.000 & 3.673 & 1.000 \\
\hline$a_{6}$ & -0.379 & 1.000 & -0.658 & 1.000 & -0.675 & 1.000 & -0.911 & 1.000 & -0.850 & 1.000 \\
\hline$a_{7}$ & 0.0 & -- & 0.070 & 0.9994 & 0.062 & 0.9924 & 0.146 & 1.000 & 0.074 & 0.9997 \\
\hline$a_{8}$ & 0.0 & - & -0.146 & 1.000 & -0.168 & 1.000 & -0.137 & 0.9952 & -0.163 & 1.000 \\
\hline
\end{tabular}


TABLE 3-2. OUTLIERS FROM REGRESSION ANALYSES OF STRENGTH PARAMETERS

\begin{tabular}{|c|c|c|c|c|c|c|c|c|c|}
\hline \multirow[b]{2}{*}{$\begin{array}{l}\text { Strength } \\
\text { Parameter, P }\end{array}$} & \multicolumn{2}{|c|}{ Accelerograph Station } & \multicolumn{3}{|c|}{ Earthquake Event } & \multirow[b]{2}{*}{$\begin{array}{l}\text { Site } \\
\text { Classification }\end{array}$} & \multirow[b]{2}{*}{$\begin{array}{l}\text { Direction-- } \\
\text { Horizontal (H), } \\
\text { or Vertical (V) }\end{array}$} & \multirow[b]{2}{*}{$\begin{array}{l}\text { Value of } \\
\text { Parameter }\end{array}$} & \multirow[b]{2}{*}{$\begin{array}{l}\text { Deviatign } \\
\text { of in } p(1)\end{array}$} \\
\hline & Location & $\begin{array}{c}\text { Epicentral } \\
\text { Distance, } \\
\mathrm{km}\end{array}$ & Location & Date & Magni tude & & & & \\
\hline $\begin{array}{l}\text { Peak } \\
\text { Acceleration } \\
\left(\text { in } / \sec ^{2}\right)\end{array}$ & $\begin{array}{l}\text { Long Beach, California } \\
\text { Public Utilities Bldg } \\
\text { El Centro, Callfornla } \\
\text { Terminal Substation } \\
\text { Cholame-Shandon, } \\
\text { Callfornia, Array No. } 5\end{array}$ & $\begin{array}{r}62 \\
236 \\
324\end{array}$ & $\begin{array}{l}\text { Torrance-Gardena, } \\
\text { Callfornia } \\
\text { Imperial valley, } \\
\text { Callfornia } \\
\text { Parkfield, } \\
\text { Callifornia }\end{array}$ & $\begin{array}{l}11-14-41 \\
1-13-53 \\
6-27-66\end{array}$ & $\begin{array}{l}54 \\
55 \\
60\end{array}$ & $\begin{array}{l}\text { Undefined } \\
\text { Deep Soil } \\
\text { Undef ined }\end{array}$ & $\begin{array}{l}\checkmark \\
H \\
H\end{array}$ & $\begin{array}{r}334 \\
284 \\
16759\end{array}$ & $\begin{array}{l}-420 \\
-370 \\
+310\end{array}$ \\
\hline $\begin{array}{l}\text { Peak } \\
\text { Velocity } \\
\text { (ips) }\end{array}$ & $\begin{array}{l}\text { Long Beach, Callfornia } \\
\text { Public Utlilities BIdg } \\
\text { Tehachapl Pumplng Plant, } \\
\text { Grapevine, California } \\
\text { Temblor, California } \\
\text { Mo } 2 \\
\text { Ft Tejon, } \\
\text { Tejon, Cali fornia } \\
\text { Los Angeles, California } \\
\text { Subway Terminal, } \\
\text { Subbasement }\end{array}$ & $\begin{array}{l}272 \\
70.7 \\
310 \\
685 \\
549\end{array}$ & $\begin{array}{l}\text { Long Beach, } \\
\text { California } \\
\text { San Fernando, } \\
\text { California } \\
\text { Parkfield, } \\
\text { California } \\
\text { San Fernando, } \\
\text { Callifornia } \\
\text { Long Beach, } \\
\text { California }\end{array}$ & $\begin{array}{l}3-10-33 \\
2-9-71 \\
6-27-66 \\
2-9-71 \\
3-10-33\end{array}$ & $\begin{array}{l}63 \\
64 \\
60 \\
64 \\
63\end{array}$ & $\begin{array}{l}\text { Undefined } \\
\text { Undefined } \\
\text { Rock } \\
\text { Intermed ate } \\
\text { Undefined }\end{array}$ & $\begin{array}{l}\text { V } \\
\text { H } \\
\text { H } \\
\text { H } \\
\text { H }\end{array}$ & $\begin{array}{l}1188 \\
045 \\
887 \\
052 \\
933\end{array}$ & $\begin{array}{l}+360 \\
-330 \\
+320 \\
-310 \\
+300\end{array}$ \\
\hline $\begin{array}{l}\text { Pesk } \\
\text { olsplacement } \\
\text { (in) }\end{array}$ & $\begin{array}{l}\text { Long Beach, Callfornis } \\
\text { Pubile Utilities Bldg } \\
\text { Los Angeles, Callfornia } \\
\text { Subway Terminal. } \\
\text { Subbasement }\end{array}$ & $\begin{array}{l}272 \\
54.9\end{array}$ & $\begin{array}{l}\text { Long Beach, } \\
\text { Callifornia } \\
\text { Long Beach, } \\
\text { California }\end{array}$ & $\begin{array}{l}3-10-33 \\
3-10-33\end{array}$ & $\begin{array}{l}63 \\
63\end{array}$ & $\begin{array}{l}\text { Undefined } \\
\text { Undefined }\end{array}$ & $\begin{array}{l}V \\
\text { H }\end{array}$ & $\begin{array}{l}1039 \\
643\end{array}$ & $\begin{array}{l}+410 \\
+310\end{array}$ \\
\hline $\begin{array}{l}\text { Arlas } \\
\text { Intensity } \\
\text { (Ips) }\end{array}$ & $\begin{array}{l}\text { El Centro, Callfornla } \\
\text { Terminal Substation } \\
\text { Long Beach, Callfornia } \\
\text { Public Utilitites Bldg } \\
\text { Tehachapi Pumping Plant, } \\
\text { Grapevine, California } \\
\text { Long Beach, Callfornia } \\
\text { Public Utilities Bidg }\end{array}$ & $\begin{array}{l}236 \\
6.2 \\
707 \\
272\end{array}$ & $\begin{array}{l}\text { Imperial valley, } \\
\text { Callifornia } \\
\text { Torrance-Gardena, } \\
\text { California } \\
\text { San Fernando, } \\
\text { California } \\
\text { Long Beach, } \\
\text { California }\end{array}$ & $\begin{array}{l}1-13-53 \\
11-14-41 \\
2-9-71 \\
3-10-33\end{array}$ & $\begin{array}{l}55 \\
54 \\
64 \\
63\end{array}$ & $\begin{array}{l}\text { Deep Soil } \\
\text { Undefined } \\
\text { Undef ined } \\
\text { Undefined }\end{array}$ & $\begin{array}{l}H \\
\text { V } \\
\text { H } \\
\text { V }\end{array}$ & $\begin{array}{r}024 \\
053 \\
073 \\
15041\end{array}$ & $\begin{array}{l}-440 \\
-350 \\
-330 \\
+300\end{array}$ \\
\hline $\begin{array}{l}\text { Spectrum } \\
\text { Intensity } \\
\text { (in) }\end{array}$ & $\begin{array}{l}\text { Los Angeles, California } \\
\text { Subway Terminal, } \\
\text { Subbasement } \\
\text { Hollister Public Library } \\
\text { El Centro, California } \\
\text { Terminal Substation } \\
\text { Ft Tejon, } \\
\text { Tejon, Cailfornia } \\
\text { Tehachapi Punping Plant, } \\
\text { Grapevine, California } \\
\text { Los Angeles, California } \\
\text { Subway Terminal, } \\
\text { Subbasement }\end{array}$ & $\begin{array}{l}549 \\
390 \\
236 \\
685 \\
707 \\
549\end{array}$ & $\begin{array}{l}\text { Long Beach, } \\
\text { California } \\
\text { Northern Call fornia } \\
\text { Imperial Valley } \\
\text { California } \\
\text { San Fernando, } \\
\text { California } \\
\text { San Fernando, } \\
\text { California } \\
\text { Long Beach, } \\
\text { California }\end{array}$ & $\begin{array}{l}3-10-33 \\
12-18-67 \\
1-13-53 \\
2-9-71 \\
2-9-71 \\
3-10-33\end{array}$ & $\begin{array}{l}63 \\
52 \\
55 \\
64 \\
64 \\
63\end{array}$ & $\begin{array}{l}\text { Undefined } \\
\text { Undef Ined } \\
\text { Deep SoIl } \\
\text { Intermed iate } \\
\text { Undef ined } \\
\text { Undefined }\end{array}$ & $\begin{array}{l}V \\
V \\
\text { H } \\
\text { H } \\
\text { H } \\
\text { H }\end{array}$ & $\begin{array}{l}1757 \\
700 \\
065 \\
077 \\
077 \\
2056\end{array}$ & $\begin{array}{l}+430 \\
+380 \\
-350 \\
-330 \\
-330 \\
+320\end{array}$ \\
\hline
\end{tabular}

Hote (1) $\sigma$ - standard deviation of $2 n \mathrm{P}$, where $P$ is the strength oarameter (see Table 3-3) 
TABLE 3-3. DATA-FIT PARAMETERS--STRENGTH OF GROUND SHAKING

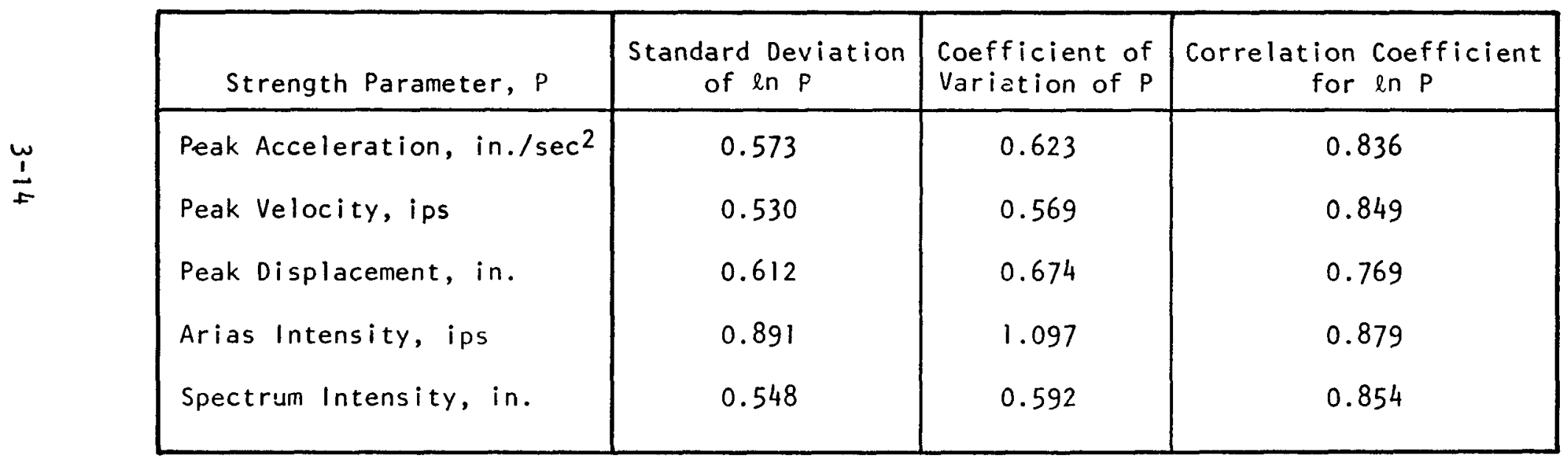




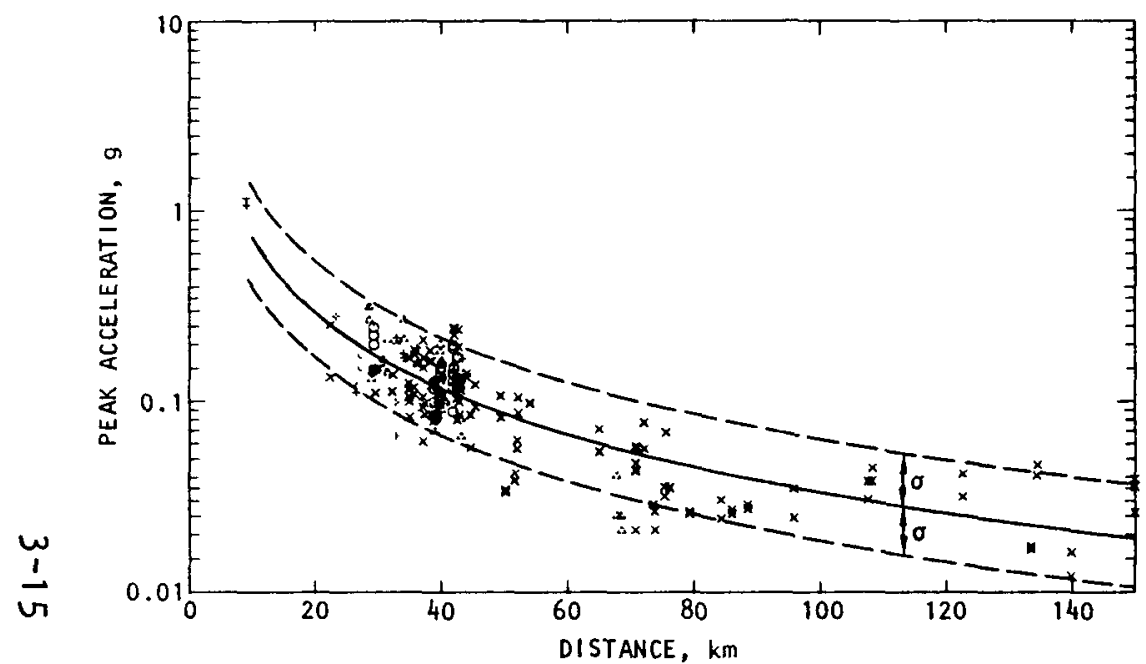

(a) Horizontal

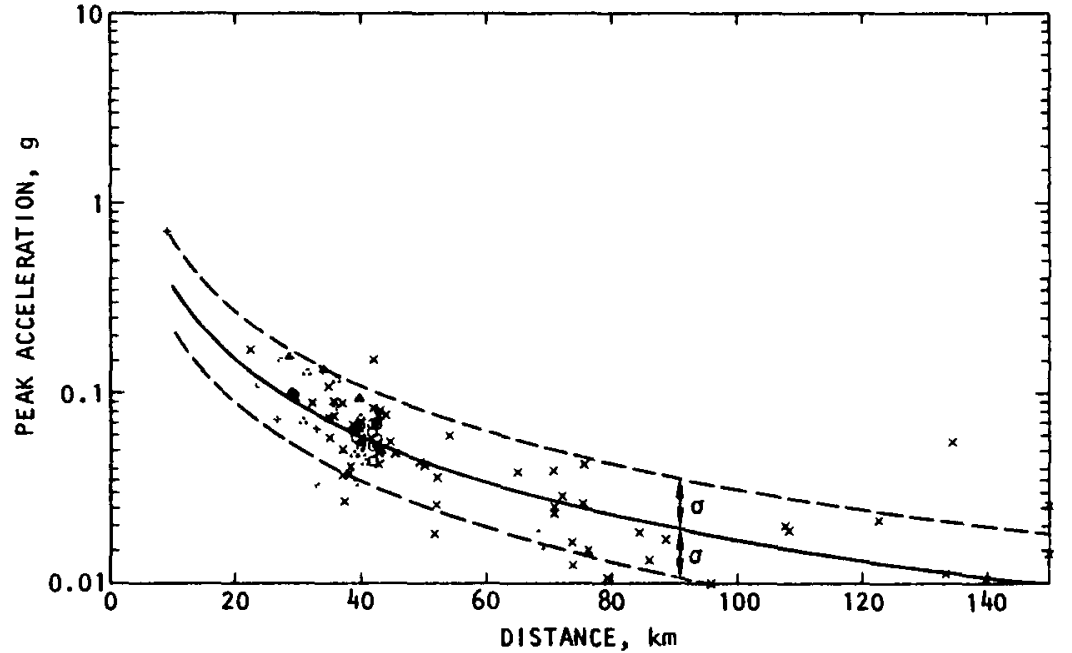

(b) Vertical

LEGEND:

DATA POINTS

- DEEP SOIL SITE

$\triangle$ INTERMEDIATE SITE

+ ROCK SITE

$\times$ UNDEFINED SITE CONDITIONS
REGRESSION ANALYSIS (FOR TYPE I EVENTS) 50 th PERCENTILE (ALL SITE CONDITIONS) 16th PERCENTILE AND 84 th PERCENTILE BOUNDS (ALL SITE CONDITIONS)
NOTE :

- - standard oeviation of in (PEAK ACCELERATION) FIGURE 3-1. COMPARISON BETWEEN COMPUTED AND RECORDED PEAK ACCELERATIONS - TYPE 1
EARTHQUAKE EVENTS 


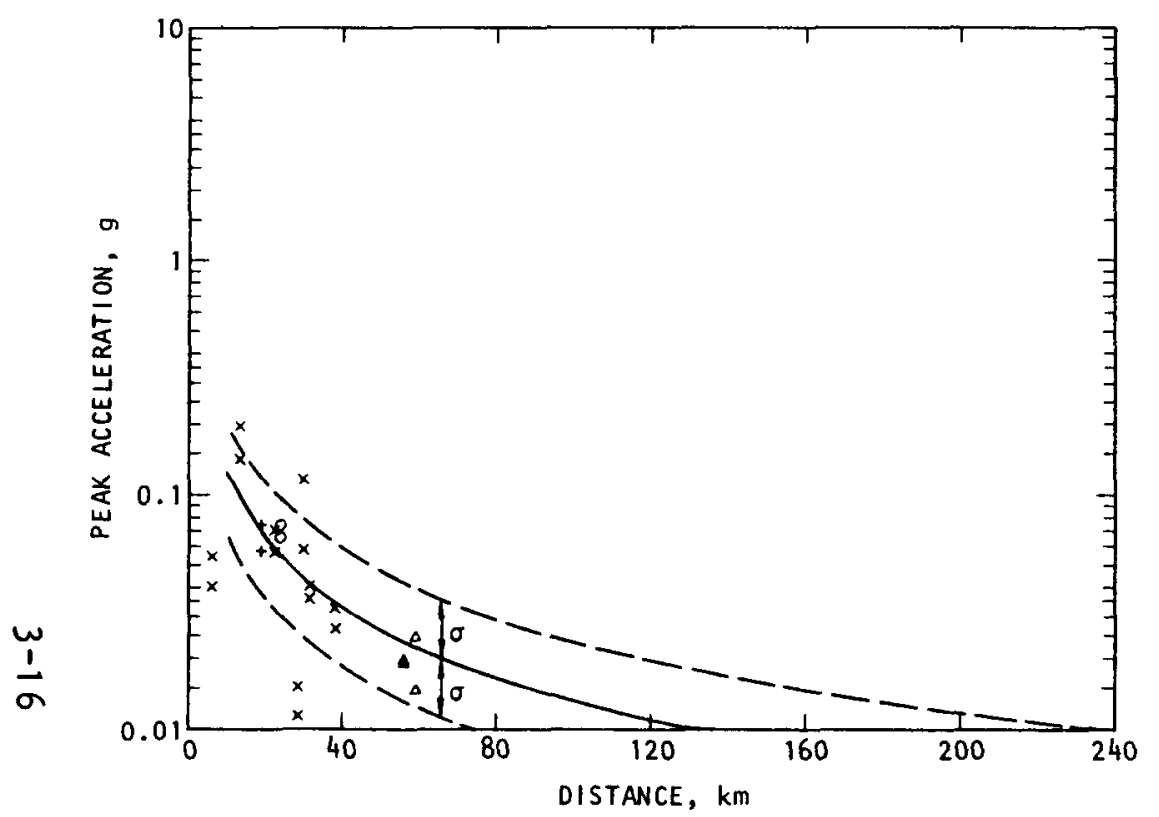

(a) Horizontal

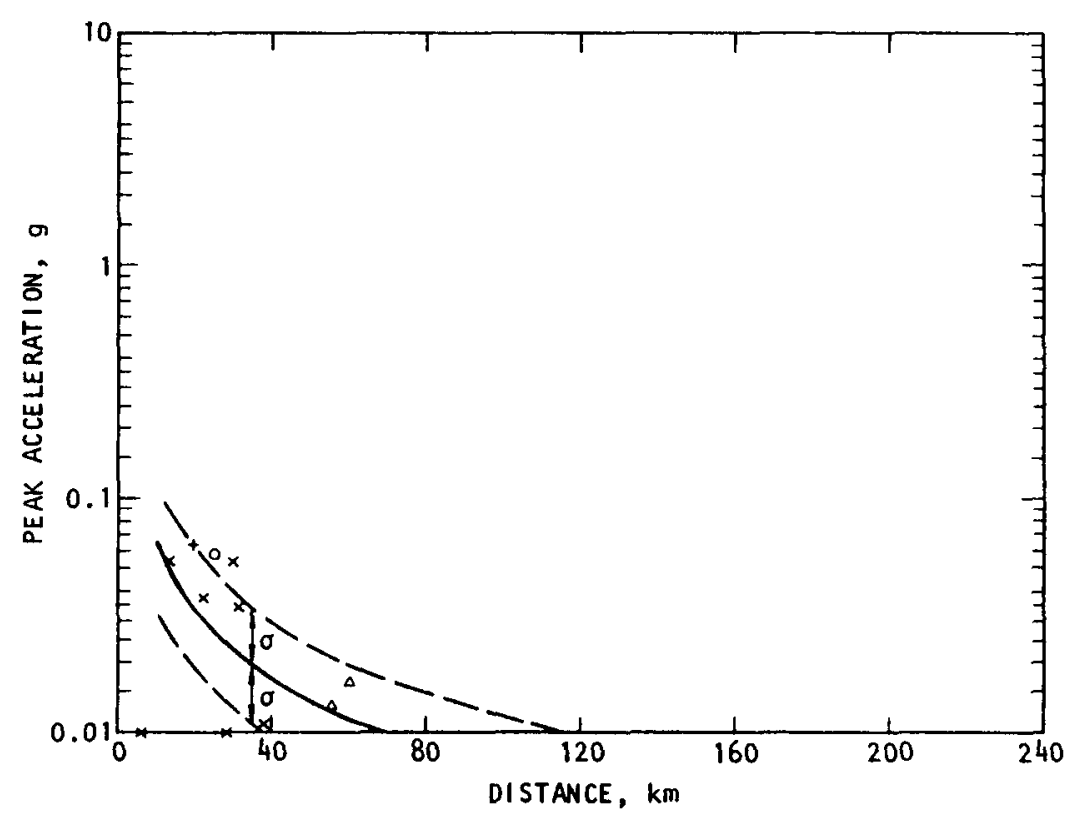

(b) Vertical

LEGEND:

DATA POINTS

- DEEP SOIL SITE

$\triangle$ INTERMEDIATE SITE

+ ROCK SITE

$\times$ UNDEFINED SITE CONDITIONS
REGRESSION ANALYSIS (FOR TYPE 2 EVENTS)

50th PERCENTILE (ALL SITE CONDITIONS)

16th PERCENTILE AND 84th PERCENTILE BOUNDS (ALL SITE CONDITIONS)
NOTE:

$\sigma$ - STANOARD DEVIATION OF In (PEAK ACCELERATION)

FIGURE 3-2. COMPARISON BETWEEN COMPUTED AND RECORDED PEAK ACCELERATIONS - TYPE 2 EARTHQUAKE EVENTS WITH MAGNITUDE 5.4 


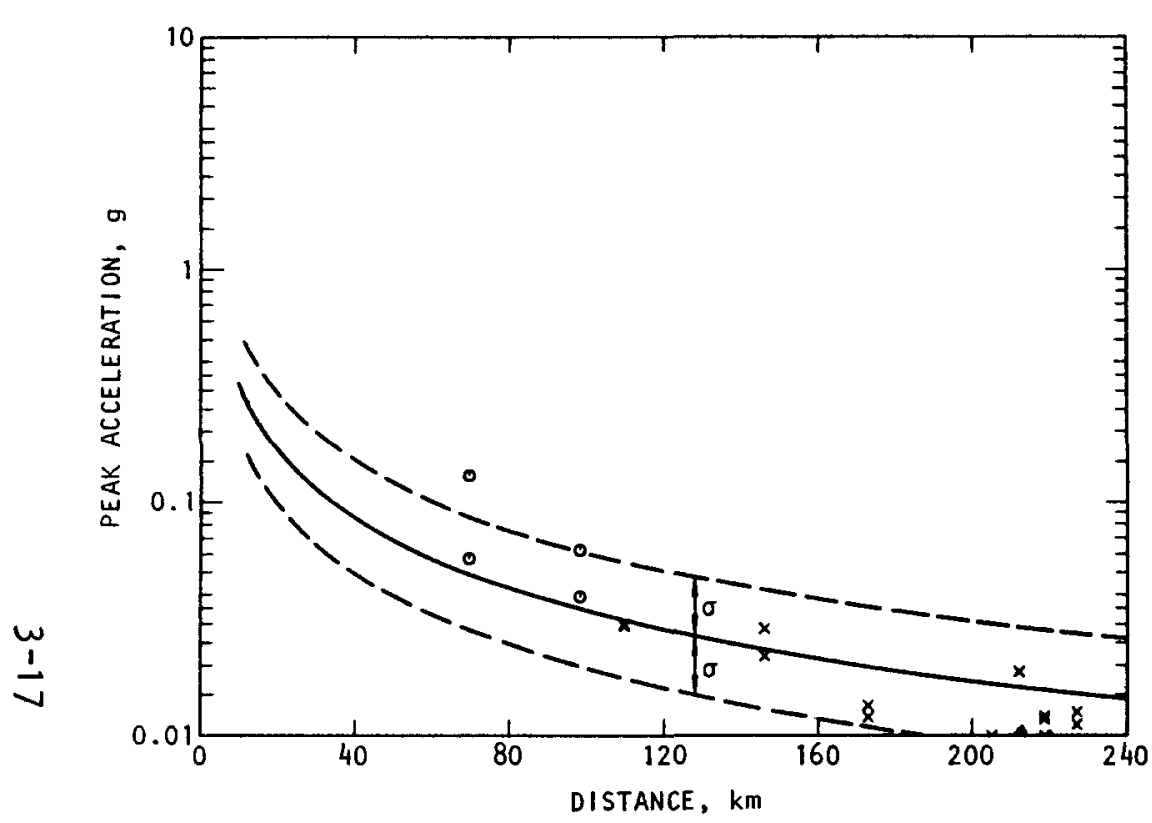

(a) Horizontal

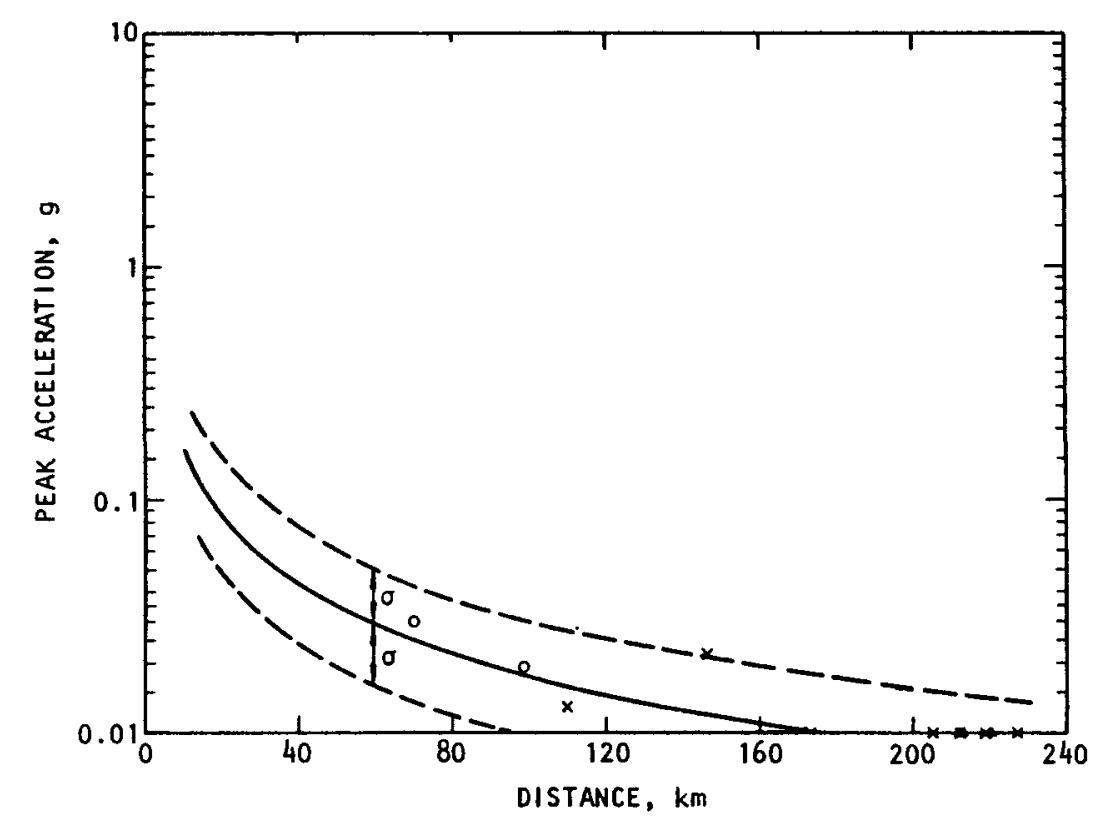

(b) Vertical

LEGEND:

DATA POINTS

- DEEP SOIL SITE

$\triangle$ INTERMEDIATE SITE

+ ROCK SITE

$\times$ UNDEFINED SITE CONDITIONS
REGRESSION ANALYSIS (FOR TYPE 2 EVENTS)

50th PERCENTILE (ALL SITE CONDITIONS)

16 th PERCENTILE AND 84th PERCENTILE

BOUNDS (ALL SITE CONDITIONS)
NOTE :

$\sigma=$ STANDARD DEVIATION OF In (PEAK ACCELERATION)

FIGURE 3-3. COMPARISON BETWEEN COMPUTED AND RECORDED PEAK ACCELERATIONS - TYPE 2 EARTHQUAKE EVENTS WITH MAGNITUDE 6.4 


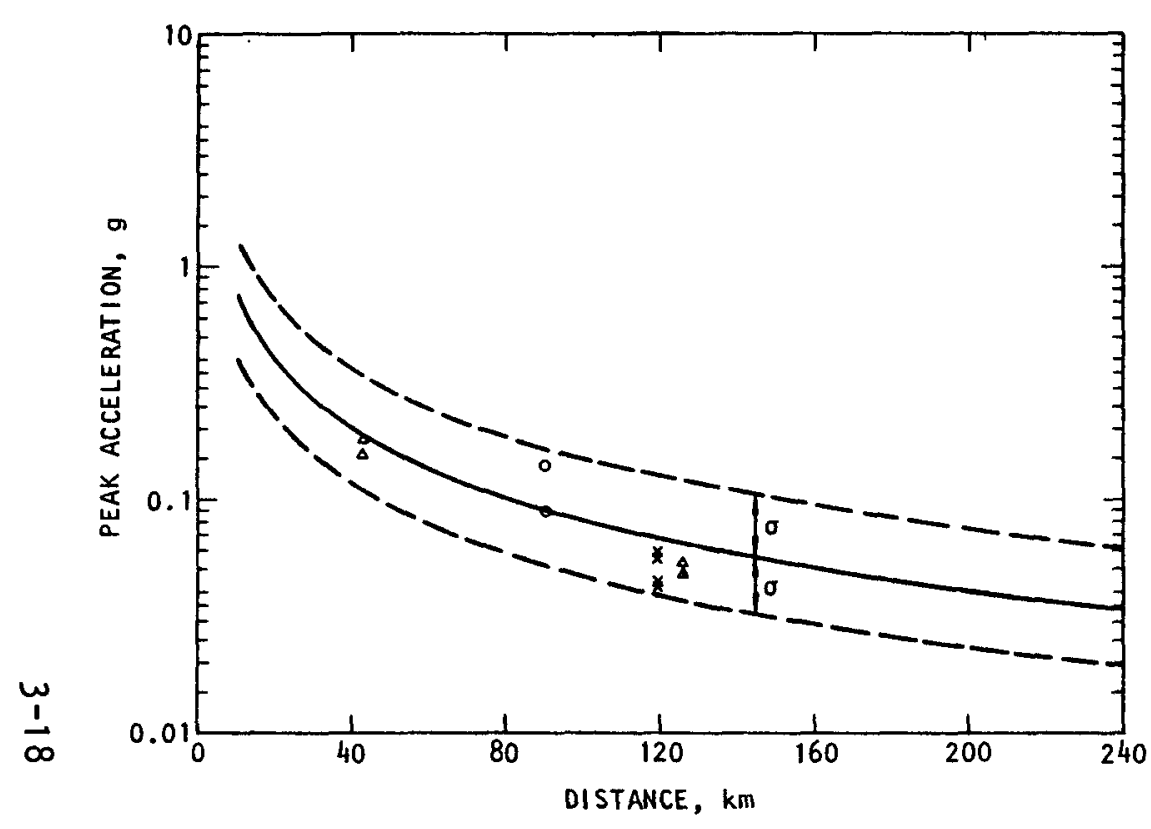

(a) Horizontal

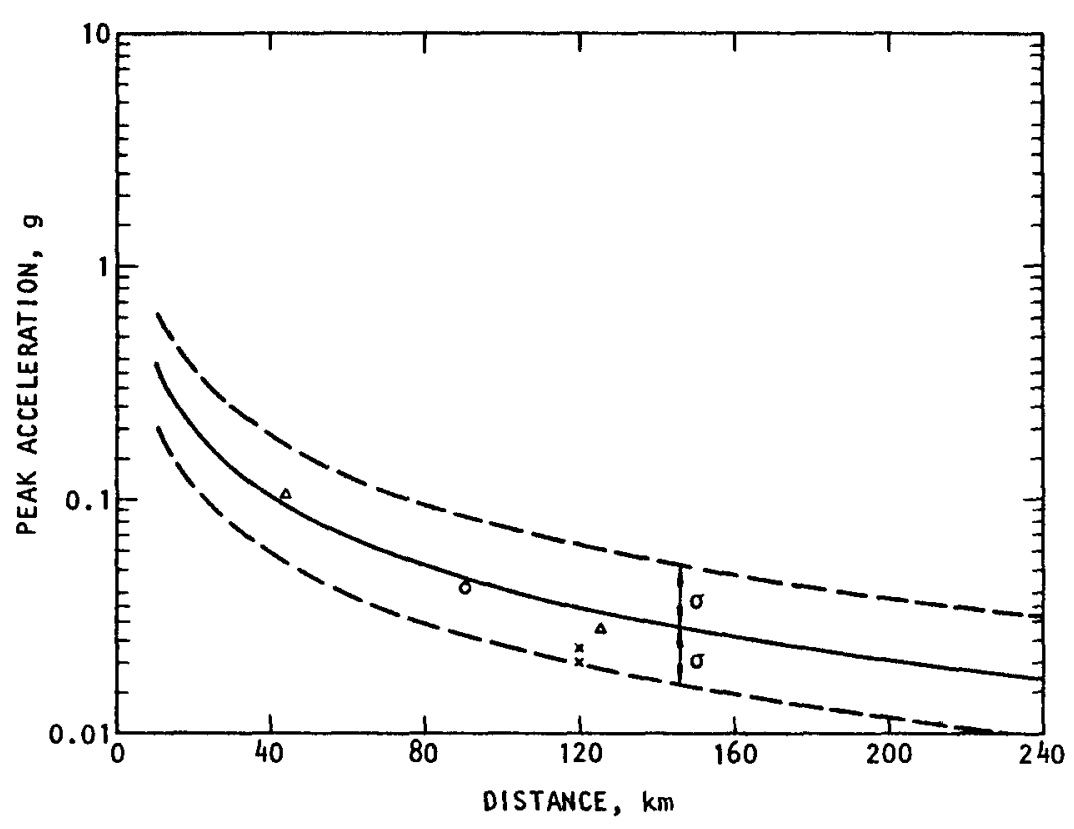

(b) Vertical
LEGEND:

DATA POINTS

- DEEP SOIL SITE

$\triangle$ INTERMEDIATE SITE

+ ROCK SITE

$\times$ UNDEFINED SITE CONDITIONS
REGRESSION ANALYSIS (FOR TYPE 2 EVENTS) 50th PERCENTILE (ALL SITE CONDITIONS) 16 th PERCENTILE AND 84th PERCENTILE BOUNDS (ALL SITE CONDITIONS)
NOTE:

O = STANDARD DEVIATION OF In (PEAK ACCELERATION)

FIGURE 3-4. COMPARISON BETWEEN COMPUTED AND RECORDED PEAK ACCELERATIONS - TYPE 2 EARTHQUAKE EVENTS WITH MAGN ITUDE 7.7 


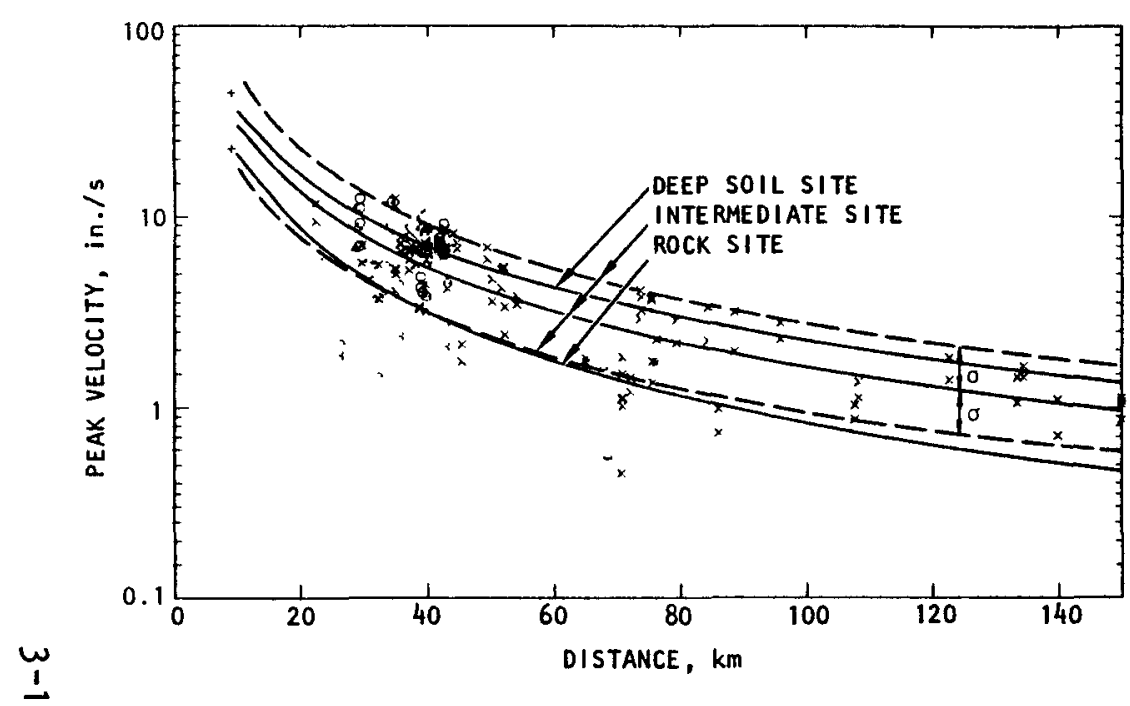

(a) Horizontal

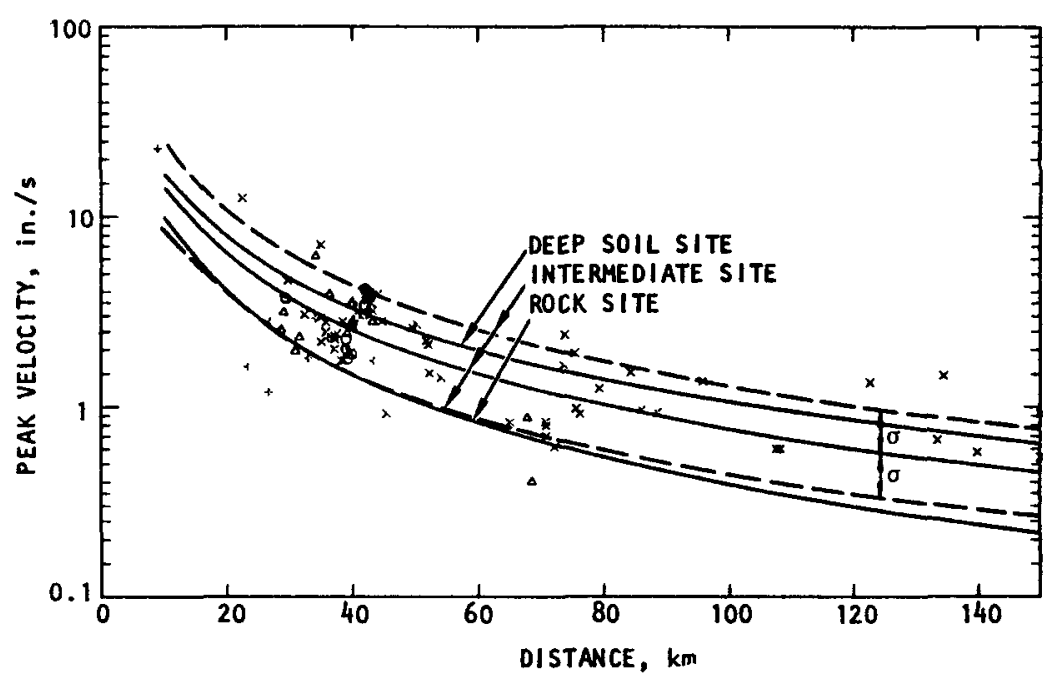

(b) Vertical

LEGEND:

DATA POINTS

- DEEP SOIL SITE

$\triangle$ INTERMEDIATE

+ ROCK SITE

$x$ UNDEFINED SITE CONDITIONS
REGRESSION ANALYSIS (FOR TYPE I EVENTS)

50th PERCENTILE (FOR EACH SITE CONDITION)

- -16 th PERCENTILE AND 84th PERCENTILE BOUNDS (FOR INTERMEDIATE SITE CONDITION ONLY)
NOTE :

$\sigma=$ STANDARD DEVIATION OF

In (PEAK VELOCITY)

FIGURE 3-5. COMPARISON BETWEEN COMPUTED AND RECORDED PEAK VELOCITIES FOR VARIOUS SITE CONDITIONS - TYPE 1 EARTHQUAKE EVENTS 


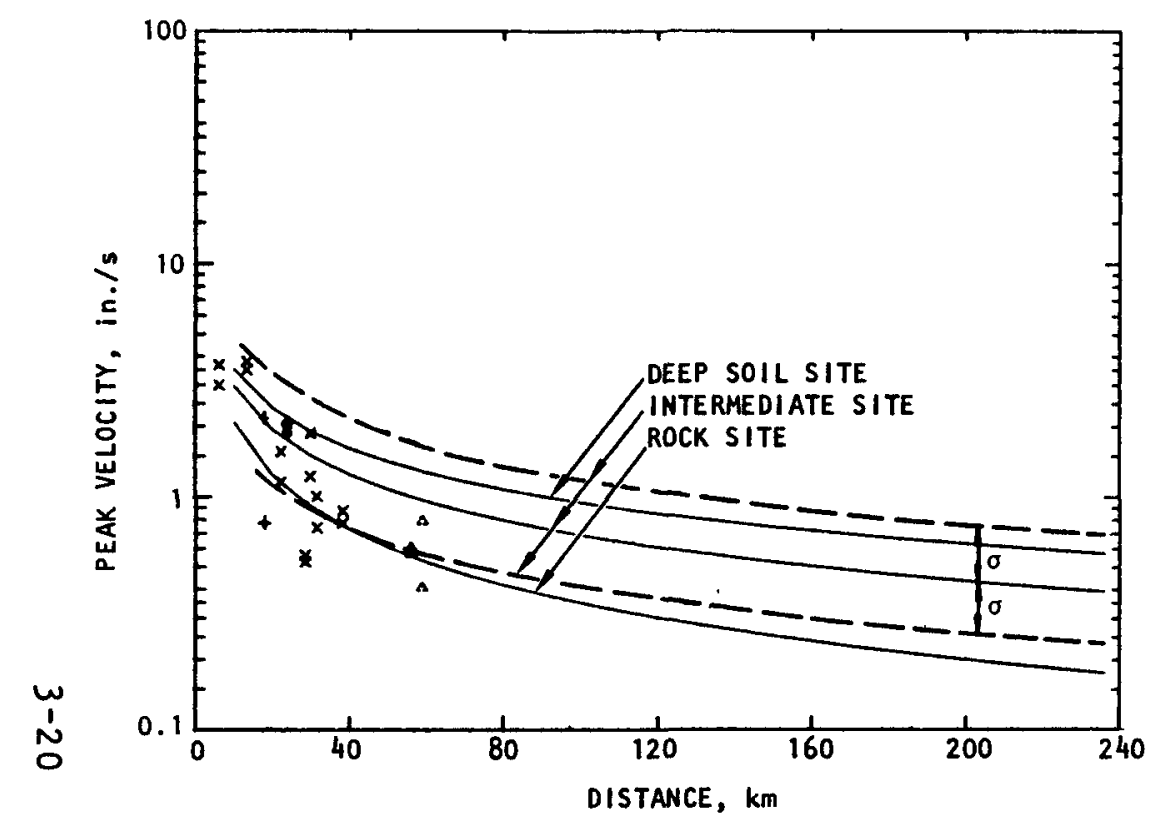

(a) Horizontal

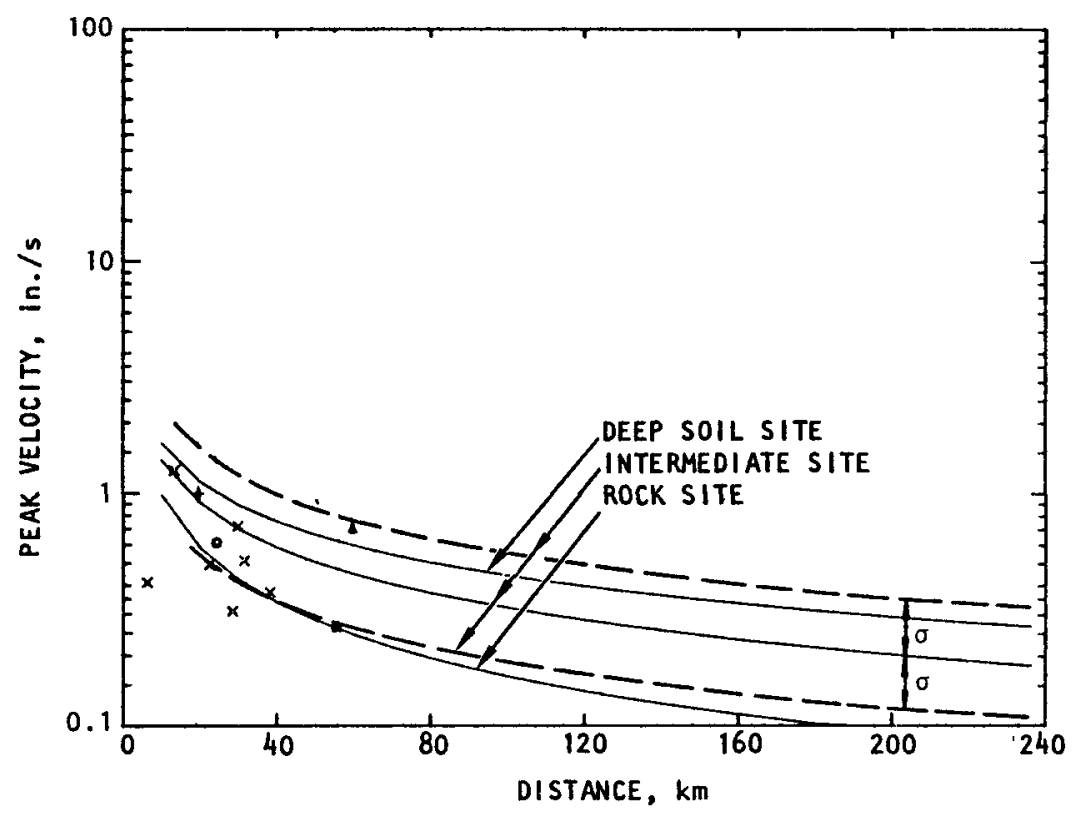

(b) Vertical

LEGEND:

DATA POINTS

- DEEP SOIL SITE

$\triangle$ INTERMEDIATE

+ ROCK SITE

$\times$ UNDEFINED SITE CONDITIONS
REGRESSION ANALYSIS (FOR TYPE 2 EVENTS)

50th PERCENTILE (FOR EACH SITE CONDITION)

- - 16th PERCENTILE AND 84th PERCENTILE BOUNDS (FOR INTERMEDIATE SITE CONDITION ONLY)
NOTE : $\begin{aligned} \sigma= & \text { STANDARD DEVIATION OF } \\ & \ln \text { (PEAK VELOCITY) }\end{aligned}$

FIGURE 3-6. COMPARISON BETWEEN COMPUTED AND RECORDED PEAK VELOCITIES FOR VARIOUS SITE CONDITIONS - TYPE 2 EARTHQUAKE EVENTS WITH MAGNITUDE 5.4 


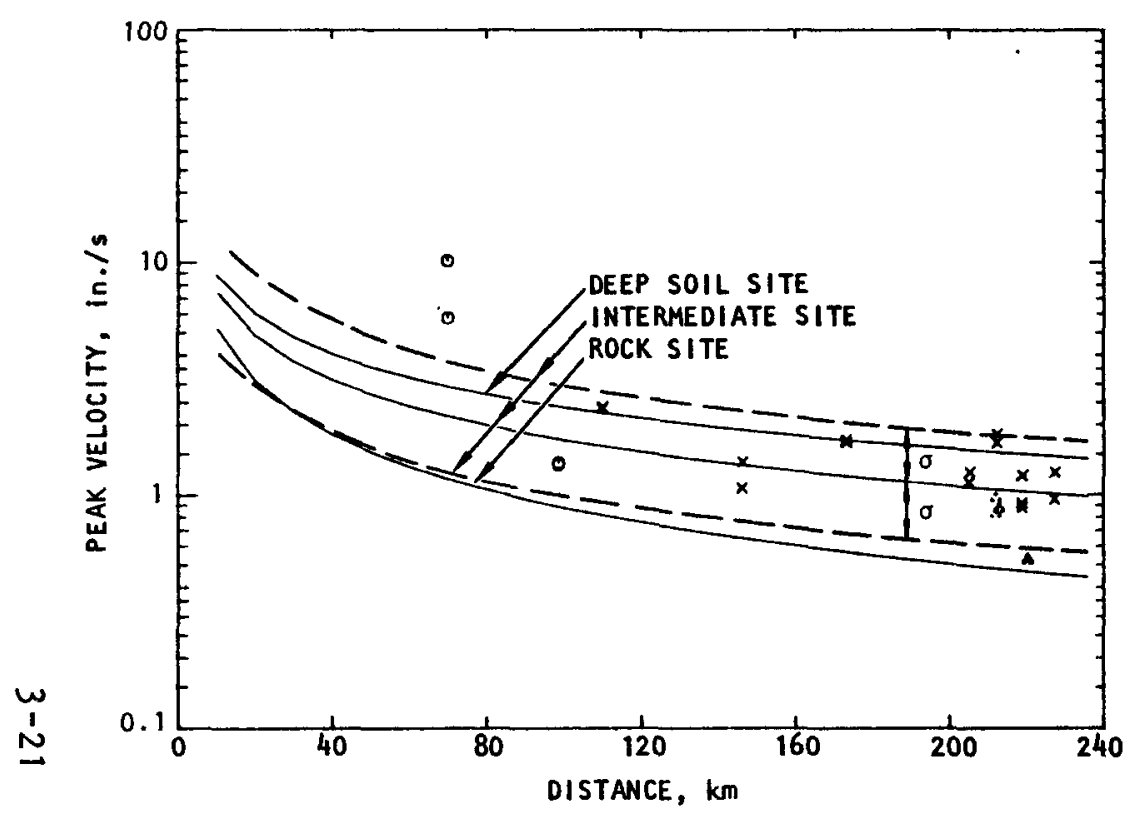

(a) Horizontal

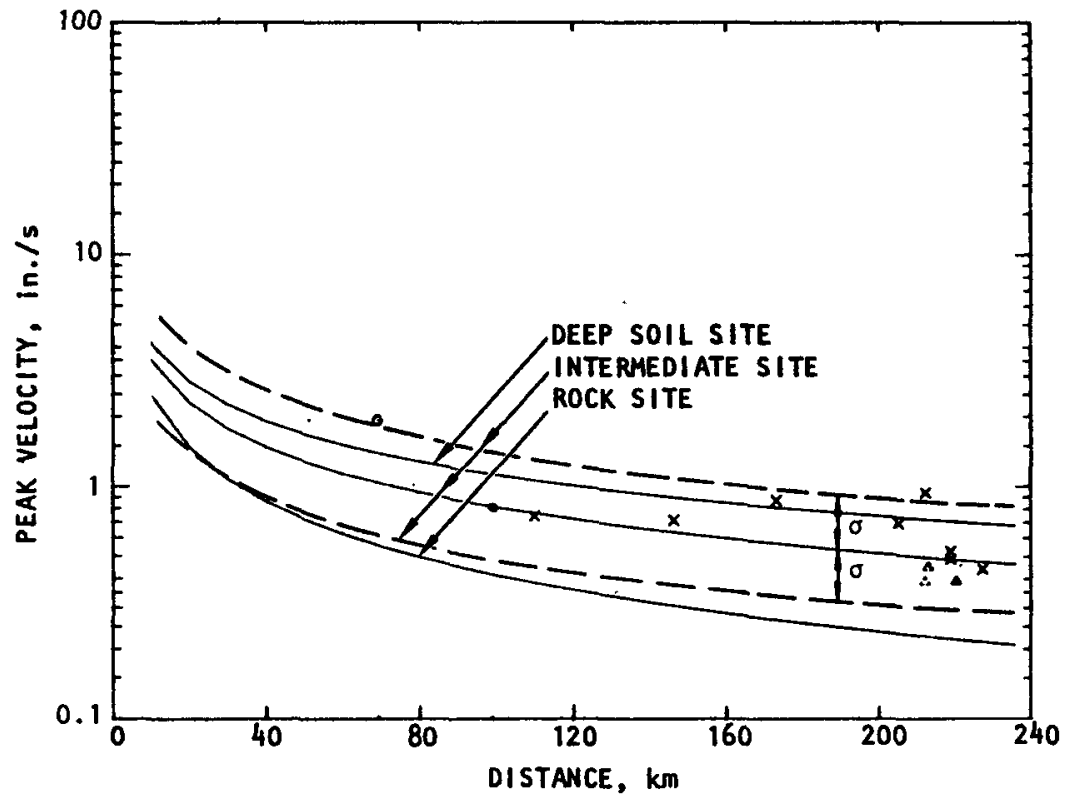

(b) Vertical

LEGEND :

DATA POINTS

- DEEP SOIL SITE

$\triangle$ INTERMEDIATE

+ ROCK SITE

$x$ UNDEFINED SITE CONDITIONS

\section{REGRESSION ANALYSIS (FOR TYPE 2 EVENTS)}

50th PERCENTILE (FOR EACH SITE CONDITION)

- 16 th PERCENTILE AND 84 th PERCENTILE BOUNDS

(FOR INTERMEDIATE SITE CONDITION ONLY)
NOTE :

$\sigma$ = STANDARD DEVIATION OF

ln (PEAK VELOCITY)

FIGURE 3-7. COMPARISON BETWEEN COMPUTED AND RECORDED PEAK VELOCITIES FOR VARIOUS SITE CONDITIONS - TYPE 2 EARTHQUAKE EVENTS WITH MAGNITUDE 6.4 


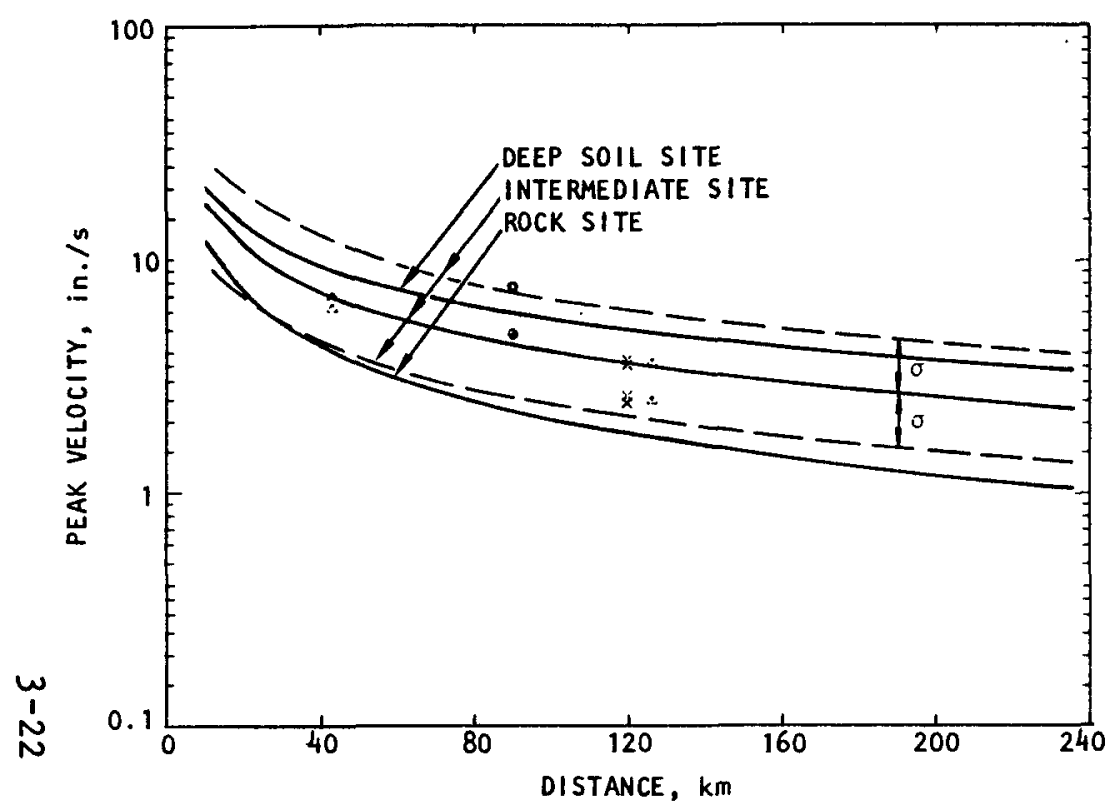

(a) Horizontal

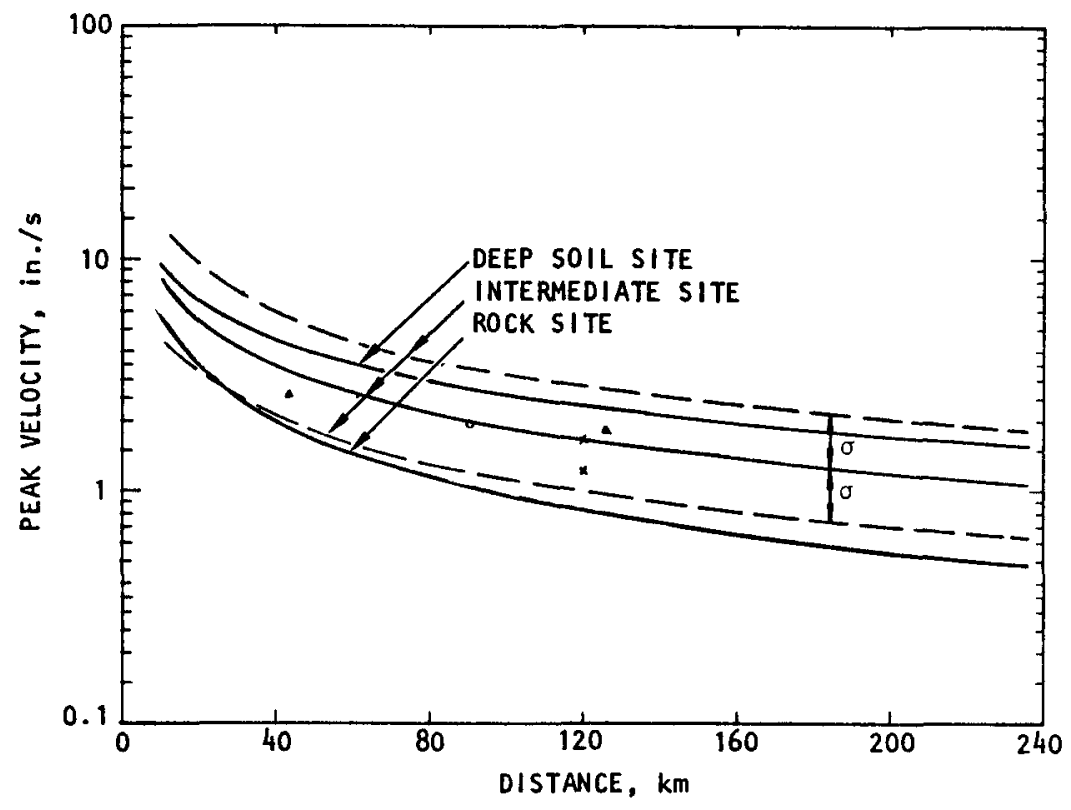

(b) Vertical

LEGEND:

DATA POINTS

- DEEP SOIL SITE

$\triangle$ INTERMEDIATE

+ ROCK SITE

$x$ UNDEFINED SITE CONDITIONS

\section{REGRESSION ANALYSIS (FOR TYPE 2 EVENTS)}

50th PERCENTILE (FOR EACH SITE CONDITION)

- -16 th PERCENTILE AND 84th PERCENTILE BOUNDS (FOR INTERMEDIATE SITE CONDITION ONLY)
NOTE :

$\sigma=$ STANDARD DEVIATION OF ln (PEAK VELOCITY)

FIGURE 3-8. COMPARISON BETWEEN COMPUTED AND RECORDED PEAK VELOCITIES FOR VARIOUS SITE CONDITIONS - TYPE 2 EARTHQUAKE EVENTS WITH MAGNITUDE 7.7 


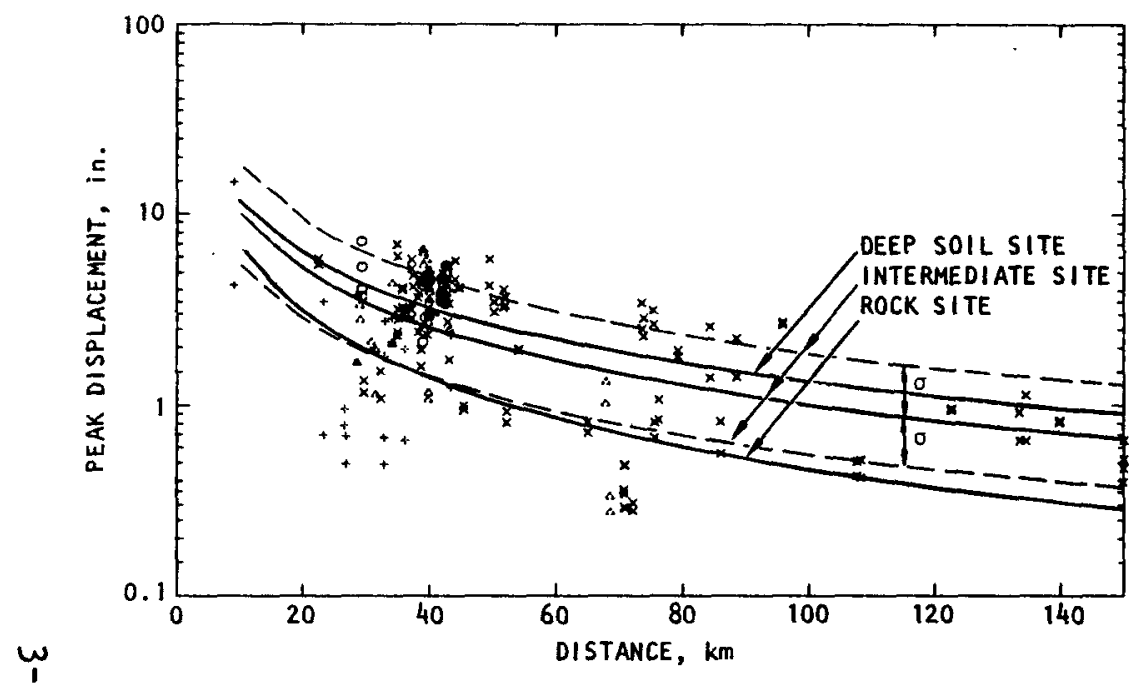

(a) Horizontal

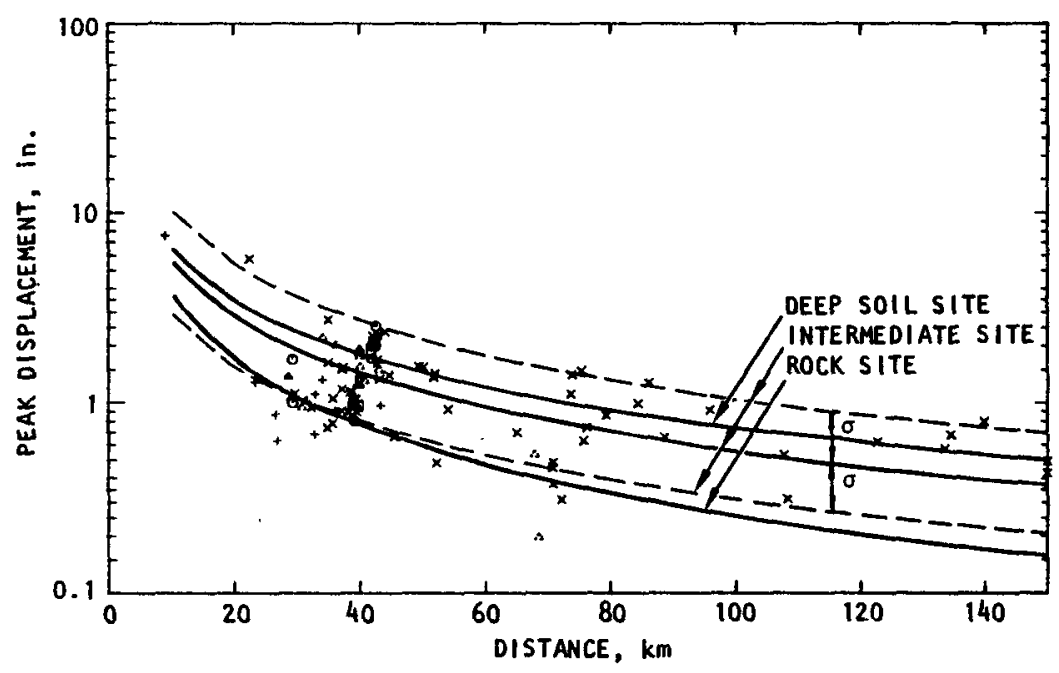

(b) Vertical

LEGEND:

DATA POINTS

- DEEP SOIL SITE

$\triangle$ INTERMEDIATE

+ ROCK SITE

$\triangle$ UNDEFINED SITE CONDITIONS
REGRESSION ANALYSIS (FOR TYPE 1 EVENTS)

50th PERCENTILE (FOR EACH SITE CONDITION)

16 th PERCENT!LE AND 84 th PERCENTILE BOUNDS (FOR INTERMEDIATE SITE CONDITION ONLY)
NOTE:

$\sigma=$ STANDARD DEVIATION OF ln (PEAK DISPLACEMENT)

FIGURE 3-9. COMPARISON BETWEEN COMPUTED AND RECORDED PEAK DISPLACEMENTS FOR VARIOUS SITE CONDITIONS - TYPE 1 EARTHQUAKE EVENTS 


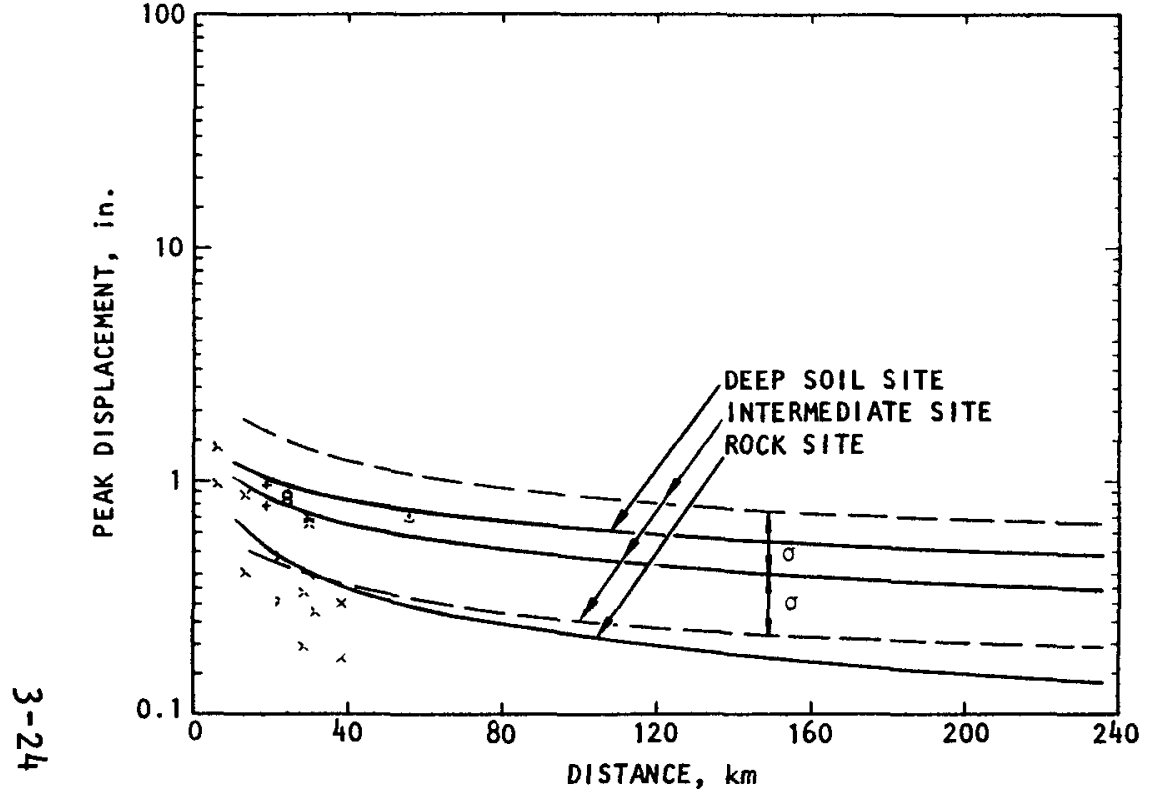

(a) Horizontal

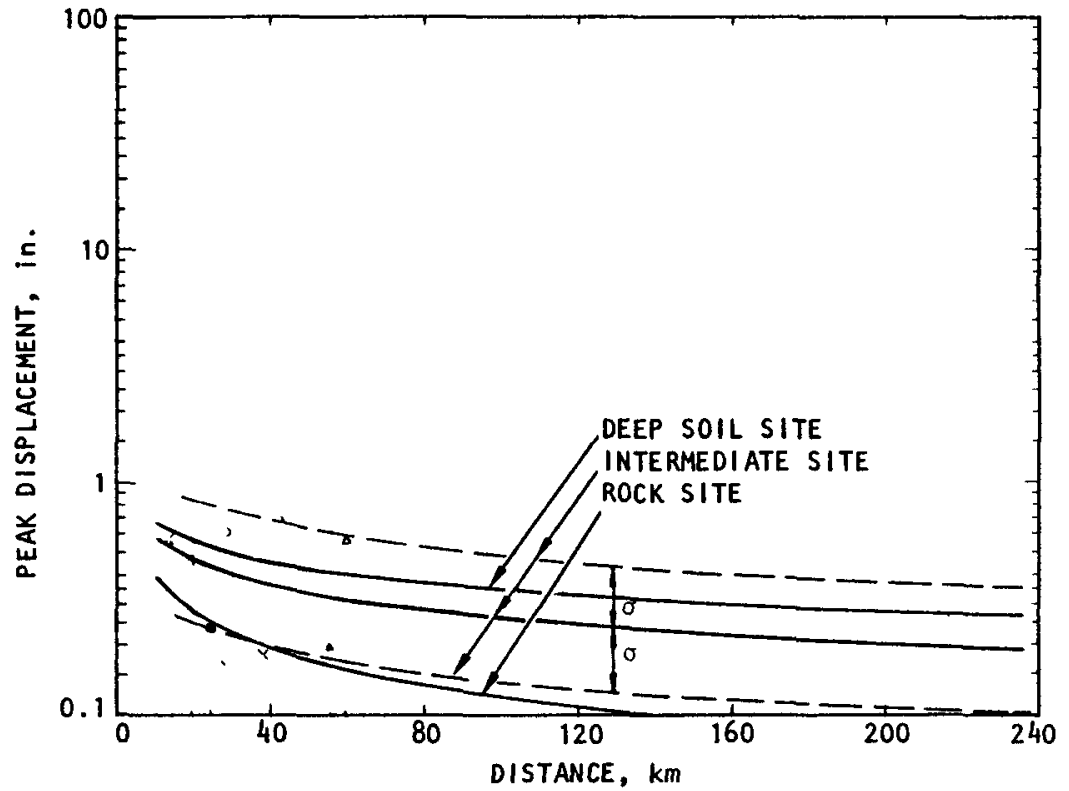

(b) Vertical

LEGEND:

DATA POINTS

- DEEP SOIL SITE

$\triangle$ INTE RMEDIATE

+ ROCK SITE

$\times$ UNDEFINED SITE CONDITIONS
REGRESSION ANALYSIS (FOR TYPE 2 EVENTS)

50th PERCENTILE (FOR EACH SITE CONDITION)

- - 16 th PERCENTILE AND 84th PERCENTILE BOUNDS (FOR INTERMEDIATE SITE CONDITION ONLY)
NOTE :

$\sigma=$ STANDARD DEVIATION OF in (PEAK DISPLACEMENT)

FIGURE 3-10. COMPARISON BETWEEN COMPUTED AND RECORDED PEAK DISPLACEMENTS FOR VARIOUS SITE CONDITIONS - TYPE 2 EARTHQUAKE EVENTS WITH MAGNITUDE 5.4 


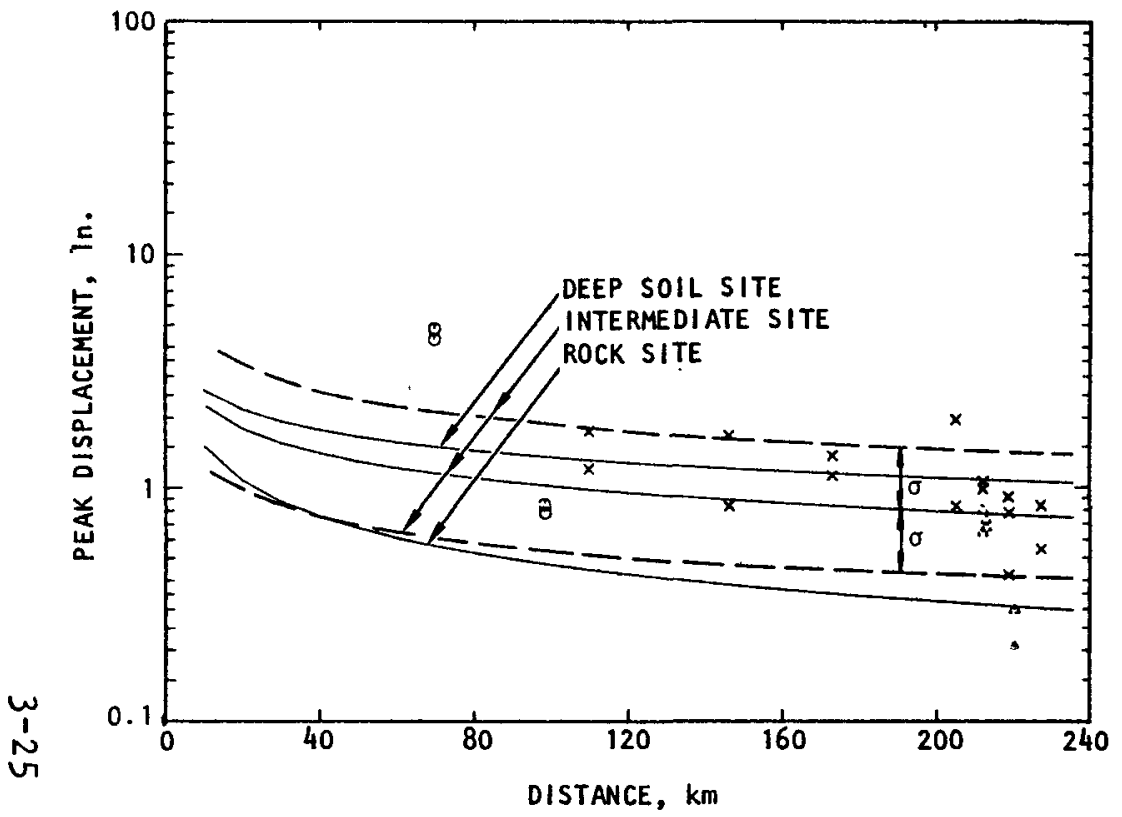

(a) Horizontal

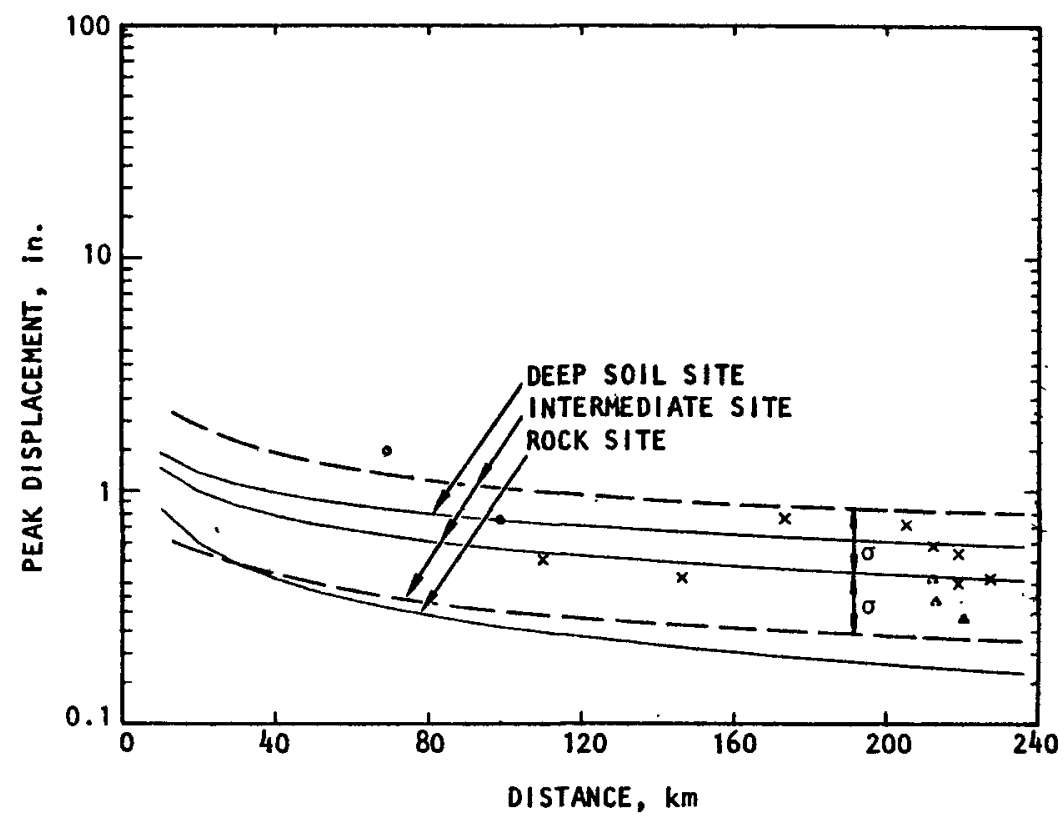

(b) Vertical

LEGEND:

DATA POINTS

- DEEP SOIL SITE

$\triangle$ INTERMEDIATE

+ ROCK SITE

$x$ UNDEFINED SITE CONDITIONS
REGRESSION ANALYSIS (FOR TYPE 2 EVENTS)

50th PERCENTILE (FOR EACH SITE CONDITION)

16th PERCENTILE AND 84th PERCENTILE BOUNDS

(FOR INTERMEDIATE SITE CONDITION ONLY)
NOTE :

$\sigma=$ STANDARD DEVIATION OF en (PEAK DISPLACEMENT)

FIGURE 3-11. COMPARISON BETWEEN COMPUTED AND RECORDED PEAK DISPLACEMENTS FOR VARIOUS SITE CONDITIONS - TYPE 2 EARTHQUAKE EVENTS WITH MAGNITUDE 6.4 


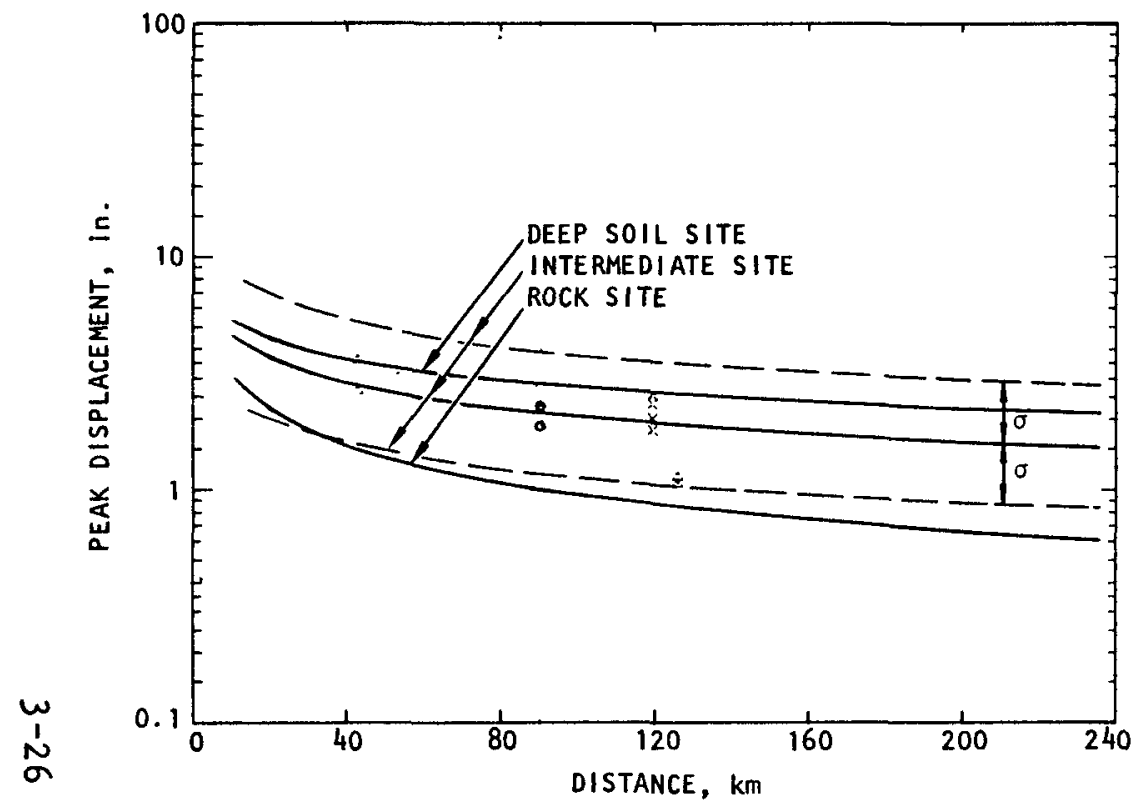

(a) Horizontal

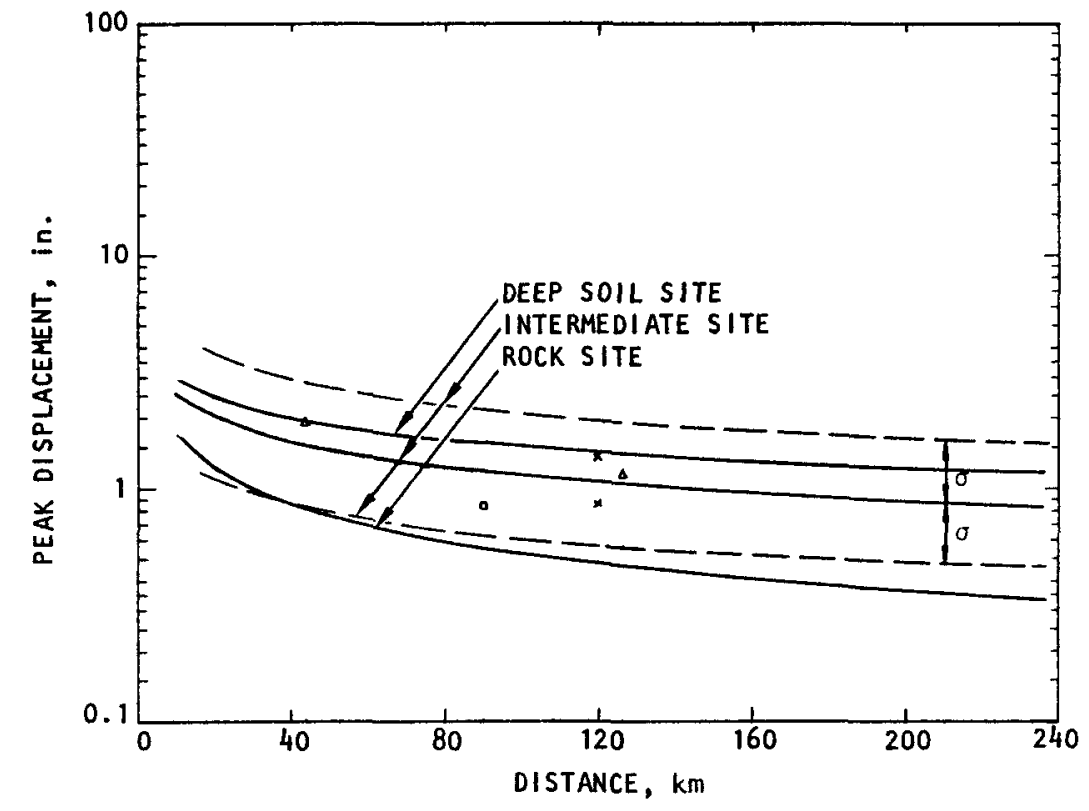

(b) Vertical

LEGEND:

DATA POINTS

- DEEP SOIL SITE

$\triangle$ INTERMEDIATE

+ ROCK SITE

$\times$ UNDEFINED SITE CONDITIONS
REGRESSION ANALYSIS (FOR TYPE 2 EVENTS)

50 th PERCENTILE (FOR EACH SITE CONDITION)

- - 16th PERCENTILE AND 84 th PERCENTILE BOUNDS (FOR INTERMEDIATE SITE CONDITION ONLY)
NOTE : $\begin{aligned} \sigma= & \text { STANDARD DEVIATION OF } \\ & \ell n \text { (PEAK DISPLACEMENT) }\end{aligned}$

FIGURE 3-12. COMPARISON BETWEEN COMPUTED AND RECORDED PEAK DISPLACEMENTS FOR VARIOUS SITE CONDITIONS - TYPE 2 EARTHQUAKE EVENTS WITH MAGNITUDE 7.7 


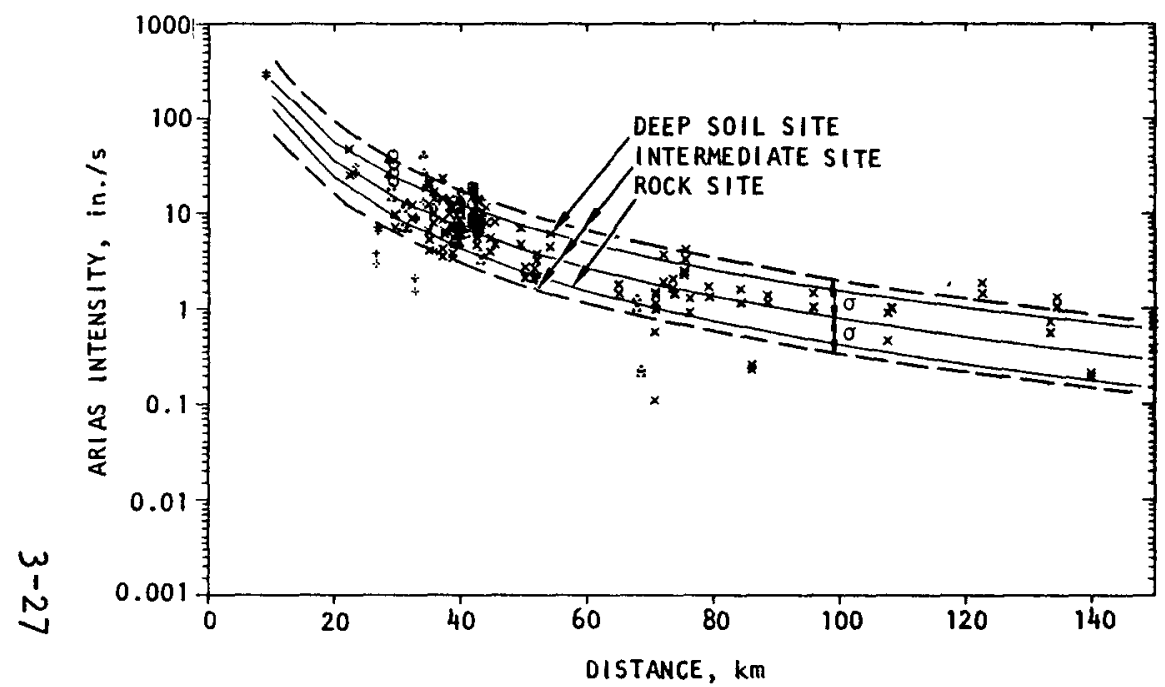

(a) Horizontal

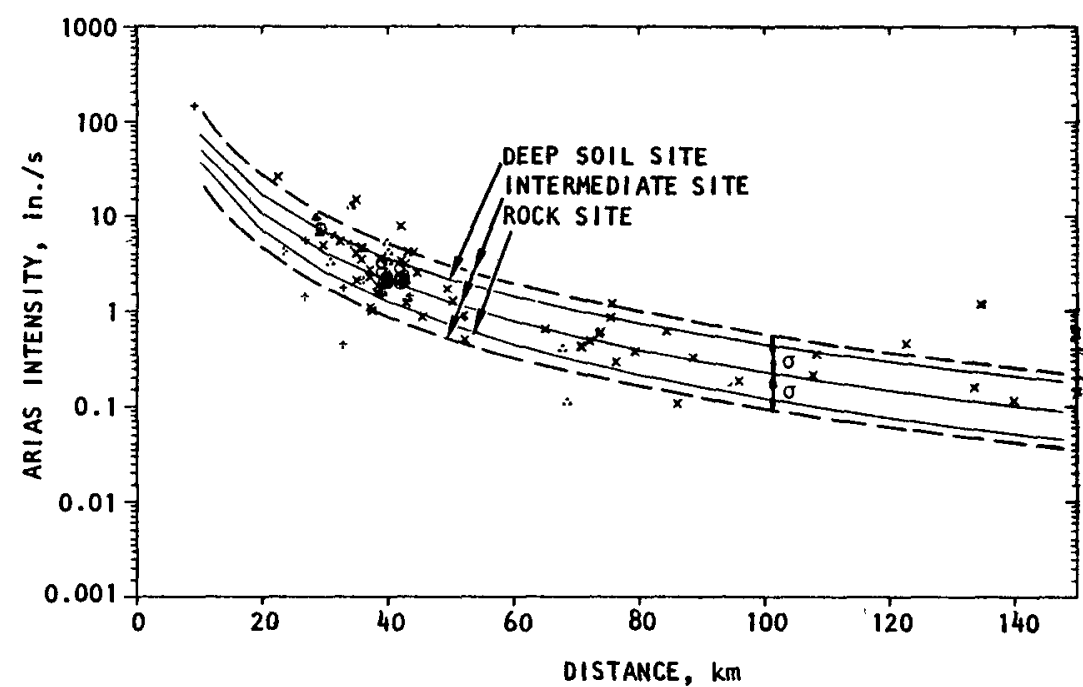

(b) Vertical LEGEND:

DATA POINTS

- DEEP SOIL SITE

$\triangle$ INTERMEDIATE

+ ROCK SITE

$x$ UNDEFINED SITE CONDITIONS
REGRESSION ANALYSIS (FOR TYPE 1 EVENTS)

50th PERCENTILE (FOR EACH SITE CONDITION) 16 th PERCENTILE AND 84 th PERCENTILE BOUNDS (FOR INTERMEDIATE SITE CONDITION ONLY)
NOTE :

$\sigma=$ STANDARD DEVIATION OF en (ARIAS INTENSITY)

FIGURE 3-13. COMPARISON BETWEEN COMPUTED AND RECORDED ARIAS INTENSITIES FOR VARIOUS SITE CONDITIONS - TYPE 1 EARTHQUAKE EVENTS 


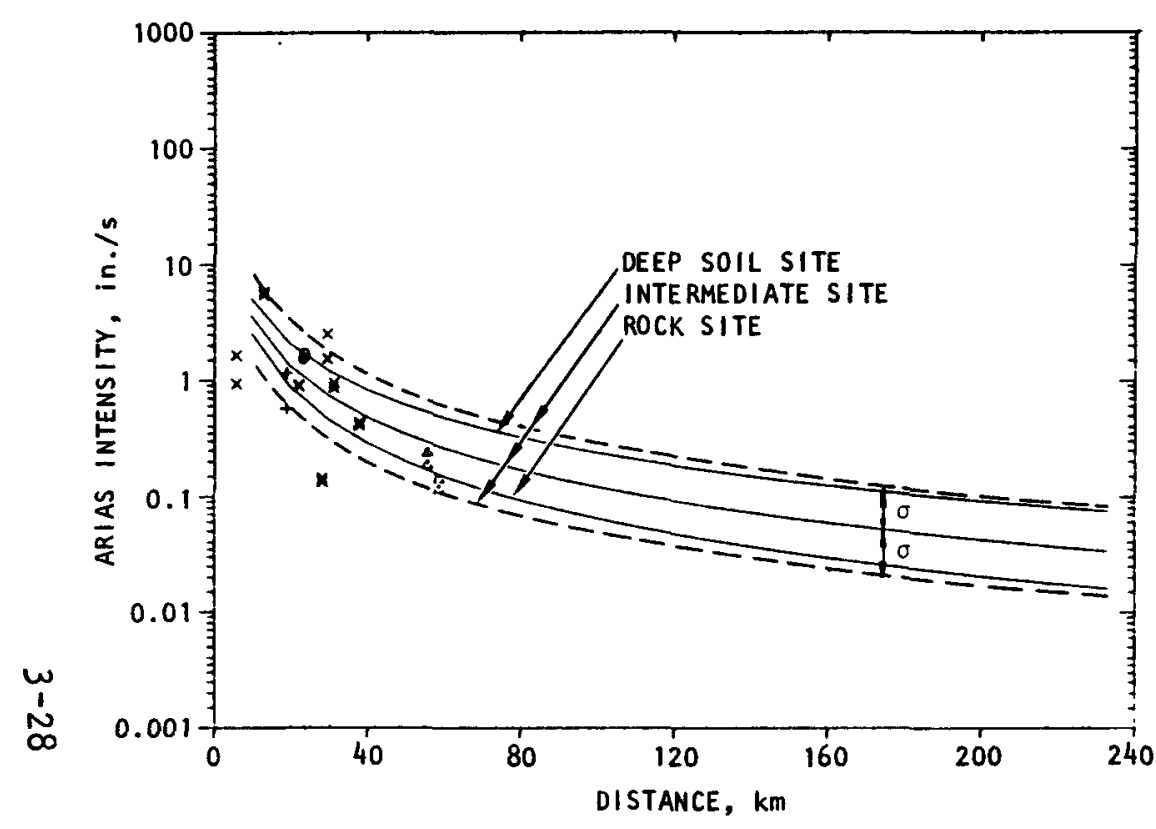

(a) Horizontal

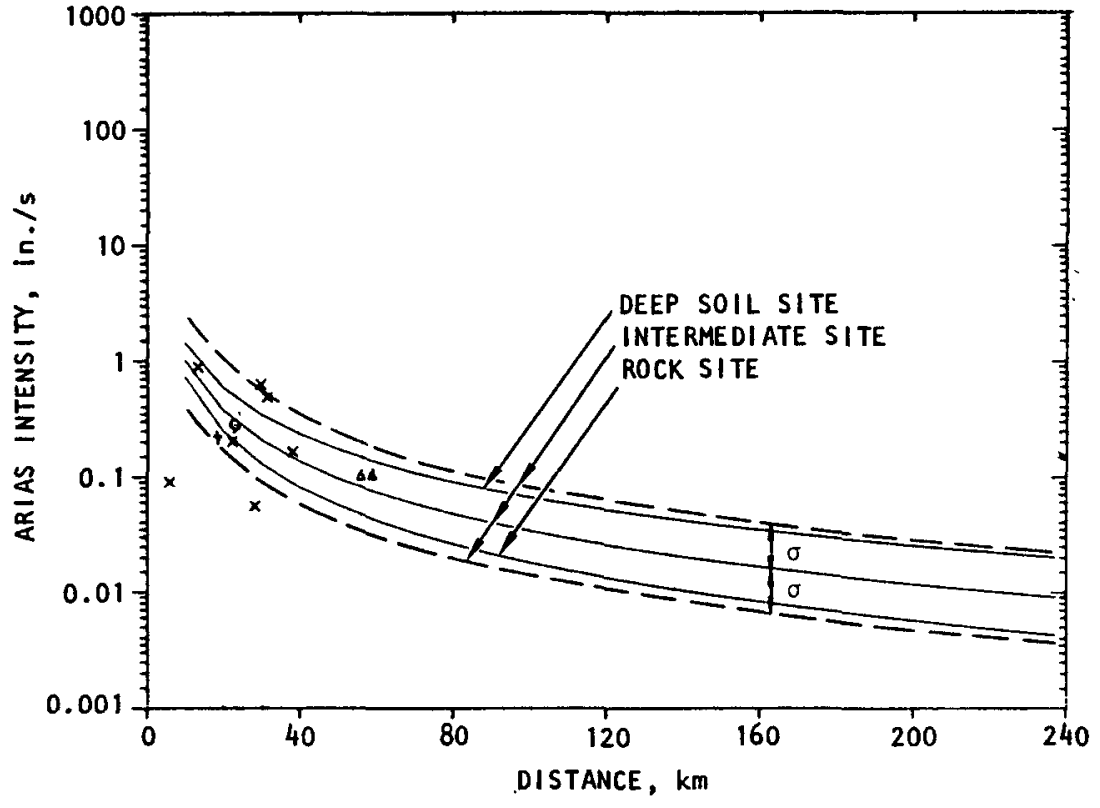

(b) Vertical

LEGEND:

DATA POINTS

- DEEP SOIL SITE

$\triangle$ INTERMEDIATE

+ ROCK SITE

$x$ UNDEFINED SITE CONDITIONS

\section{REGRESSION ANALYSIS (FOR TYPE 2 EVENTS)}

\section{0th PERCENTILE (FOR EACH SITE CONDITION)}

16th PERCENTILE AND 84th PERCENTILE BOUNDS (FOR INTERMEDIATE SITE CONDITION ONLY)
NOTE :

$$
\sigma=\text { STANDARD DEVIATION OF }
$$
ln (ARIAS INTENSITY)

FIGURE 3-14. COMPARISON BETWEEN COMPUTED AND RECORDED ARIAS INTENSITIES FOR VARIOUS SITE CONDITIONS - TYPE 2 EARTHQUAKE EVENTS WITH MAGNITUDE 5.4 


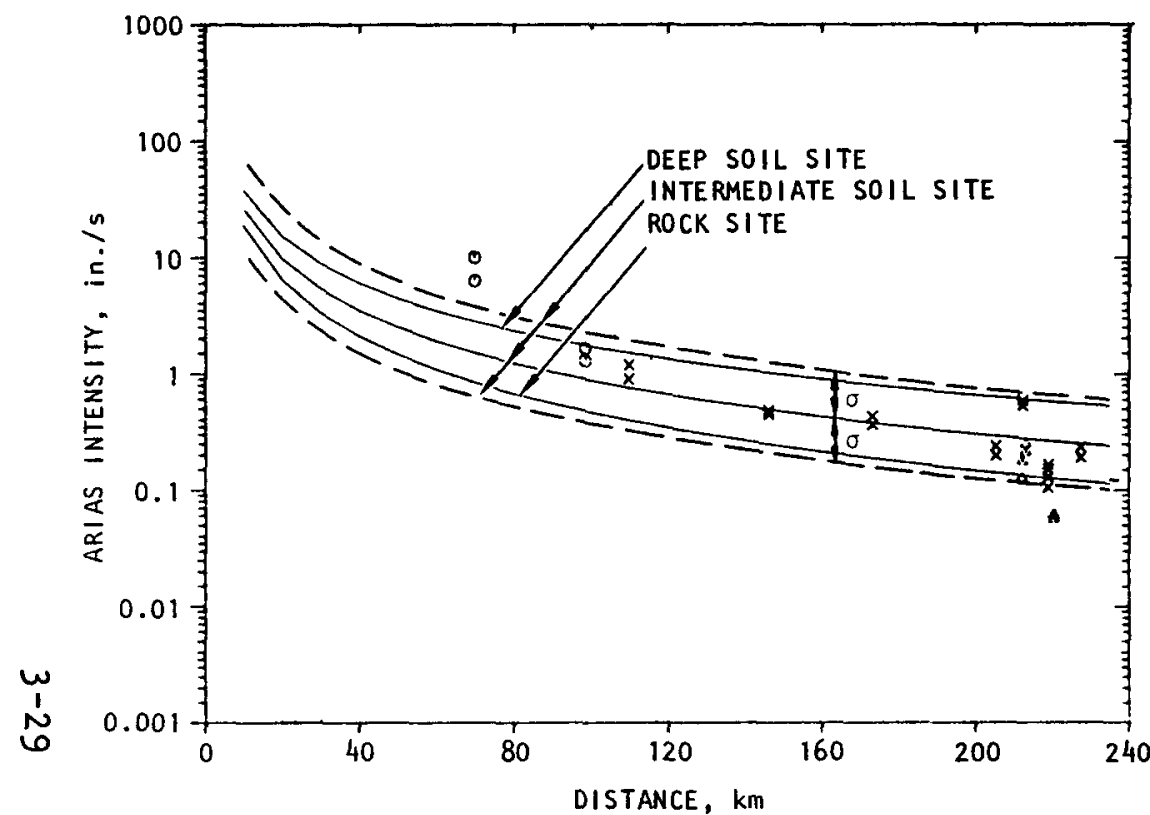

(a) Horizontal

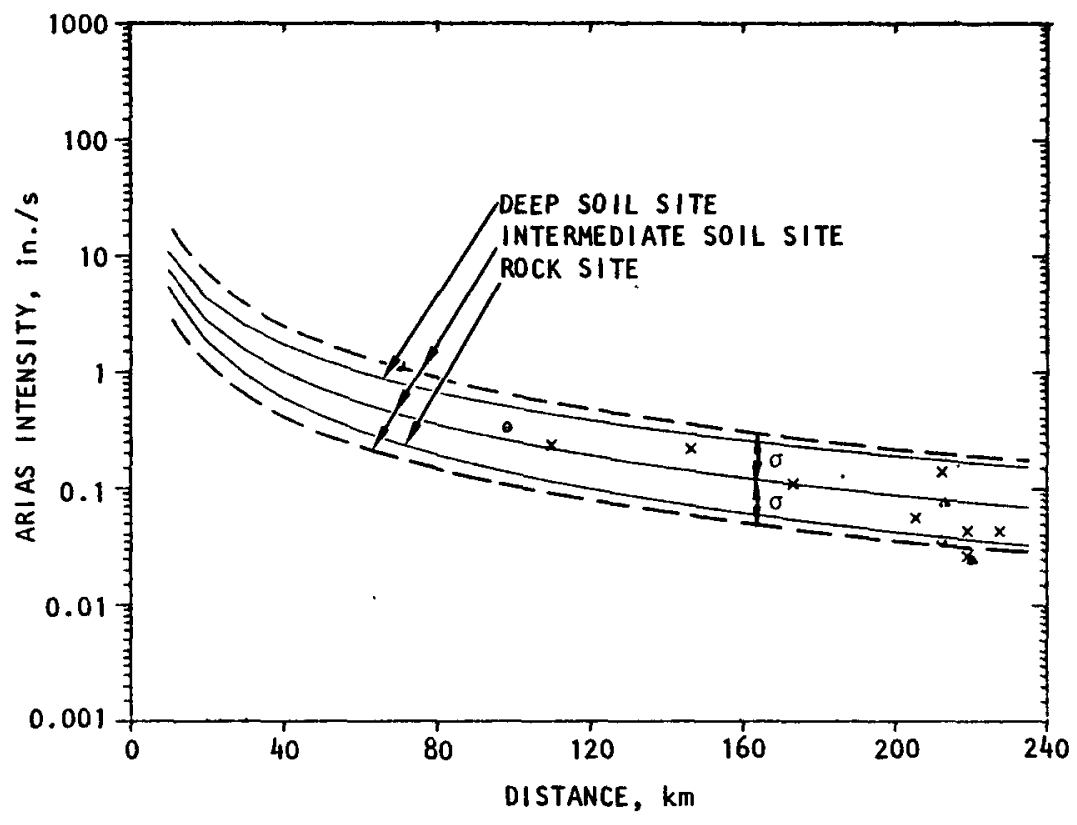

(b) Vertical

LEGEND :

DATA POINTS

- DEEP SOIL SITE

$\triangle$ INTERMEDIATE

+ ROCK SITE

$\times$ UNDEFINED SITE CONDITIONS
REGRESSION ANALYSIS (FOR TYPE 2 EVENTS)

50th PERCENTILE (FOR EACH SITE CONDITION)

- 16 th PERCENTILE AND 84th PERCENTILE BOUNDS (FOR INTERMEDIATE SITE CONDITION ONLY)
NOTE :

$\sigma=$ STANDARD DEVIATION OF en (ARIAS INTENSITY)

FIGURE 3-15. COMPARISON BETWEEN COMPUTED AND RECORDED ARIAS INTENSITIES FOR VARIOUS SITE CONDITIONS - TYPE 2 EARTHQUAKE EVENTS WITH MAGNITUDE 6.4 


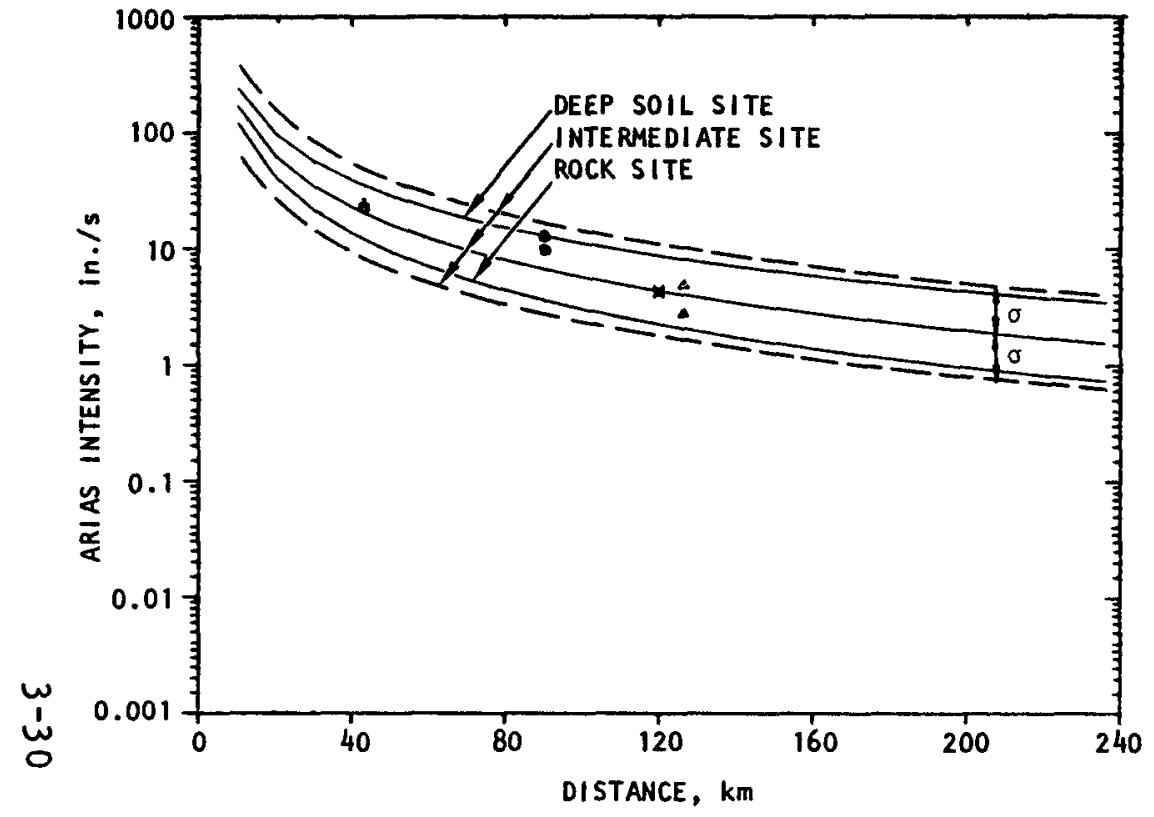

(a) Horizontal

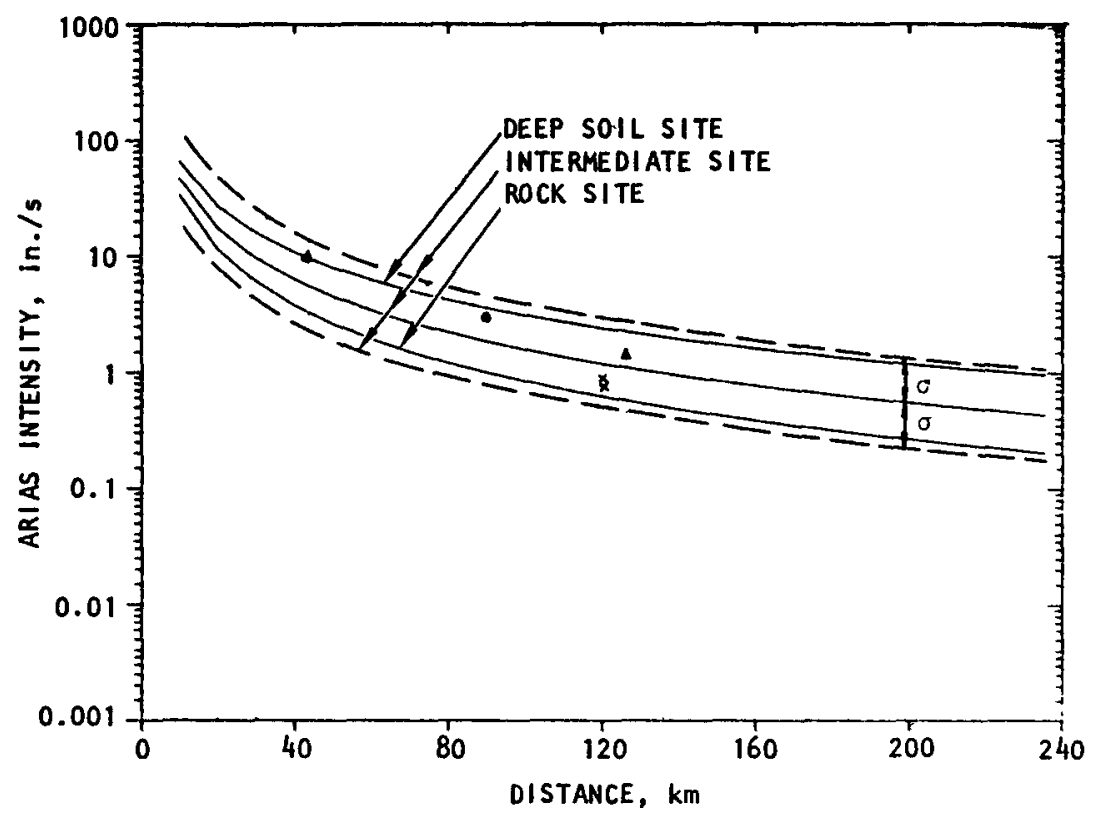

(b) Vertical

LEGEND:

DATA POINTS

- DEEP SOIL SITE

$\triangle$ INTERMEDIATE

+ ROCK SITE

$\times$ UNDEFINED SITE CONDITIONS
REGRESSION ANALYSIS (FOR TYPE 2 EVENTS)

50th PERCENTILE (FOR EACH SITE CONDITION)

- - 16th PERCENTILE AND 84 th PERCENTILE BOUNDS (FOR INTERMEDIATE SITE CONDITION ONLY)
NOTE :

$\sigma=$ STANDARD DEVIATION OF \&n (ARIAS INTENSITY)

FIGURE 3-16. COMPARISON BETWEEN COMPUTED AND RECORDED ARIAS INTENSITIES FOR VARIOUS SITE CONDITIONS - TYPE 2 EARTHQUAKE EVENTS WITH MAGNITUDE 7.7 


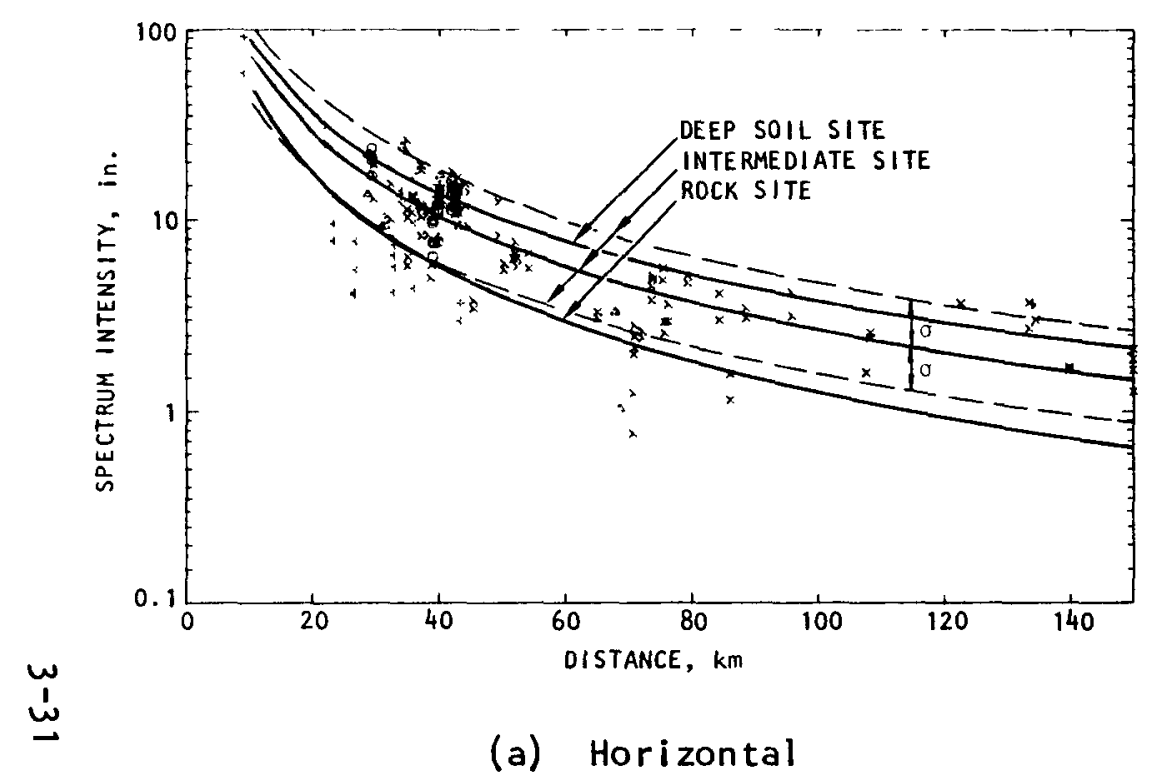

LEGEND:

DATA POINTS

- DEEP SOIL SITE

$\triangle$ INTERMEDIATE

+ ROCK SITE

$x$ UNDEFINED SITE CONDITIONS

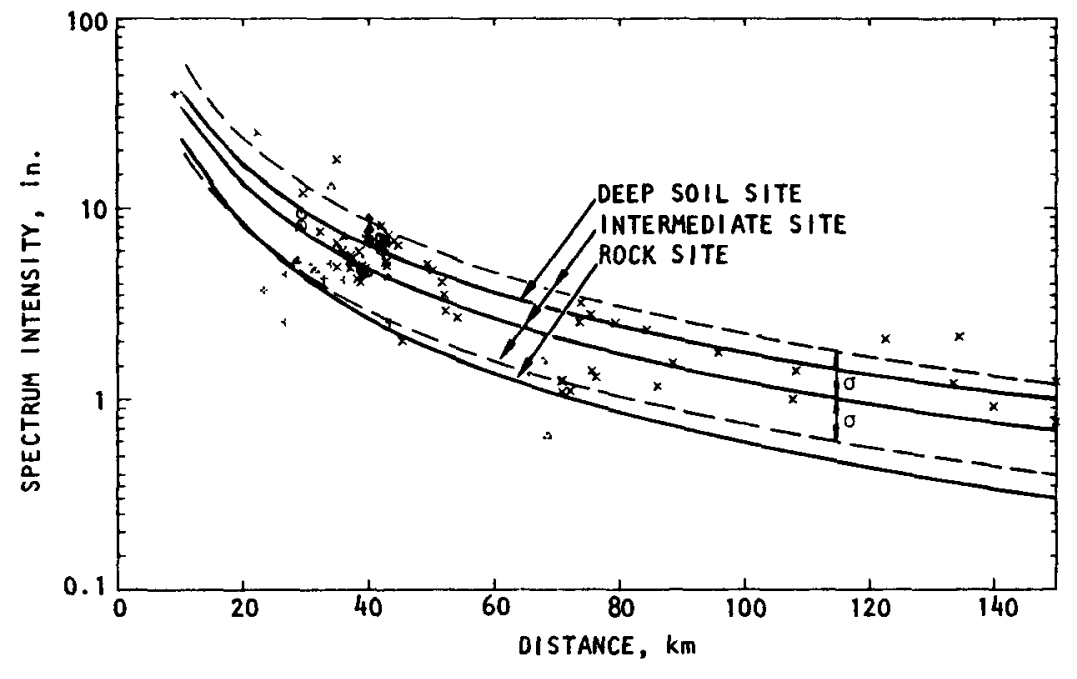

(b) Vertical

FIGURE 3-17. COMPARISON BETWEEN COMPUTED AND RECORDED SPECTRUM INTENSITIES FOR VARIOUS

REGRESSION ANALYSIS (FOR TYPE 1 EVENTS)

50th PERCENTILE (FOR EACH SITE CONDITION)

16th PERCENTILE AND 84 th PERCENTILE BOUNDS

(FOR INTERMEDIATE SITE CONDITION ONLY)
NOTE:

$\sigma=$ STANDARD DEVIATION OF en (SPECTRUM INTENSITY)

\section{SITE CONDITIONS - TYPE 1 EARTHQUAKE EVENTS}




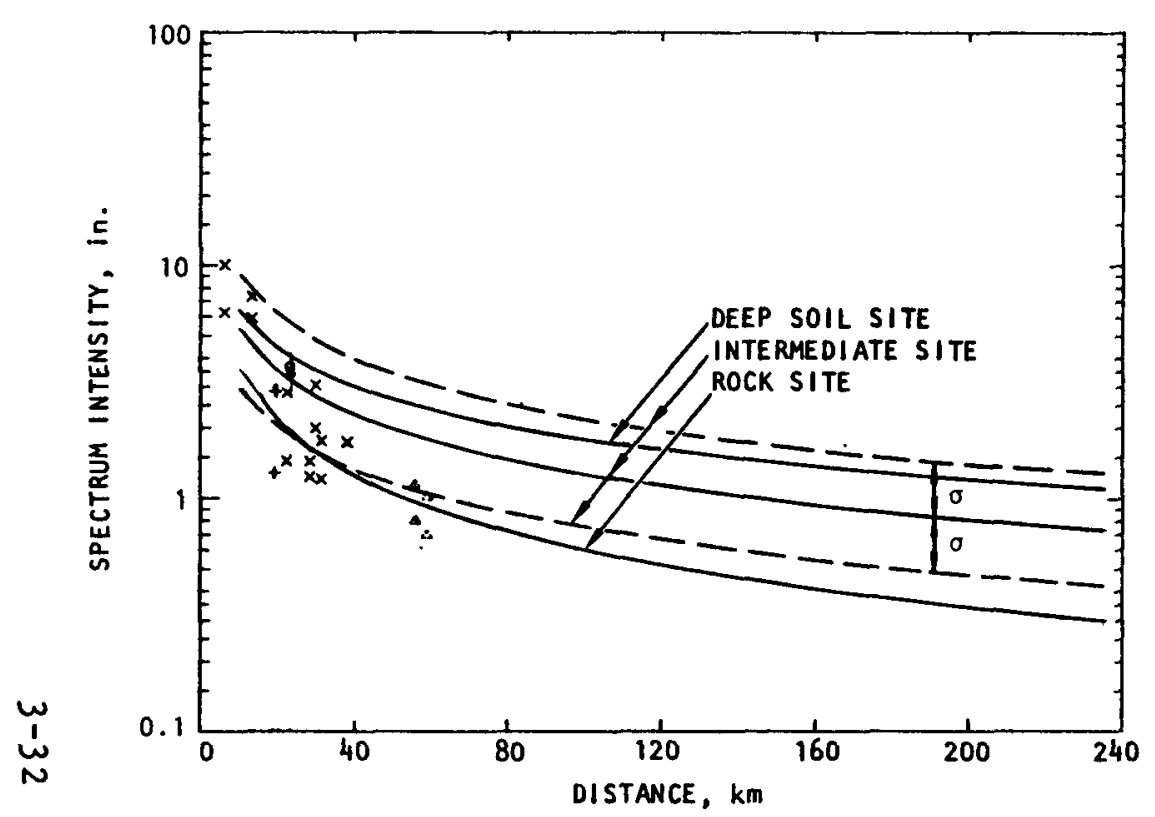

(a) Horizontal

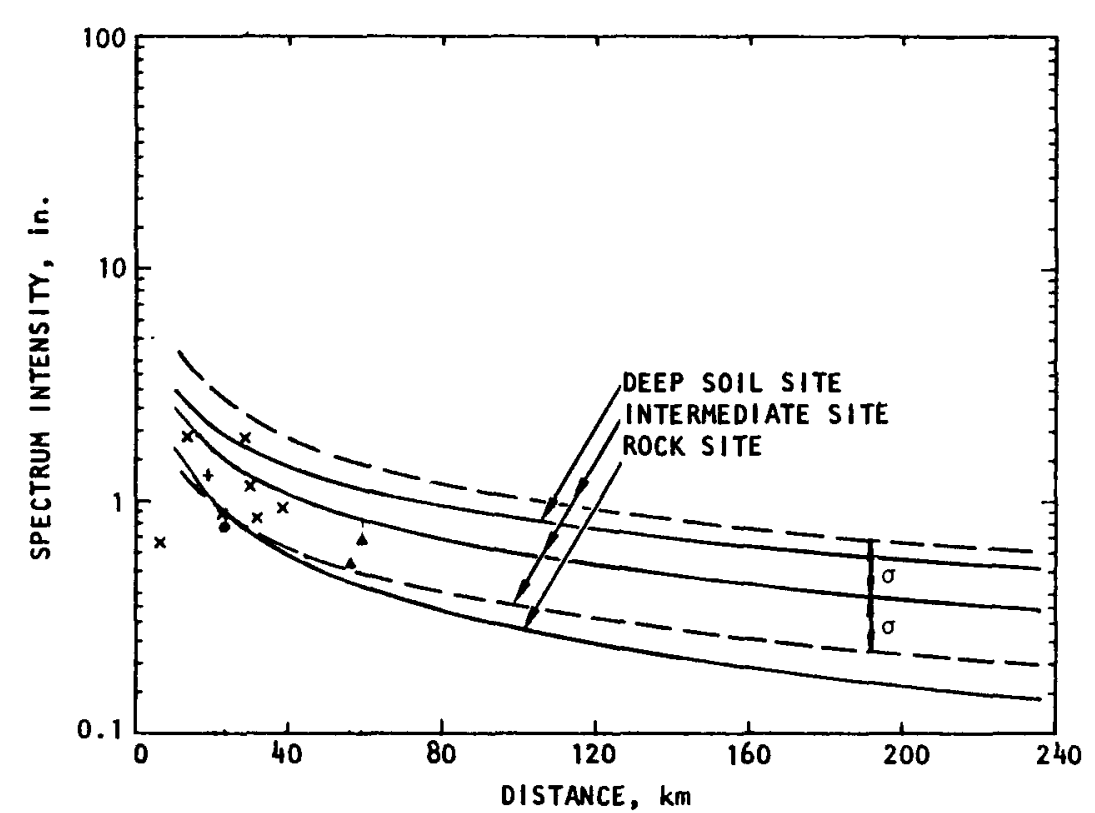

(b) Vertical

LEGEND:

DATA POINTS

- DEEP SOIL SITE

$\triangle$ INTERMEDIATE

+ ROCK SITE

$x$ UNDEFINED SITE CONDITIONS
REGRESSION ANALYSIS (FOR TYPE 2 EVENTS)

50th PERCENTILE (FOR EACH SITE CONDITION)

16 th PERCENTILE AND 84 th PERCENTILE BOUNDS

FOR INTERMEDIATE SITE CONDITION ONLY
NOTE :

$\sigma=$ STANDARD DEVIATION OF en (SPECTRUM INTENSITY)

FIGURE 3-18. COMPARISON BETWEEN COMPUTED AND RECORDED SPECTRUM INTENSITIES FOR VARIOUS SITE CONDITIONS - TYPE 2 EARTHQUAKE EVENTS WITH MAGNITUDE 5.4 


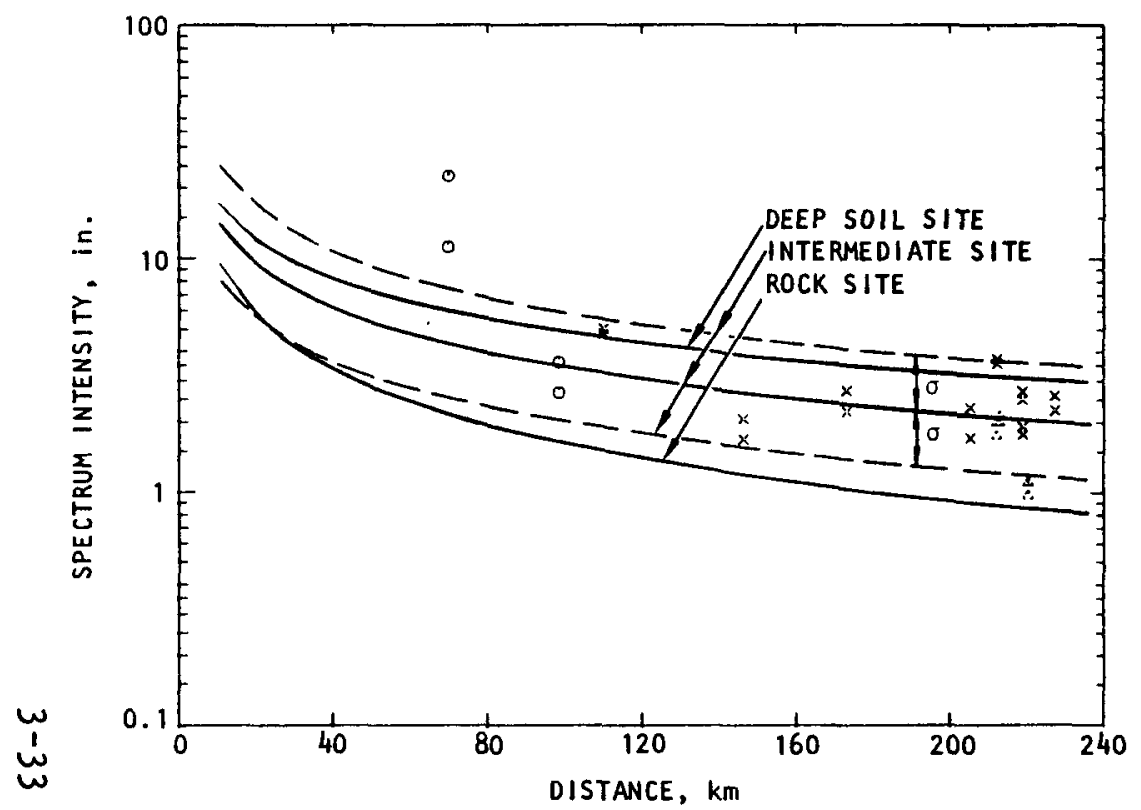

(a) Horizontal

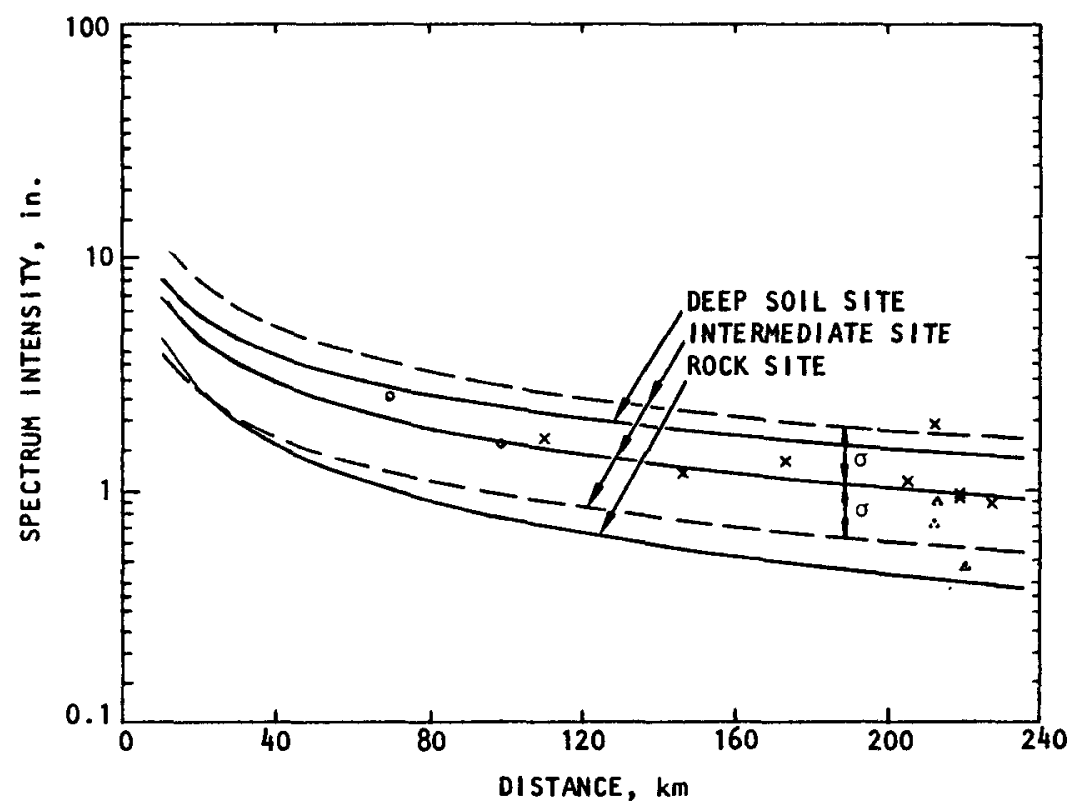

(b) Vertical

LEGEND:

DATA POINTS

- DEEP SOIL SITE

$\triangle$ INTERMEDIATE

+ ROCK SITE

$\times$ UNDEFINED SITE CONDITIONS
REGRESSION ANALYSIS (FOR TYPE 2 EVENTS)

50th PERCENTILE (FOR EACH SITE CONDITION)

- - 16th PERCENTILE AND 84th PERCENTILE BOUNDS (FOR INTERMEDIATE SITE CONDITION ONLY)
NOTE :

$\sigma=$ STANDARD DEVIATION OF en (SPECTRUM INTENSITY)

FIGURE 3-19. COMPARISON BETWEEN COMPUTED AND RECORDED SPECTRUM INTENSITIES FOR VARIOUS SITE CONDITIIONS - TYPE 2 EARTHQUAKE EVENTS WITH MAGNITUDE 6.4 


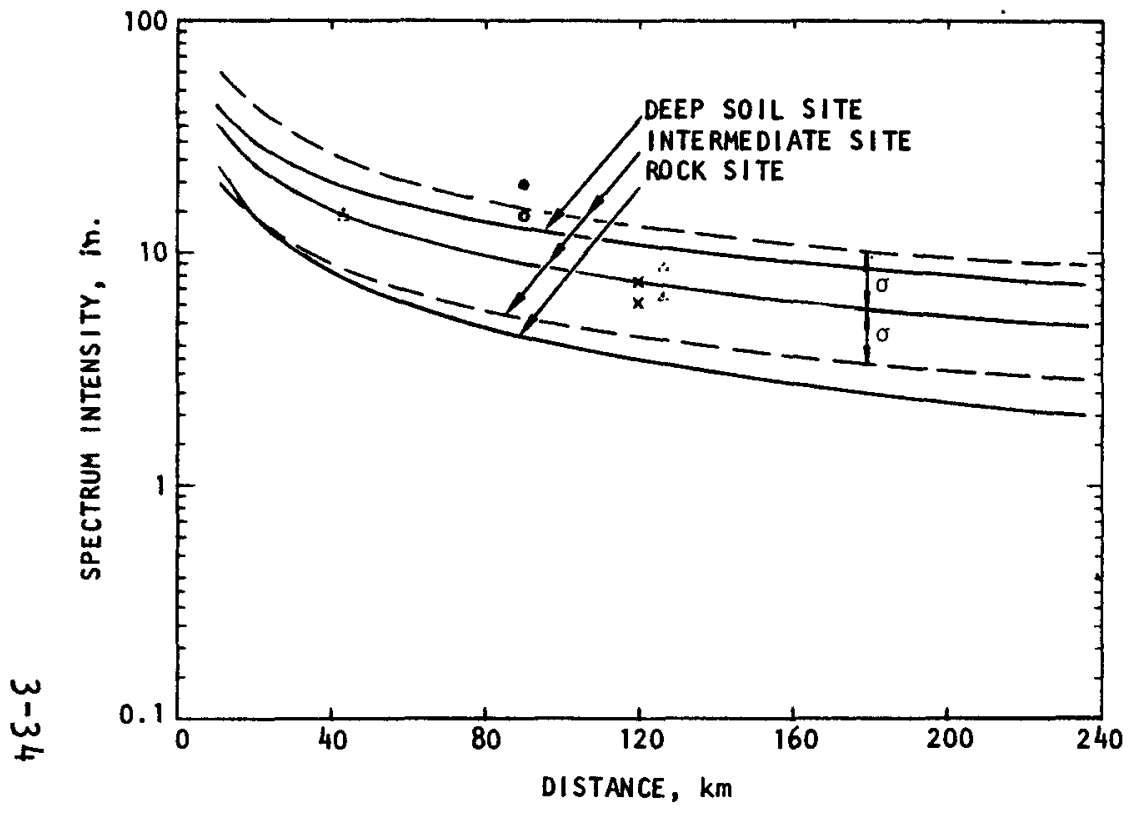

(a) Horizontal

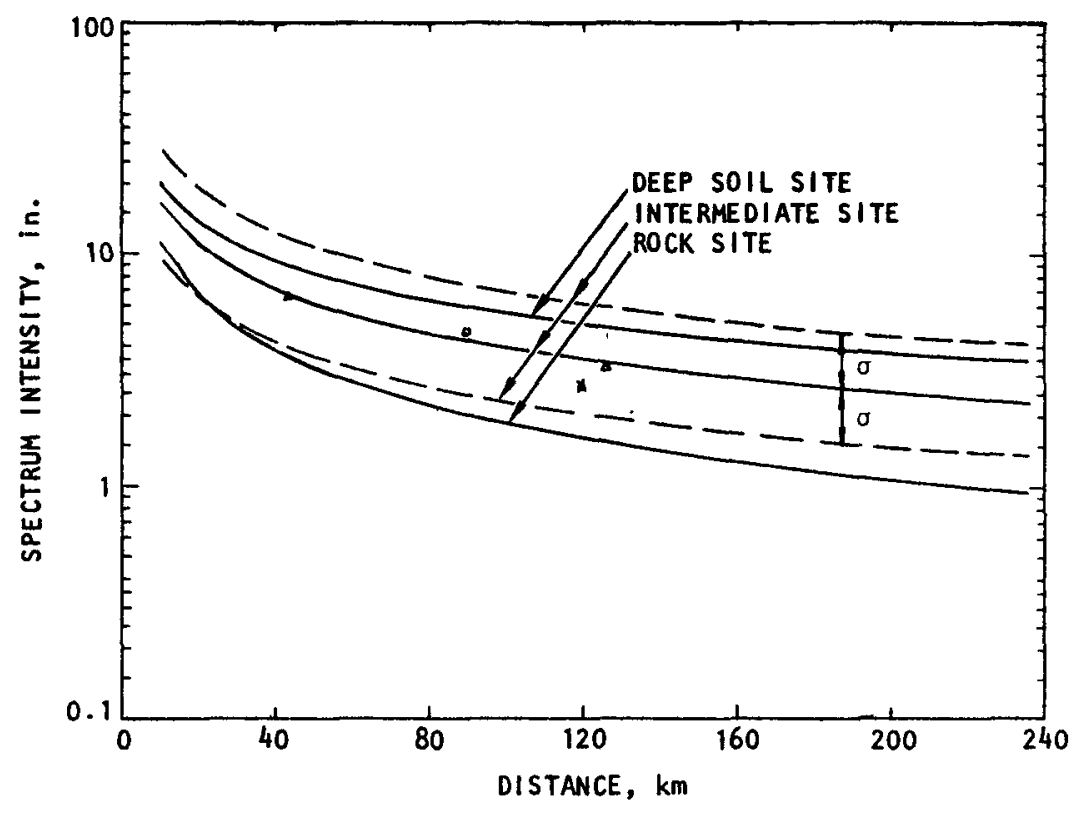

(b) Vertical

LEGEND:

DATA POINTS
- DEEP SOIL SITE
$\triangle$ INTERMEDIATE
+ ROCK SITE
$x$ UNDEFINED SITE CONDITIONS

REGRESSION ANALYSIS (FOR TYPE 2 EVENTS)

50th PERCENTILE (FOR EACH SITE CONDITION)

-16 th PERCENTILE AND 84th PERCENTILE BOUNDS
(FOR INTERMEDIATE SITE CONDITION ONLY)
NOTE:

$\sigma=$ STANDARD DEVIATION OF In (SPECTRUM INTENSITY)

FIGURE 3-20. COMPARISON BETWEEN COMPUTED AND RECORDED SPECTRUM INTENSITIES FOR VARIOUS SITE CONDITIONS - TYPE 2 EARTHQUAKE EVENTS WITH MAGNITUDE 7.7 


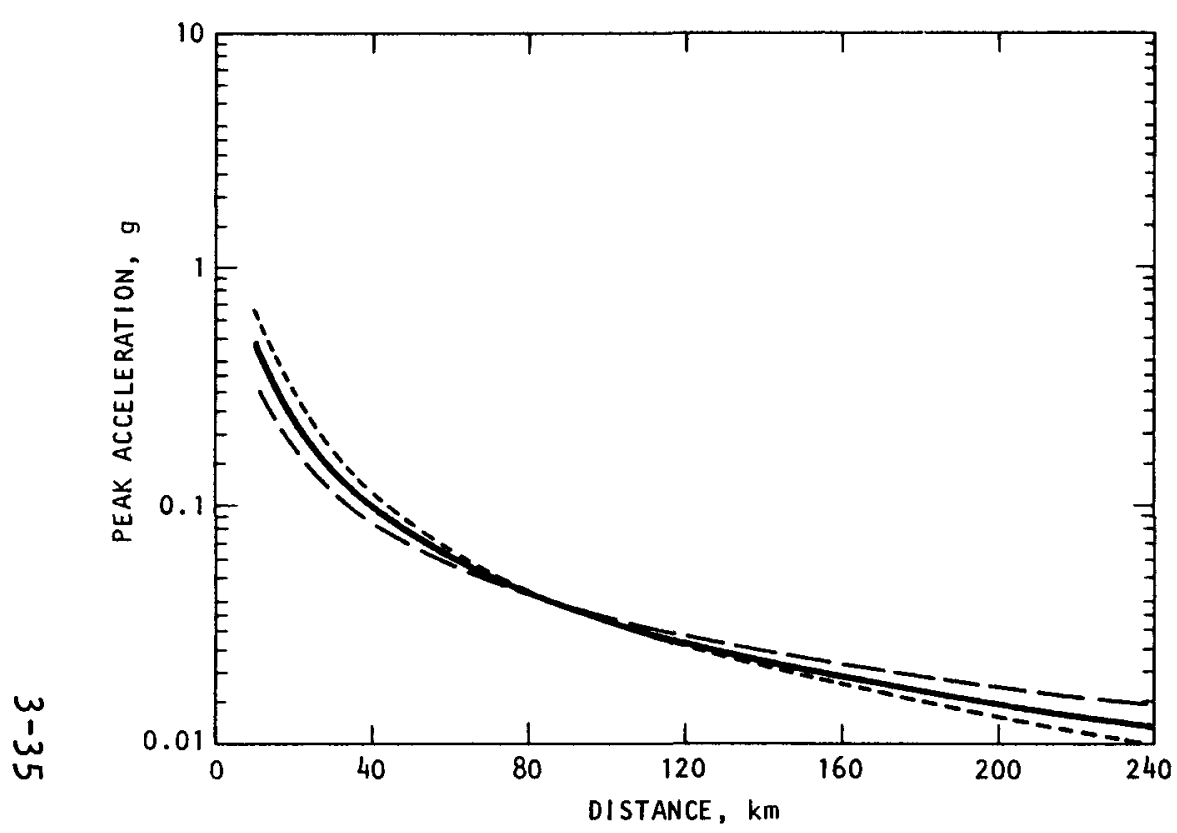

(a) Horizontal

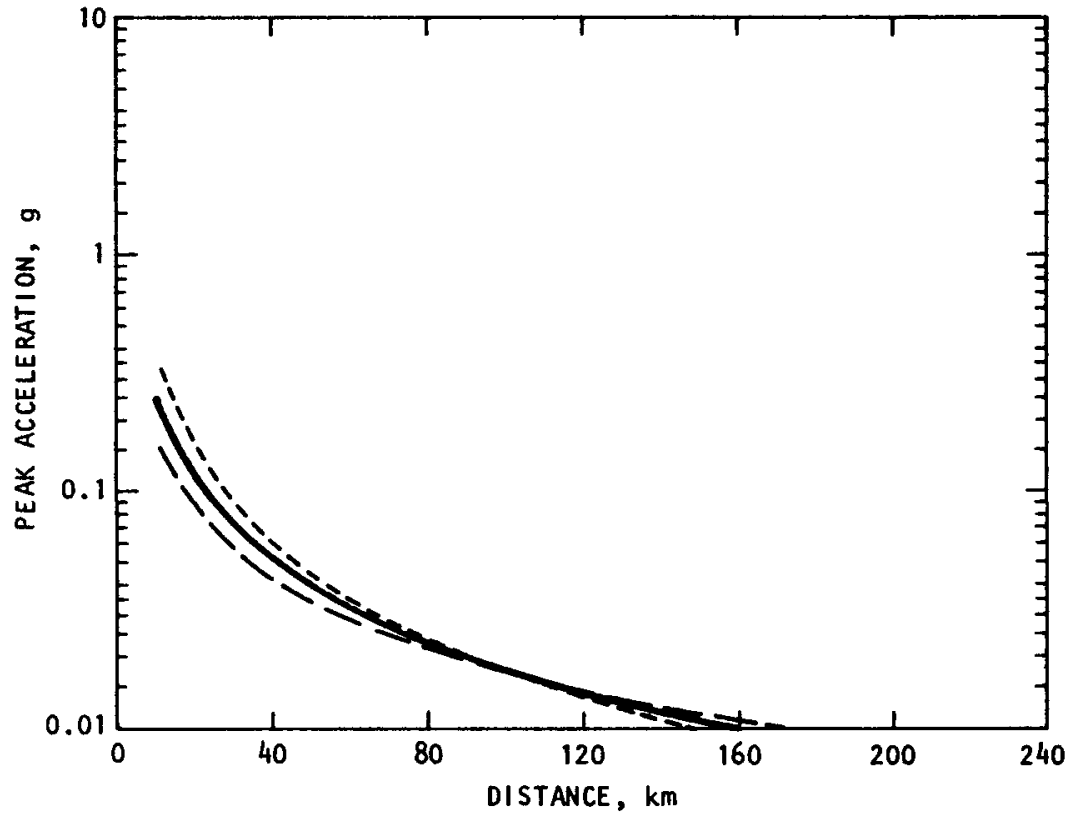

(b) Vertical

LEGEND

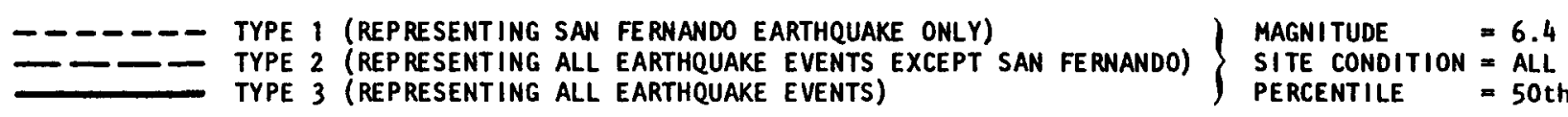

FIGURE 3-21. EFFECT OF EARTHQUAKE EVENT TYPE ON PEAK ACCELERATIONS 


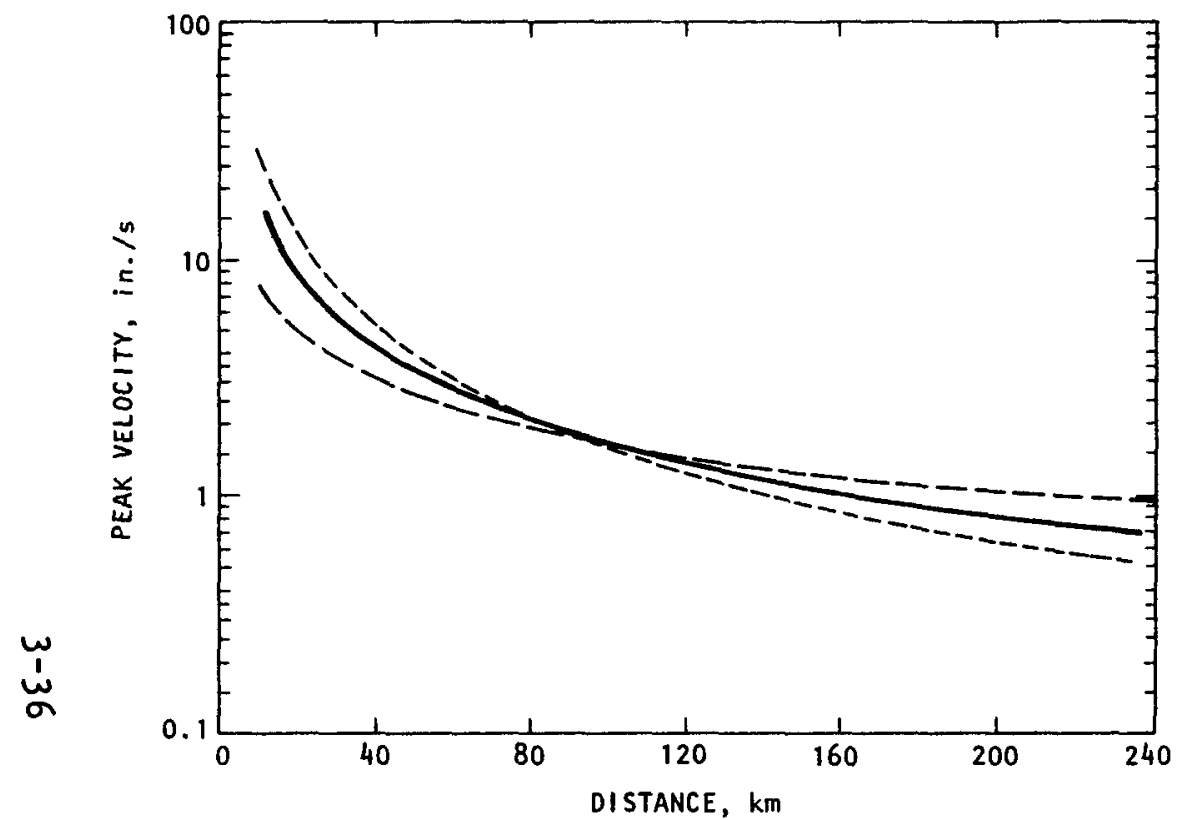

(a) Horizontal

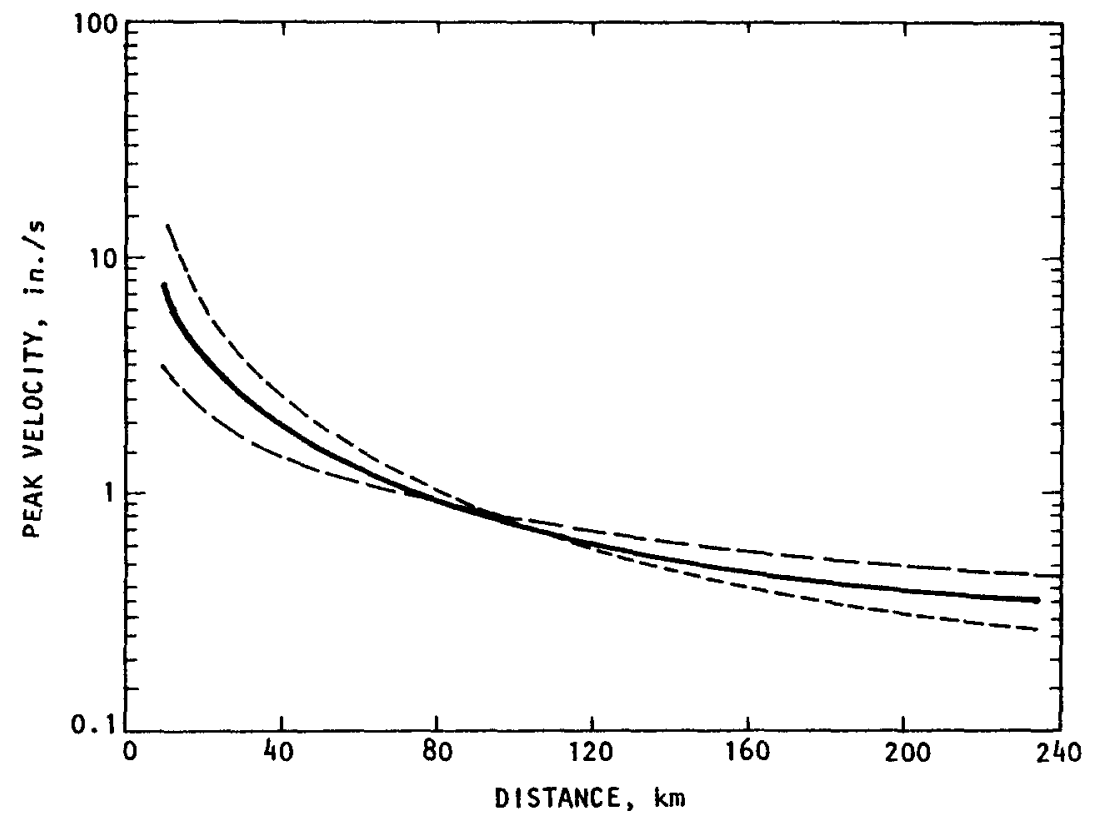

(b) Vertical

LEGEND

$\left.\begin{array}{lll}- & \text { TYPE } 1 \text { (REPRESENTING SAN FERNANDO EARTHQUAKE ONLY) } \\ \text { TYPE } 2 \text { (REPRESENTING ALL EARTHQUAKE EVENTS EXCEPT SAN FERNANDO) } & \text { TYPE } 3 \text { (REPRESENTING ALL EARTHQUAKE EVENTS) }\end{array}\right\} \begin{aligned} & \text { MAGNITUDE } \\ & \text { SITE CONDITION }=6.4 \\ & \text { PERCENTILE INTERMEDIATE } \\ & =50 \text { th }\end{aligned}$

FIGURE 3-22. EFFECT OF EARTHQUAKE EVENT TYPE ON PEAK VELOCITIES 


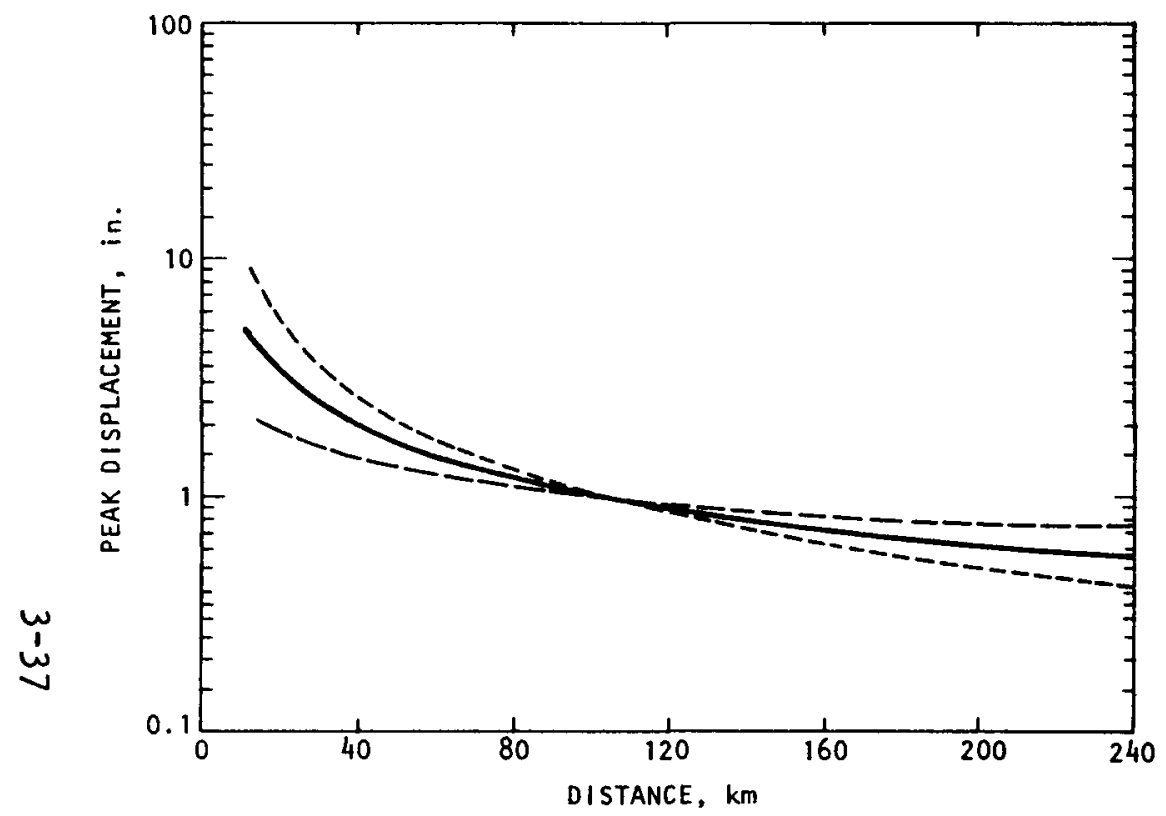

(a) Horizontal

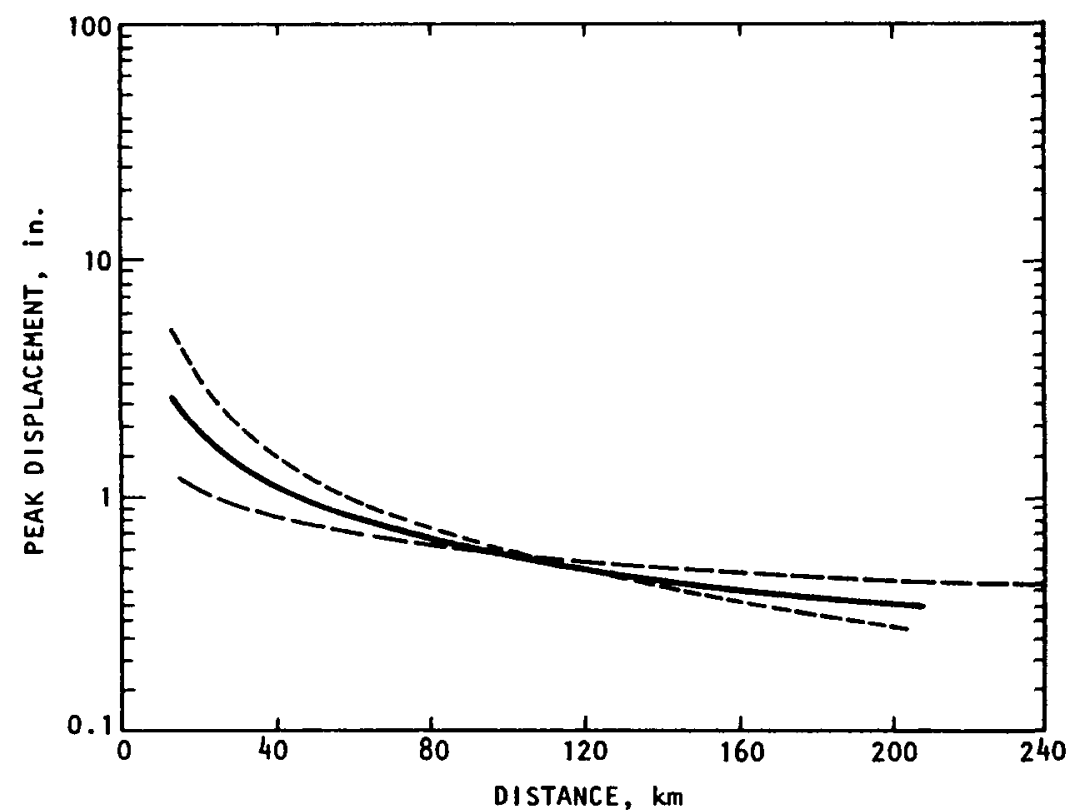

(b) Vertical

LEGEND

$\left.\begin{array}{l}--1 \text { TYPE } 1 \text { (REPRESENTING SAN FERNANDO EARTHQUAKE ONLY) } \\ - \text { TYPE } 2 \text { (REPRESENTING ALL EARTHQUAKE EVENTS EXCEPT SAN FERNANDO) }\end{array}\right\} \begin{aligned} & \text { MAGNITUDE SITE CONDITION }=6.4 \\ & \text { INTERMEDIATE }\end{aligned}$

- TYPE 3 (REPRESENTING ALL EARTHQUAKE EVENTS)

FIGURE 3-23. EFFECT OF EARTHQUAKE EVENT TYPE ON PEAK DISPLACEMENTS 


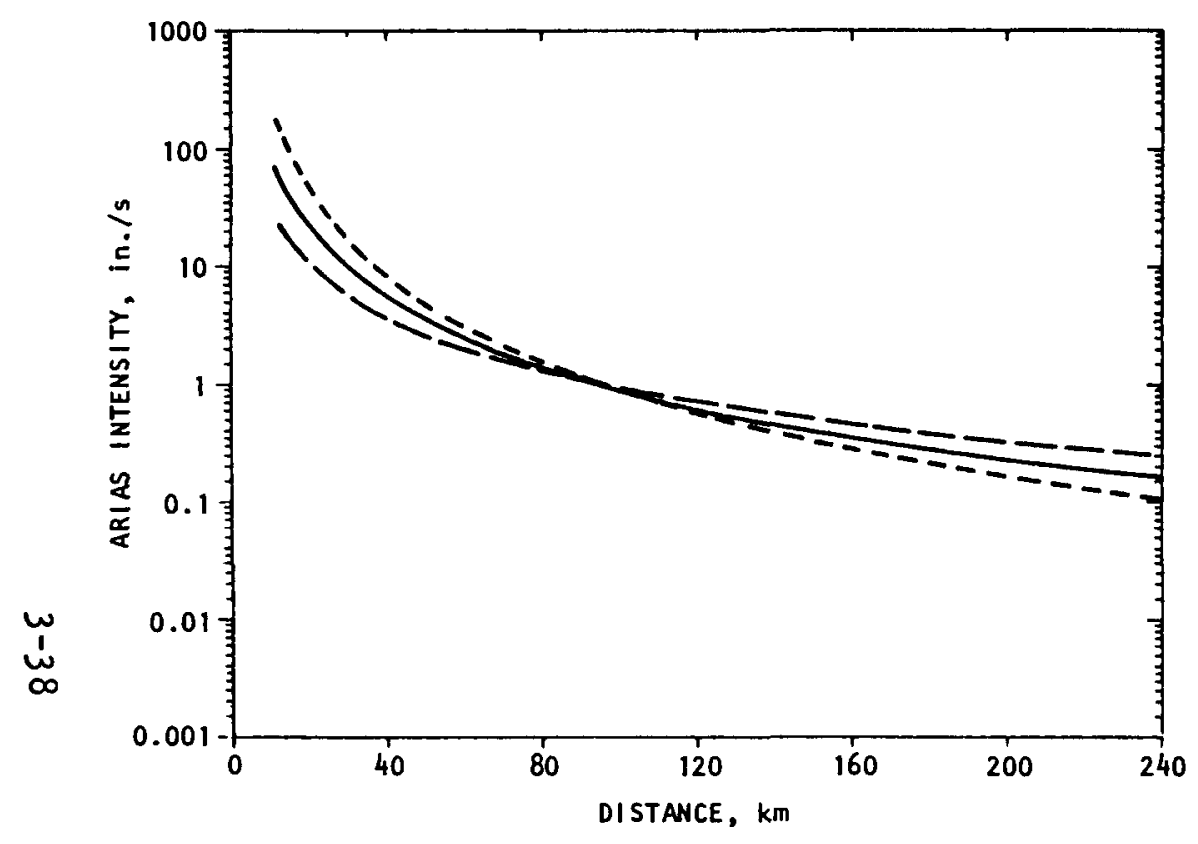

(a) Horizontal

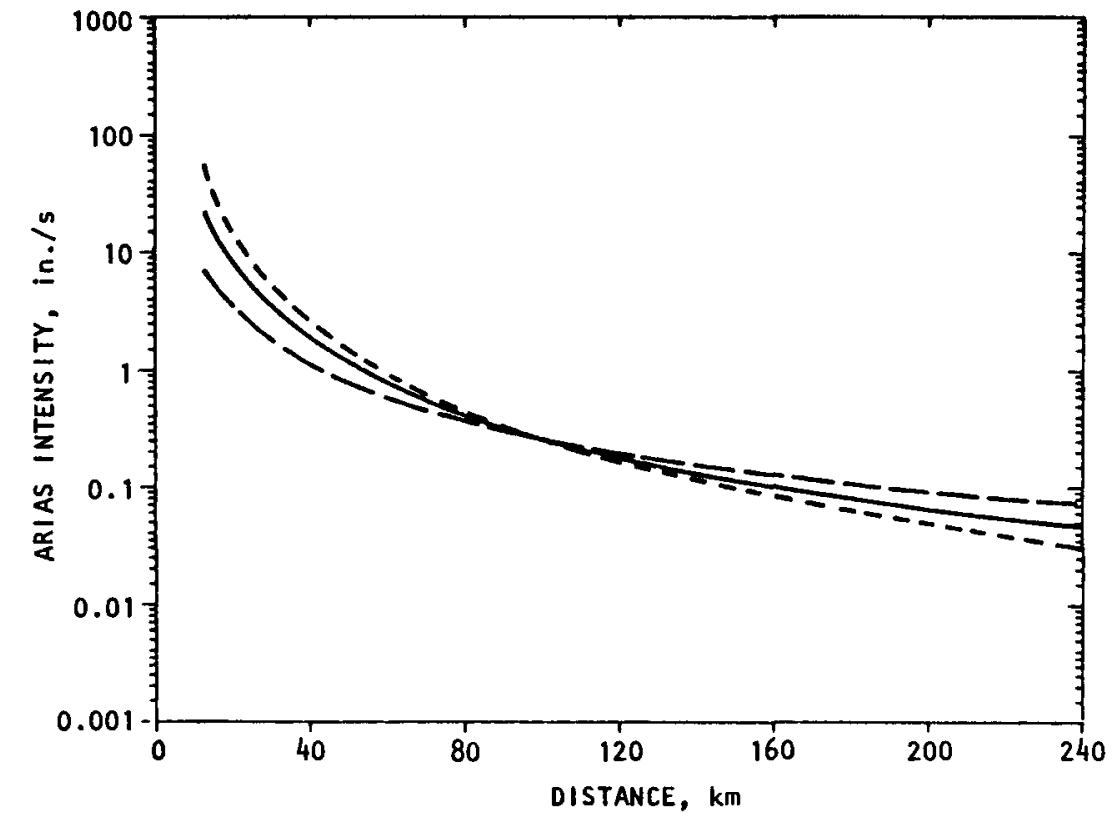

(b) Vertical

LEGEND

TYPE 1 (REPRESENTING SAN FERNANDO EARTHQUAKE ONLY)

- TYPE 2 (REPRESENTING ALL EARTHQUAKE EVENTS EXCEPT SAN FERNANDO)

TYPE 3 (REPRESENTING ALL EARTHQUAKE EVENTS)

MAGN ITUDE

$=6.4$

SITE CONDITION = INTERMEDIATE

PERCENTILE

$=50 \mathrm{th}$

FIGURE 3-24. EFFECT OF EARTHQUAKE EVENT TYPE ON ARIAS INTENSITIES 


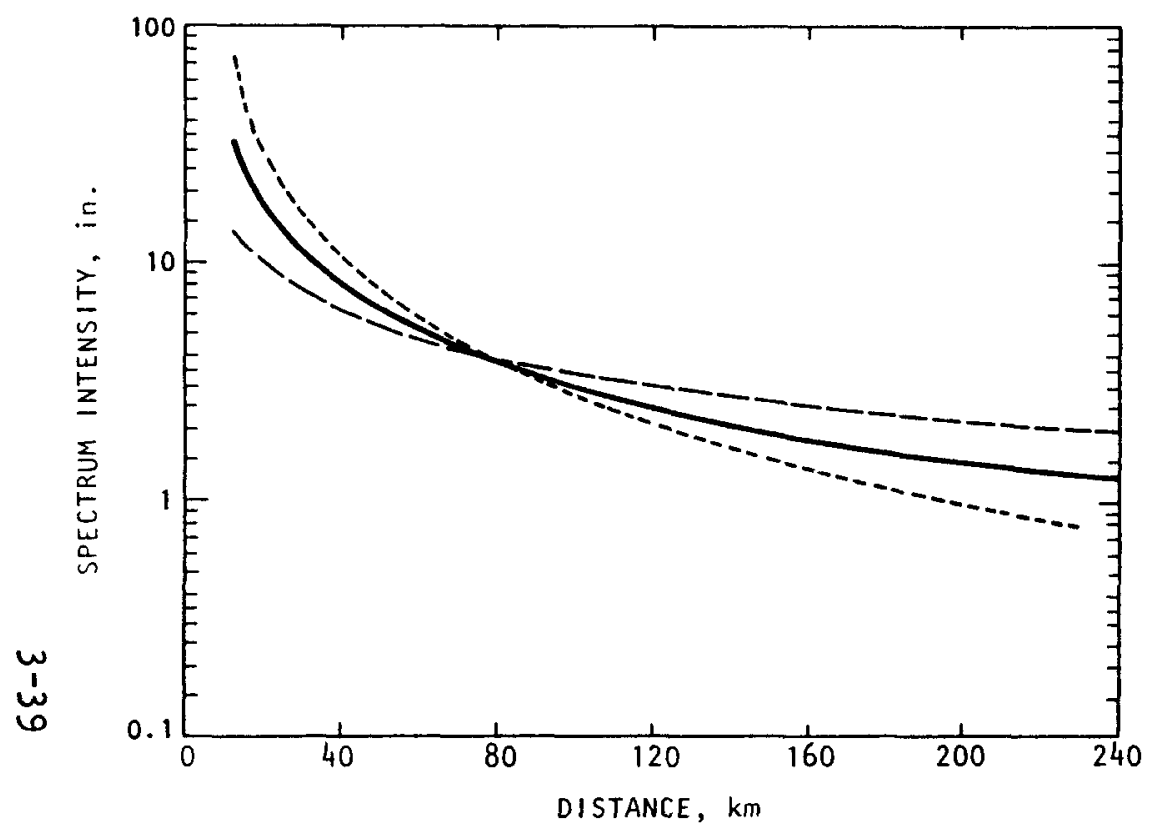

(a) Horizontal

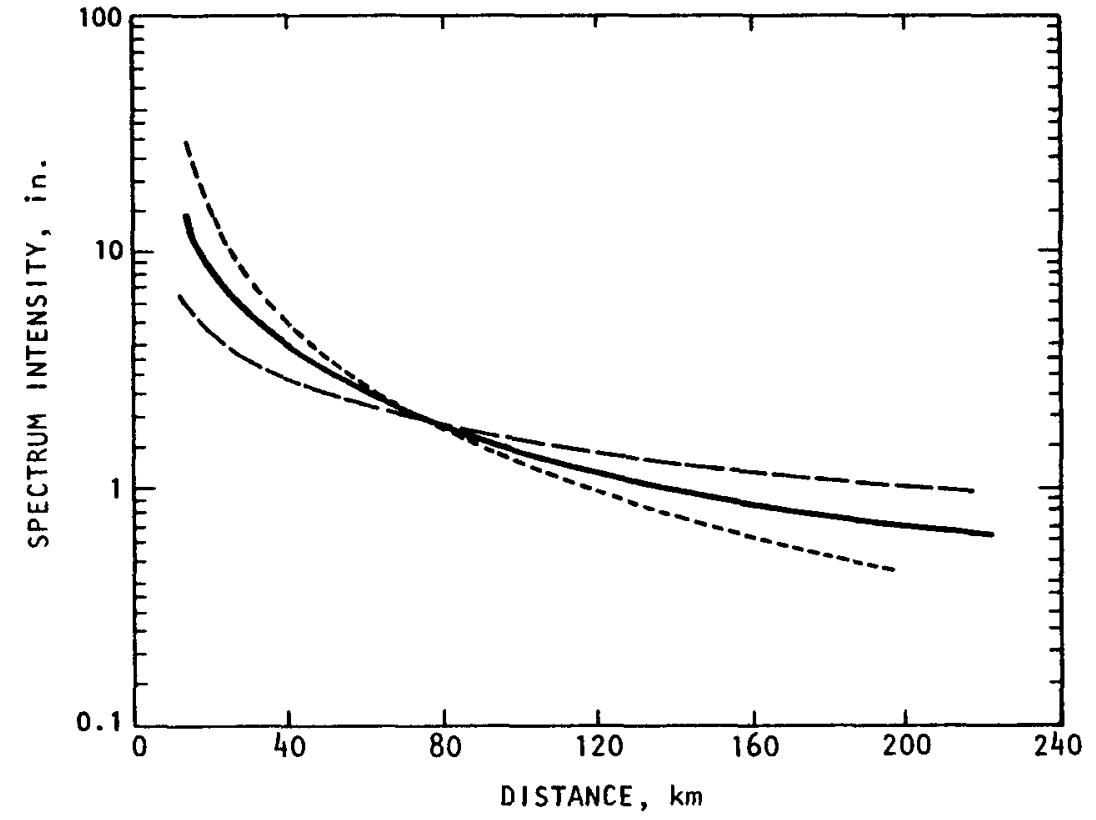

(b) Vertical

\section{LEGEND}

$$
\begin{aligned}
& \text { - } 1 \text { (REPRESENTING SAN FERNANDO EARTHQUAKE ONLY) } \\
& \begin{array}{l}
\text { - TYPE } 2 \text { (REPRESENTING ALL EARTHQUAKE EVENTS EXCEPT SAN FERNANDO) } \\
\text { SITE CONDITION }=\text { INTERMEDIATE }
\end{array} \\
& \text { TYPE } 3 \text { (REPRESENTING ALL EARTHQUAKE EVENTS) } \\
& \text { PERCENTILE }=50 \text { th }
\end{aligned}
$$

FIGURE 3-25. EFFECT OF EARTHQUAKE EVENT TYPE ON SPECTRUM INTENSITIES 


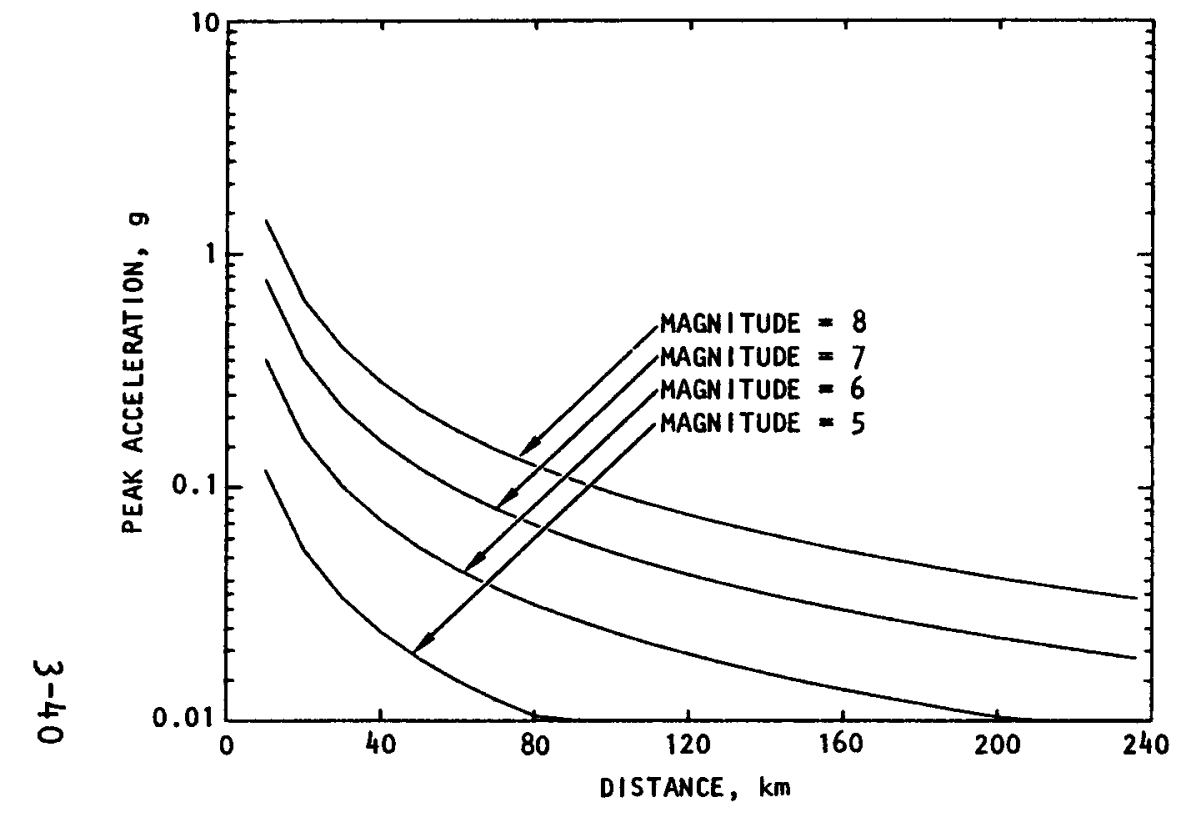

(a) Horizontal

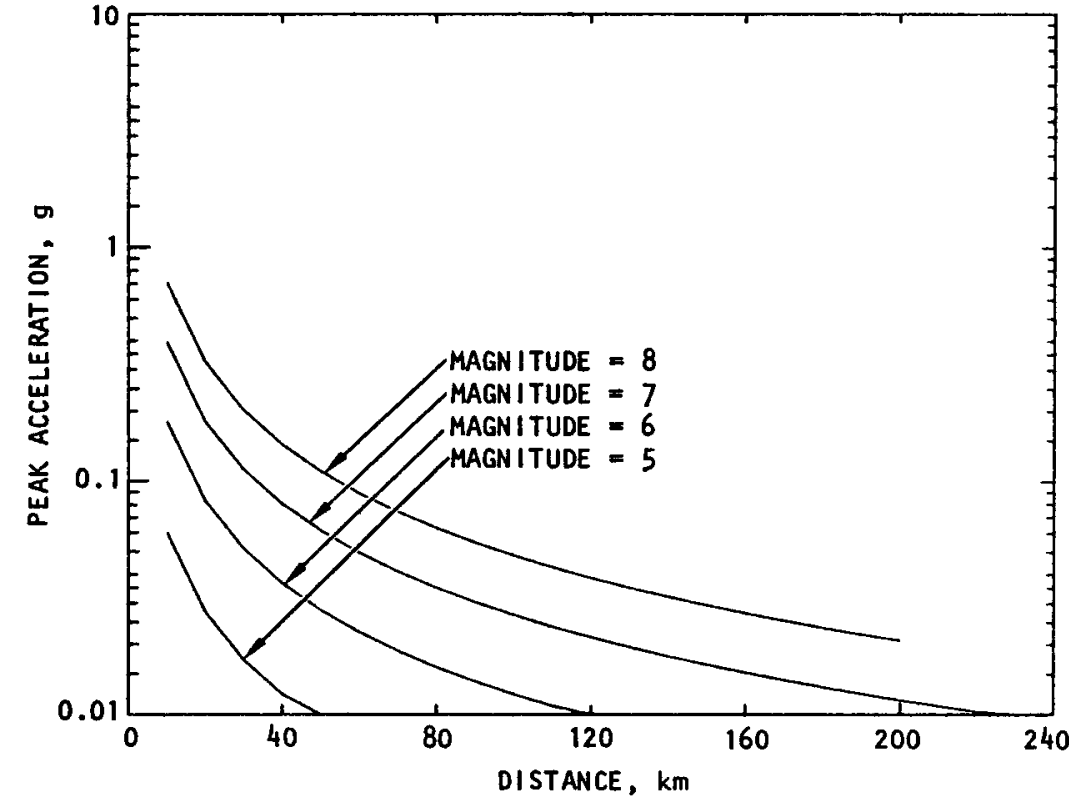

(b) Vertical

NOTE :

EARTHQUAKE EVENT $=$ TYPE
SITE CONDITION $=$ ALL
PERCENTILE

FIGURE 3-26. EFFECT OF MAGNITUDE ON PEAK ACCELERATIONS 


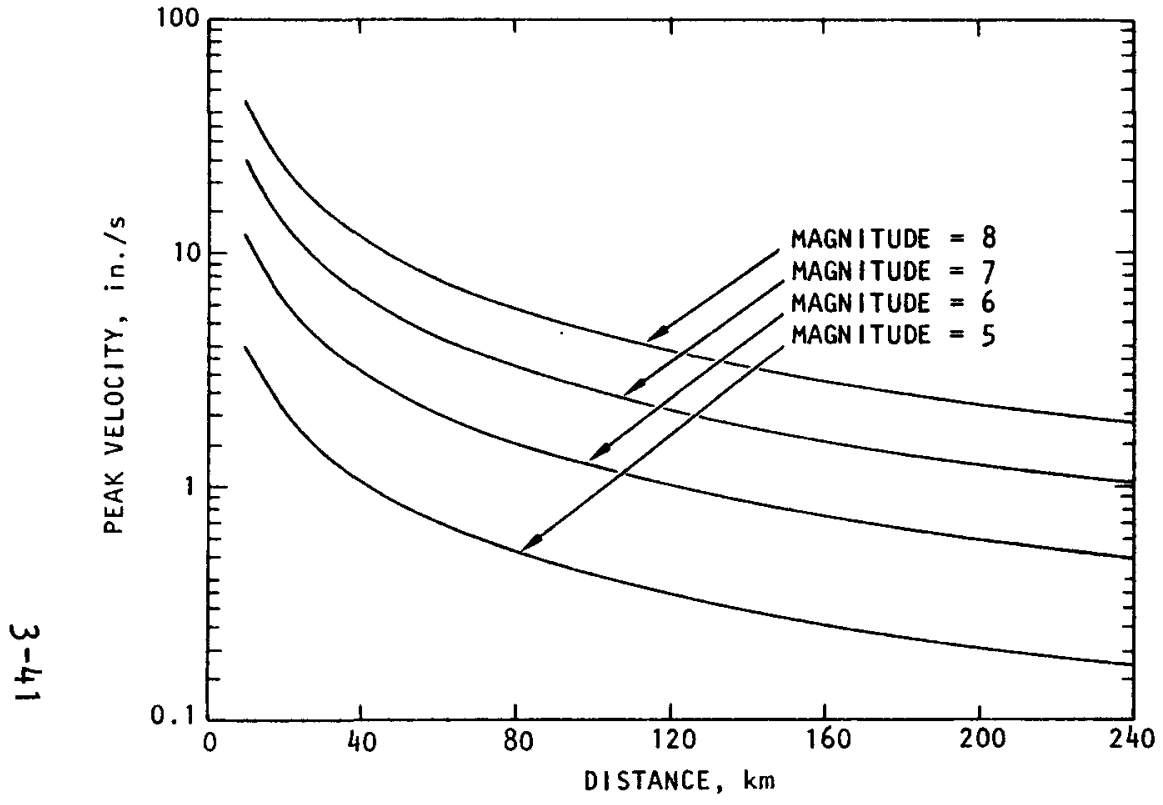

(a) Horizontal

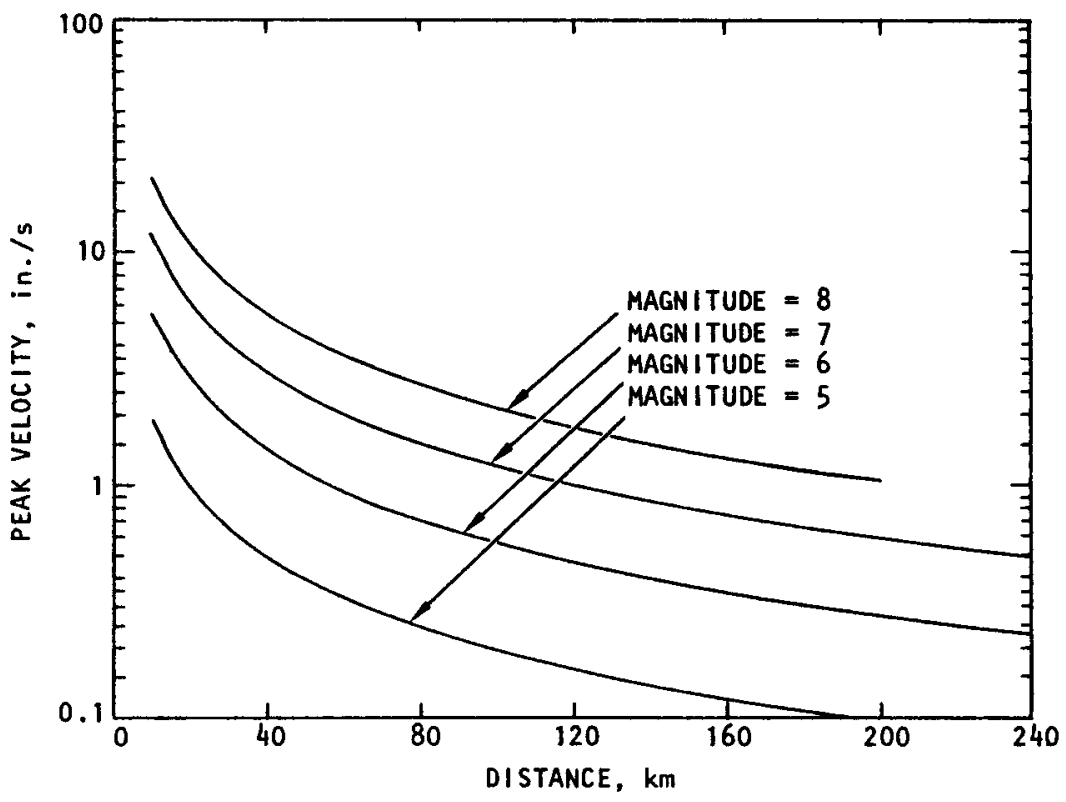

(b) Vertical

NOTE :

EARTHQUAKE EVENT = TYPE 3

SITE CONDITION = INTERMEDIATE

PERCENTILE $\quad=50$ th

FIGURE 3-27. EFFECT OF MAGNITUDE ON PEAK VELOCITIES 


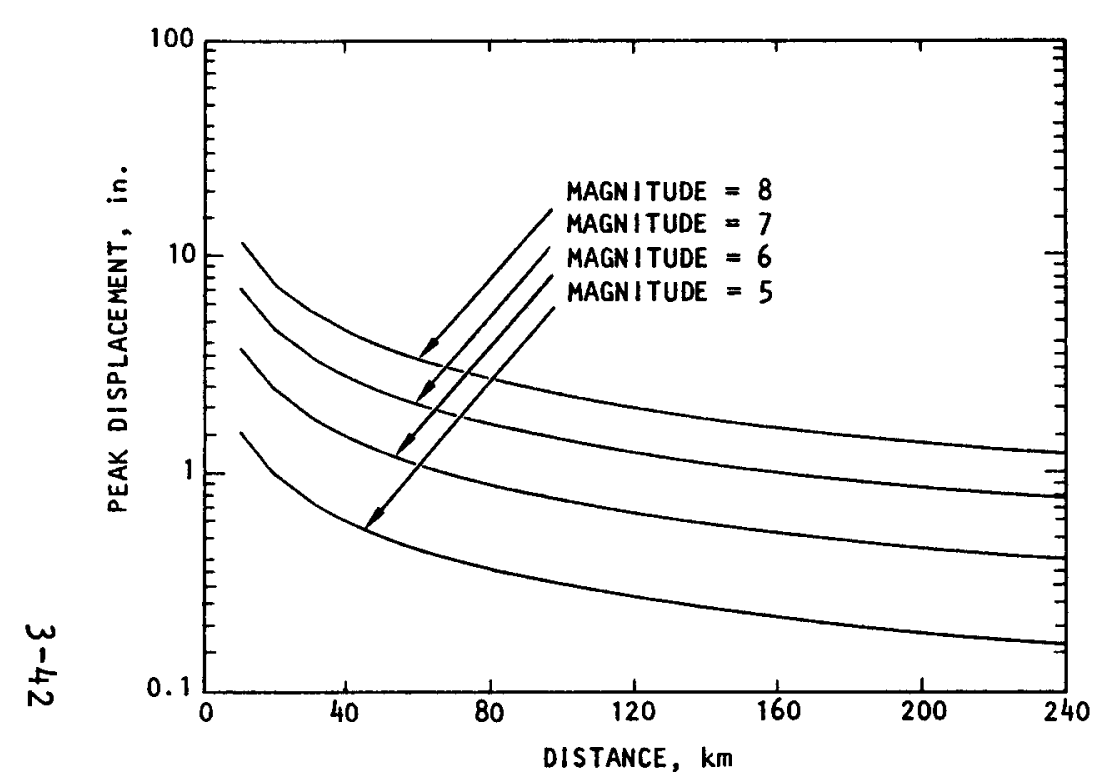

(a) Horizontal

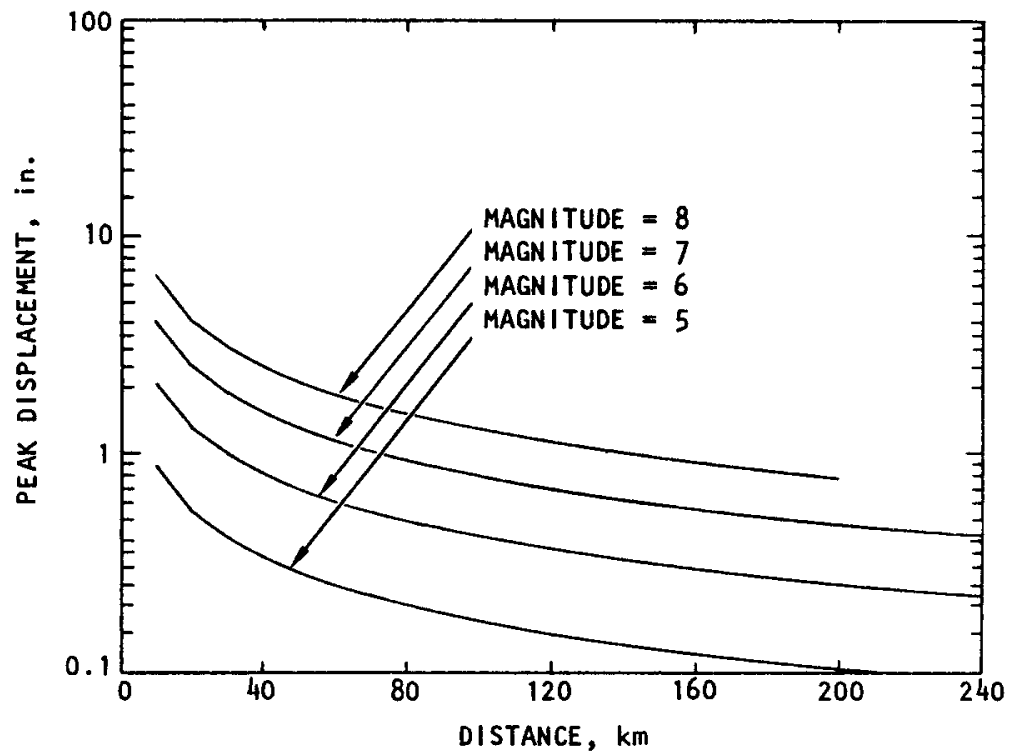

(b) Vertical

NOTE :

EARTHQUAKE EVENT $=$ TYPE 3

SOIL CONDITION = INTERMEDIATE

PERCENTILE $\quad=50$ th

FIGURE 3-28. EFFECT OF MAGNITUDE ON PEAK DISPLACEMENTS 


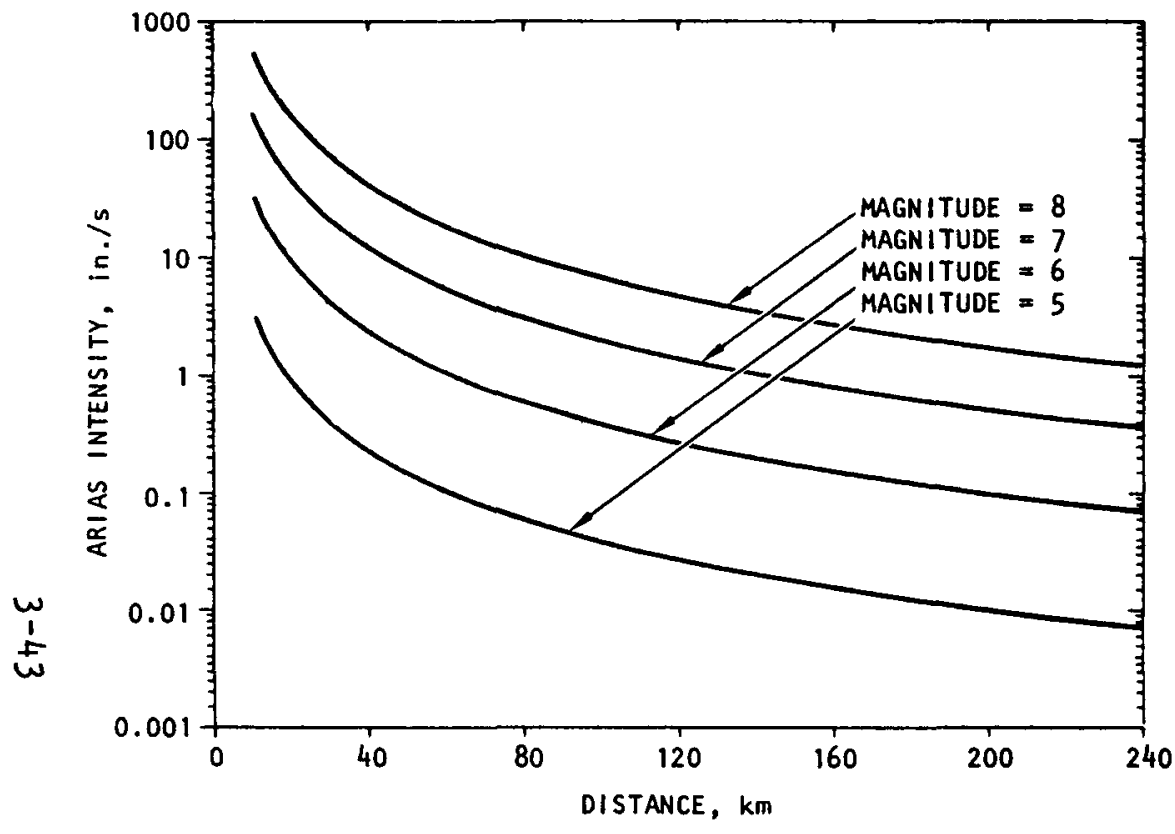

(a) Horizontal

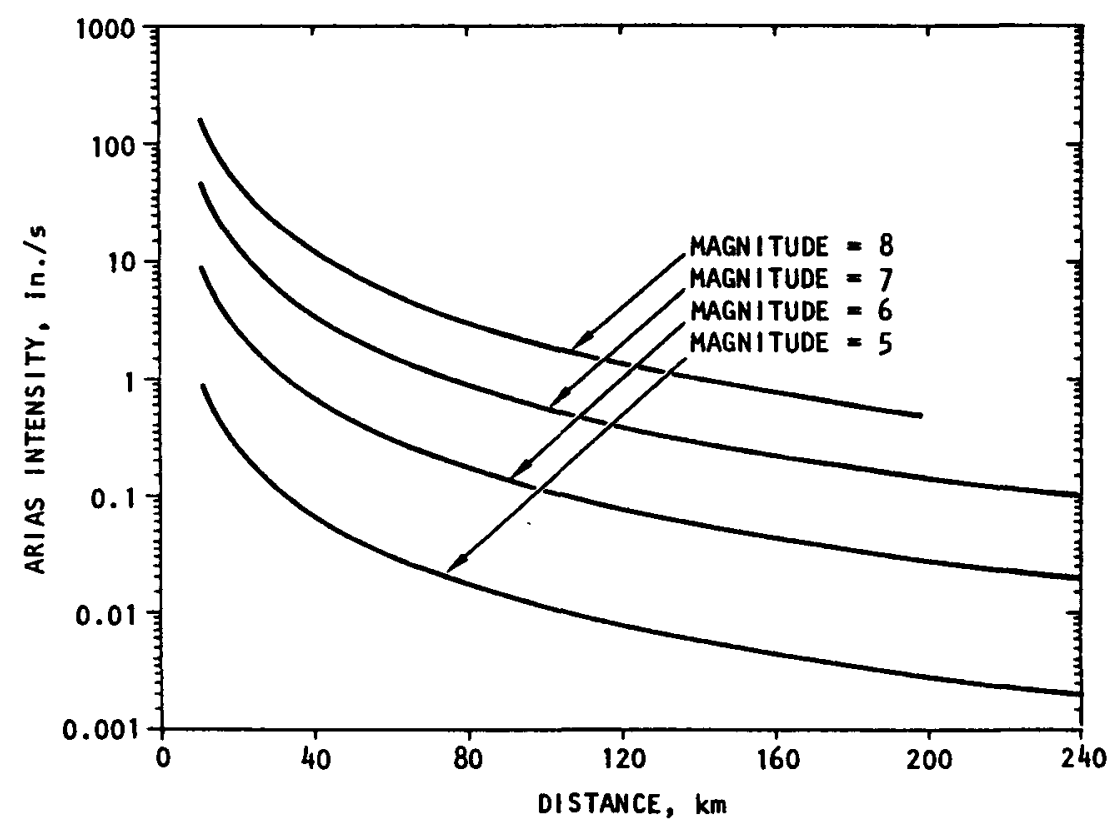

(b) Vertical

NOTE :

EARTHQUAKE EVENT = TYPE 3

SITE CONDITION = INTERMEDIATE

PERCENTILE $=50$ th

FIGURE 3-29. EFFECT OF MAGNITUDE ON ARIAS INTENSITIES 


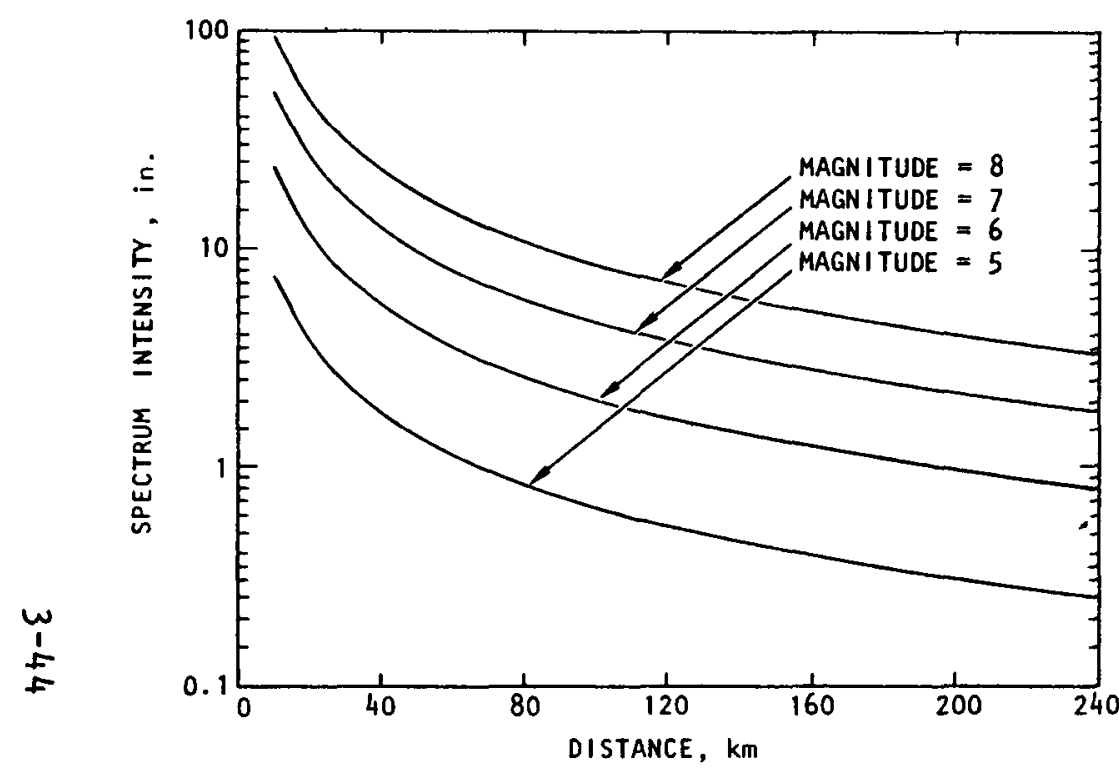

(a) Horizontal

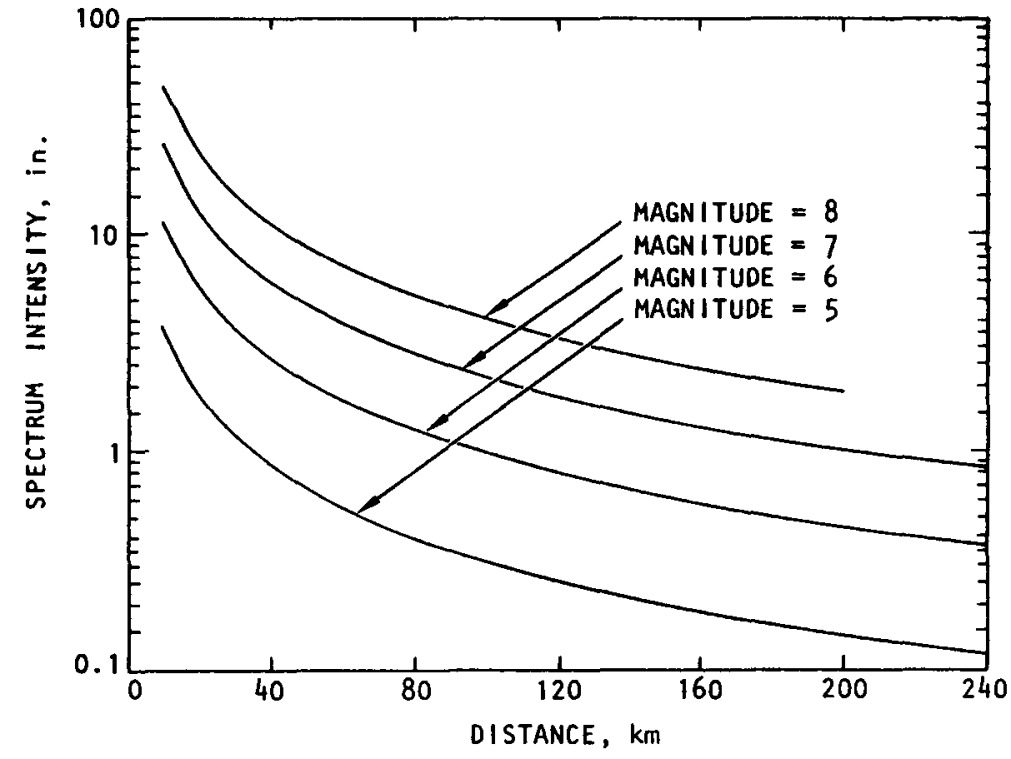

(b) Veritcal

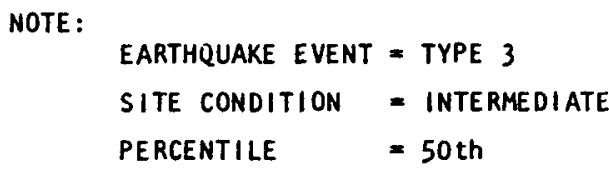

FIGURE 3-30. EFFECT OF MAGNITUDE ON SPECTRUM INTENSITIES 


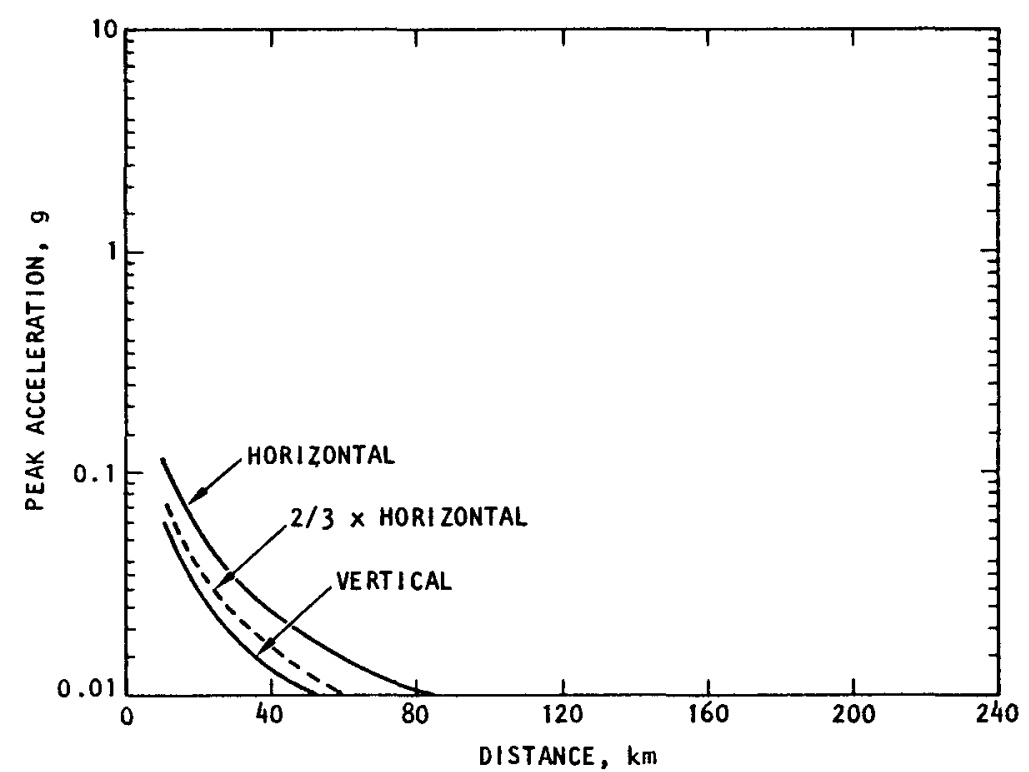

$w$
1
$w$

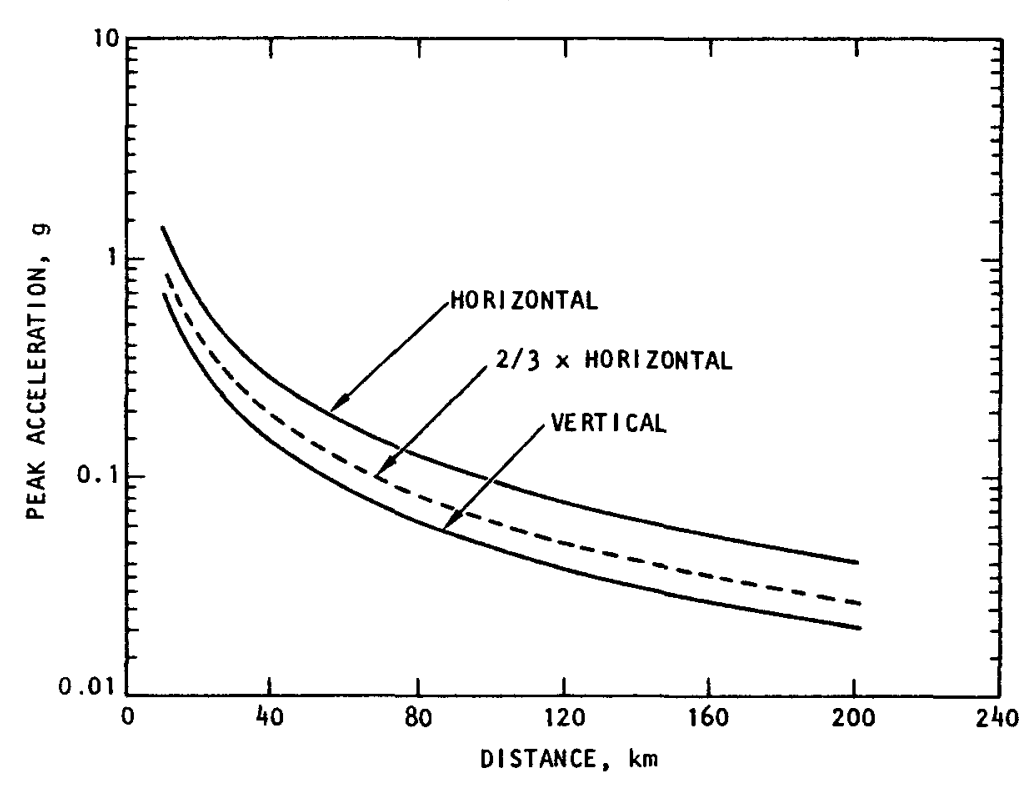

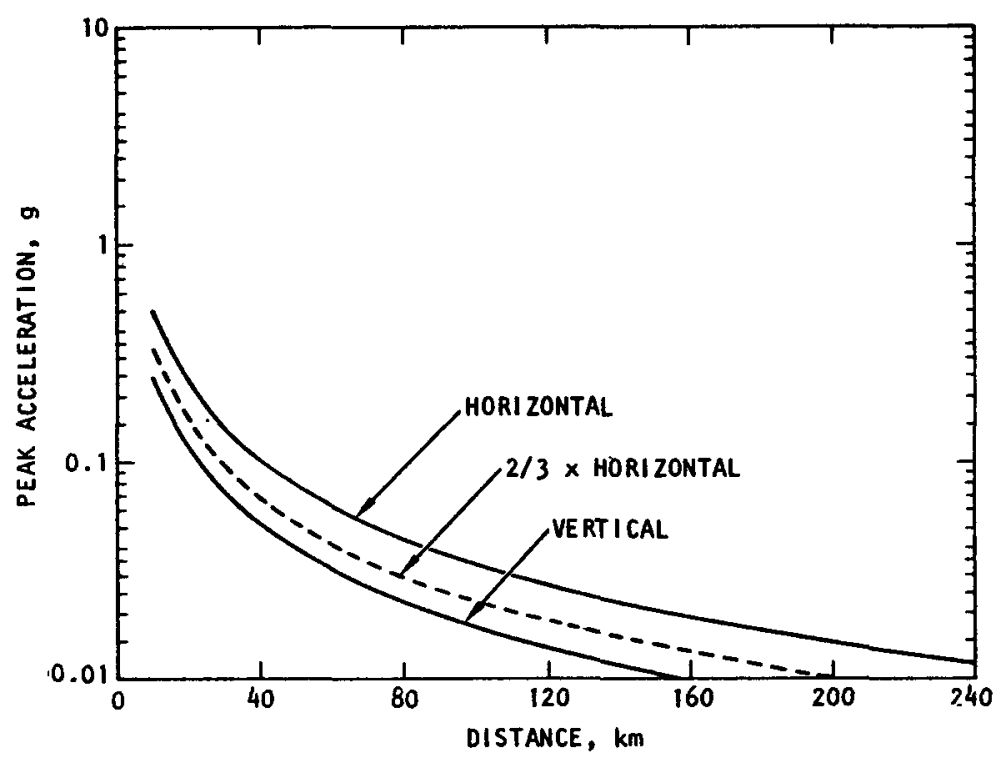

(b) Magnitude $=6.4$
NOTE :

EARTHQUAKE EVENT = TYPE 3

SITE CONDITION = ALL

PERCENTILE

$=50$ th

(c) Magnitude $=8.0$

FIGURE 3-31. COMPARISON BETWEEN HORIZONTAL AND VERTICAL PEAK ACCELERATIONS 


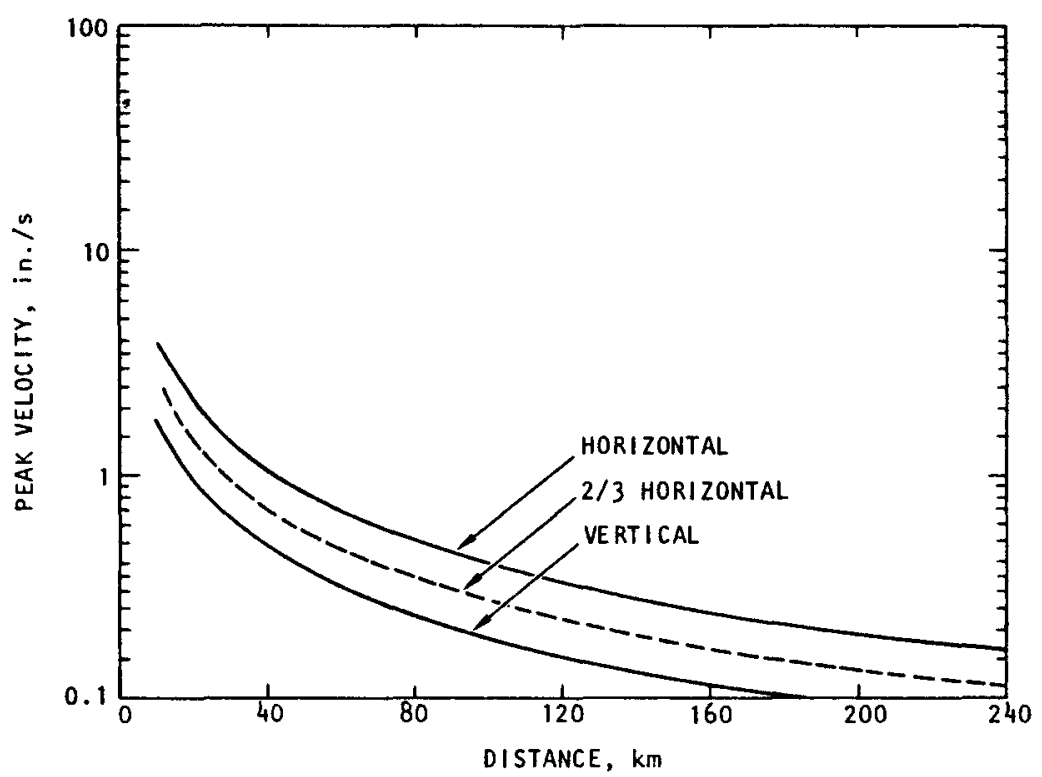

(a) Magnitude $=5.0$

$\stackrel{w}{1}$

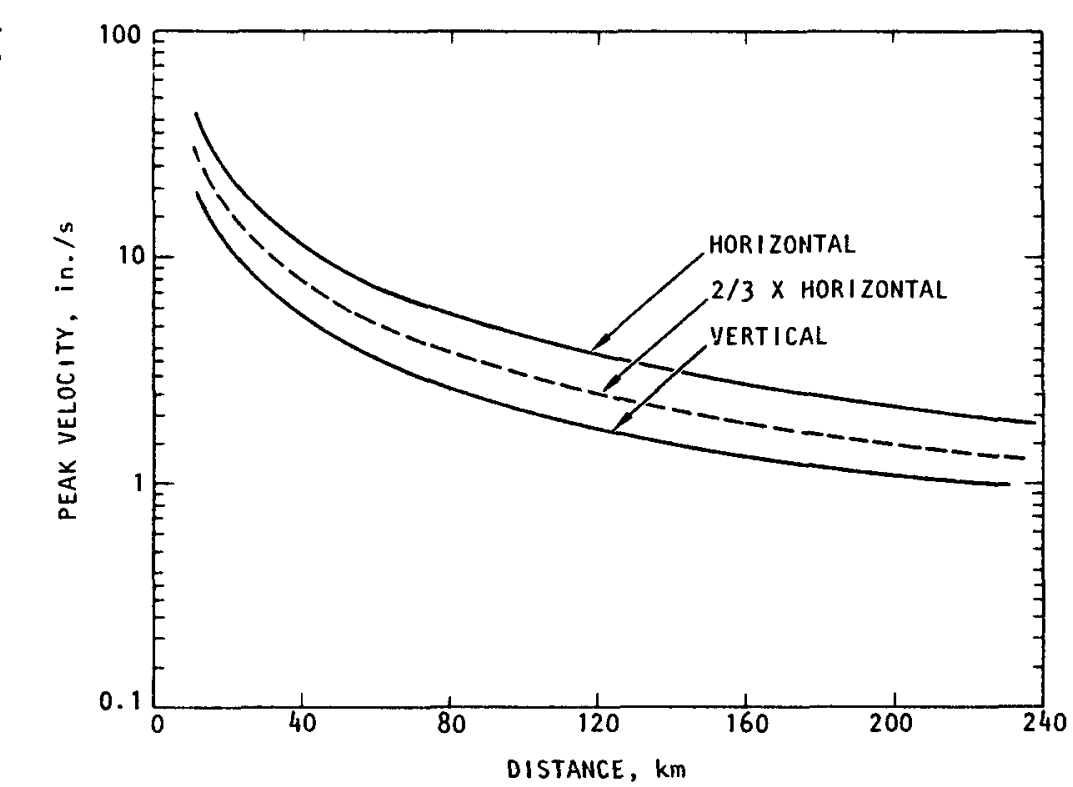

(c) Magnitude $=8.0$

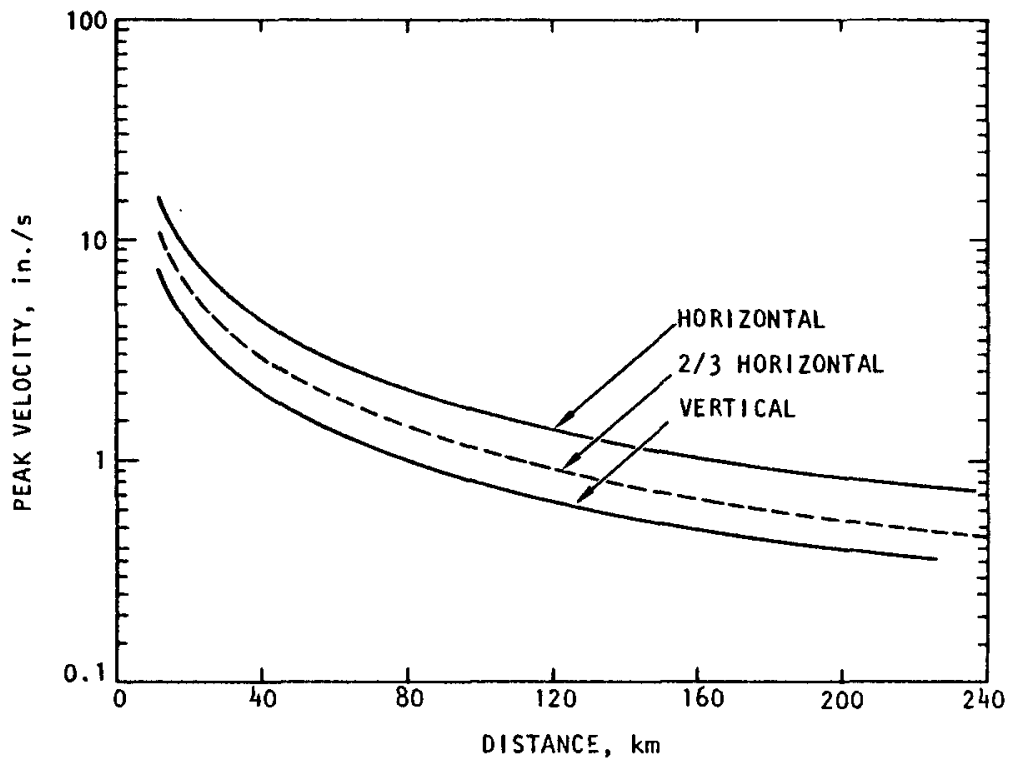

(b) Magnitude $=6.4$

NOTE : EARTHQUAKE EVENT = TYPE 3 SITE CONDITIONS = INTERMEDIATE PERCENTILE = 50 th

FIGURE 3-32. COMPARISON BETWEEN HORIZONTAL AND VERTICAL PEAK VELOCITIES 


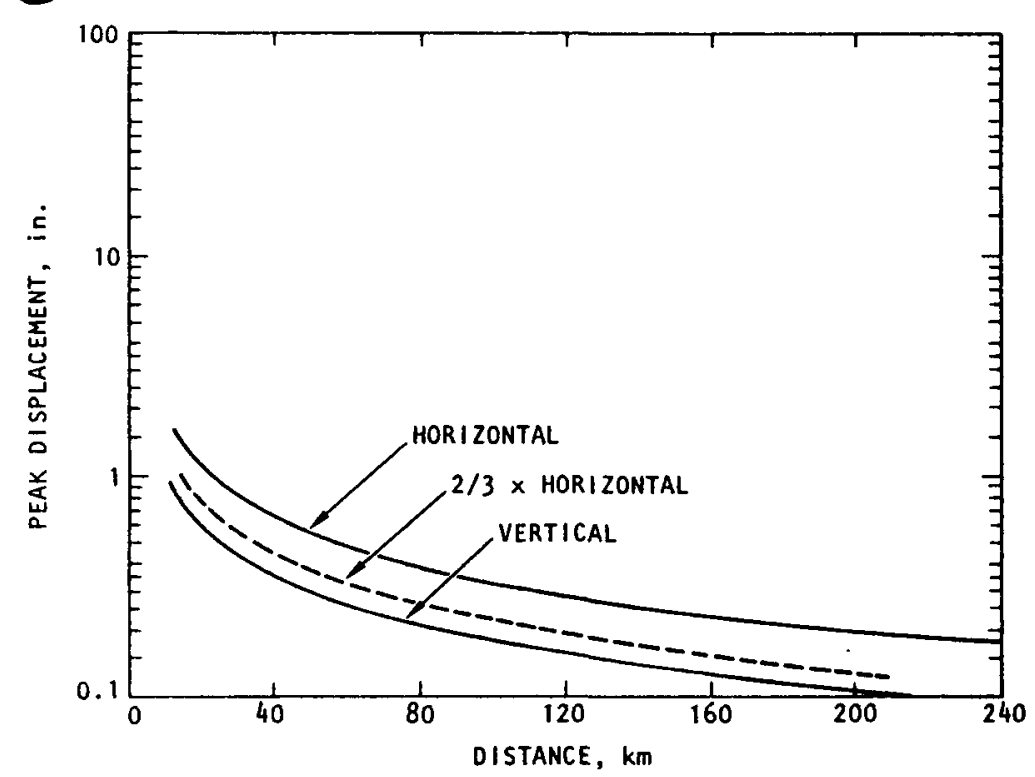

(a) Magnitude $=5.0$

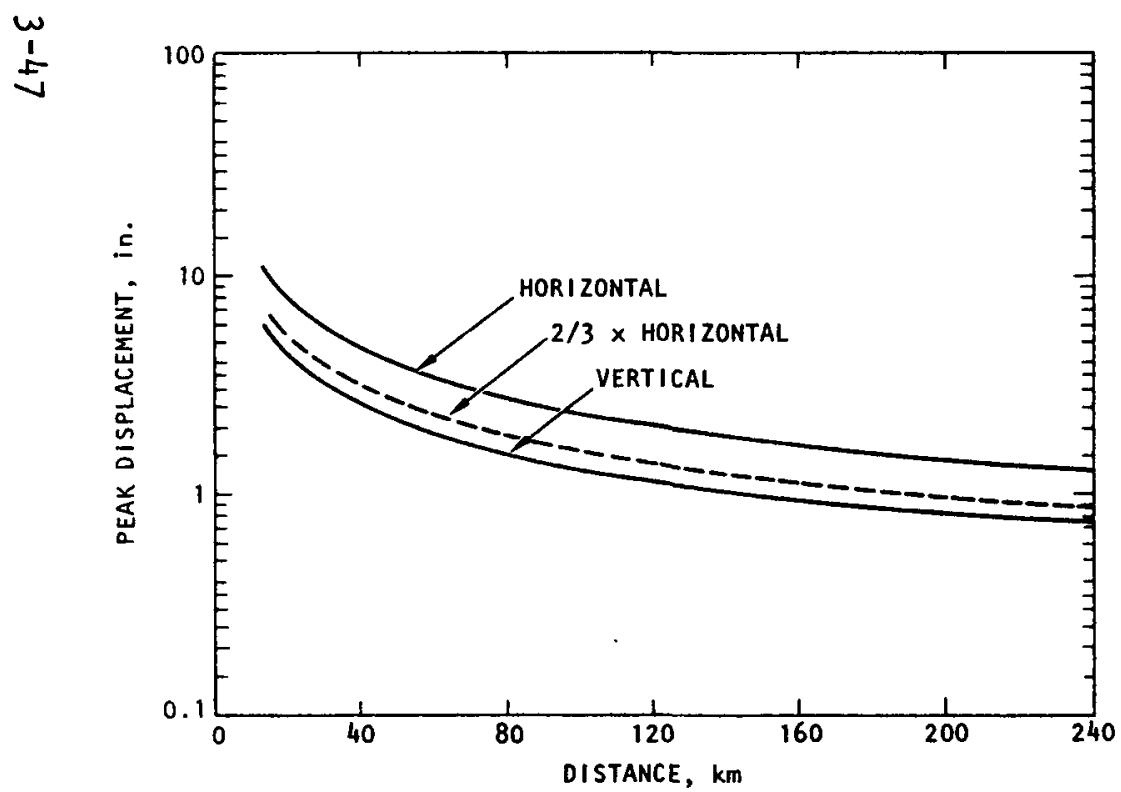

(c) Magni tude $=8.0$

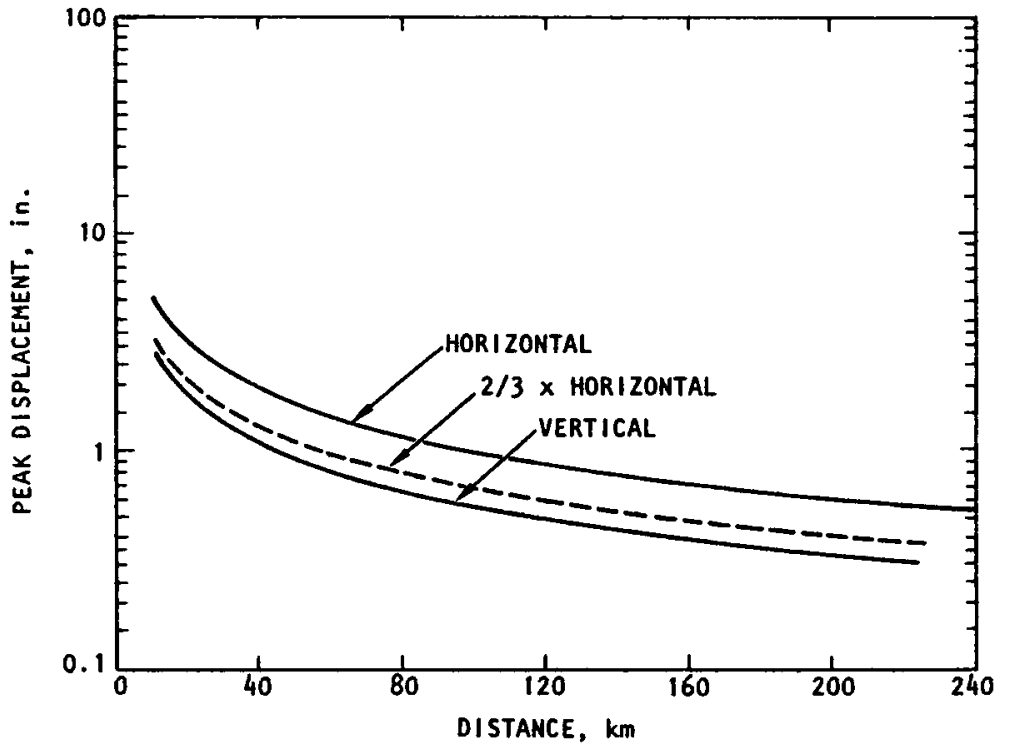

(b) Magnitude $=6.4$
NOTE: EARTHQUAKE EVENT = TYPE 3 SITE CONDITION = INTERMEDIATE PERCENTILE

FIGURE 3-33. COHPARISON BETWEEN HORIZONTAL AND VERTICAL PEAK DISPLACEMENTS 


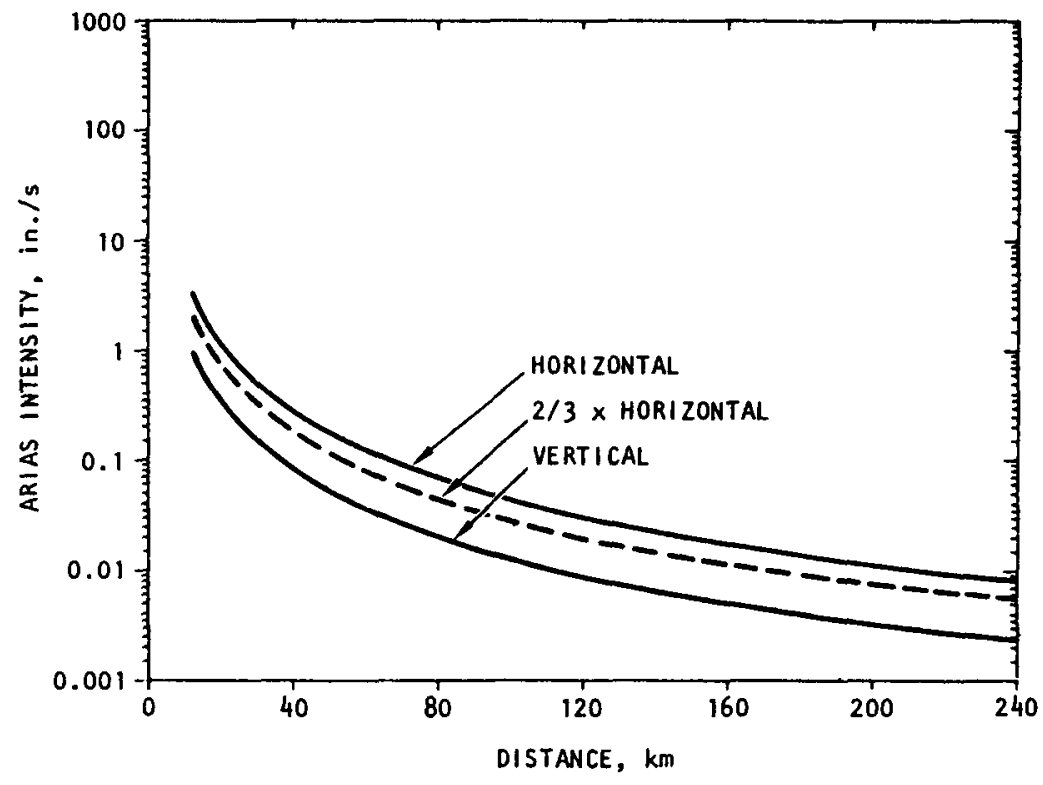

(a) Magnitude $=5.0$

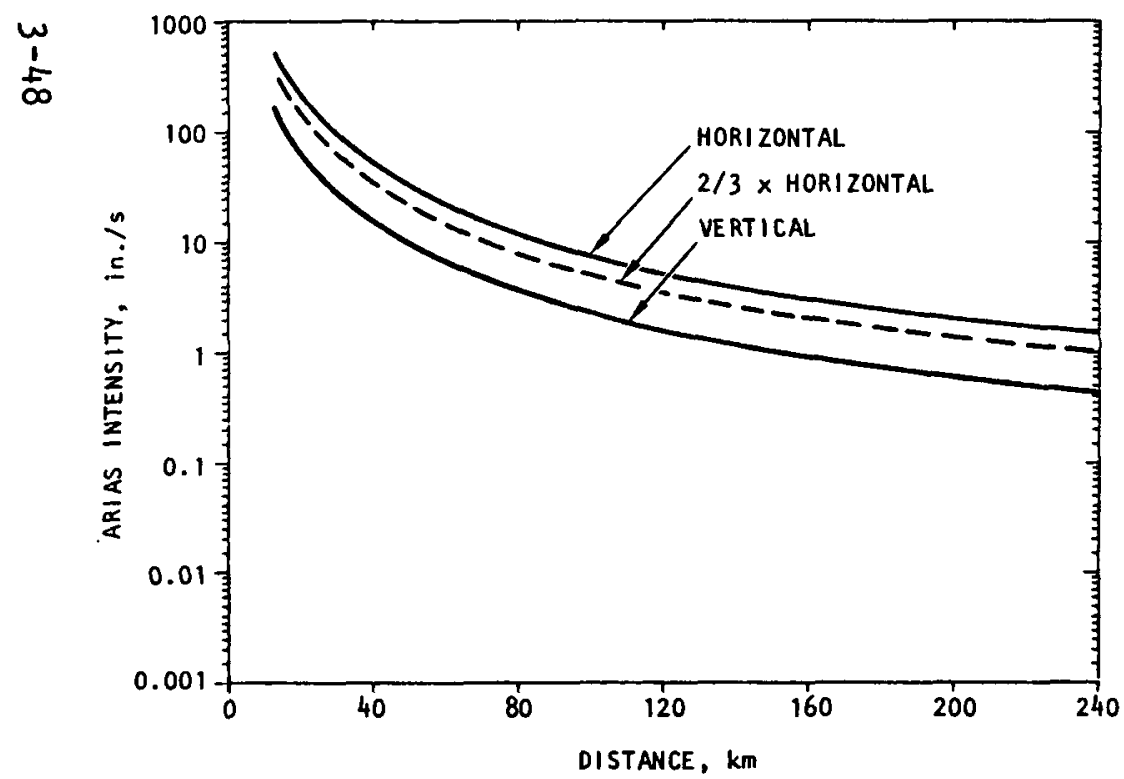

(c) Magnitude $=8.0$

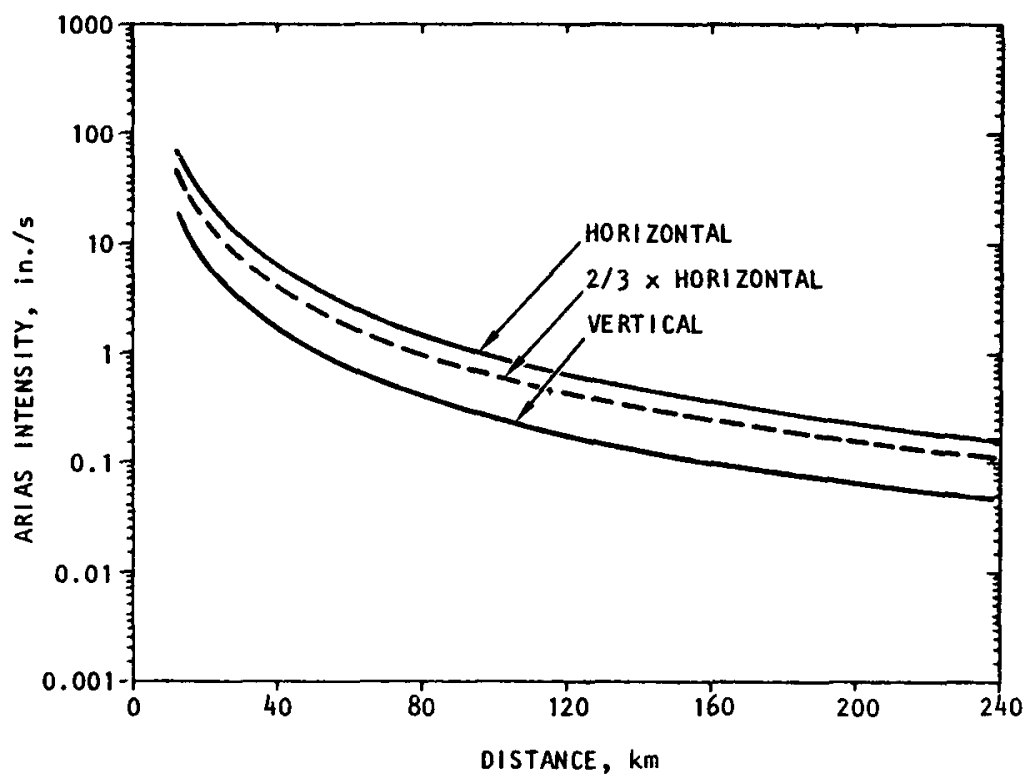

(b) Magni tude $=6.4$
NOTE :

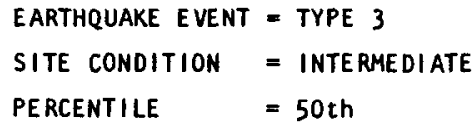

EARTHQUAKE EVENT = TYPE 3

SITE CONDITION = INTERMEDIATE

PERCENTILE

FIGURE 3-34. COMPARISON BETWEEN HORIZONTAL AND VERTICAL ARIAS INTENSITIES 


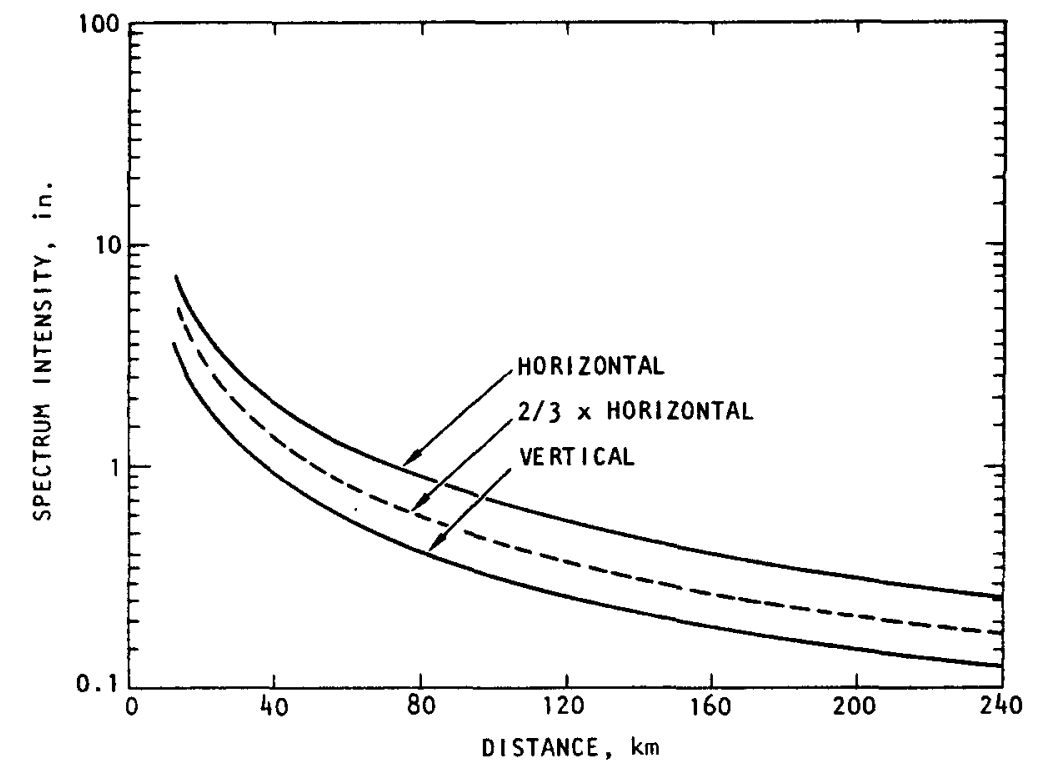

(a) Magnitude $=5.0$

$w$
1
5

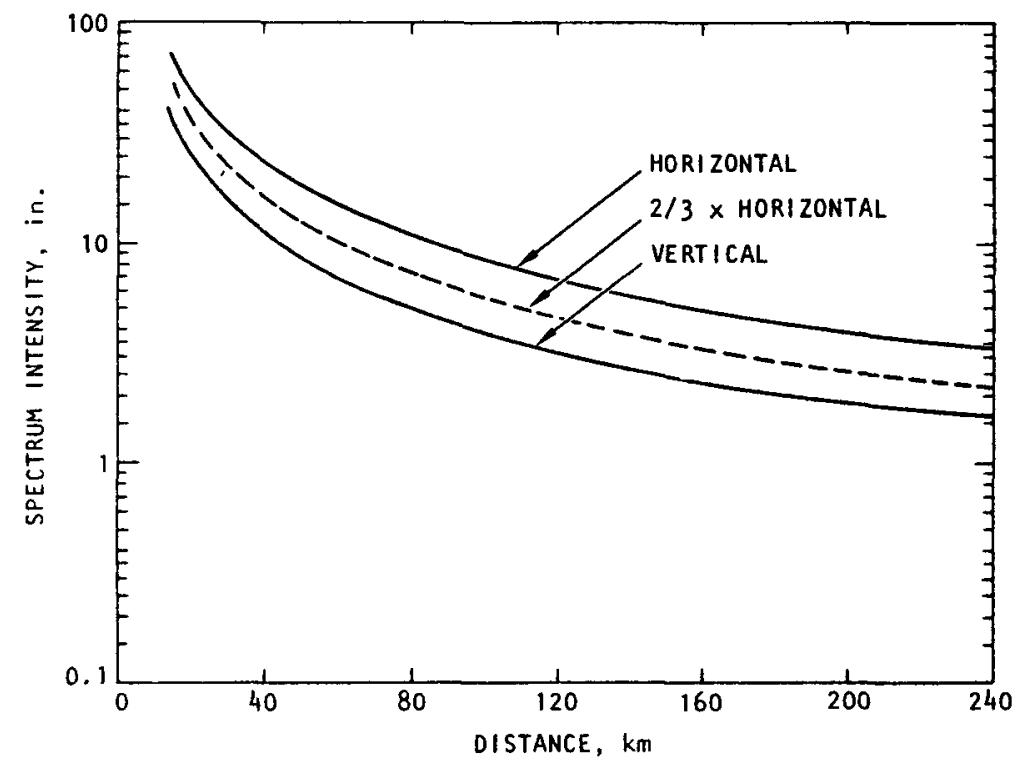

(c) Magni tude $=8.0$

FIGURE 3-35. COMPARISON BETWEEN HORIZONTAL AND VERTICAL SPECTRUM INTENSITIES

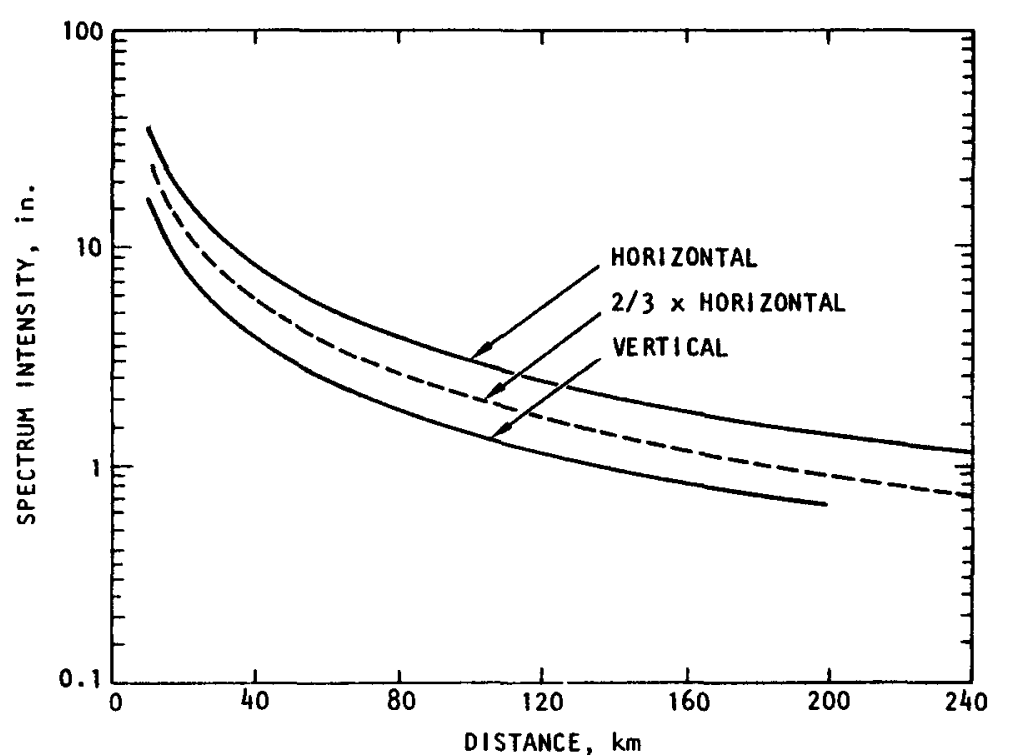

(b) Magnitude $=6.4$

NOTE :

ARTHUUAKE EVENT $=$ TYPE

SITE CONOITION = INTERMEDIATE

PERCENTILE $=50$ th 


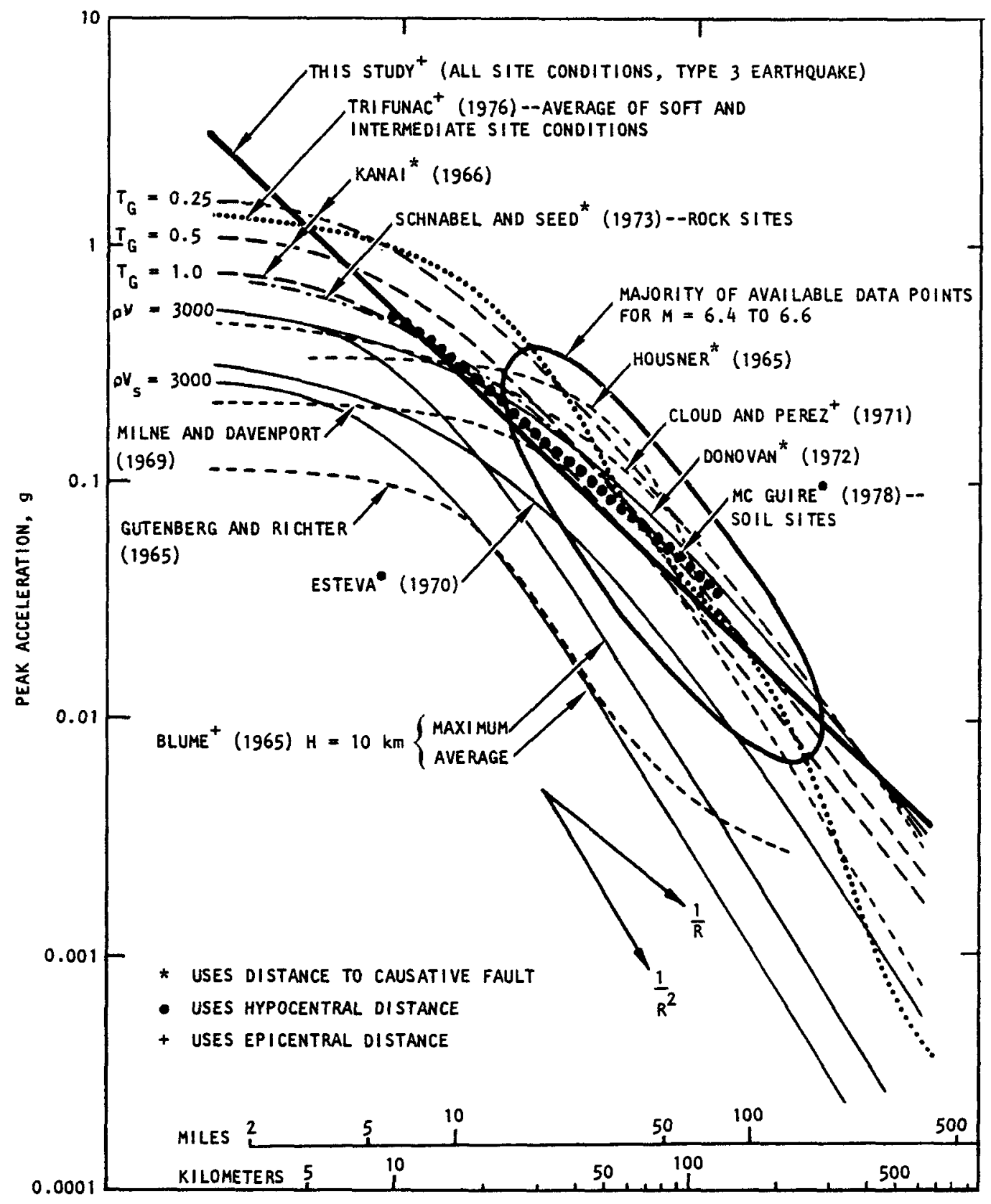

DISTANCE, $\mathrm{km}$ or $\mathrm{mi}$

FIGURE 3-36. COMPARISON BETWEEN PEAK HORIZONTAL ACCELERATION RESULTS FROM THIS STUDY AND FROM PRIOR INVESTIGATIONS FOR

MAGNITUDE 6.5 EARTHQUAKES (Modified from Trifunac, 1976) 


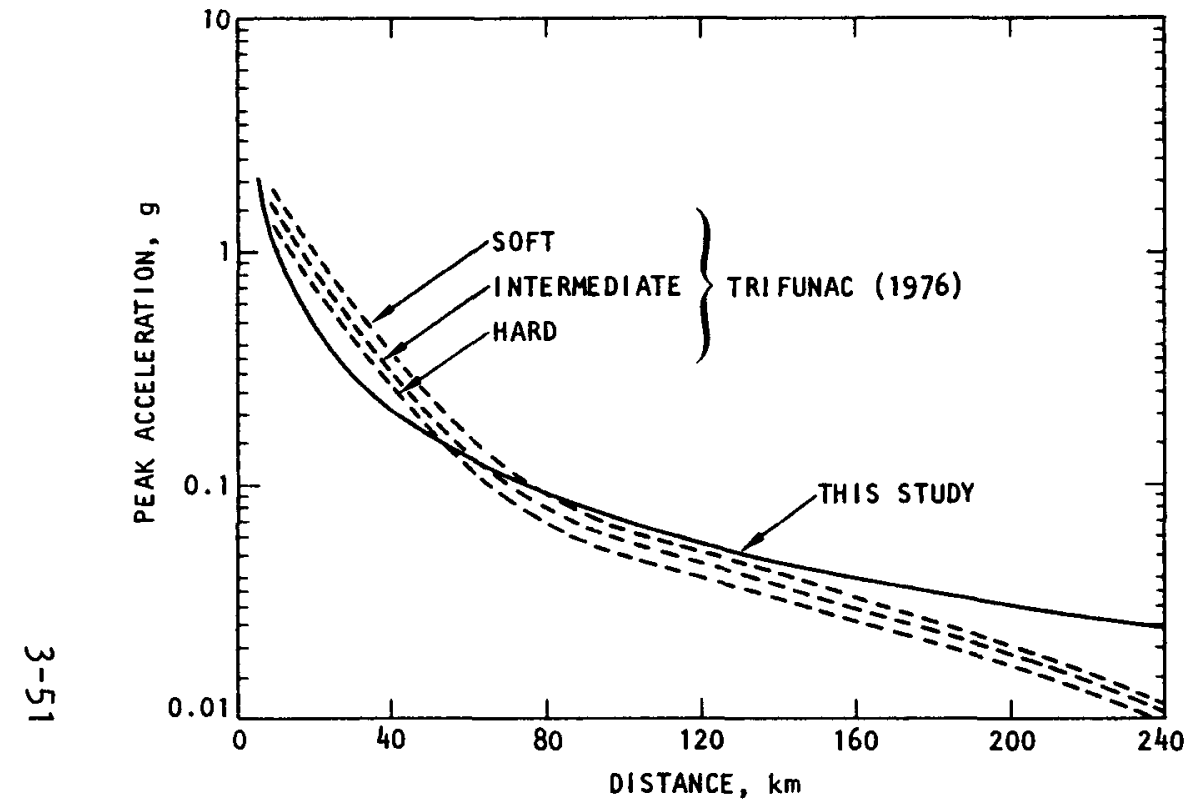

(a) Horizontal

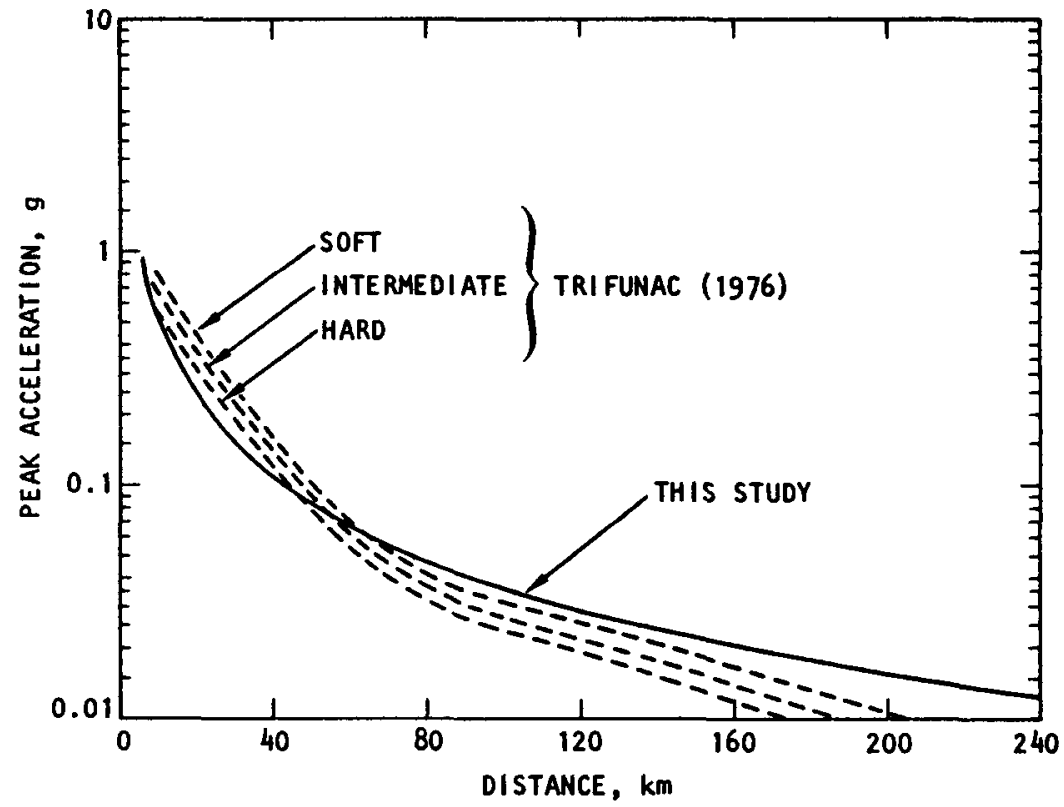

(b) Vertical

NOTE :

MAGNITUDE $=6.4$
SITE CONDITION $=$ ALL
PERCENTILE $=90 \mathrm{th}$

FIGURE 3-37. COMPARISON OF PEAK ACCELERATION RESULTS FROM THIS STUDY WITH THOSE OF TRIFUNAC (1976) 


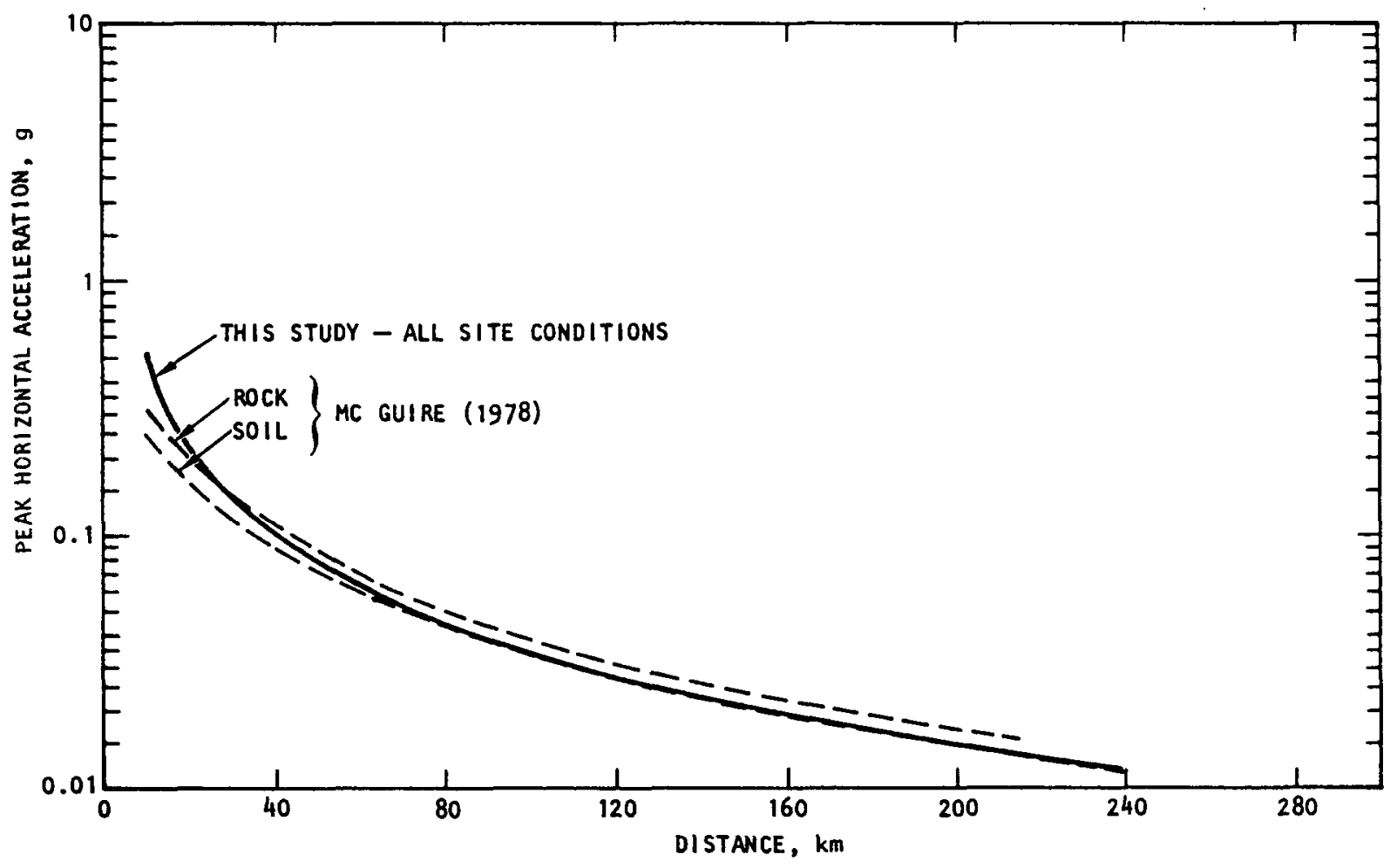

(a) Comparisons for Magnitude $=6.4$

\begin{tabular}{|c|c|c|c|}
\hline \multirow{2}{*}{ Magnitude } & \multirow{2}{*}{$\begin{array}{c}\text { Epicentral } \\
\text { Distance, } \\
\mathrm{km}\end{array}$} & \multicolumn{2}{|c|}{ Peak Horizontal Acceleration, $\mathrm{g}^{\text {(2) }}$} \\
\cline { 2 - 4 } & 30 & This Study & McGui re (1978) \\
\hline 5.0 & 100 & $\begin{array}{c}0.034 \\
0.0080\end{array}$ & $\begin{array}{l}0.035 \\
0.0097\end{array}$ \\
\hline 6.4 & 30 & 0.142 & 0.122 \\
& 100 & 0.034 & 0.034 \\
\hline 8.0 & 30 & 0.396 & 0.508 \\
& 100 & 0.094 & 0.140 \\
\hline
\end{tabular}

(1)

McGuire results, originally given in terms of hypocentral distance, were converted to epicentral distance assuming focal depth $=15 \mathrm{~km}$.

(2)

McGuire (1978) results shown for soil sites only. Results from this study shown only for Type 3 earthquake event and for all site conditions.

(b) Magnitude dependence of peak acceleration comparisons

FIGURE 3-38. COMPARISON OF PEAK HORIZONTAL ACCELERATION RESULTS FROM THIS STUDY WITH THOSE OF MC GUIRE (1978) 


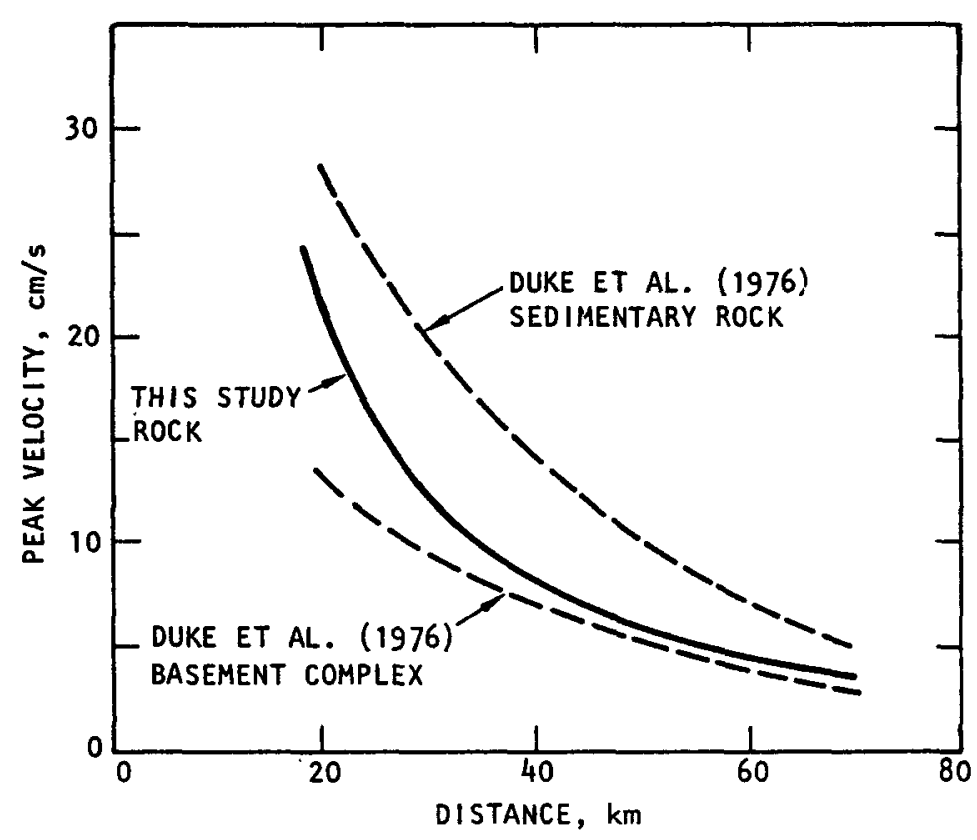

(a) Rock sites

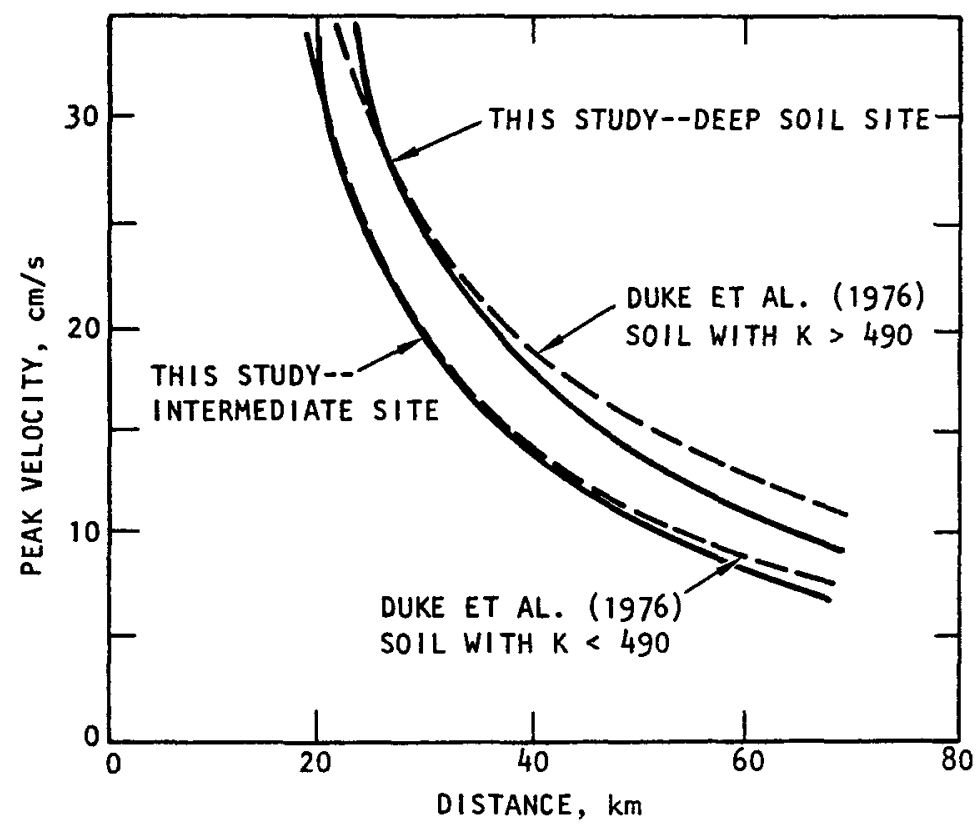

(b) Soil sites

FIGURE 3-39. COMPARISON OF PEAK HORIZONTAL VELOCITY RESULTS FROM THIS STUDY WITH THOSE OF DUKE ET AL. (1976) FOR SAN FERNANDO EARTHQUAKE 


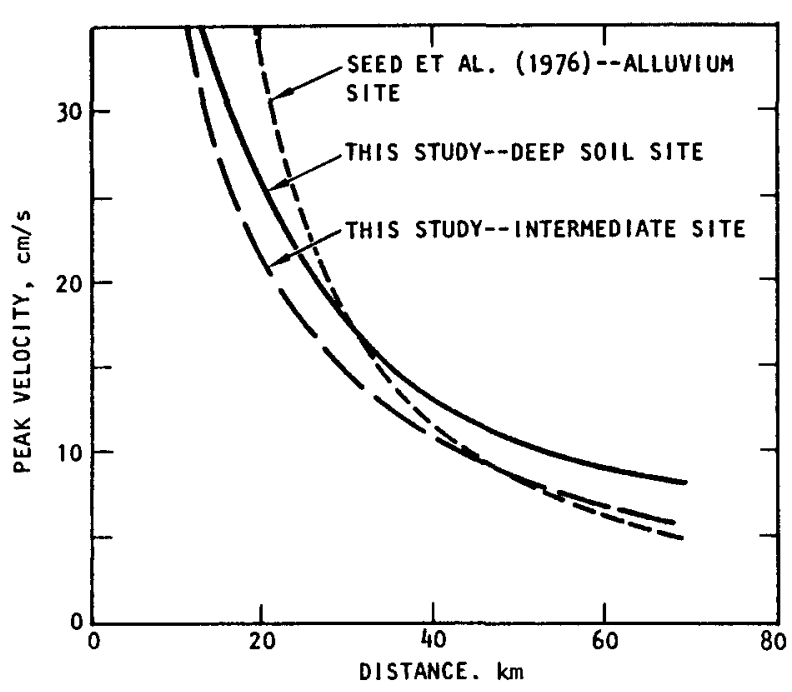

(a) Soil sites--Type 3 events

$\underset{1}{w}$

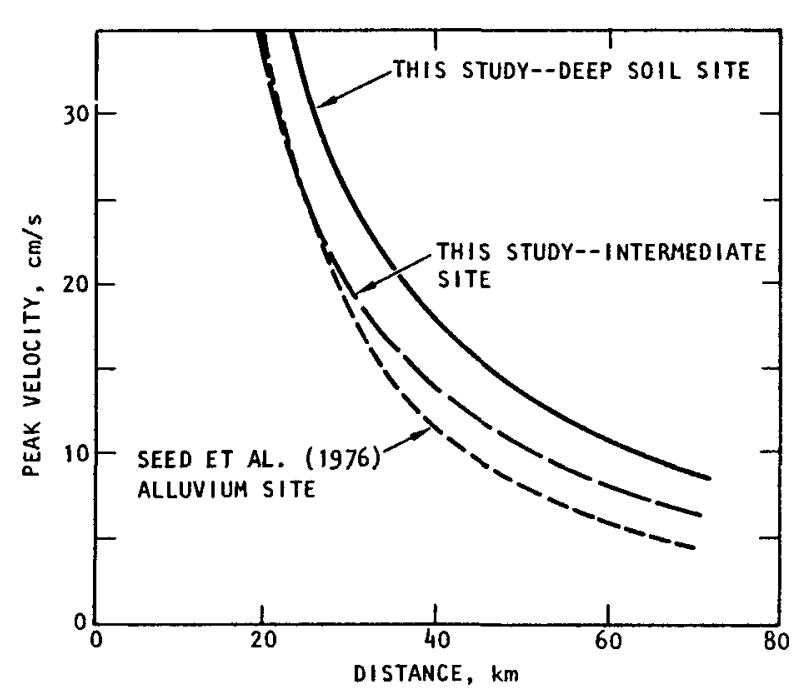

(c) Soil sites--Type 1 event

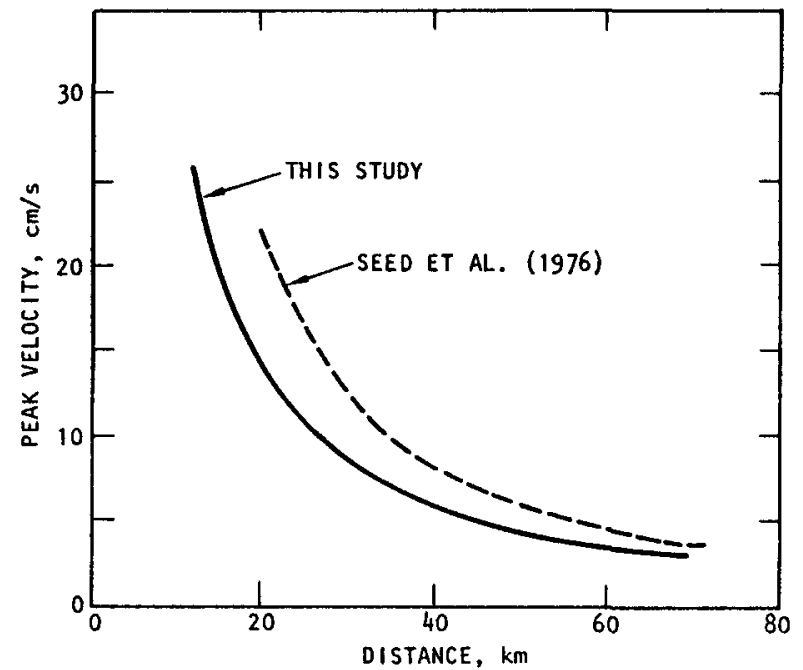

(b) Rock sites--Type 3 events

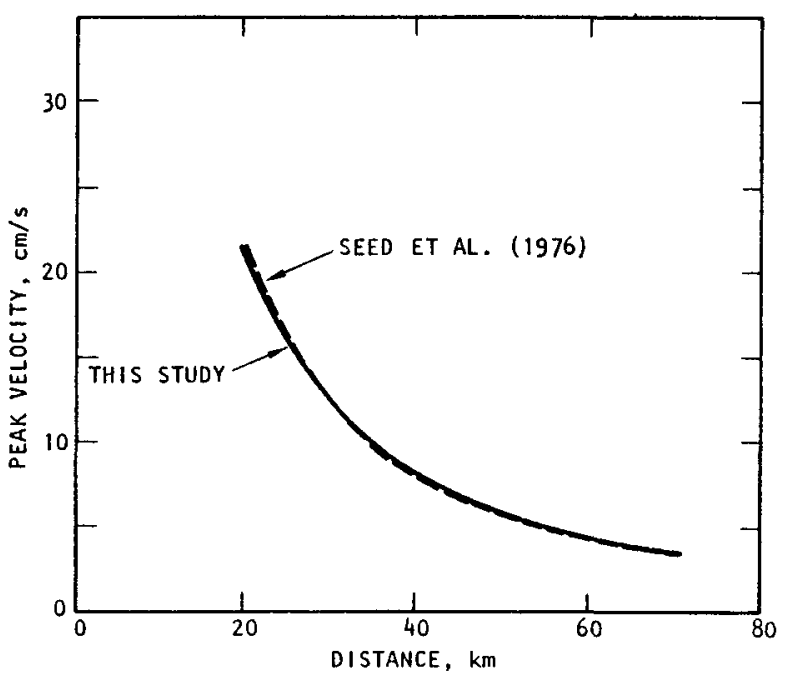

(d) Rock sites--Type 1 event

FIGURE 3-40. COMPARISON OF PEAK HORIZONTAL VELOCITY RESULTS FROM THIS STUDY WITH THOSE OF SEED ET AL. (1976) --MAGNITUDE 6.5, 50th PERCENTILE 


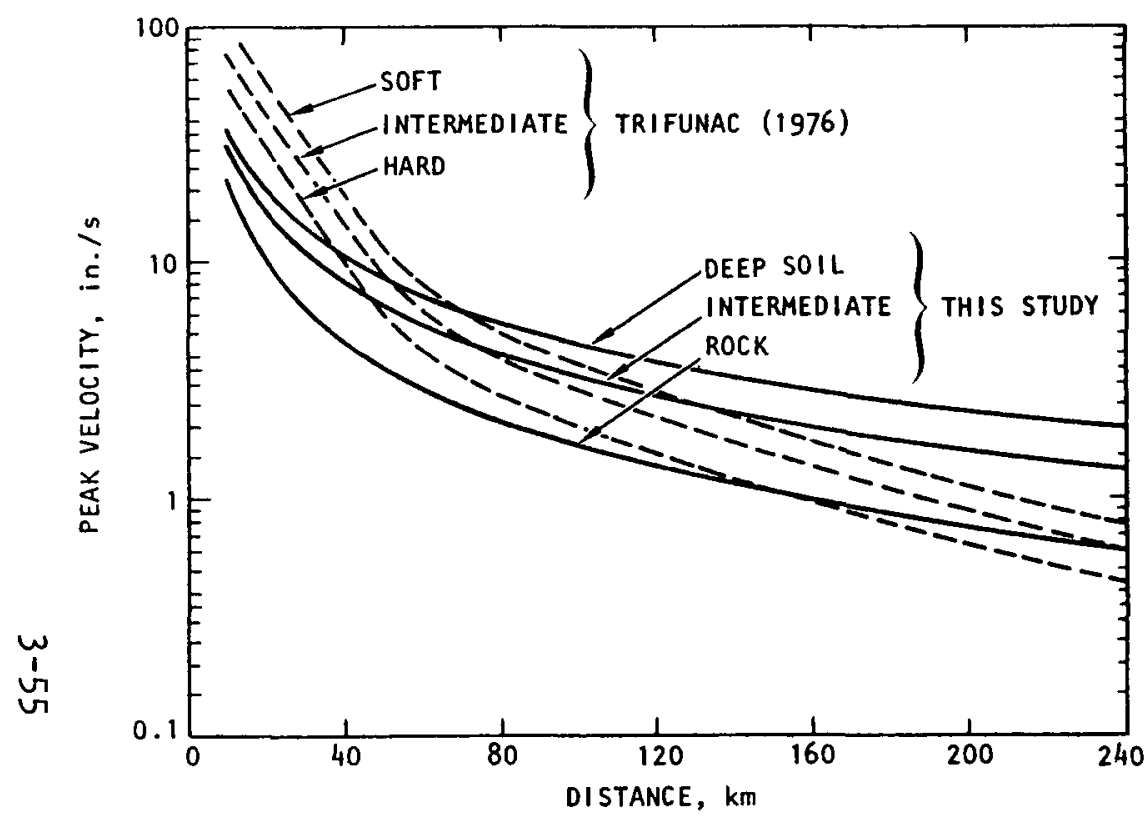

(a) Horizontal

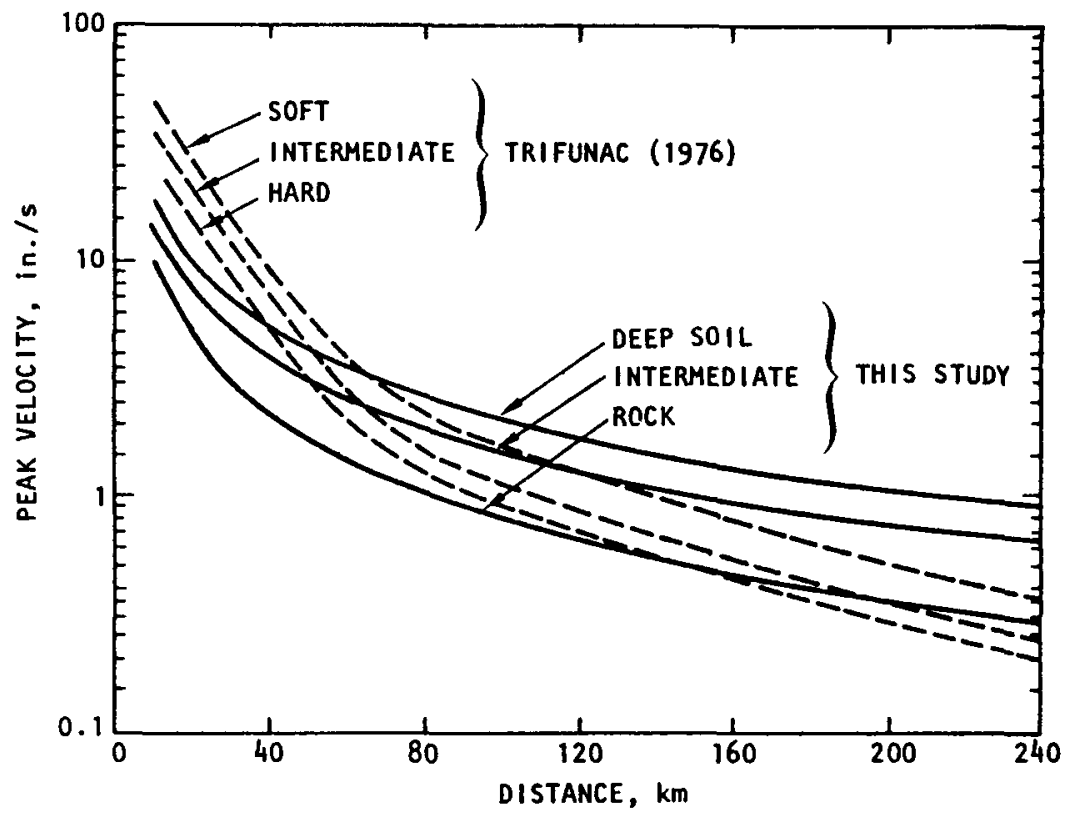

(b) Vertical

NOTE :

$\begin{array}{ll}\text { EARTHQUAKE EVENT } & =\text { TYPE } 3 \\ \text { MAGNITUDE } & =6.4 \\ \text { PERCENTILE } & =90 \mathrm{th}\end{array}$

FIGURE 3-41. COMPARISON OF PEAK VELOCITY RESULTS FROM THIS STUDY WITH THOSE OF TRIFUNAC (1976) 


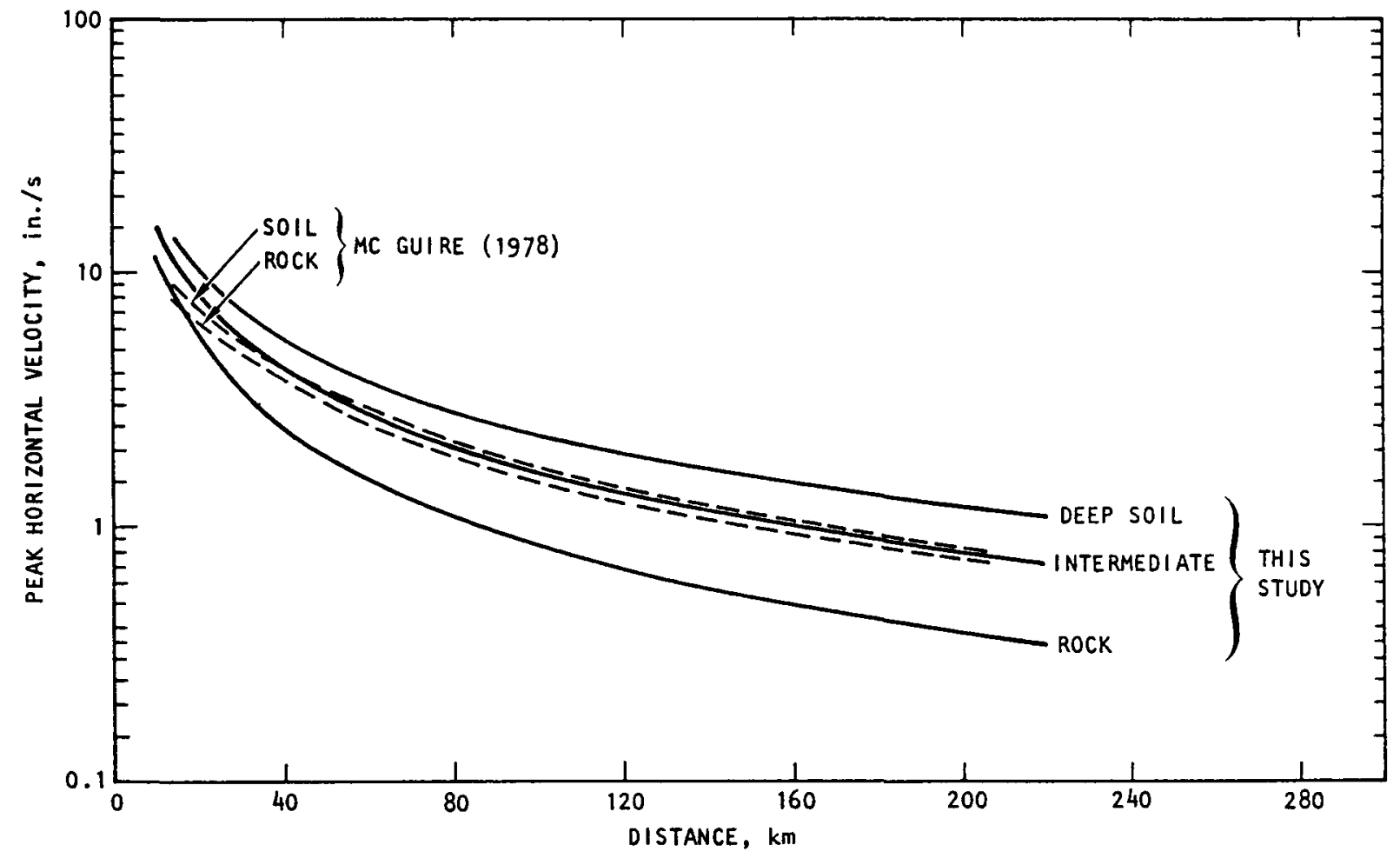

(a) Comparisons for Magnitude $=6.4$

\begin{tabular}{|c|c|c|c|}
\hline \multirow{2}{*}{ Magnitude } & $\begin{array}{c}\text { Epicentral } \\
\text { Distance, } \\
\mathrm{km}\end{array}$ & \multicolumn{2}{|c|}{ Peak Horizontal Velocity, in./s } \\
\cline { 2 - 4 } & 30 & This Study & McGuire (1978) \\
\hline \multirow{2}{*}{5.0} & 100 & 1.38 & 1.12 \\
& 30 & 0.41 & 0.39 \\
\hline \multirow{2}{*}{6.4} & 100 & 5.70 & 5.10 \\
& 30 & 1.71 & 1.76 \\
\hline \multirow{2}{*}{8.0} & 100 & 15.20 & 27.85 \\
& 4.62 & 9.65 \\
\hline
\end{tabular}

(1) IqcGuire results, originally given in terms of hypocentral distance, were converted to epicentra: Histance assuming focal depth $=15 \mathrm{~km}$.

(2)

McGuire (1978) results shown for soil sites only. Results from this study shown only for Type 3 earthquake event and for intermediate site condition.

(b) Magnitude dependence of peak velocity comparison

FIGURE 3-42. COMPARISON OF PEAK HORIZONTAL VELOCITY RESULTS FROM THIS STUDY WITH THOSE OF MC GUIRE (1978)

$$
\text { 3-56 }
$$




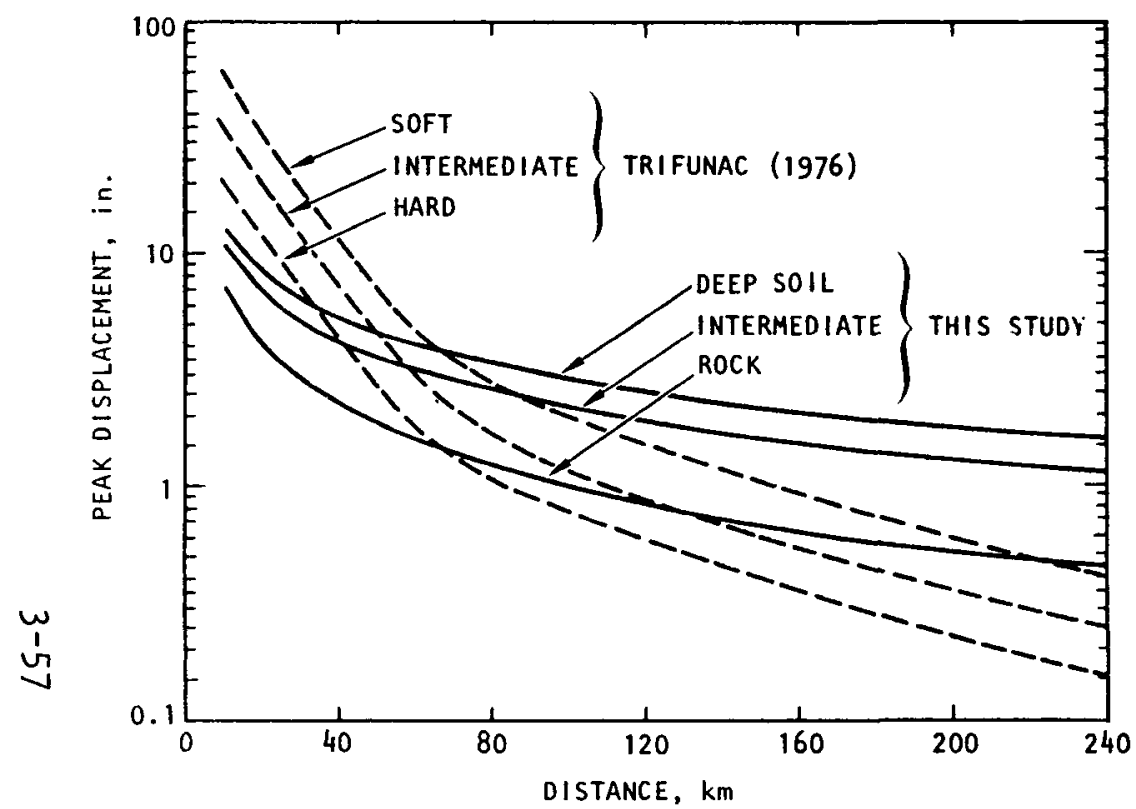

(a) Horizontal

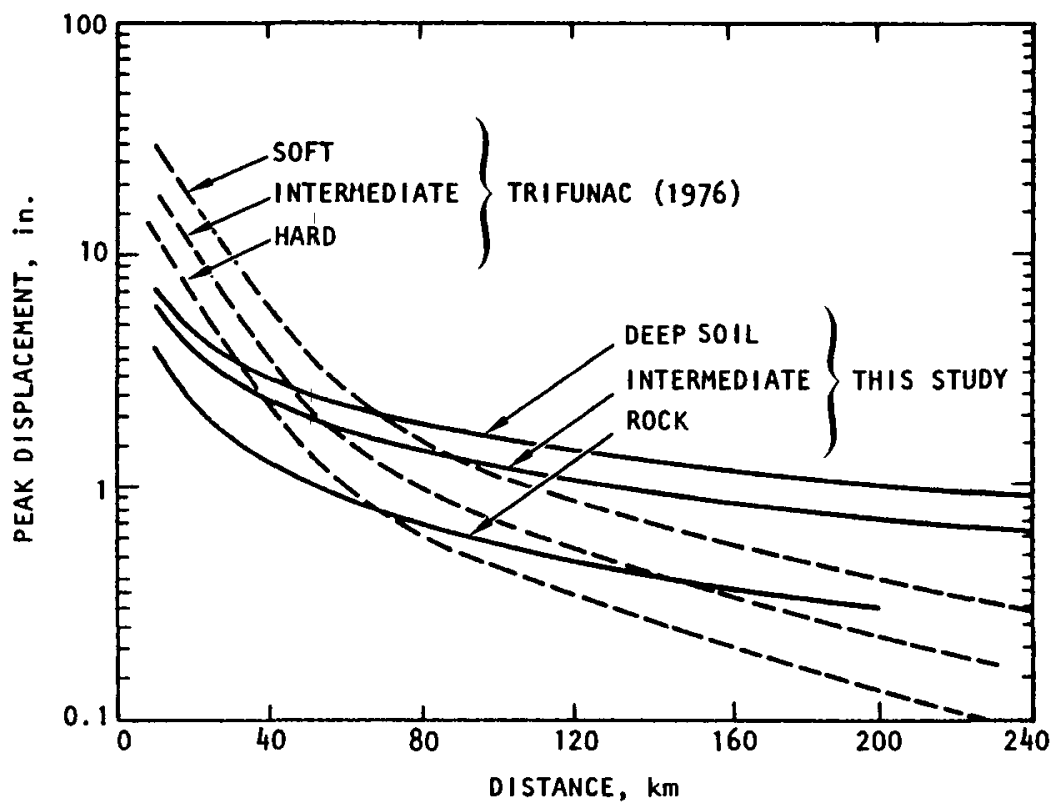

(b) Vertićal

NOTE: EARTHQUAKE EVENT $=$ TYPE 3

$\begin{array}{ll}\text { MAGNITUDE } & =6.4 \\ \text { PERCENTILE } & =90 \mathrm{th}\end{array}$

FIGURE 3-43. COMPARISON OF PEAK DISPLACEMENT RESULTS FROM THIS STUDY WITH THOSE OF TRIFUNAC (1976) 


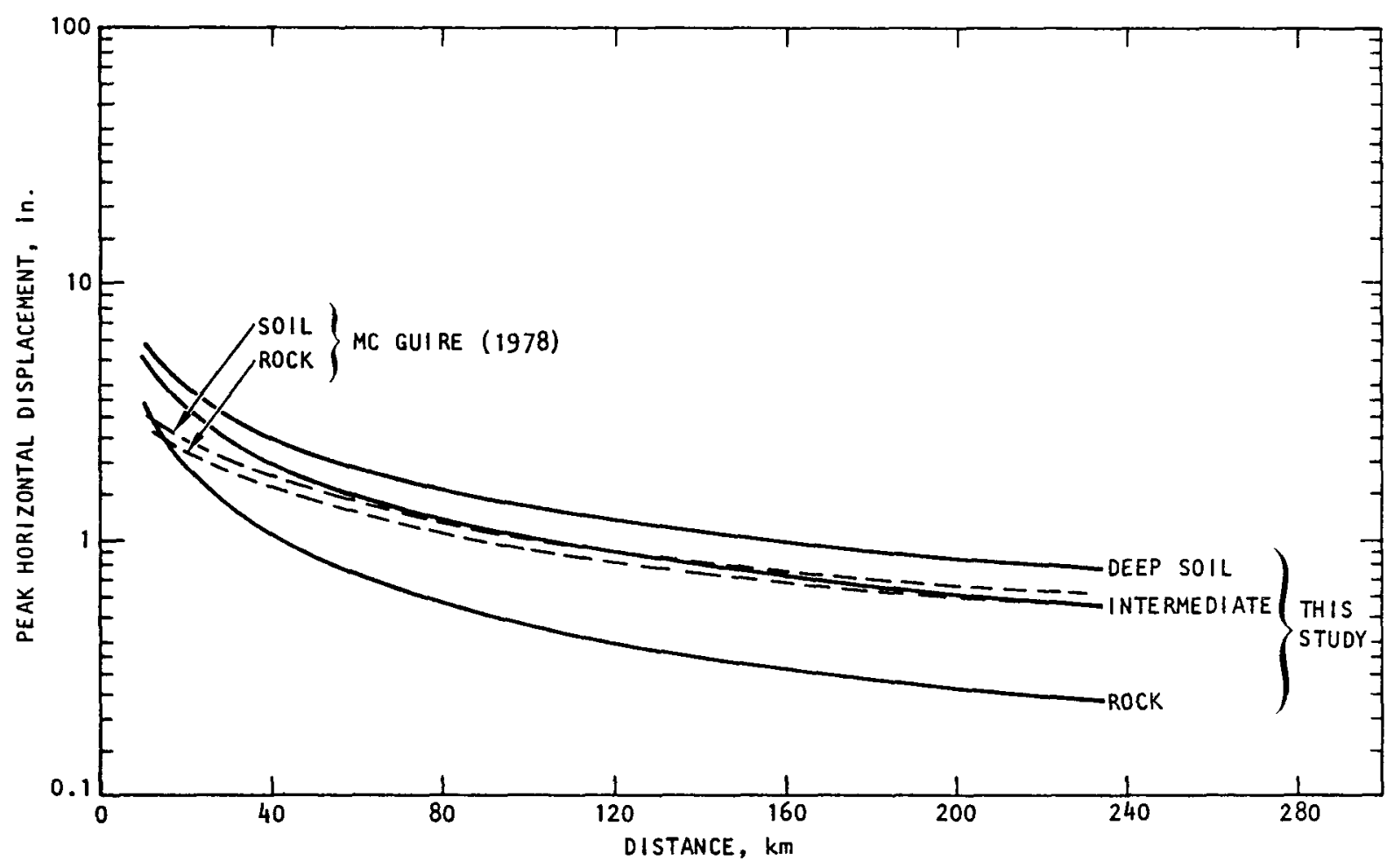

(a) Comparisons for Magnitude $=6.4$

\begin{tabular}{|c|c|c|c|}
\hline \multirow{2}{*}{ Magnitude } & \multirow{2}{*}{$\begin{array}{c}\text { Epicentral } \\
\text { Distance, } \\
\mathrm{km}\end{array}$} & \multicolumn{2}{|c|}{ Peak Horizontal Velocity, in./s } \\
\cline { 2 - 4 } & 30 & This Study & McGuire (1978) \\
\hline 5.0 & 100 & $\begin{array}{l}0.74 \\
0.31\end{array}$ & $\begin{array}{l}0.48 \\
0.24\end{array}$ \\
\hline 6.4 & 30 & 2.39 & 1.94 \\
& 100 & 1.02 & 0.97 \\
\hline \multirow{2}{*}{8.0} & 30 & 5.58 & 9.64 \\
& 100 & 2.36 & 0.97 \\
\hline
\end{tabular}

(1) McGuire results, originally given in terms of hypocentral distance, were converted to epicentral distance assuming focal depth $=15 \mathrm{~km}$.

(2) McGuire (1978) results shown for soil sites only. Results from this study shown only for Type 3 earthquake event and for intermediate site condition.

(b) Magnitude dependence of peak displacement comparison

FIGURE 3-44. COMPARISON OF PEAK HORIZONTAL DISPLACEMENT RESULTS FROM THIS STUDY WITH THOSE OF MC GUIRE (1978) 


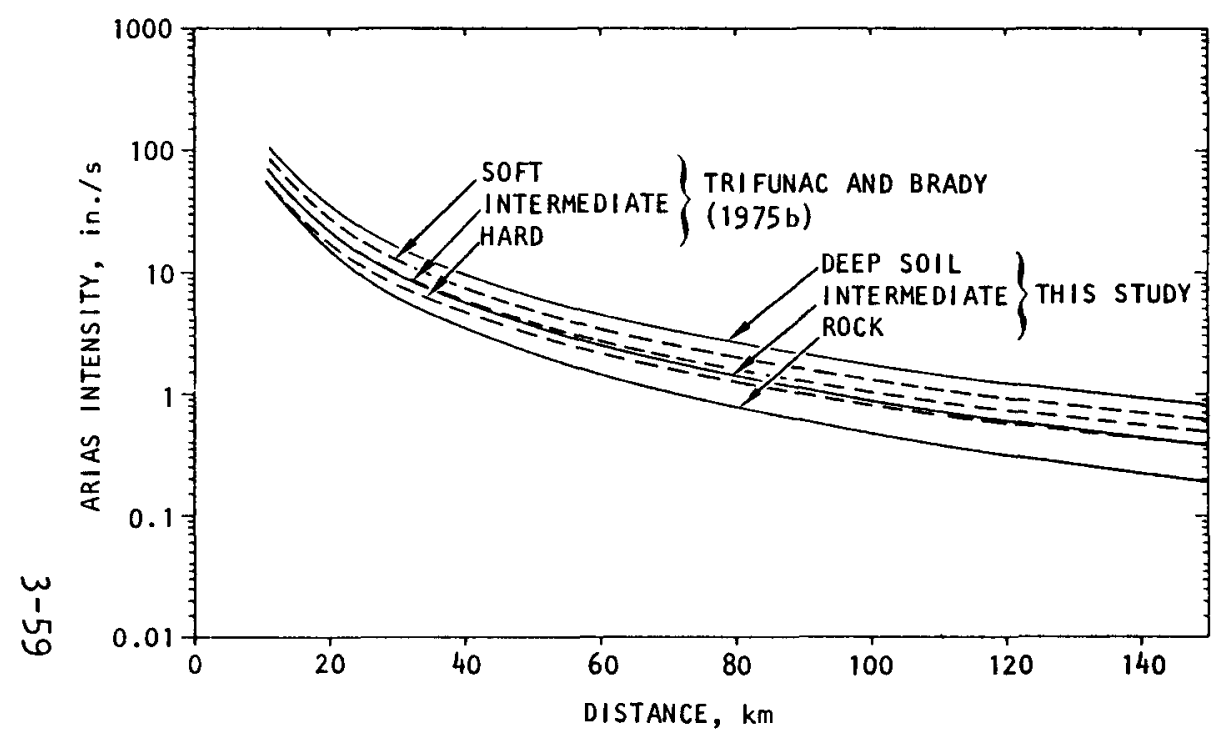

(a) Horizontal

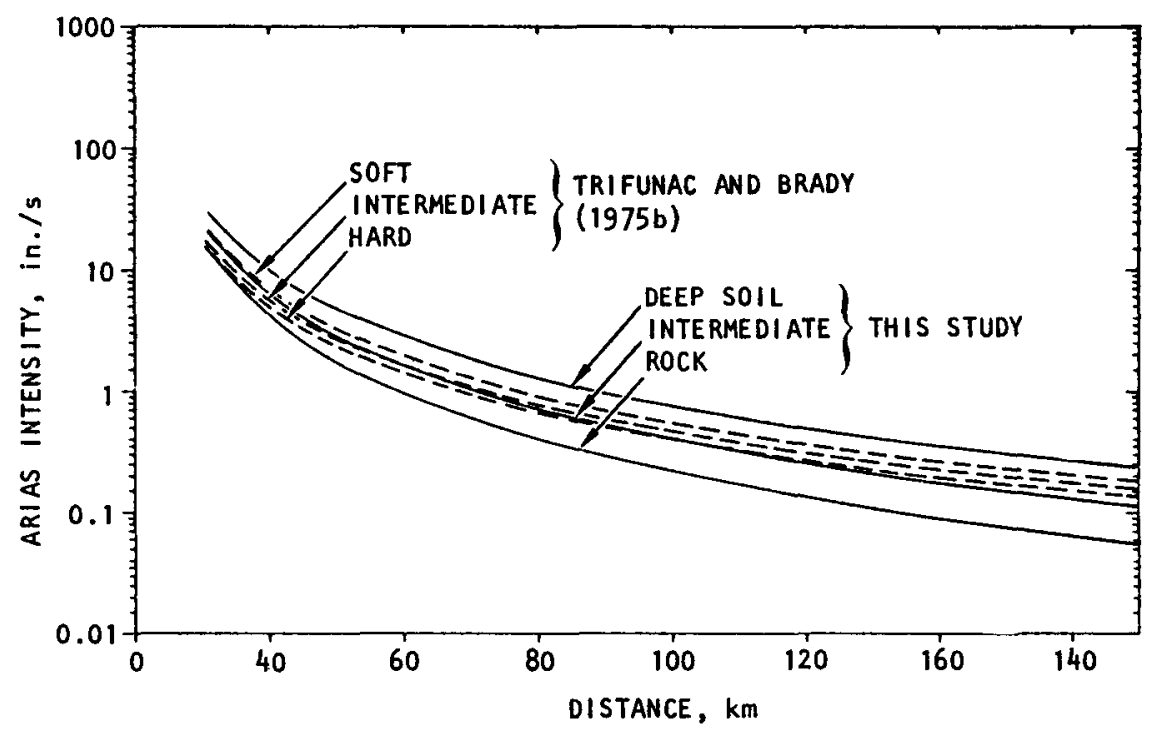

(b) Vertical

NOTE :

$\begin{array}{ll}\text { EARTHQUAKE EVENT } & =\text { TYPE } 3 \\ \text { MAGNITUDE } & =6.4 \\ \text { PERCENITLE } & =50 \mathrm{th}\end{array}$

FIGURE 3-45. COMPARISON OF ARIAS INTENSITY RESULTS FROM THIS STUDY WITH THOSE OF TRIFUNAC AND BRADY (1975b) 
CHAPTER 4

DURATION OF STRONG SHAKING

\subsection{GENERAL DISCUSSION}

The duration of strong shaking is one of the more important parameters characterizing earthquake ground shaking. It is a measure of the number of cycles of strong shaking to which the structure and soil medium are subjected and, as such, it has been related to the potential damage that can be inflicted to structures by the ground shaking, as well as to the liquefaction potential of saturated sandy soil sites. In this regard, it is recognized that longduration ground motion is more damaging than short-duration ground motion with the same peak acceleration.

Several methods have been proposed for characterizing the duration of strong shaking. Two of the more widely used are:

- Bracketed Duration--the time between the first and last excursion of the absolute value of acceleration above some threshold level, usually $0.05 \mathrm{~g}$ (Bolt, 1973) (Fig. 4-1a).

- Trifunac-Brady (1975b) Duration--the time required for $90 \%$ of the total energy (defined as the Arias intensity for the component of motion considered) to arrive; the duration of strong shaking is determined to begin when $5 \%$ of the total energy has been recorded and to end when 95\% has been recorded (Fig. 4-1b).

Other proposed definitions include those of Vanmarke and Lai (1977), Perez (1974), and Trifunac and Westermo (1977).

All of the above definitions represent different interpretations of the duration of strong shaking and therefore lead to markedly different duration values. Unfortunately, no single definition is universally accepted by earthquake engineers, although, as noted above, the bracketed duration and the Trifunac-Brady duration are the most widely used in current practice. 
With this as background, this chapter describes a study of the bracketed duration and the Trifunac-Brady duration using regression analysis procedures. The analyses indicate the dependence of these duration quantities on magnitude, epicentral distance, site conditions, earthquake event type, and direction of motion. It is noted that the bracketed duration, as considered in this study, is based on a threshold acceleration level of $0.05 \mathrm{~g}$ for both horizontal and vertical motions.

\subsection{REGRESSION ANALYSIS}

For the bracketed duration (BD), and the Trifunac-Brady duration (TBD), the following regression equations were developed:

$$
(B D)^{1 / 4}=\operatorname{Maximum}\left(0, f_{1}\right)
$$

where

$$
\begin{aligned}
f_{1}=a_{1} & +a_{2} M+a_{3} \sqrt{R}+a_{4} E+a_{5} \sqrt{R} \cdot M \\
& +a_{6} \sqrt{R} \cdot E+a_{7} \sqrt{R} \cdot V+a_{8} M \cdot V
\end{aligned}
$$

and

$$
(T B D)^{1 / 4}=a_{1}+a_{2} \sqrt{R}+a_{3} V+a_{4} S_{D}+a_{5} S_{R}
$$

In this, $a_{i}(i=1,2, \ldots)$ are the regression coefficients given in Table 4-1, and the remaining notation is as follows:

$$
\begin{aligned}
M & =\text { Local magnitude } \\
\mathrm{R} & =\text { Epicentral distance, } \mathrm{km} \\
\mathrm{V} & =1 \text { (if vertical motion) } \\
& =0 \text { (if horizontal motion) } \\
\mathrm{E} & =1 \text { (to represent San Fernando earthquake--Type } 1 \text { event) } \\
& =0 \text { (to represent all other earthquakes--Type } 2 \text { event) } \\
& =0.545 \text { (to represent all earthquakes--Type } 3 \text { event) }
\end{aligned}
$$




$$
\begin{aligned}
S_{D} & =1 \text { (if deep soil site) } \\
& =0 \text { (otherwise) } \\
S_{R} & =1 \text { (if rock site) } \\
& =0 \text { (otherwise) }
\end{aligned}
$$

Two factors regarding Equations 4-1 and 4-2 warrant comment. First, on the left side of these equations, the transformation $y^{1 / 4}$ has been used, where $y$ is the dependent variable. This differs from the $\mathrm{ln} y$ transformation used in the regression analyses of the strength parameters (Chap. 3) and the response spectral amplitudes (Chap. 5). There are two reasons for this. First, skewness and heteroscedasticity* in the data could only be removed by a great deal of shrinkage (through the use of a low-power transformation). Second, it was considered desirable to use the same transformation for both the $B D$ and the TBD variables, and $\ell$ n $y$ was not possible because many of the data had zero values for BD (which arise when the assumed threshold acceleration exceeds the peak acceleration of a given record).

A second factor of note is the different form of the right-hand sides of Equations 4-1 and 4-2. This arises from the fact that $B D$ and TBD represent markedly different interpretations of the duration of strong shaking, and therefore have a very different dependence on magnitude, distance, and the other independent variables considered in this study. The particular terms that appear on the right sides of Equations 4-1 and 4-2 were obtained using the procedures outlined in Section 2.3 and Appendix A.

\subsection{COMPARISONS WITH RECORDED DATA}

Visual comparisons of durations of strong shaking from regression analyses and from recorded data are shown in Figures 4-2 to 4-5 for BD and in Figure 4-6 for TBD. As noted for similar figures involving the strength

\footnotetext{
* See Section A-1, Appendix A.
} 
parameters (Chap. 3), these comparisons are intended to show trends in the data, the degree to which the computed regression analysis results fit the data, and the scatter of the data about the computed results.

The BD for horizontal and vertical motion has been shown in Section 4.2 to be dependent on magnitude and on earthquake event type, as well as epicentral distance; therefore, two sets of BD comparisons have been made. The first (Fig. 4-2) is for Type 1 (San Fernando) earthquake events, while the second (Figs. 4-3 to 4-5) is for Type 2 (other than San Fernando) events and for three magnitude levels for which Type 2 recorded data exist. These figures show the previously noted large number of zero-duration data, particularly for vertical motions.

In contrast to the $B D$, the TBD is independent of both magnitude and earthquake event type. For this reason, only a single figure (Fig. 4-6) is necessary to compare TBD's from computations and recorded data for various site classifications and epicentral distances.

Data-fit parameters for the $B D$ and TBD are given in Table 4-2. This table shows that the standard deviation and coefficient of variation associated with the BD are larger than the corresponding quantities for the TBD; therefore, the BD data has the most scatter. " The correlation coefficient for the $B D$ is also larger; however, rather than a measure of how much scatter exists, this indicates that the $B D$ regression equation did a somewhat better job of fitting the data and in relating the scatter to the effects of the independent variables.

\footnotetext{
*For BD, the data-fit parameters pertain to $f_{1}$ rather than to $B D=$ maximum $\left(0, f_{1}\right)$. It is seen from Table 4-1 that $f_{1}$ can become negative for certain combinations of parameters for which the BD from recorded data are instead zero, e.g., for large epicentral distances. Therefore, had the data-fit parameters been instead based on $B D$, which does not allow negative values, the standard deviation and coefficient of variation shown in Table 4-2 would have been somewhat smaller, and the correlation coefficient would have been somewhat larger. However, the scatter in $B D$, even with this change, would be greater than that for the TBD.
} 
Outliers from the regression analyses for the duration of strong shaking are given in Table 4-3. These outliers correspond to records whose deviation from the regression equation exceeds $2.7 \sigma$, where $\sigma$ is the standard deviation of $\left(f_{1}\right)^{1 / 4}$ for $B D$ or (duration) ${ }^{1 / 4}$ for the TBD. Very few outliers are seen to exist, and no single record is an outlier for both the BD and the TBD.

\subsection{PARAMETRIC EFFECTS}

\subsubsection{BRACKETED DURATION (BD)}

As shown by Equation 4-1, the BD is subjected to statistically significant effects of magnitude, epicentral distance, earthquake event type, and direction of motion (i.e., whether horizontal or vertical). The effects of local site conditions were not significant according to the tests described in Section 2.3 and Appendix $A$, and therefore have not been included in Equation 4-1.

\subsubsection{Magnitude and Epicentral Distance Effects}

The effects of magnitude on $B D$ and, for a given magnitude, the effects of distance are shown in Figure 4-7 for Type 3 earthquake events. This figure shows that, for a given distance, the BD increases with increasing magnitude; these magnitude effects increase markedly with decreasing epicentral distance. Figure 4-7 also shows that, for a given magnitude, the $B D$ decreases with increasing distance. This rate of decrease becomes larger as the magnitude increases.

\subsubsection{Earthquake Event Type and Epicentral Distance Effects}

The effects of earthquake event type on $B D$ and, for a given event type, the effects of distance are shown in Figure 4-8 for Magnitude 6.4 earthquakes. This figure shows that significant BD's occur only at epicentral distances less than about 60 to $70 \mathrm{~km}$. Within this distance range, the Type 1 
earthquake events are seen to exhibit larger BD's than do the Type 2 events. Also, the BD of Type 1 earthquakes is seen to decrease much faster with distance than that of the Type 2 events. The Type 3 results are intermediate between those of Type 1 and Type 2 .

\subsubsection{Directional and Epicentral Distance Effects}

Comparisons between BD's for horizontal and vertical motions are shown in Figure 4-9 for various magnitude levels and epicentral distances. These comparisons are seen to be dependent on the magnitude level. For lowmagnitude earthquakes (Magnitude 5.0), the BD's of vertical and horizontal motions are comparable to one another, with the vertical motion $B D$ being slightly greater (Fig. 4-9a). As the magnitude increases to 6.4 , the horizontal motion $B D$ exceeds the vertical motion $B D$ at a given epicentral distance (Fig. 4-9b). When the magnitude reaches 8.0 , the horizontal motion BD exceeds the vertical motion BD by a substantial amount (Fig. 4-9c).

\subsubsection{TRIFUNAC-BRADY DURATION (TBD)}

Equation 4-2 shows that, from the results of this regression analysis, the TBD is subjected to statistically significant effects of epicentral distance, site conditions, and direction of motion ( $i . e$. , whether horizontal or vertical). The effects of magnitude and earthquake event type were not significant according to the test described in Section 2.3 and Appendix $A$, and therefore have not been included in Equation 4-2. However, magnitude effects are discussed in the paragraphs that follow, together with the effects of the more significant independent variables listed above.

\subsubsection{Site Condition and Epicentral Distance Effects}

The effects of local site conditions and, for given site conditions, the effects of epicentral distance are shown in Figure 4-10. This figure shows that, for a given epicentral distance, deep soil sites have the largest 
TBD, followed in order by intermediate and rock sites. Also, for a given site condition, the TBD increases with increasing epicentral distance. This trend is opposite to the epicentral distance effects noted for the BD--a direct consequence of the differences between the two duration definitions. To illustrate, the increase in TBD with increasing distance can be attributed to dispersion effects, whereby signals of different frequency travel at different wave velocities; this causes a spreading of the strong motion segment of the ground motion history. In this sense, the TBD is not sensitive to any absolute measure of the strength of the shaking; rather, it is related to the time distribution of the portion of the shaking that contributes most to its total Arias intensity, regardless of what that Arias intensity level is. The BD, on the other hand, is based on the time span between the first and last excursions greater than some prescribed acceleration threshold; i.e., it is sensitive to an absolute measure of the strength of the shaking. Since the strength of the shaking decreases with increasing epicentral distance (Chap. 3), it follows that the $B D$ should attenuate in a similar manner. This trend is opposite to that exhibited by the TBD; yet both appear plausible in view of the differences in the two duration definitions (Werner, 1976).

\subsubsection{Directional and Epicentral Distance Effects}

Comparisons between TBD's for horizontal and vertical motions are shown in the duration vs. distance plots of Figure 4-11. This figure shows that, for all site conditions, the vertical motions exhibit a larger TBD than do the horizontal motions. This trend is opposite to that exhibited by the $B D^{\prime} s$. Also, the rate of increase of TBD with increasing distance is the same for horizontal and vertical motions (see Eq. 4-2).

\subsubsection{Magnitude Effects}

As noted earlier, magnitude effects on the TBD's were shown to be statistically insignificant according to the tests described in Section 2.3 and Appendix A. To illustrate that these effects are also small in an 
engineering sense, a new regression analysis was carried out with an additional term, $a_{6} M$, added to the right side of Equation 4-2. This new analysis resulted in values for the other regression coefficients, $a_{1}$ to $a_{5}$, that are slightly different from those given in Table 4-1.

Magnitude-dependent results from this new regression analysis are compared to results using Equation 4-2 (no magnitude dependence) in Figure 4-12 for intermediate sites and 50 th percentile duration levels. The results show that even when the magnitude is varied substantially (from Magnitude 5 to Magnitude 8 ) relatively small differences in TBD take place. Also, the TBD's computed for Magnitude 5 (lower bound) and Magnitude 8 (upper bound) are seen from Figure 4-12 and Table 4-4 to typically fall within about $\pm 10 \%$ of the TBD computed neglecting magnitude effects (using Equation 4-2).

\subsection{COMPARISONS WITH RESULTS FROM OTHER STUDIES}

\subsubsection{BRACKETED DURATION (BD)}

To date (October, 1979) only one other statistical study of BD is known to exist--that of McGuire and Barnhard (1979). However, this particular study used only records with nonzero values of BD. In the present study, however, it has been noted that a large number of measured strong motion records have zero $B D$; this means that there are numerous conditions (i.e., combinations of magnitude, distance, etc.) for which the peak acceleration will fall below the assumed threshold acceleration level of $0.05 \mathrm{~g}$ * To neglect such data, as McGuire and Barnhard have done, is to invalidly bias the results of the regression analysis. For this reason, results from the McGuire-Barnhard study and the present investigation are not compared here.

\subsubsection{TRIFUNAC-BRADY DURATION (TBD)}

In this section, the TBD results from this investigation are compared with those from the original Trifunac-Brady (1975b) study of this parameter.

\footnotetext{
* See the peak acceleration regression analysis in Chapter 3.
} 
The Trifunac-Brady study used similar ground motion data base, but a different regression form from that of the present investigation. Also Trifunac and Brady used three site classifications--soft, intermediate, and hard--that differ from those used herein (see Sec. 2.2.1).

Results from the comparison of horizontal and vertical motion results from this study and from Trifunac-Brady (1975b) are provided in Figure 4-13.* For short epicentral distances, the results for deep, intermediate, and rock sites from this study are seen to compare very closely to the Trifunac-Brady results for soft, intermediate, and hard sites, respectively. These two sets of results begin to diverge with increasing epicentral distance; however, they are within 20 to $30 \%$ of one another in all cases.

*The Trifunac-Brady regression equations contain a magnitude term which, for purposes of this comparison, was set to be 6.5 . However, the Trifunac-Brady study showed the effects of magnitude to be small; therefore, the comparisons in Figure 4-13 will not be strongly sensitive to the magnitude level used to represent the Trifunac-Brady results. 
TABLE 4-1. REGRESSION COEFFICIENTS FOR DURATION PARAMETERS

(a) Bracketed Duration (BD)

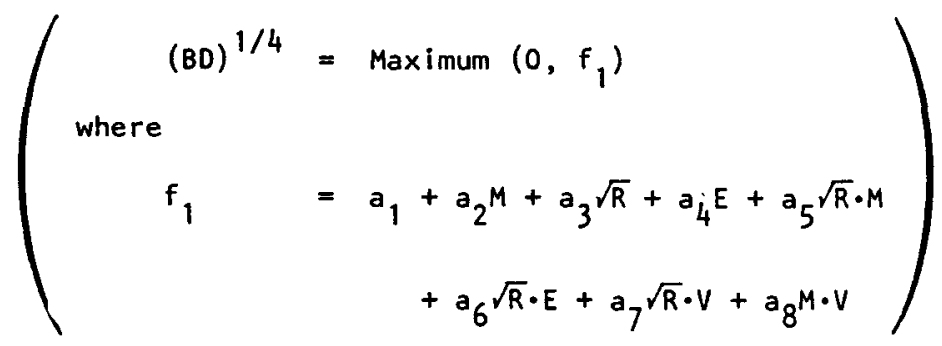

\begin{tabular}{|l|c|c|c|c|c|c|c|c|}
\hline $\begin{array}{l}\text { Regression } \\
\text { Coefficient }\end{array}$ & $a_{1}$ & $a_{2}$ & $a_{3}$ & $a_{4}$ & $a_{5}$ & $a_{6}$ & $a_{7}$ & $a_{8}$ \\
\hline Value & -5.164 & 1.164 & 0.414 & 1.389 & -0.910 & -0.176 & 0.069 & -0.158 \\
Significance & 1.0000 & 1.0000 & 0.9999 & 1.0000 & 1.0000 & 1.0000 & 0.9998 & 1.0000 \\
\hline
\end{tabular}

(b) Trifunac-Brady Duration (BD)

$\left((T B D)^{1 / 4}=a_{1}+a_{2} \sqrt{R}+a_{3} V+a_{4} S_{D}+a_{5} S_{R}\right)$

\begin{tabular}{|l|c|c|c|c|c|}
\hline $\begin{array}{l}\text { Regression } \\
\text { Coefficient }\end{array}$ & $a_{1}$ & $a_{2}$ & $a_{3}$ & $a_{4}$ & $a_{5}$ \\
\hline Value & 1.589 & 0.061 & 0.103 & 0.216 & $\begin{array}{c}-0.158 \\
0.9993\end{array}$ \\
\hline
\end{tabular}

(c) Notation

$M=$ Local magnitude

$R=$ Epicentral distance, $\mathrm{km}$

$V=1$ (if vertical motion)

$=0$ (if horizontal motion)

$E=1$ (to represent San Fernando earthquake--Type 1 event)

$=0$ (to represent all other earthquakes--Type 2 event)

$=0.545$ (to represent all earthquakes--Type 3 event)

$$
4-10
$$

$$
\begin{aligned}
S_{D} & =1 \text { (if deep soil site) } \\
& =0 \text { (otherwise) } \\
S_{R} & =1 \text { (if rock site) } \\
& =0 \text { (otherwise) } \\
a_{i} & =\text { Regression coefficients }
\end{aligned}
$$


TABLE 4-2. DATA-FIT PARAMETERS--DURATION OF STRONG SHAKING

\begin{tabular}{|l|c|c|c|}
\hline Duration, D & $\begin{array}{c}\text { Standard } \\
\text { Deviation of } \\
D^{1 / 4}\end{array}$ & $\begin{array}{c}\text { Coefficient of } \\
\text { Variation of } \\
\text { D }^{(1)}\end{array}$ & $\begin{array}{c}\text { Correlation } \\
\text { Coefficient of } \\
D^{1 / 4}\end{array}$ \\
\hline $\begin{array}{l}\text { Bracketed } \\
\text { Duration }\end{array}$ & $0.503^{(2)}$ & $2.407^{(2)}$ & $0.790^{(2)}$ \\
\hline $\begin{array}{l}\text { Trifunac-Brady } \\
\text { Duration }\end{array}$ & 0.254 & 0.480 & 0.628 \\
\hline
\end{tabular}

Note:

(1) Estimated as $4 \times C_{v}\left(D^{1 / 4}\right)$ where

$$
C_{v}\left(D^{1 / 4}\right)=\frac{\sigma\left(D^{1 / 4}\right)}{\mu\left(D^{1 / 4}\right)}=\text { Coefficient of variation of } D^{1 / 4}
$$

and

$$
\begin{aligned}
\sigma\left(D^{1 / 4}\right) & =\text { Standard deviation of } D^{1 / 4} \text { (see above table) } \\
\mu\left(D^{1 / 4}\right) & =\text { Mean value of } D^{1 / 4} \\
& = \begin{cases}0.836 \text { (bracketed duration) } \\
2.118 \text { (Trifunac-Brady duration) }\end{cases}
\end{aligned}
$$

(2) For bracketed duration, these parameters correspond to the standard deviation of $\left(f_{1}\right)^{1 / 4}$ and the coefficient of variation of $f_{1}$, where $f_{1}$ is defined in Equation 4-1 and Table 4-1. 
TABLE 4-3. OUTLIERS FROM REGRESSION ANALYSES OF DURATION OF STRONG SHAKING

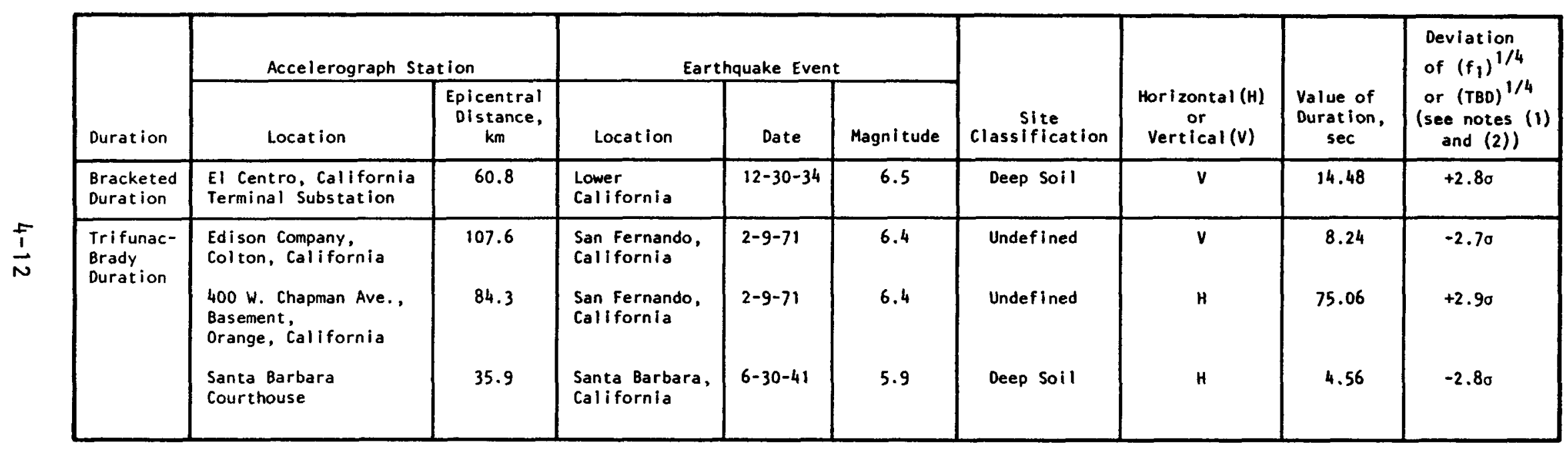

Note:

(1) For bracketed duration $(B D)$, the deviation corresponds to the deviation of $\left(f_{1}\right)^{1 / 4}$, where $f_{1}$ is defined in Equation 4-1. For Trifunac-Brady duration (TBD), it corresponds to (TBD) ${ }^{1 / 4}$.

(2) 0 corresponds to the standard deviation of $\left(f_{1}\right)^{1 / 4}$ for BD, or (TBD $)^{1 / 4}$ for Trifunac-Brady duration. 
TABLE 4-4. RELATIVE EFFECTS OF MAGNITUDE ON TRIFUNAC-BRADY DURATION (TBD)

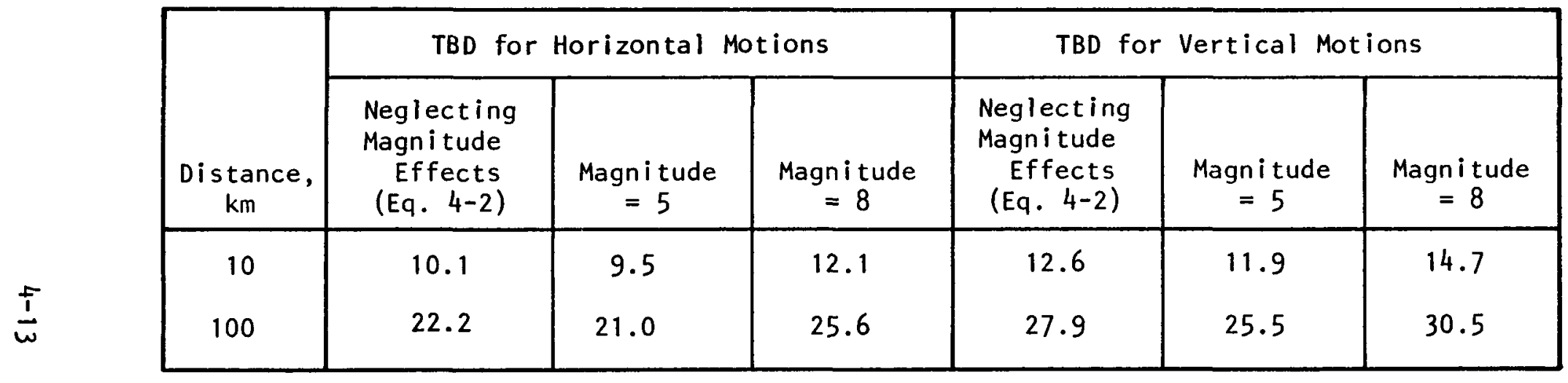




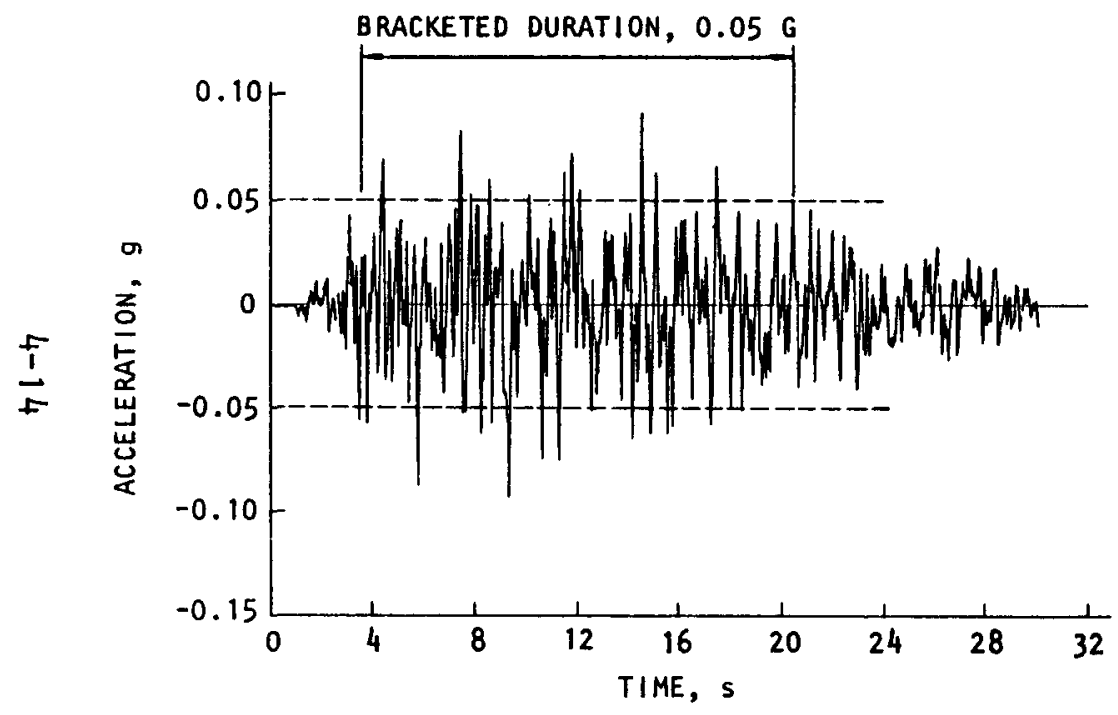

(a) Bracketed duration (Bolt, 1973)

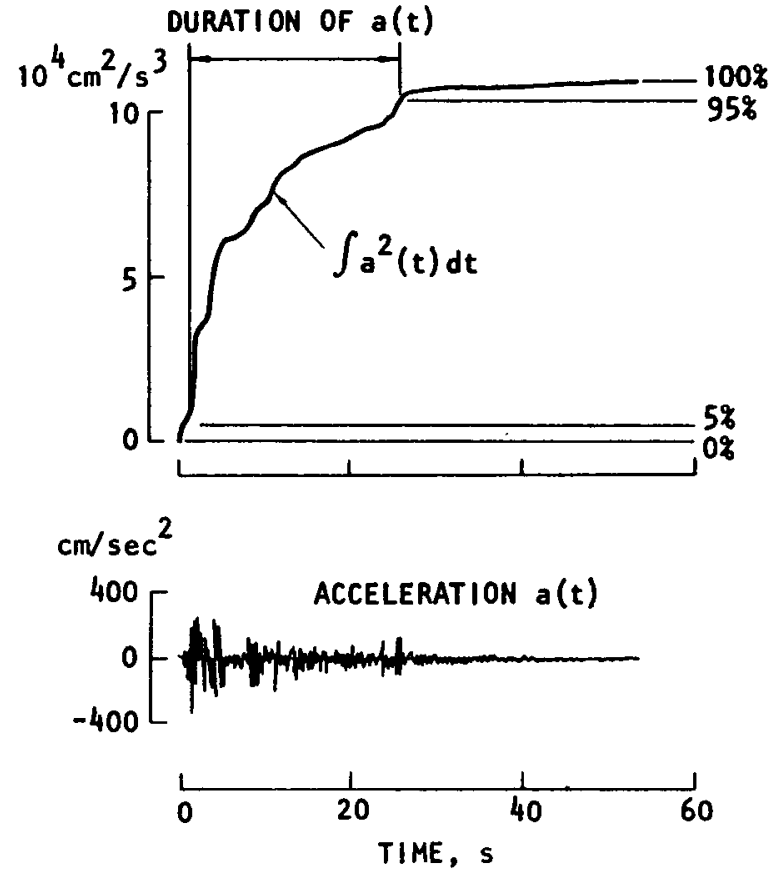

(b) Trifunac and Brady (1975b) duration

FIGURE 4-1. DEFINITIONS OF DURATION OF STRONG SHAKING CONSIDERED IN THIS STUDY 


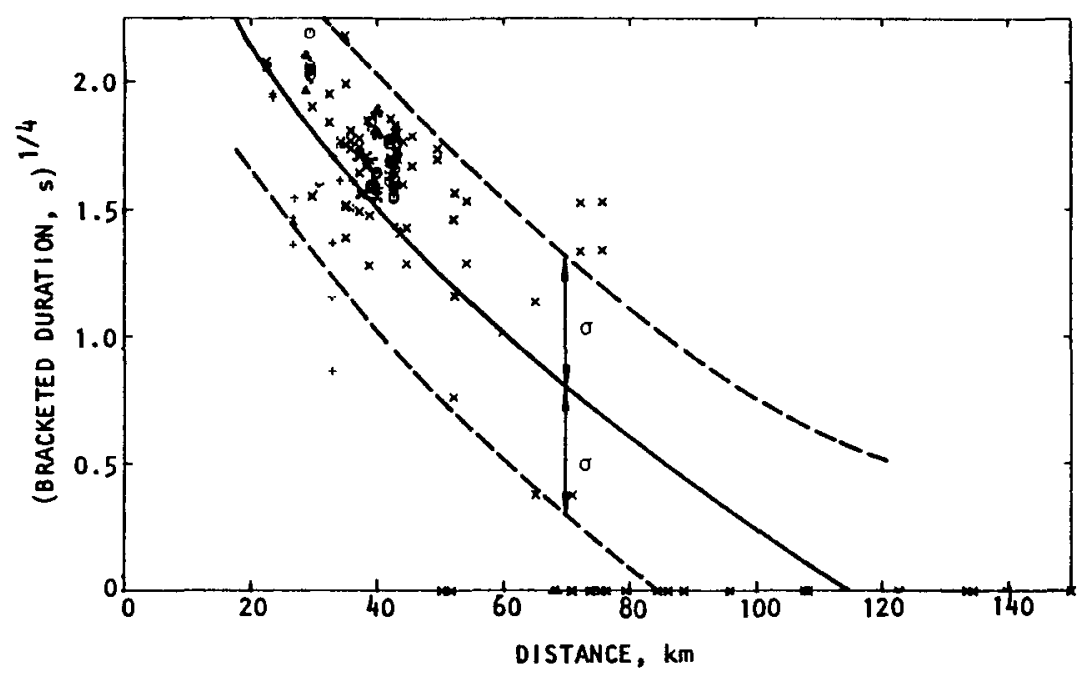

(a) Horizontal

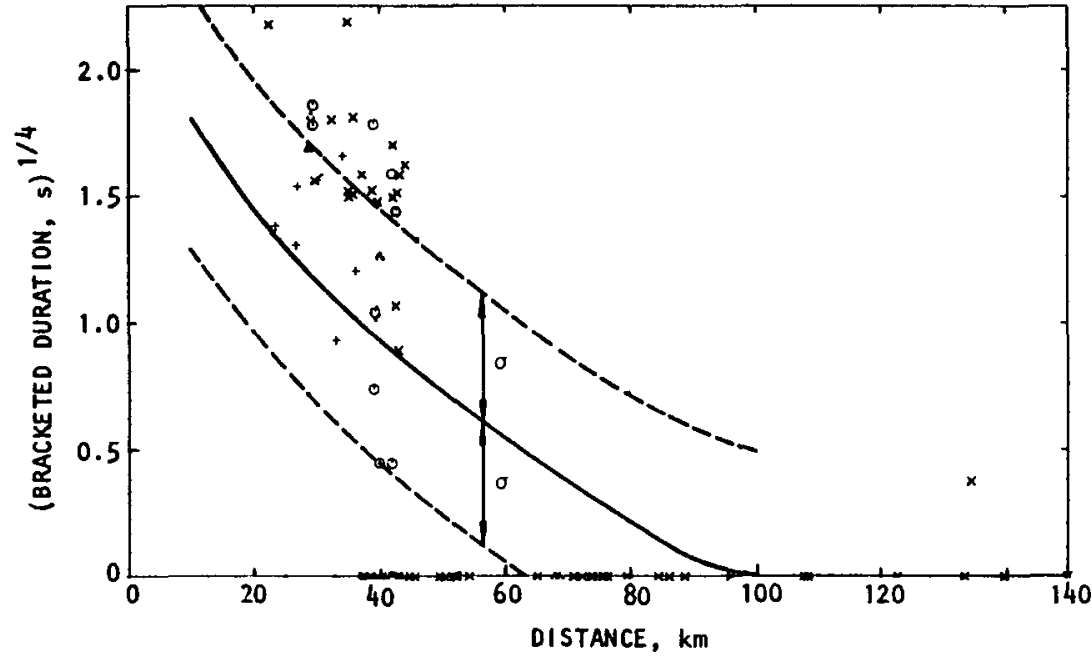

(b) Vertical

LEGEND:

DATA POINTS

- DEEP SOIL SITE

$\triangle$ INTERMEDIATE

+ ROCK SITE

$\times$ UNDEFINED SITE CONDITIONS
REGRESSION ANALYSIS (FOR TYPE 1 EVENTS)

50th PERCENTILE (ALL SITE CONDITIONS)

16 th PERCENTILE AND 84th PERCENTILE

BOUNDS (ALL SITE CONDITIONS)
NOTE :

$\sigma=$ STANDARD DEVIATION OF (BRACKETED DURATION) $1 / 4$

FIGURE 4-2. COMPARISON BETWEEN COMPUTED AND RECORDED BRACKETED DURATIONS - TYPE 1 EARTHQUAKE EVENTS 


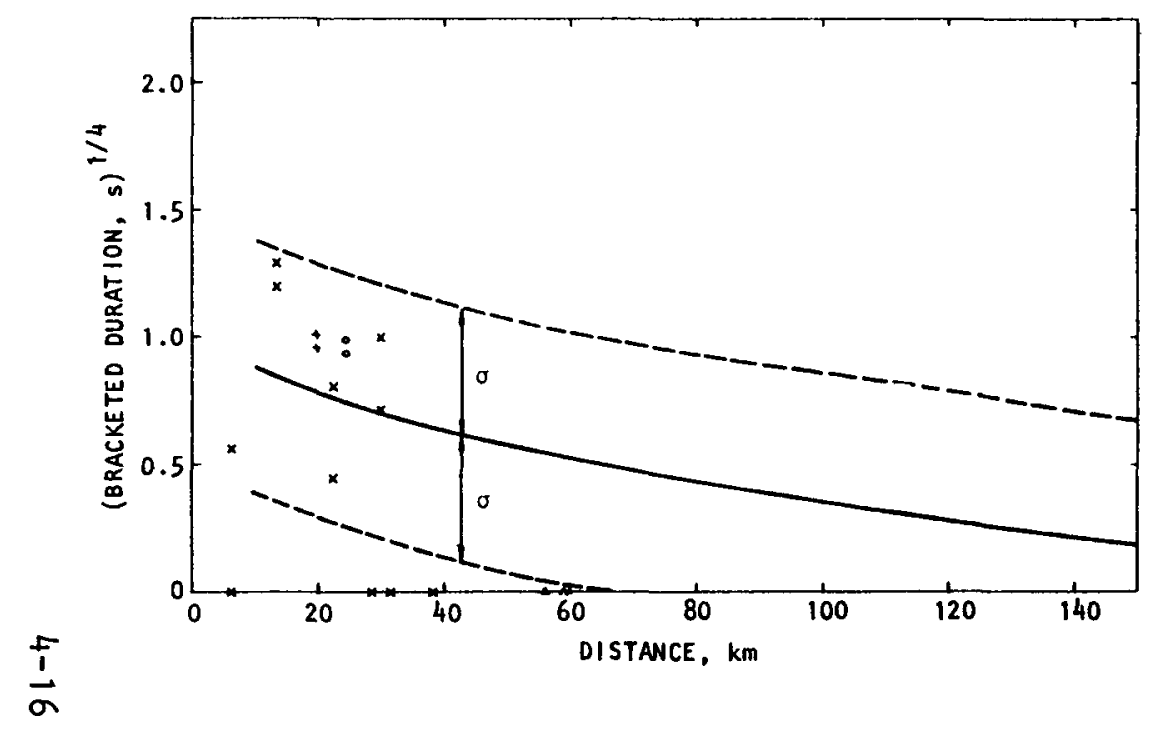

(a) Horizontal

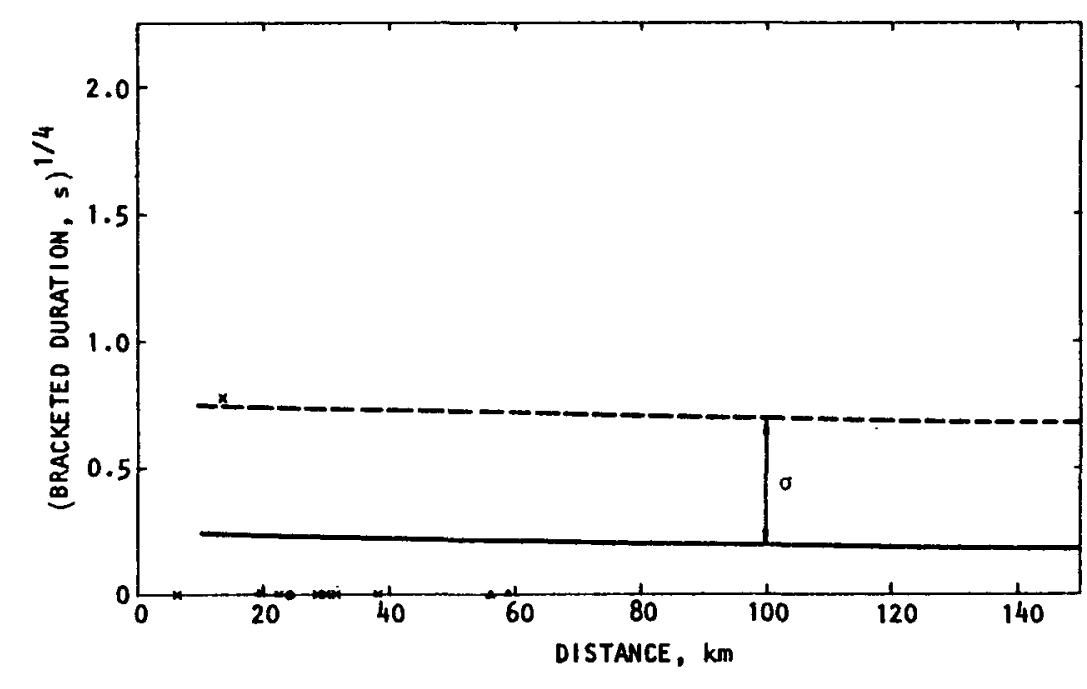

(b) Vertical

LEGEND :

DATA POINTS

- DEEP SOIL SITE

$\triangle$ INTERMEDIATE

+ ROCK SITE

$\times$ UNDEFINED SITE CONDITIONS
REGRESSION ANALYSIS (FOR TYPE 2 EVENTS) 50th PERCENTILE (ALL SITE CONDITIONS)

- - $16 \mathrm{th}$ PERCENTILE AND 84th PERCENTILE BOUNDS (ALL SITE CONDITIONS)
NOTE:

$\sigma$ - STANDARD DEVIATION OF (BRACKETED DURATION) $1 / 4$

FIGURE 4-3. COMPARISON BETWEEN COMPUTED AND RECORDED BRACKETED DURATIONS - TYPE 2 EARTHQUAKE EVENTS WITH MAGNITUDE 5.4 


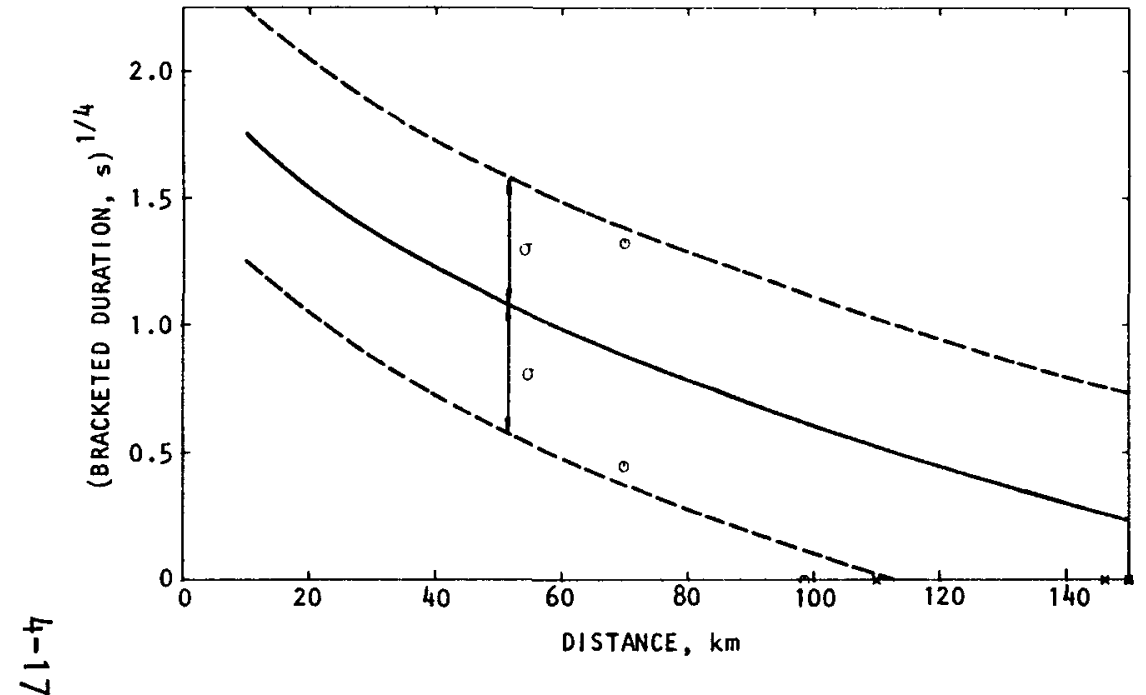

(a) Horizontal

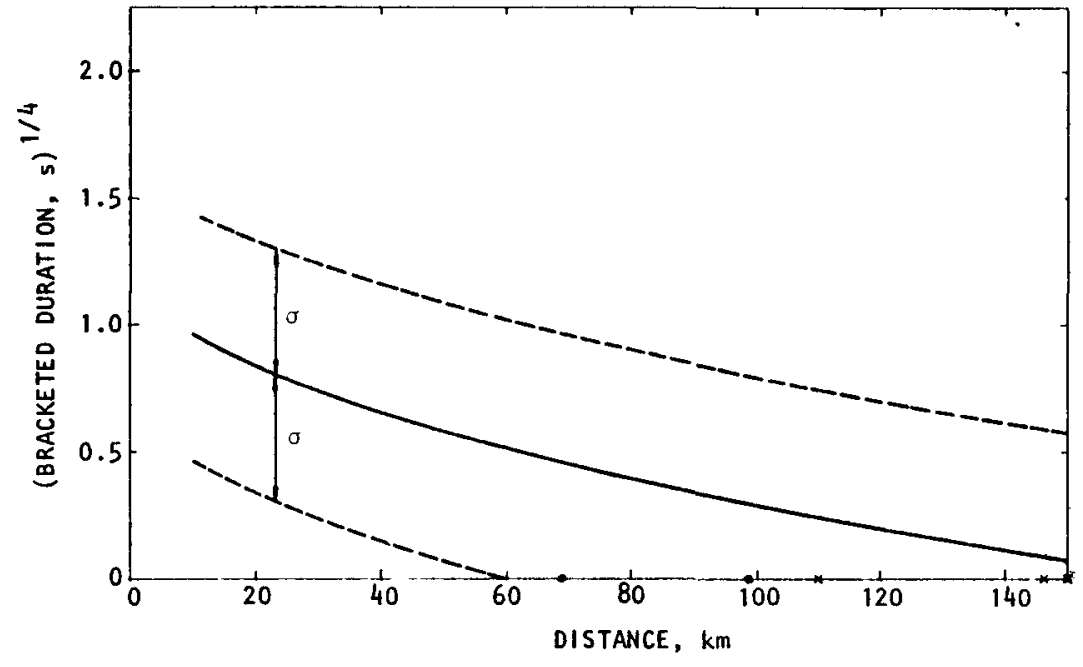

(b) Vertical

LEGEND:

DATA POINTS

- DEEP SOIL SITE

$\triangle$ INTERMEDIATE

+ ROCK SITE

$X$ UNDEFINED SITE CONDITIONS
REGRESSION ANALYSIS (FOR TYPE 2 EVENTS)

50th PERCENTILE (ALL SITE CONDITIONS)

- -16 th PERCENTILE AND 84th PERCENTILE BOUNDS (ALL SITE CONDITIONS)
NOTE :

$\sigma=$ STANDARD DEVIATION OF (BRACKETED DURATION) $1 / 4$

FIGURE 4-4. COMPARISON BETWEEN COMPUTED AND RECORDED BRACKETED DURATIONS - TYPE 2 EARTHQUAKE EVENTS WITH MAGNITUDE 6.4 


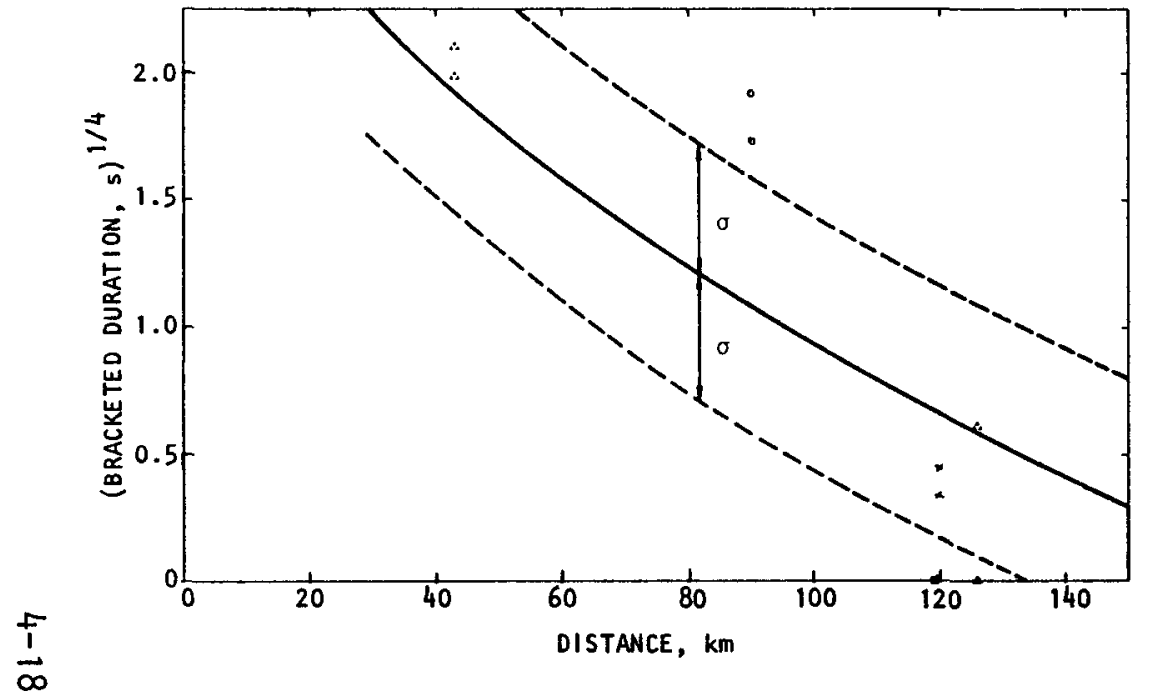

(a) Horizontal

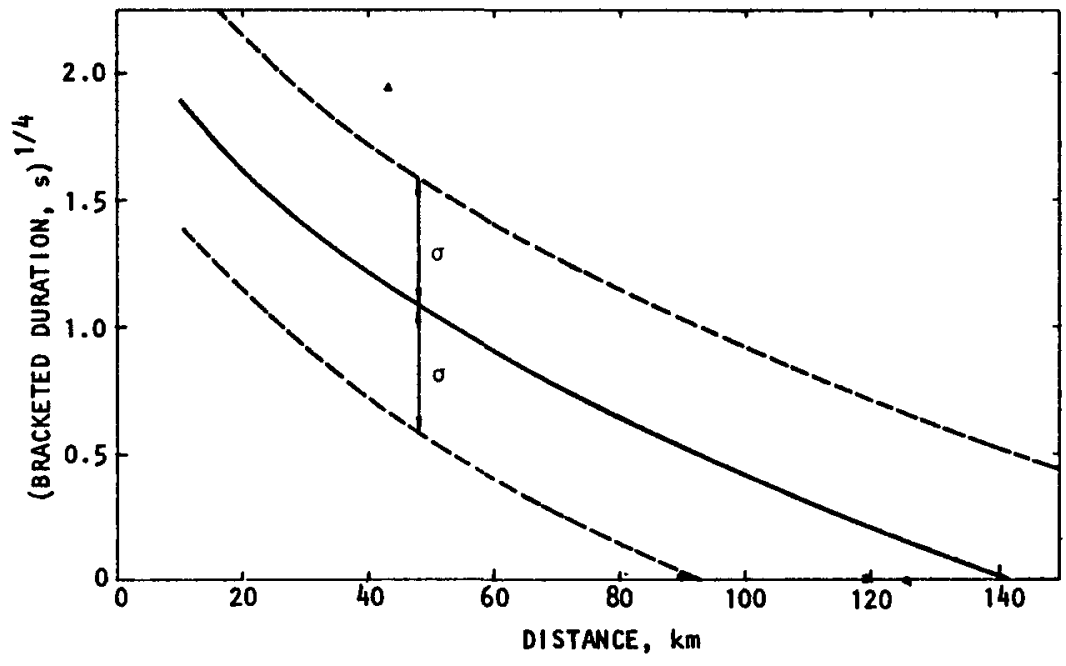

(b) Vertical

LEGEND :

DATA POINTS

- DEEP SOIL SITE

- INTERMEDIATE

+ ROCK SITE

$x$ UNDEFINED SITE CONDITIONS
REGRESSION ANALYSIS (FOR TYPE 2 EVENTS)

50th PERCENTILE (ALL SITE CONDITIONS)

16th PERCENTILE AND 84th PERCENTILE

BOUNDS (ALL SITE CONDITIONS)
NOTE :

0 - STANDARD DEVIATION OF (BRACKETED DURATION) $1 / 4$

FIGURE 4-5. COMPARISON BETWEEN COMPUTED AND RECORDED BRACKETED DURATIONS - TYPE 2 EARTHQUAKE EVENTS WITH MAGNITUDE 7.7 


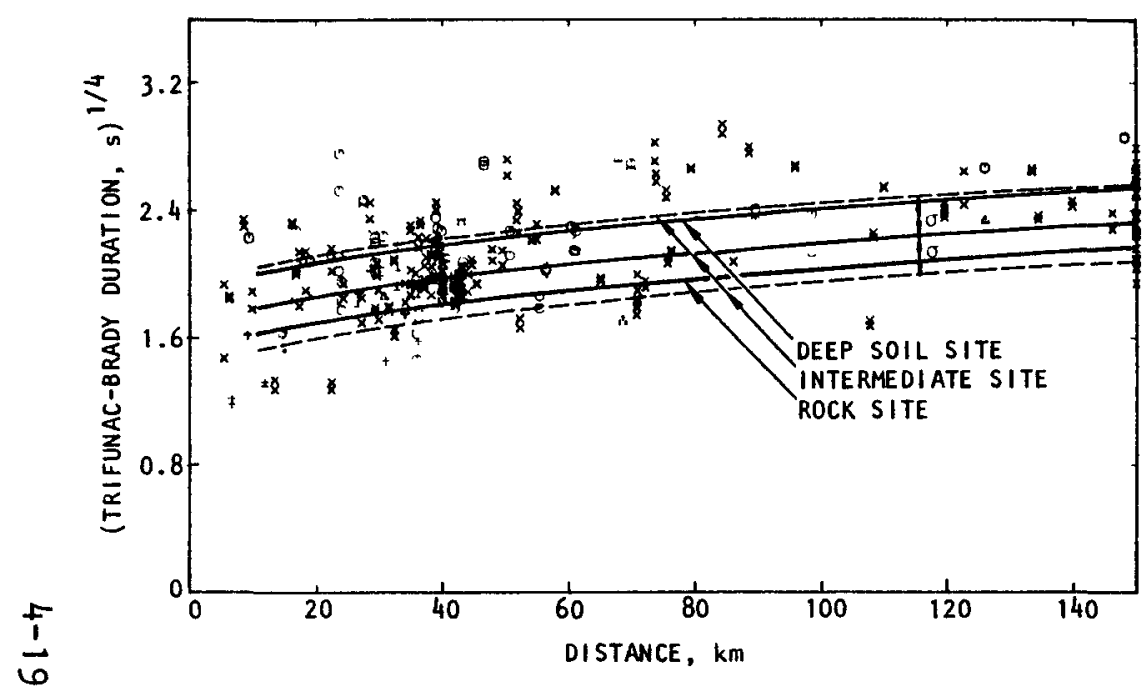

(a) Horizontal

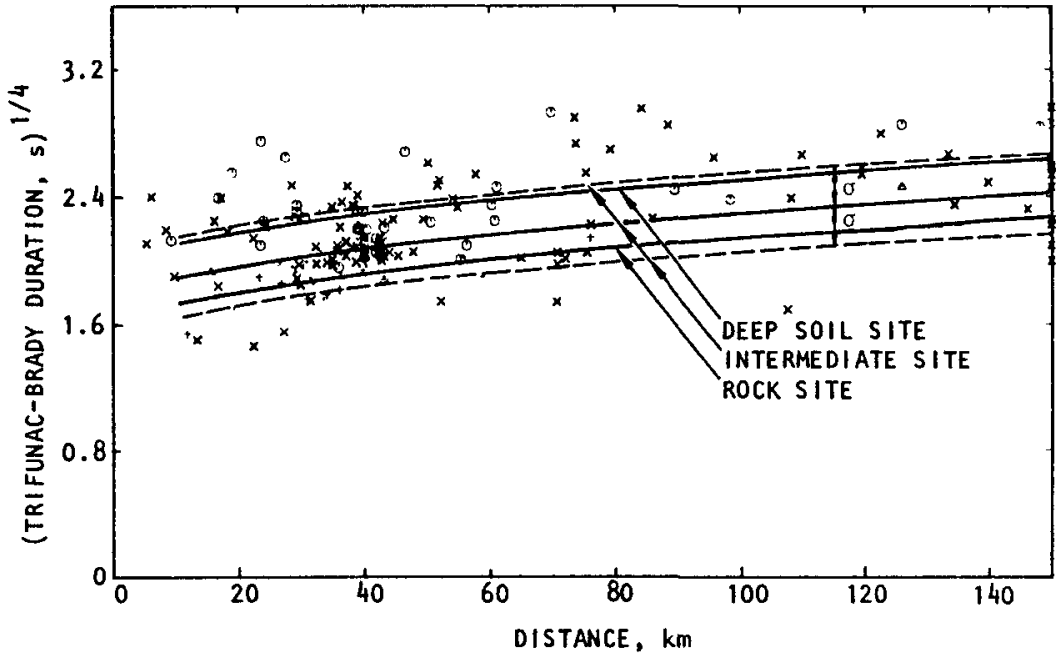

(b) Vertical

LEGEND:

\section{DATA POINTS}

- DEEP SOIL SITE

$\triangle$ INTERMEDIATE

+ ROCK SITE

$\times$ UNDEFINED SITE CONDITIONS

\section{REGRESSION ANALYSIS (FOR ALL DATA)}

50th PERCENTILE (FOR EACH SITE CONDITION)

- - - 16th PERCENTILE AND 84th PERCENTILE BOUNDS (FOR INTERMEDIATE SITE CONDITION ONLY)
NOTE :

$\begin{aligned} \sigma= & \text { STANDARD DEVIATION OF } \\ & \text { (TRIFUNAC-BRADY DURATION) } 1 / 4\end{aligned}$

FIGURE 4-6. COMPARISON BETWEEN COMPUTED AND RECORDED TRIFUNAC-BRADY DURATIONS FOR VARIOUS SITE CONDITIONS 


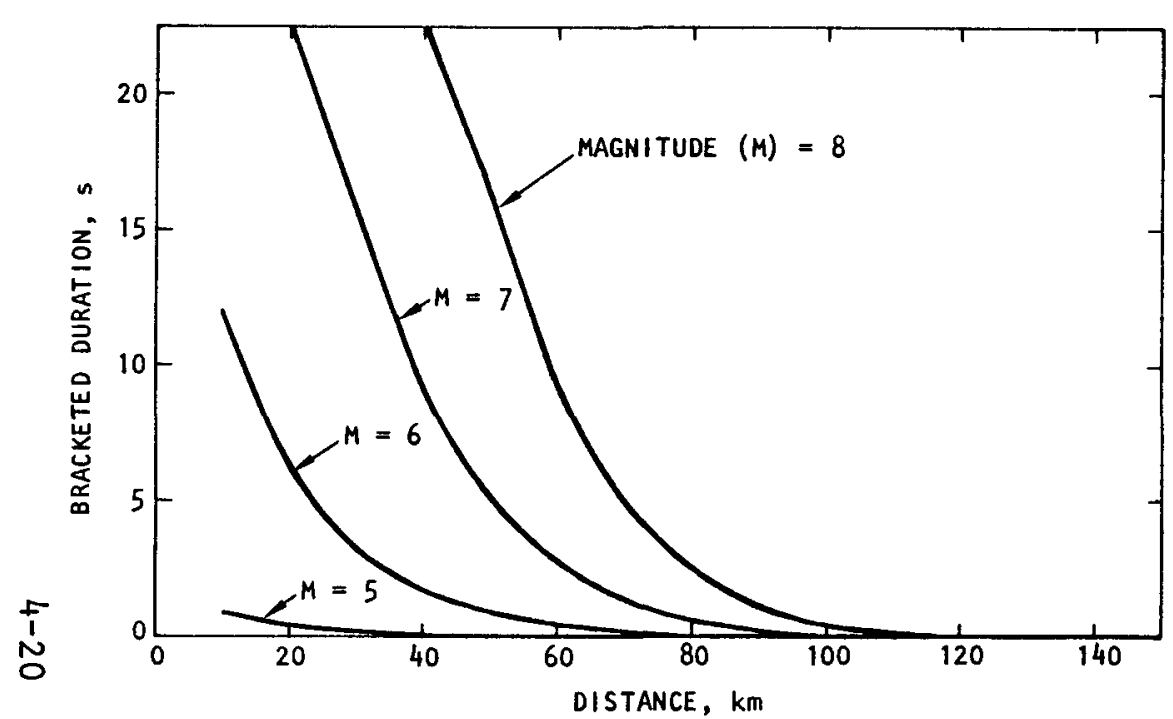

(a) Horizontal motion

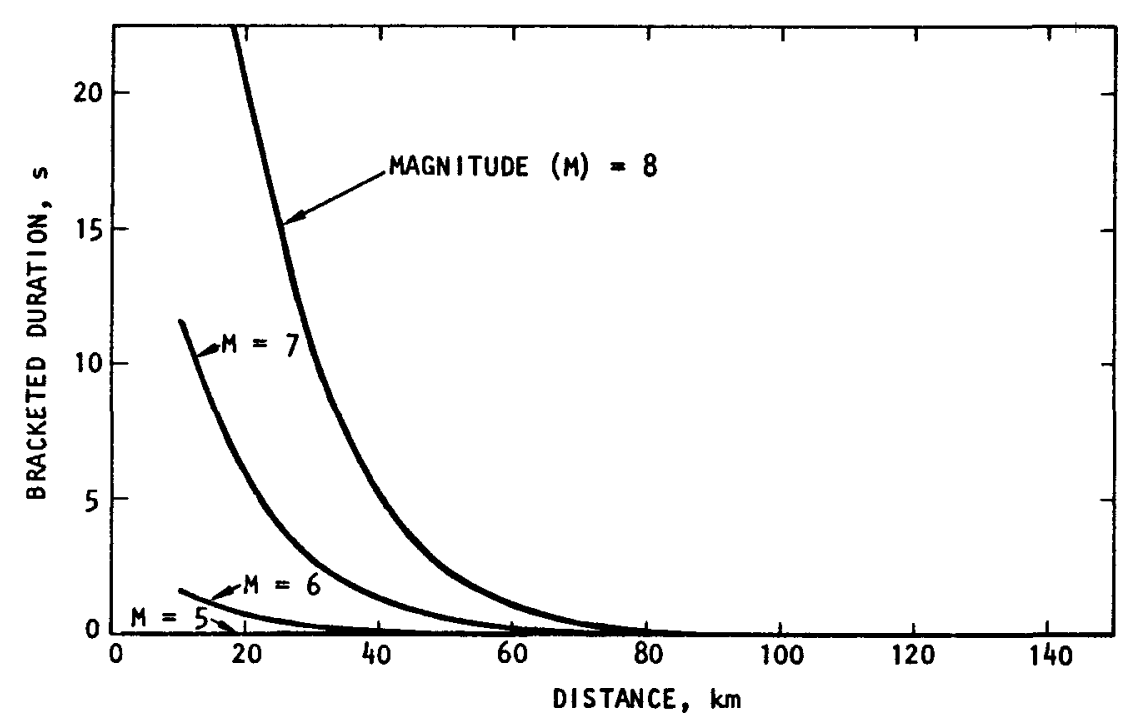

(b) Vertical motion

NOTE:

EARTHQUAKE EVENT $=$ TYPE 3

PERCENTILE $=50$ th

FIGURE 4-7. EFFECTS OF MAGNITUDE AND DISTANCE ON BRACKETED DURATION 


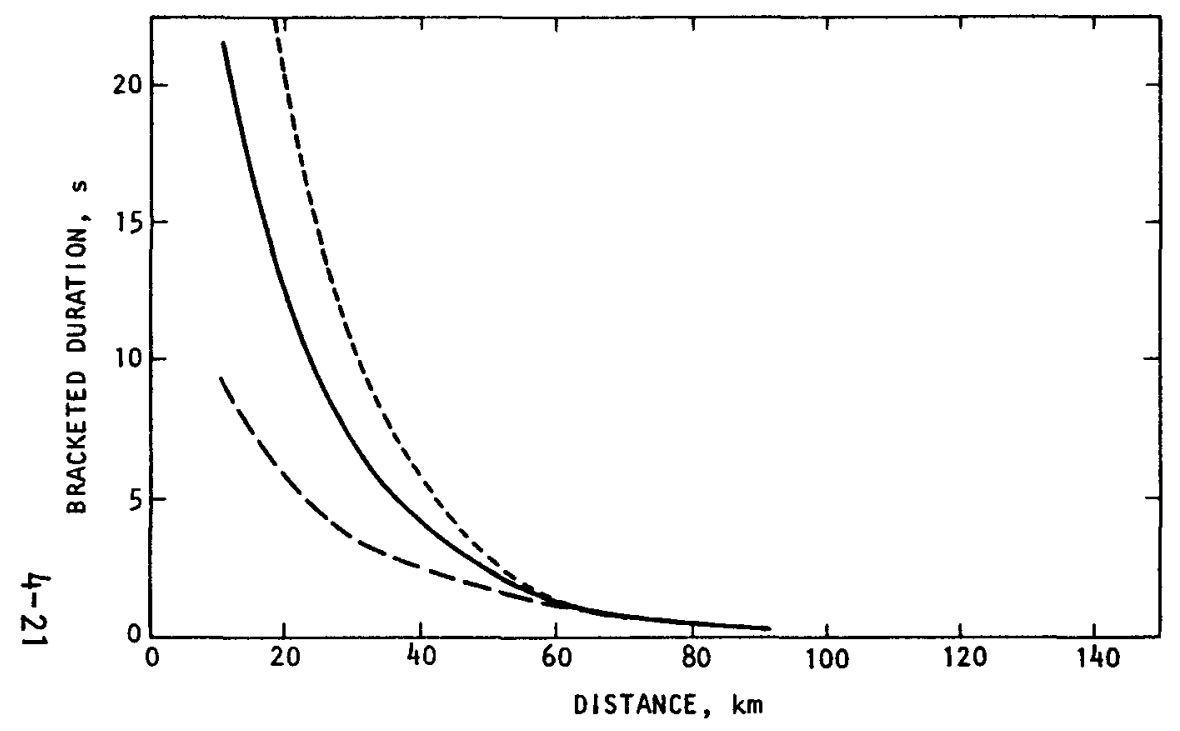

(a) Horizontal

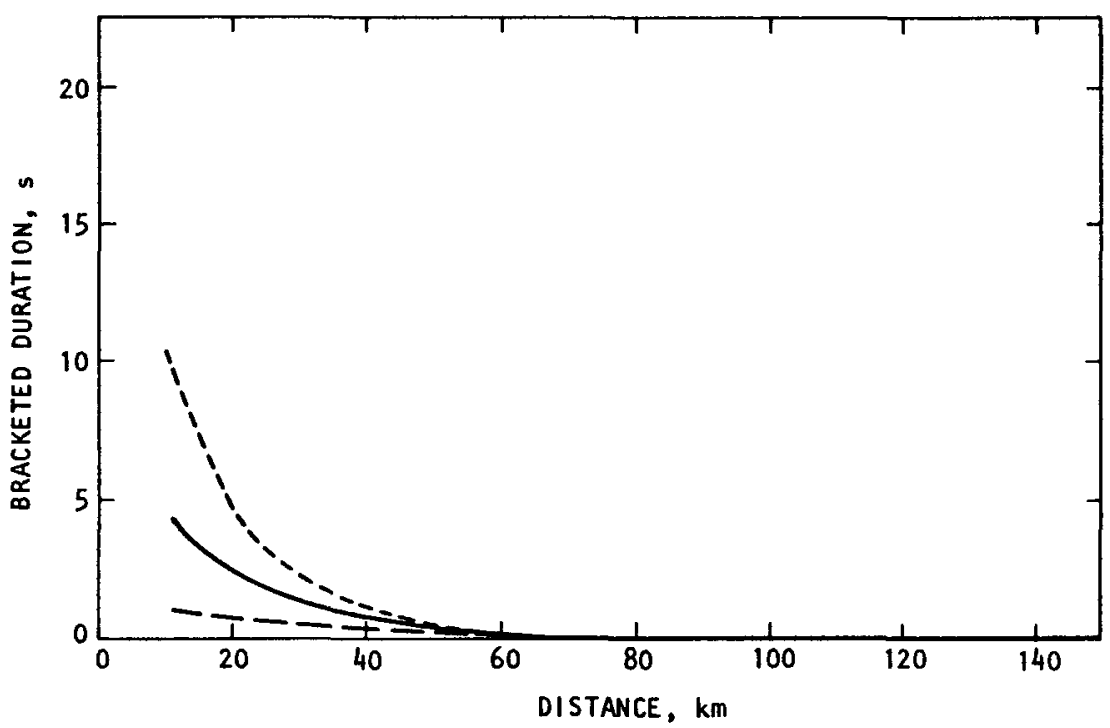

(b) Vertical

LEGEND

$$
\begin{aligned}
& --1 \text { TYPE } 1 \text { (SAN FERNANDO EARTHQUAKE ONLY) } \\
& - \text { TYPE } 2 \text { (ALL EARTHQUAKE EVENTS EXCEPT SAN FERNANDO) }
\end{aligned}\left\{\begin{array}{l}
\text { MAGNITUDE }=6.4 \\
\text { TYPE } 3 \text { (ALL EARTHQUAKE EVENTS) }
\end{array}\right.
$$

FIGURE 4-8. EFFECTS OF EARTHQUAKE EVENT TYPE ON BRACKETED DURATION 


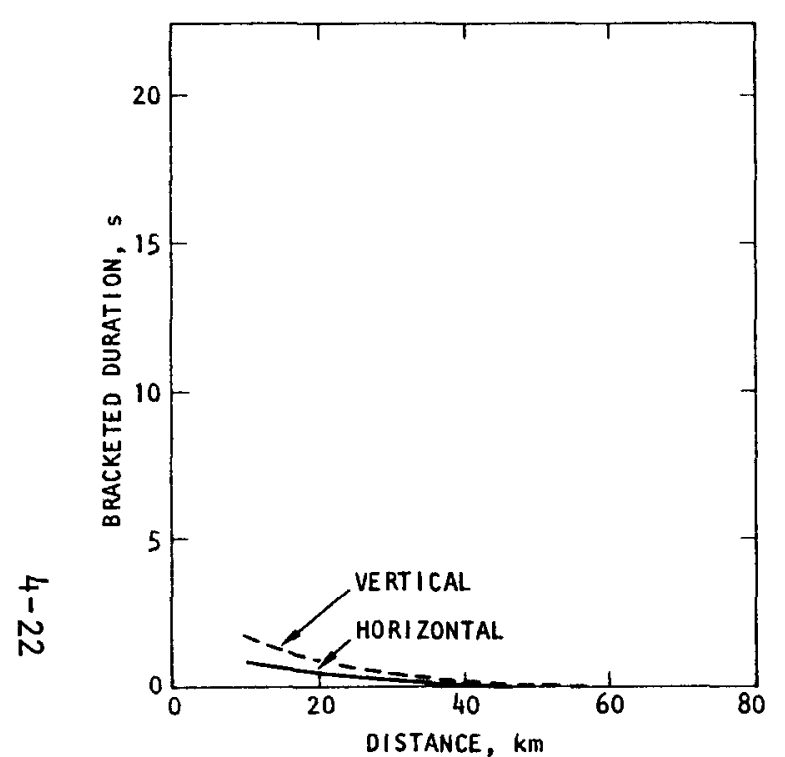

(a) Magnitude $=5.0$

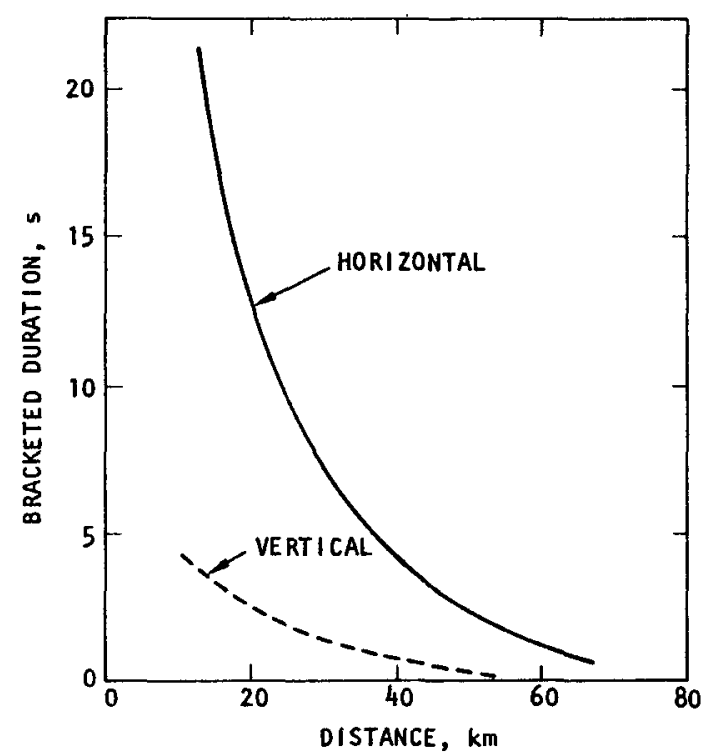

(b) Magnitude $=6.4$

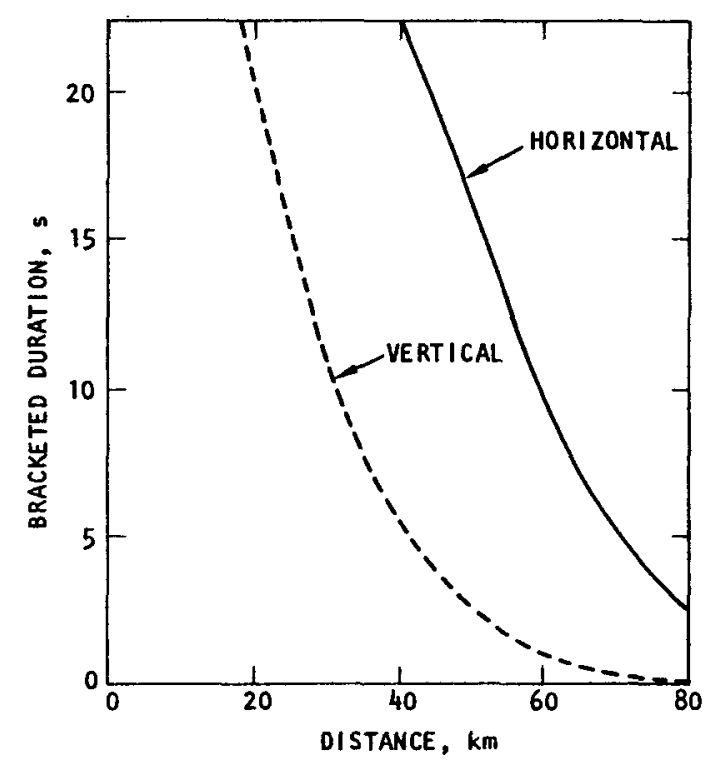

(c) Magnitude $=8.0$

NOTE :

EARTHQUAKE EVENT = TYPE 3

PERCENTILE $\quad=50 \mathrm{th}$

FIGURE 4-9. COMPARISON OF BRACKETED DURATIONS OF HORIZONTAL AND VERTICAL MOTIONS 


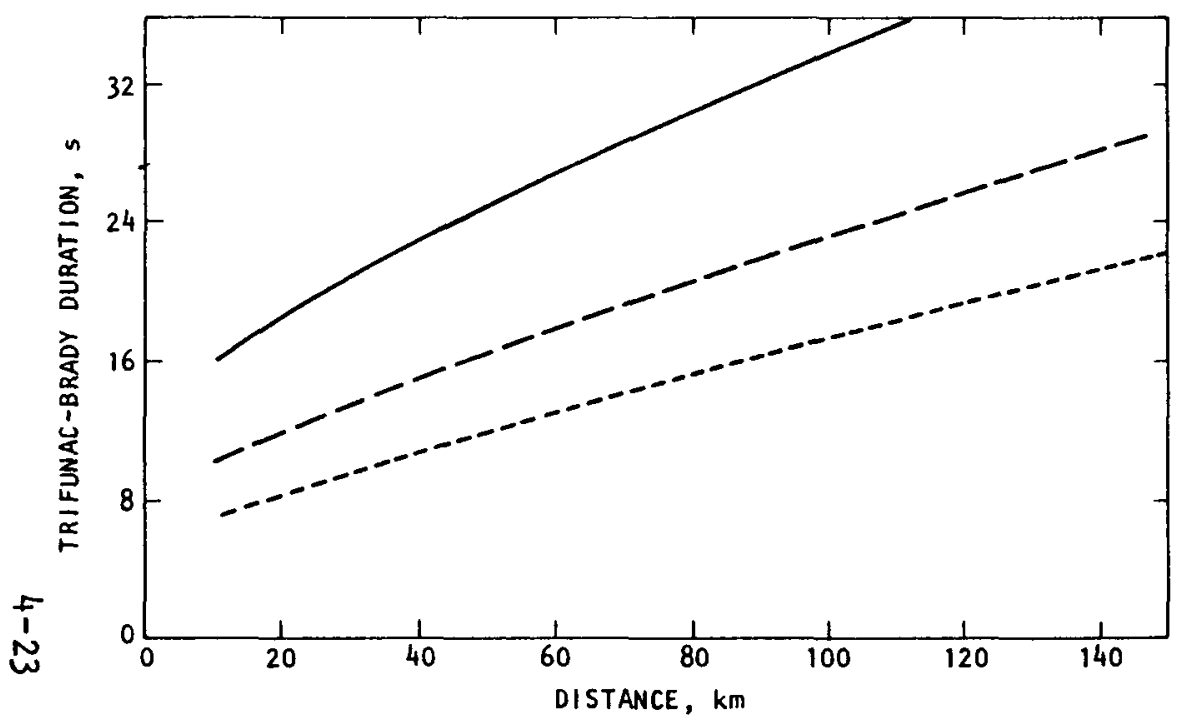

(a) Horizontal motion

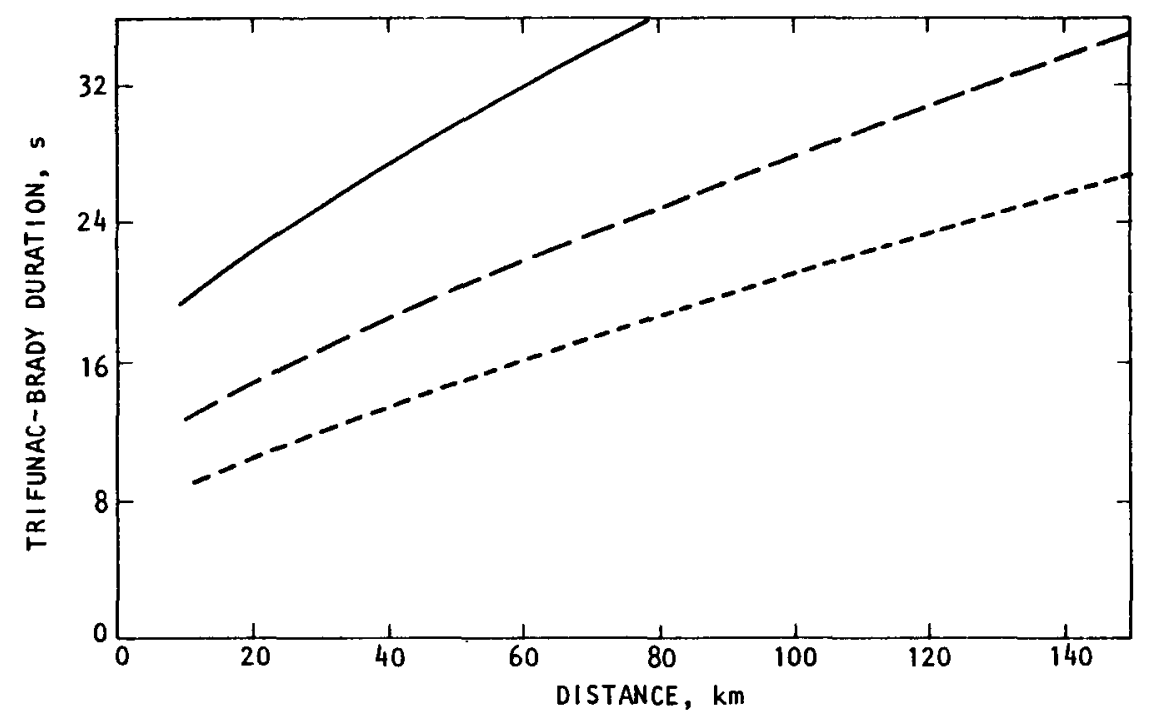

(b) Vertical motion

$$
\text { LEGEND }
$$

FIGURE 4-10. EFFECTS OF LOCAL SITE CONDITIONS ON TRIFUNAC-BRADY DURATION 


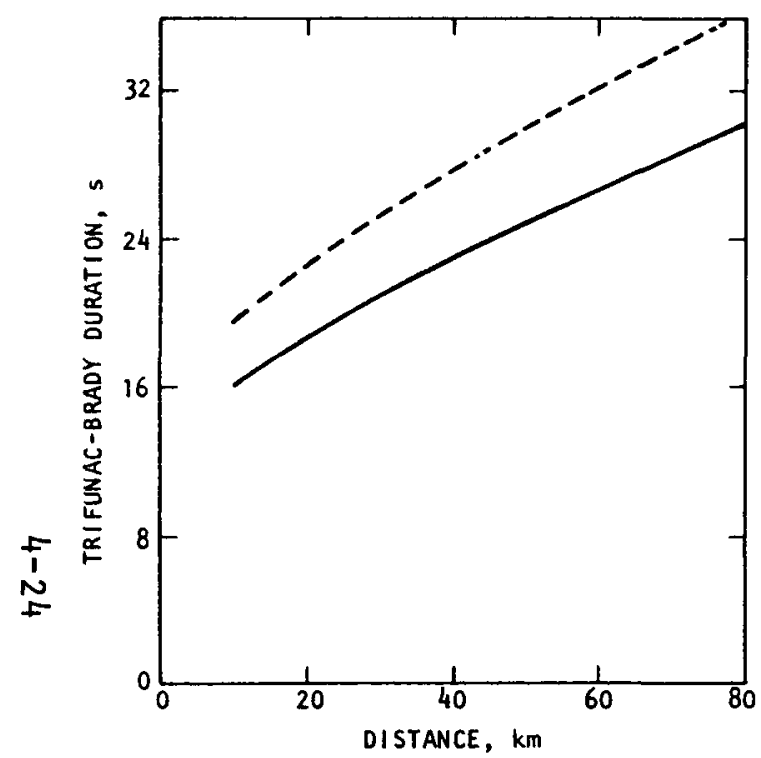

(a) Deep soil sites

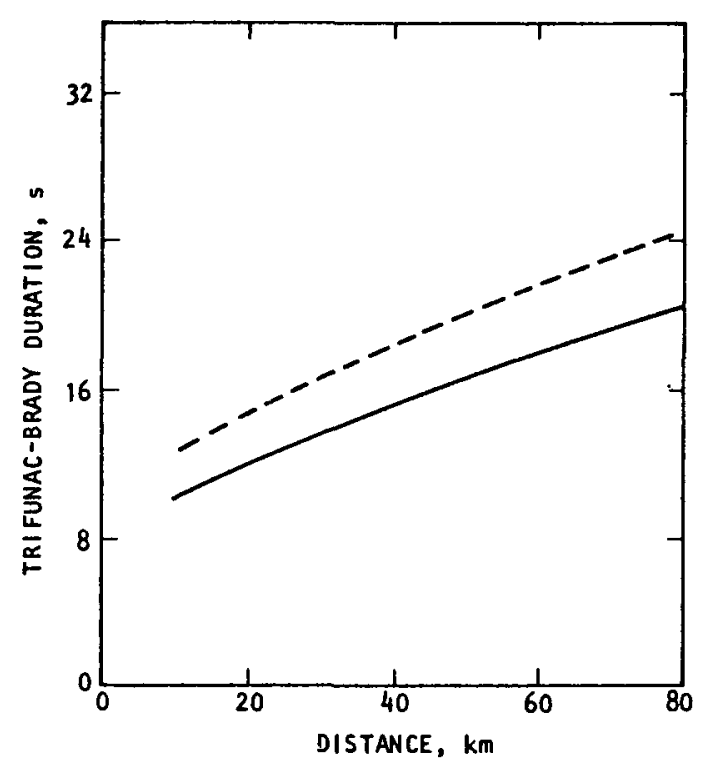

(b) Intermediate sites

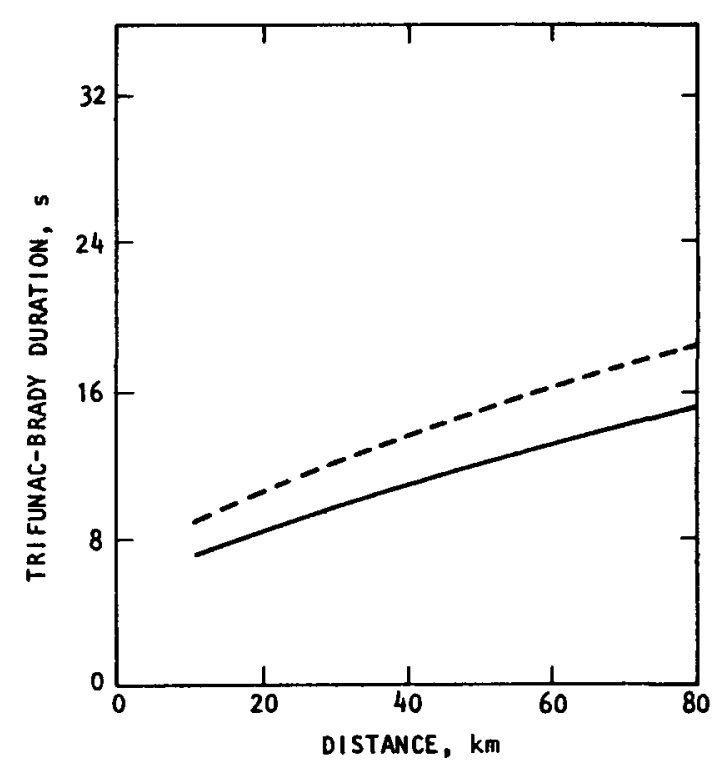

(c) Rock sites

LEGEND

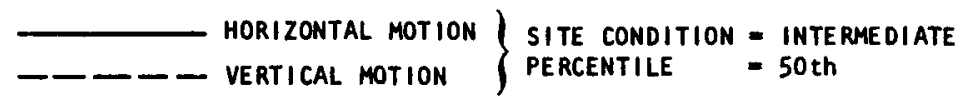

FIGURE 4-11. COMPARISON OF TRIFUNAC-BRADY DURATIONS FOR HORIZONTAL AND VERTICAL MOTION 


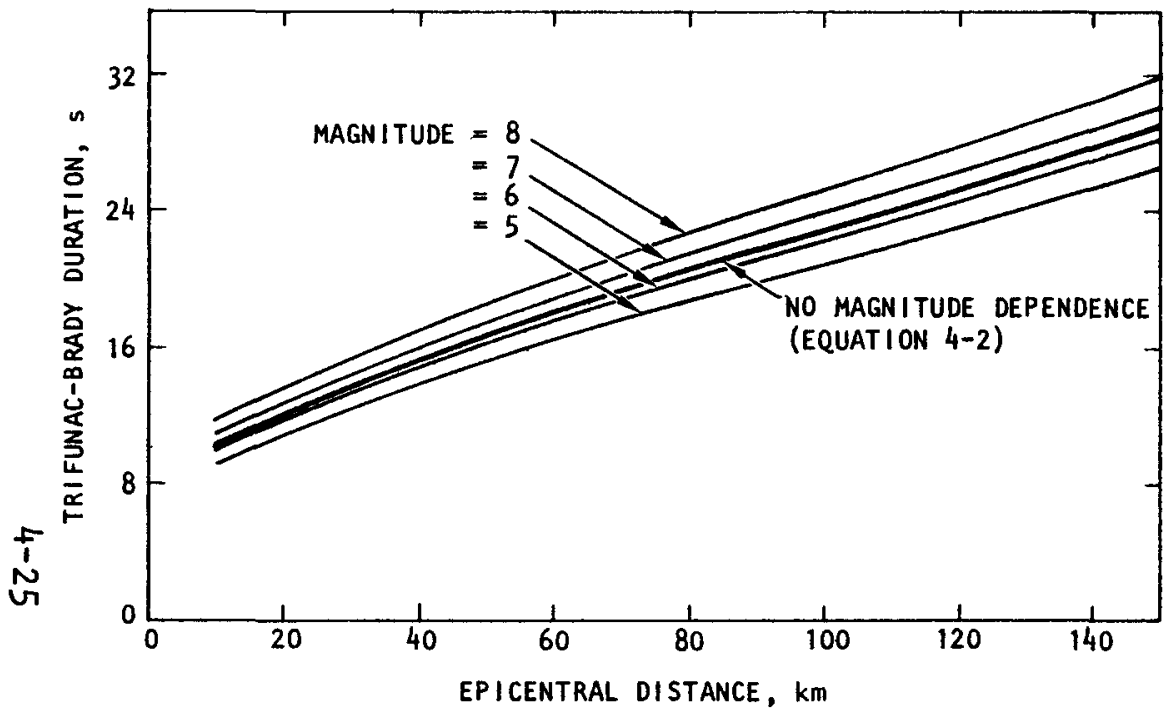

(a) Horizontal motion

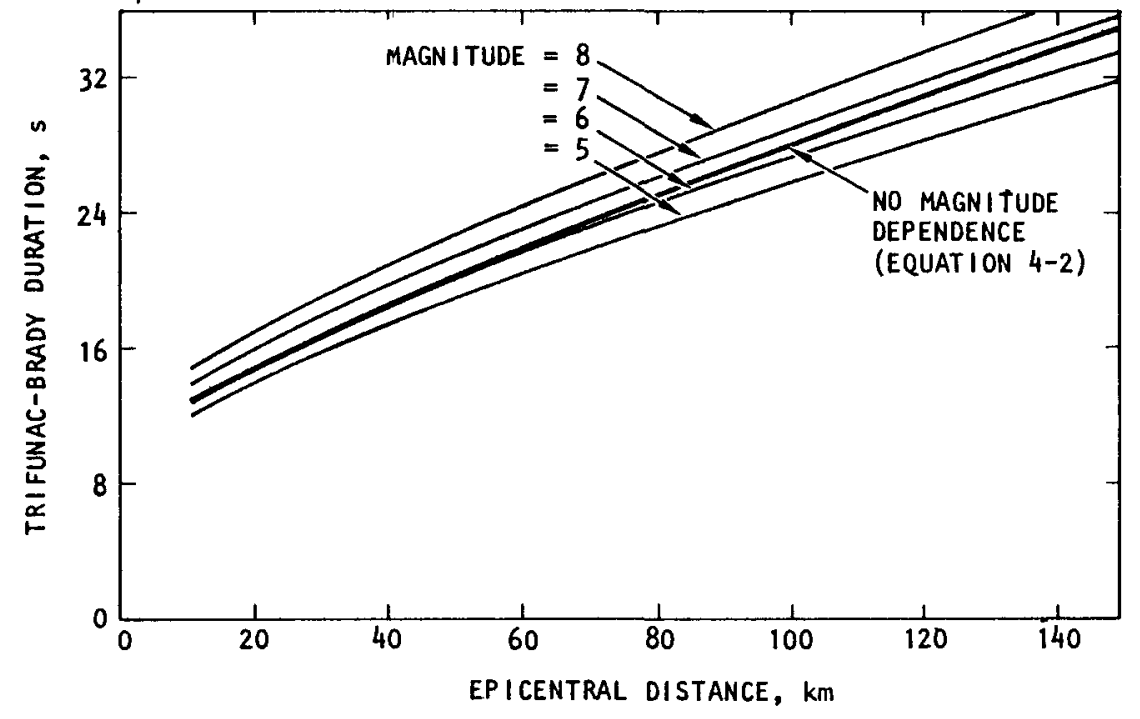

(b) Vertical motion

NOTE :

SITE CONDITION = INTERMEDIATE

PERCENTILE $=50$ th

FIGURE 4-12. EFFECTS OF MAGNITUDE ON TRIFUNAC-BRADY DURATION 


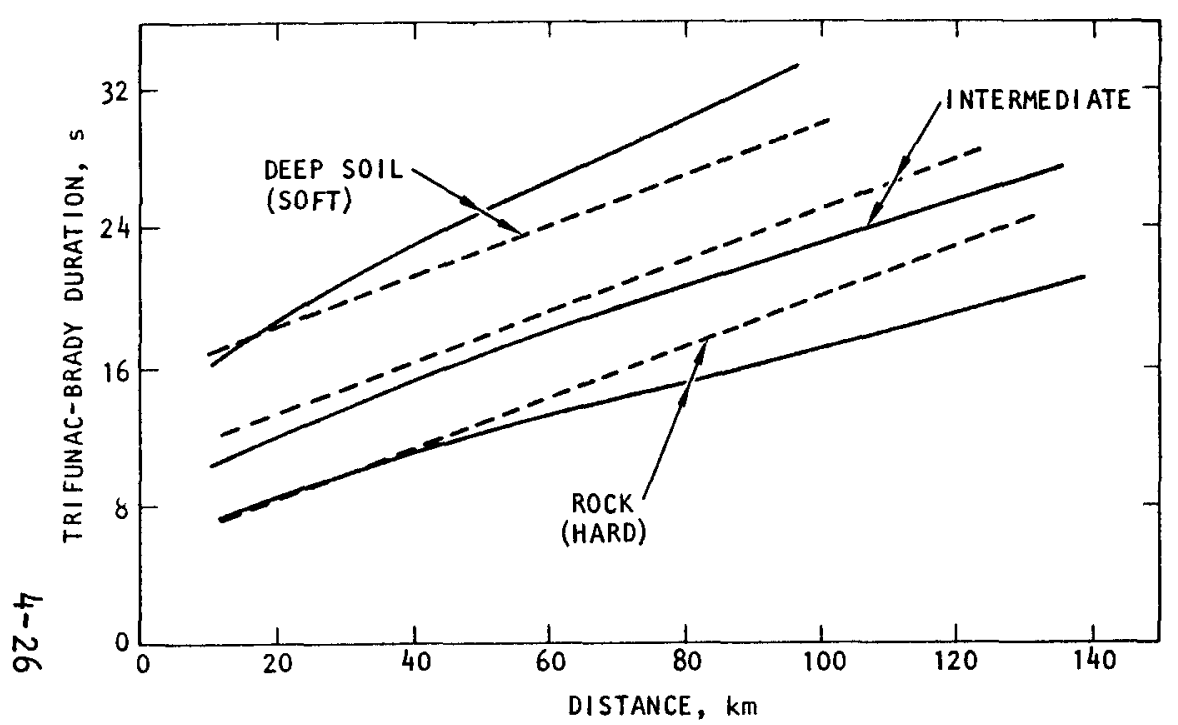

(a) Horizontal motion

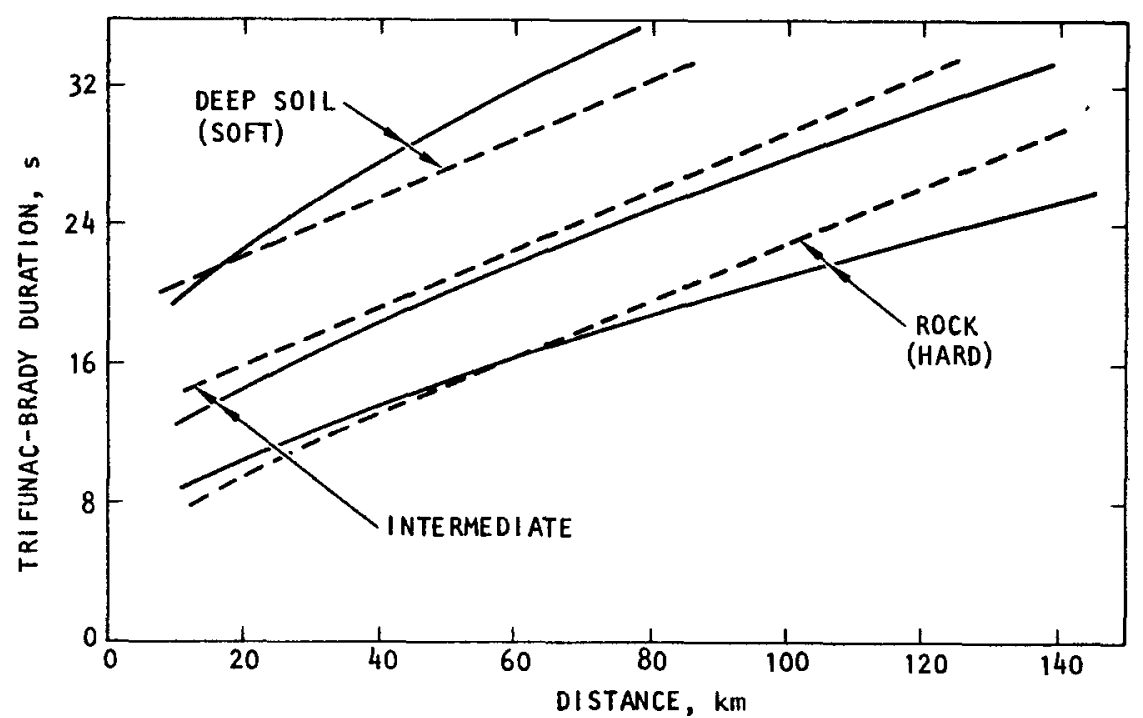

(b) Vertical motion

LEGEND

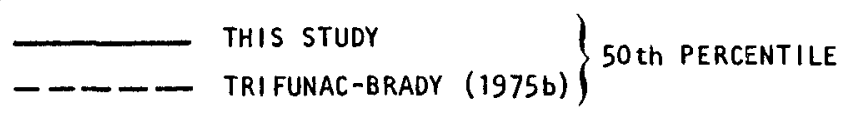

NOTE: TRIFUNAC-BRADY SITE CLASSIFICATIONS GIVEN IN PARENTHESES

FIGURE 4-13. COMPARISON OF TRIFUNAC-BRADY DURATIONS FROM THIS STUDY AND FROM TRI FUNAC-BRADY (1975b) 
CHAPTER 5

RESPONSE SPECTRA

\subsection{GENERAL DISCUSSION}

In most designs of nuclear plants and other major structures in seismic areas, the seismic input criteria is specified in terms of ground response spectra for various damping ratios. Generally, these spectra are developed from fixed spectral amplification factors that have been normalized according to peak acceleration; to obtain the spectra, these factors are scaled according to a peak acceleration level obtained from seismologic and geologic studies of the region and the site.

Spectral amplification factors which define a fixed spectrum shape were first developed by Housner (1959)." Subsequent widely used spectrum shapes were developed by Newmark and Hall (1969). The currently accepted procedure for developing criteria spectra, for nuclear plants in particular, is based on spectral amplification factors specified by Newmark, Blume, and Kapur (1973) and set forth in the Nuclear Regulatory Commission's Regulatory Guide (RG) 1.60. (USAEC, 1973). More recent factors that define spectrum shapes for particular site classifications were developed by Seed, Ugas, and Lysmer (1976) and by Mohraz (1976).

Despite the wide usage of normalized spectral amplification factors, the following shortcomings associated with such factors have been noted:

- It has been shown that the entire spectrum shape changes with changing Modified Mercalli Intensity or with changing magnitude and distance (Werner and Ts'ao 1977; Trifunac 1977). Such shape changes cannot possibly be represented using fixed spectral amplification factors.

\footnotetext{
* Housner intended that his spectrum shape be scaled according to spectrum intensity, but in practice it has typically been scaled using peak acceleration.
} 
- The peak acceleration, which is most of ten used in current practice to scale spectral amplification factors, is a high frequency component of motion and is therefore not suitable for scaling intermediate and low frequency spectral amplitudes.

- Instead of peak acceleration, it has been suggested that peak displacement and velocity be used instead to normalize lowand intermediate-frequency spectral amplitudes, respectively (e.g., Brady, 1975). However, this has been shown to lead to inconsistencies regarding site-dependent effects on spectral amplitudes (Werner and Ts'ao, 1978).

- The statistical scatter in the normalized spectral amplitudes is not consistent throughout the frequency range when either peak accelerations or peak displacements have been used as a normalizing parameter (Hall, Mohraz, and Newmark, 1976).

In view of this, it would appear that ground response spectra can best be determined, for design purposes, directly from statistical analyses of spectral amplitudes over a range of frequencies. This circumvents the above shortcomings associated with peak motion scaling or with the normalized spectral amplification factors themselves. The present investigation develops spectra from such analyses and differs from previous studies in that it incorporates a greater number of variables, more definitive site classification definitions. and statistical significance testing procedures (Sec.1.2).

\subsection{REGRESSION ANALYSIS}

The statistical analysis of the response spectral amplitudes (pseudovelocities) is carried out at each of 32 frequencies ranging from $0.067 \mathrm{~Hz}$ to $25 \mathrm{~Hz}$. The analysis at each frequency is based on a regression equation whose form is identical to that given in Equation 3-4 (see Table 5-1). A separate set of regression coefficients is obtained for each frequency to accommodate frequency-dependent effects of magnitude, distance, site conditions, earthquake event type, and direction of shaking. These coefficients are given in Table 5-1 for each frequency. 
Outliers at representative low, intermediate, and high frequencies $(0.067 \mathrm{~Hz}, 1.18 \mathrm{~Hz}$, and $25.0 \mathrm{~Hz}$, respectively) are listed in Table 5-2. There is a similarity between these outlier lists and those previously compiled for peak displacement, peak velocity, and peak acceleration, respectively (Table 3-2); i.e., these lists and those of Table 3-2 have several similar entries. This is to be expected, particularly at very low and very high frequencies, since the low-frequency spectral displacements are approaching the peak displacement of the ground shaking and the high-frequency spectral accelerations are approaching the peak acceleration.

\subsection{COMPARISONS WITH RECORDED DATA}

\subsubsection{VISUAL COMPARISONS}

The first set of spectral results to be presented corresponds to visual comparisons of spectra from measured records with those from the regression analysis. In these comparisons, the regression analysis results are computed for magnitudes, distances, site classifications, and earthquake event types that are identical to those conditions under which selected measured records are obtained. In this way, the comparisons illustrate the adequacy of the regression analysis model.

The measured records used in these comparisons were selected at random, with the only requirements being that the sites of the records have defined rather than undefined site classifications and that the records encompass a range of magnitudes and distances. A total of 13 records were selected, with 7 from Type I (San Fernando) earthquake events and 6 from Type 2 (other than San Fernando) events. Spectra from both horizontal and vertical components of motion were developed for each record.

Spectra computed from the regression equation were obtained to represent the $16 \mathrm{th}, 50 \mathrm{th}$, and 84 th percentile. These spectra were then compared to the spectra from the corresponding measured record. On the average, 68 percent of the measured pseudovelocities at the various frequency points should fall within the bounds defined by the 16 th and 84 th percentile computed spectra. Whether or not this actually occurs here depends on the characteristics of the particular records chosen for these comparisons. 


\subsubsection{Spectra from Type 1 Earthquake Events}

The first set of comparisons correspond to horizontal and vertical ground response spectra from records measured during the 1971 San Fernando earthquake. A total of 7 sets of spectra were selected corresponding to records from Pacoima Dam, Millikan Library, 111 N. Hope Street, Castaic, 15250 Ventura Boulevard, 3345 Wilshire Boulevard, and Lake Hughes No. 4.

The comparisons (Figs. 5-1 to 5-7) show that, on the whole, the computed spectra compare well with the spectra from the measured records. Particular features of these comparisons are as follows:

- Very good overall comparisons between computations and measurements are seen for the Hope Street, Wilshire Boulevard, and Ventura Boulevard spectra. For these cases, the measured spectra have shapes and amplitudes that closely follow those of the computed spectra and fall well within the 16 th percentile and 84 th percentile bounds (Figs. 5-1 to 5-3).

- Some prominent differences exist between computed and measured lower frequency spectral amplitudes at the Castaic and Lake Hughes No. 4 sites. (Figs. 5-4, 5-5). One reason for this may be that both of these sites are located north of the causative fault, while the majority of the records obtained during the San Fernando earthquake were measured south of the fault, or in the direction of its thrusting action. Conceivably different waves propagating in these different directions could cause spectra from records north and south of the fault to differ.

- The Pacoima Dam and Millikan Library spectra compare reasonably well with the computed spectra. The differences that do exist at these sites are most prominent at lower frequencies (Figs. 5-6, 5-7). 


\subsubsection{Spectra from Type 2 Earthquake Events}

The second set of comparisons between recorded and computed ground response spectra corresponds to records measured during all earthquakes except San Fernando. A total of 6 sets of horizontal and vertical spectra were considered, corresponding to El Centro, 1940; Golden Gate Park, 1957; Taft, 1952; Jet Propulsion Laboratory, 1968; Ferndale, 1941; and 0lympia, 1949.

The comparison between the computed and recorded spectra are seen in Figures 5-8 to 5-13 to be adequate, but not quite as favorable overall as those previously described for the Type 1 earthquake events. The reason for this is that the enisemble of Type 2 earthquake records represents a variety of different earthquake events, each with its own unique source mechanism and propagating seismic waves. Therefore, there is much more scatter among the Type 2 earthquake records than the Type 1 records, which represent only a single earthquake event. For this reason, it is more difficult for computed spectra to closely match spectra from a given Type 2 earthquake record than from a Type 1 record.

With this as background, particular features of the recorded and computed Type 2 spectral amplitudes are as follows:

- Of the various spectra considered in these comparisons, the most favorable comparisons of spectral shape and amplitude are those involving the Taft (1952) records (Fig. 5-8). The Olympia (1949), and Golden Gate (1957) spectra also show good overall comparisons that are somewhat better for horizontal motions than for vertical motions (Figs. 5-9 to 5-10).

- The El Centro (1940) horizontal spectra exhibit low frequency spectral amplitudes that are on the high side when compared to the computed. spectra, and high frequency spectral amplitudes that tend toward the low side. The vertical spectrum from the El Centro (1940) record is essentially flat over most of the frequency range; this shape differs from the shapes of the 
computed vertical spectra (Fig. 5-11). It is noted that this particular accelerograph station is characterized by soft soil deposits and a very thick foundation mat that may result in a filtering of high frequency spectral amplitudes, due to soil/ structure interaction effects (SW/AA, 1979).

- The least favorable overall comparison between computed and measured spectra is exhibited by the Jet Propulsion Laboratory (1968) and Ferndale (1941) records. For these cases, the amplitudes of the measured horizontal spectra fall below the 16 th percentile computed spectra, particularly at low frequencies. The measured vertical spectra also fall on the low side of the computed vertical spectra at low frequencies (Figs. 5-12, 5-13).

\section{3 .2 DATA-FIT PARAMETERS}

The second type of comparison between the regression analysis results and the spectra from measured records is in the form of data-fit parameters. Three sets of parameters--the standard deviation, coefficient of variation, and correlation coefficient--are provided in Table 5-3 for pseudovelocities at $0.067 \mathrm{~Hz}, 1.18 \mathrm{~Hz}$, and $25.0 \mathrm{~Hz}$. The parameters for $1.18 \mathrm{~Hz}$ and $25.0 \mathrm{~Hz}$ are very similar to those previously shown in Table 3-3 for the peak velocity and peak acceleration, respectively. The standard deviation and coefficient of variation at $0.067 \mathrm{~Hz}$ are similar to those shown in Table 3-3 for peak displacement; however, the correlation coefficients differ. This indicates that the spectral displacement at this low frequency, while approaching the peak displacement, has not yet reached this limiting value.

\subsection{PARAMETRIC EFFECTS}

This section describes how the various parameters considered in this investigation affect the horizontal and vertical 50 th percentile ground response spectra. 


\subsubsection{EFFECTS OF EARTHQUAKE EVENT TYPE AND EPICENTRAL DISTANCE}

The effects of earthquake event type and, for each event type, the effects of variations in epicentral distance are described in this subsection. These particular parametric effects are studied for Magnitude 6.4 events, intermediate site conditions, and 50 th percentile spectra.

Figures 5-14 and 5-15 show ground response spectra for Types 1, 2, and 3 earthquake events and for horizontal and vertical motions respectively. Two sets of spectra are provided in each figure, one corresponding to an epicentral distance of $25 \mathrm{~km}$, and the other to a distance of $100 \mathrm{~km}$. These figures show that:

- At a distance of $25 \mathrm{~km}$, each earthquake event type has its own shape that is distinctly different from the spectrum shapes of the other event types. The Type 1 (San Fernando) spectra feature, in the intermediate frequency range, a shape that is inclined with highest pseudovelocities at the low end of the range; the Type 2 spectra, on the other hand, are inclined in the opposite way in this intermediate frequency range, with the highest pseudovelocities at the high end of the range. The Type 3 spectra represent a condition that is intermediate between the Type 1 and Type 2 cases and therefore is essentially flat in the intermediate frequency range.

- At a distance of $100 \mathrm{~km}$, the various spectra are quite similar to one another, indicating that at these long distances the the spectra are independent of the earthquake event type.

Figure 5-16 represents a cross-plotting of the results shown in Figures 5-14 and 5-15 and indicates the following distance attenuation characteristics of the horizontal and vertical spectra for each earthquake type:

- The shapes of the spectra are strongly affected by variations in epicentral distance.

- The spectra from the Type 1 earthquake events attenuate faster with distance than do the Type 2 and Type 3 spectra. 
- For the Type 2 events, the rate of attenuation of spectral amplitude with distance is slowest at low frequencies and increases with increasing frequency. This frequency dependence of the distance attenuation rate is not as prominent for the Type 1 and Type 3 events; i.e., for these events, the attenuation rate is slowest at low frequencies, but is very similar at intermediate and high frequencies. This trend is caused by the influence of the ${ }_{6} 6 \ln (R+1) \cdot E$ attenuation term in Table 5-1, which appears in the regression equation for the Type 1 and Type 3 events only; as shown in Table 5-1, $a_{6}$ is a negative number that is largest in the intermediate frequency range. This can be contrasted with the other attenuation term for intermediate sites, $a_{3} \cdot \ln (R+1)$, which is the only attenuation term appearing in the regression equation for Type 2 events; Table 5-1 shows that $a_{3}$ is a negative number that is largest at low frequencies and steadily increases with increasing frequency.

\subsubsection{EFFECTS OF MAGNITUDE AND EPICENTRAL DISTANCE}

The effects of magnitude and, for a given magnitude, the effects of epicentral distance, are described in this subsection. These particular parametric effects are studied for Type 3 earthquake events, intermediate site conditions, and 50 th percentile spectra.

Ground response spectra plotted vs. magnitude for horizontal and vertical motions are provided in Figures 5-17 and 5-18 respectively. In each of these figures, two sets of spectra are presented, corresponding to epicentral distances of $25 \mathrm{~km}$ and $100 \mathrm{~km}$. For all cases, Figures $5-17$ and 5-18 show that, as the magnitude increases, the ground response spectra increase at a decreasing rate.

Figure 5-19 provides a cross-plotting of the results shown in Figures 5-17 and 5-18, in order to illustrate distance attenuation effects for various magnitude levels. The results, presented for Magnitudes 5 and 8 , 
are similar to those discussed in Section 5.4 .1 for the Type 3, Magnitude 6.4 case (Fig. 5-16). They show, for all magnitudes, that the intermediate frequency components attenuate at a rate that is comparable to that of the highfrequency components. As discussed earlier, this trend is related to the presence of the $a_{6} \cdot \ln (R+1) \cdot E$ attenuation term in the regression equation (Table 5-1).

\subsubsection{EFFECTS OF LOCAL SITE CONDITIONS AND EPICENTRAL DISTANCE}

The effects of local site conditions and, for a given site condition, the effects of epicentral distance are described in this subsection. These particular parametric effects are studied for Type 3 earthquake events of Magnitude 6.4 and for 50 th percentile response spectra.

Horizontal and vertical ground response spectra are plotted in Figure 5-20 for different site conditions and for epicentral distances of $25 \mathrm{~km}$ and $100 \mathrm{~km}$. This figure shows that:

- For a given epicentral distance, the overall shapes of the spectra from rock sites differ markedly from those for intermediate and deep soil sites.

- At low and intermediate frequencies, the deep soil sites exhibit the largest spectral amplitudes, followed in order by the intermediate and rock sites. At frequencies above about $4 \mathrm{~Hz}$, no statistically significant differences between the intermediate and rock site spectra could be found; however, at these higher frequencies, the deep soil sites still exhibit the highest spectral amplitudes.

- At a distance of $25 \mathrm{~km}$, there is a small difference between the low and intermediate frequency spectral amplitudes of the deep soil and intermediate sites and a larger difference between these spectral amplitudes and those for rock sites. At higher frequencies, differences between the three site-dependent spectra are negligible. 
- The above differences between the various site-dependent spectra are much larger at the $100 \mathrm{~km}$ epicentral distance. At low and intermediate frequencies, the differences between the deep soil and intermediate spectra are now much greater. The same can be said at high frequencies, with respect to the differences between the spectral amplitudes for deep soil sites and those for intermediate and rock sites.

- The distance attenuation effects throughout the entire frequency range are greatest for rock sites, followed in order of decreasing attenuation rate by the intermediate and deep soil sites.

\subsubsection{HORIZONTAL VS. VERTICAL GROUND RESPONSE SPECTRA}

In seismic design practlce, it is often assumed that the design criteria spectrum for vertical motions are $2 / 3$ of the corresponding spectra for horizontal motions. To assess the adequacy of this assumption, the horizontal, $2 / 3 \times$ horizontal, and vertical spectra are compared in Figure 5-21 for the specific case of a Magnitude 6.4 and Type 3 earthquake event, intermediate soil conditions, and 50 th percentile spectra. These comparisons, carried out for epicentral distances of $25 \mathrm{~km}$ and $100 \mathrm{~km}$, show that the $2 / 3 \times$ horizontal spectra everywhere exceed the vertical spectra; l.e., the assumption that the vertical criteria spectra can be represented as $2 / 3 \times$ the horizontal criteria spectra is conservative. However, it would seem that this conservatism is unnecessary, since vertical motion data is as readily available for developing composite criteria spectra as is horizontal motion data.

\subsection{COMPARISONS WITH CURRENT DESIGN PRACTICE}

This section describes comparisons of computed spectra with spectra developed from procedures widely used in current design practice for nuclear plants and other major structures. The two procedures considered in these comparisons are those set forth in the Regulatory Guide (RG) 1.60 (USAEC, 1973) and in the paper by Seed, Ugas, and Lysmer (1976). 


\subsubsection{REGULATORY GUIDE (RG) 1.60 COMPARISONS}

The procedure most widely used in current practice for developing seismic input criteria spectra is based on the procedures developed by Newmark, Blume, and Kapur (1973) and set forth in RG 1.60. These procedures consist of the use of normalized spectral amplification factors defined for different damping ratios at various discrete frequencies. The amplification factors for both horizontal and vertical motions are expressed as multiples of the peak horizontal acceleration. To develop the actual design spectra, the spectral amplification factors multiplied by the criteria peak horizontal acceleration are plotted at the appropriate frequencies on tripartite spectrum paper and are then interconnected by straight lines. It is noted that the RG 1.60 spectrum shapes are the same for all magnitudes, epicentral distances, and site conditions.

The results described in this section consist of comparisons of the RG 1.60 spectra with the 16 th, 50 th, and 84 th percentile spectra developed from the regression analysis procedures used in this study. In this, the RG 1.60 spectra are scaled using the 50 th percentile peak horizontal acceleration corresponding to the particular combination of variables considered in each comparison. These peak accelerations are obtained using the regression equations described in Chapter 3. They were shown in that chapter to be dependent on magnitude, distance, and earthquake event type, but independent of site conditions. For all comparisons described herein, the spectra and peak accelerations computed using regression analysis procedures are based on Type 3 earthquake events. Two sets of comparisons are provided--one corresponding to various magnitude levels and fixed site conditions and the other corresponding to various site conditions and fixed magnitudes. For each set of comparisons, variations in epicentral distance are also considered. 


\subsubsection{Comparisons for Various Magnitude Levels}

The first set of comparisons with RG 1.60 is shown for Magnitudes 5.0, 6.5, and 8.0 in Figures 5-22 to 5-24, respectively. For each magnitude level, comparisons are made at epicentral distances of $10 \mathrm{~km}$ and $50 \mathrm{~km}$ for both horizontal and vertical motions. The comparisons are based on a Type 3 earthquake event and intermediate site conditions.

Trends from these comparisons are as follows:

- For horizontal motions at a $10 \mathrm{~km}$ distance and for each magnitude level, the RG 1.60 spectra fall between the 50 th percentile and 84 th percentile spectra at frequencies above about $4 \mathrm{~Hz}$. At intermediate frequencies ranging from about $0.5 \mathrm{~Hz}$ to $4 \mathrm{~Hz}$, the RG 1.60 spectra are roughly comparable to the 84 th percentile computed spectra, while at lower frequencies, the RG 1.60 spectra substantially exceed the 84 th percentile computed spectra.

- For horizontal motions at a $50 \mathrm{~km}$ distance and for Magnitudes 6.5 and 8.0 , the RG 1.60 spectra are generally comparable to the 84 th percentile computed spectra. For Magnitude 5.0, the same is true for frequencies above about $0.2 \mathrm{~Hz}$; however, at lower frequencies the RG 1.60 spectra substantially exceed the 84 th percentile computed spectra.

- For vertical motions at epicentral distances of $10 \mathrm{~km}$ and $50 \mathrm{~km}$ and for all magnitude levels, the RG 1.60 spectra generally exceed the 84 th percentile computed spectra, often by a substantial amount. 


\subsubsection{Comparisons for Various Site Conditions}

The second set of comparisons with RG 1.60 is carried out for deep soil and rock sites in Figures 5-25 and 5-26 for horizontal and vertical motion, respectively. These comparisons, together with those described in Section 5.5.1.1, show how RG 1.60 compares with the computed spectra for all of the site classifications considered in this study. These comparisons are carried out for Magnitude 6.5 and Type 3 earthquake events, for epicentral distances of $10 \mathrm{~km}$ and $50 \mathrm{~km}$, and for $16 \mathrm{th}, 50 \mathrm{th}$, and $84 \mathrm{th}$ percentile spectra.

The comparisons from Figures $5-25$ and 5-26 show the following trends :

- For deep soil sites, the RG 1.60 horizontal spectrum at a 10 $\mathrm{km}$ distance falls between the $50 \mathrm{th}$ and $84 \mathrm{th}$ percentile computed horizontal spectra, except at very low frequencies where RG 1.60 substantially exceeds the 84 th percentile spectrum. At a $50 \mathrm{~km}$ distance, the $R G 1.60$ horizontal spectrum corresponds closely to the 50 th percentile computed horizontal spectrum.

- For rock sites and epicentral distances of $10 \mathrm{~km}$ and $50 \mathrm{~km}$, the RG 1.60 horizontal spectra are roughly comparable to the 84 th percentile computed horizontal spectra at frequencies above $4 \mathrm{~Hz}$; at lower frequencies, the 84 th percentile spectra are substantially exceeded by RG 1.60 .

- For rock sites at $10 \mathrm{~km}$ and $50 \mathrm{~km}$ epicentral distances, the RG 1.60 vertical spectra exceed the 84 th percentile computed vertical spectra, often by a substantial amount. 
- For deep soil sites at epicentral distances of $10 \mathrm{~km}$ and $50 \mathrm{~km}$, the RG 1.60 vertical spectra are roughly comparable to the 84 th percentile computed vertical spectra at frequencies above $4 \mathrm{~Hz}$. At lower frequencies, the RG 1.60 vertical spectrum for a $10 \mathrm{~km}$ distance exceeds the 84 th percentile computed vertical spectrum whereas, for a $50 \mathrm{~km}$ distance, the RG 1.60 vertical spectrum falls between the 50th and 84 th percentile computed vertical spectra.

\subsubsection{Seed-Ugas-Lysmer Spectra}

As previously noted, the RG 1.60 spectrum shapes are assumed to be valid for all magnitudes, epicentral distances, and site conditions. In recognition of the fact the site conditions could influence the spectrum shape, Seed, Ugas, and Lysmer (1976) carried out statistical analyses of measured records to develop mean and 34 th percentile horizontal ground response spectrum shapes, normalized to a unit peak horizontal acceleration. Four sets of spectrum shapes were developed corresponding to four different site classifications. These shapes were considered to be independent of magnitude and epicentral distance, although a majority of the records considered by Seed, Ugas, and Lysmer were from earthquake events with magnitudes in the 6.4 to 6.6 range.

This section contains a comparison of Seed, Ugas, and Lysmer (SUL) horizontal spectra with $16 \mathrm{th}, 50 \mathrm{th}$, and $34 \mathrm{th}$ percentile horizontal spectra computed during this study. The comparisons are carried out for Type 3 earthquake events with Magnitude 6.5, for epicentral distances of $10 \mathrm{~km}$ and $50 \mathrm{~km}$, and for all three site classifications. In this, the suL spectrum shapes are scaled to the 50 th percentile peak horizontal accelerations computed using the regression equations of Chapter 3 in conjunction with the particular combination of variables considered in each comparison. As noted earlier, these peak accelerations are independent of site classification.

In the following comparisons, it is assumed that the deep soil, intermediate, and rock site classifications considered in this study correspond approximately to the deep cohesionless soil, stiff soil, and rock classifications 
defined by Seed, Ugas, and Lysmer. There are, in fact, differences between the two sets of site classification definitions and in the ensembles of records grouped into each classification. Nevertheless, the general characteristics of the two sets of results can be compared as described below.

Figures 5-27, 5-28, and 5-29 contain spectral comparisons for the deep soil, intermediate, and rock site classifications respectively. These comparisons indicate the following trends.

- For an epicentral distance of $10 \mathrm{~km}$, the SUL spectra usually fall between the computed mean and 34 th percentile spectra for the corresponding site condition.

- For an epicentral distance of $50 \mathrm{~km}$, the comparisons depend on the site classification. For deep soil sites, the SUL spectra tend to fall between the 16 th and 50 th percentile computed spectra except at frequencies below $1 \mathrm{~Hz}$, where they fall between the 50 th and 84 th percentile spectra. For intermediate and rock site conditions, the SUL spectra fall between the 50 th and 84 th percentile computed spectra throughout the entire frequency range. 
TABLE 5-1. REGRESSION COEFFICIENTS FOR RESPONSE SPECTRAL AMPLITUDES

Regression Equation:

$$
\begin{aligned}
\ln \left(S_{V}(f)\right)=a_{1}(f) & +\frac{a_{2}(f)}{M}+a_{3}(f) \cdot \ln (R+1)+a_{4}(f) \cdot v+a_{5}(f) \cdot E+a_{6}(f) \cdot \ln (R+1) \cdot E \\
& +a_{7}(f) \cdot \ln (R+1) \cdot S_{n}+a_{8}(f) \cdot \ln (R+1) \cdot S_{R}
\end{aligned}
$$

where

\begin{tabular}{|c|c|c|c|c|c|c|c|c|}
\hline \multirow{2}{*}{$\begin{array}{l}\text { Frequency, f } \\
\text { (hz) }\end{array}$} & \multicolumn{8}{|c|}{ REGRESSION COEFFICIENTS } \\
\hline & $a_{1}(f)$ & $a_{2}(f)$ & $a_{3}(f)$ & $a_{4}(f)$ & $a_{5}(f)$ & $a_{6}(f)$ & $a_{7}(f)$ & $a_{B}(f)$ \\
\hline 0.067 & 4.577 & -20.422 & -0.304 & -0.425 & 2.534 & -0.641 & 0.058 & -0.122 \\
\hline 0.083 & 5.011 & -21.622 & -0.270 & -0.468 & 2.461 & -0.636 & 0.045 & -0.132 \\
\hline 0.100 & 5.476 & -22.968 & -0.311 & -0.542 & 2.339 & -0.559 & 0.051 & -0.131 \\
\hline 0.118 & 5.920 & -24.596 & -0.336 & -0.599 & 2.052 & -0.418 & 0.050 & -0.146 \\
\hline 0.143 & 6.424 & -26.774 & -0.354 & -0.729 & 2.181 & -0.375 & 0.057 & -0.162 \\
\hline 0.167 & 6.749 & -28.328 & -0.358 & -0.762 & 2.944 & -0.526 & 0.064 & -0.180 \\
\hline 0.200 & 7.094 & -29.791 & -0.380 & -0.680 & 3.834 & -0.719 & $0: 072$ & -0.222 \\
\hline 0.250 & 8.151 & -34.431 & -0.429 & -0.565 & 4.054 & -0.802 & 0.063 & -0.239 \\
\hline 0.303 & 8.554 & -35.950 & -0.458 & -0.522 & 4.093 & -0.842 & 0.066 & -0.245 \\
\hline 0.356 & 8.705 & -36.505 & -0.457 & -0.573 & 4.304 & -0.938 & 0.069 & -0.244 \\
\hline 0.416 & 9.031 & -37.570 & -0.482 & -0.585 & 4.397 & -0.984 & 0.051 & -0.238 \\
\hline 0.500 & 9.317 & -38.698 & -0.496 & -0.639 & 4.448 & -1.042 & 0.066 & -0.216 \\
\hline 0.667 & 9.826 & -39.221 & -0.593 & -0.745 & 4.136 & -0.965 & 0.092 & -0.198 \\
\hline 0.833 & 10.048 & -38.123 & -0.666 & -0.800 & 3.754 & -0.874 & 0.070 & -0.198 \\
\hline 1.000 & 10.034 & -37.551 & -0.680 & -0.839 & 3.458 & -0.808 & 0.068 & -0.182 \\
\hline 1.180 & 10.417 & -38.217 & -0.749 & -0.842 & 2.861 & -0.677 & 0.068 & -0.183 \\
\hline 1.430 & 9.834 & -34.954 & -0.749 & -0.832 & 2.341 & -0.554 & 0.061 & -0.160 \\
\hline 1.667 & 9.792 & -33.875 & -0.801 & -0.865 & 2.194 & -0.512 & 0.087 & -0.149 \\
\hline 2.000 & 9.757 & -32.841 & -0.850 & -0.858 & 1.887 & -0.434 & 0.086 & -0.118 \\
\hline 2.500 & 10.020 & -33.328 & -0.938 & -0.866 & 2.164 & -0.472 & 0.092 & -0.090 \\
\hline 3.030 & 10.425 & -34.015 & -1.028 & -0.848 & 1.343 & -0.264 & 0.070 & -0.082 \\
\hline 3.560 & 10.388 & -33.662 & -1.091 & -0.787 & 1.356 & -0.254 & 0.077 & -0.045 \\
\hline 4.160 & 9.930 & -32.090 & -1.083 & -0.708 & 1.494 & -0.292 & 0.077 & -0.010 \\
\hline 5.000 & 9.920 & -33.010 & -1.104 & -0.654 & 1.413 & -0.256 & 0.074 & 0.0 \\
\hline 6.667 & 9.451 & -31.500 & -1.157 & -0.568 & 1.651 & -0.308 & 0.078 & 0.0 \\
\hline 8.333 & 9.180 & -31.789 & -1.165 & -0.503 & 1.889 & -0.354 & 0.065 & 0.0 \\
\hline 10.000 & 9.012 & -32.557 & -1.163 & -0.476 & 1.935 & -0.377 & 0.065 & 0.0 \\
\hline 11.800 & 8.608 & -32.131 & -1.141 & -0.448 & 1.905 & -0.382 & 0.066 & 0.0 \\
\hline 14.300 & 8.216 & -32.026 & -1.119 & -0.459 & 1.989 & -0.419 & 0.063 & 0.0 \\
\hline 16.667 & 8.035 & -32.388 & -1.107 & -0.529 & 1.917 & -0.414 & 0.065 & 0.0 \\
\hline 20.000 & 7.675 & -32.099 & -1.087 & -0.593 & 1.799 & -0.390 & 0.070 & 0.0 \\
\hline 25.000 & 7.385 & -32.098 & -1.076 & -0.618 & 1.671 & -0.364 & 0.075 & 0.0 \\
\hline
\end{tabular}

$$
\begin{aligned}
S_{V}(f) & =\begin{array}{l}
\text { Pseudoveloclty (ips) for frequency } f \\
\text { and damping ratio }=0.05
\end{array} \\
M & =\text { Local magnitude } \\
R & =\text { Epicentral distance, } k m \\
V & =1 \text { (if vertical motion) } \\
& =0 \text { (if horizontal motion) } \\
& =1 \text { (to represent San Fernado earthquake--Type I event) } \\
& =0 \text { (to represent all other earthquakes--Type } 2 \text { event) } \\
& =0.545 \text { (to represent all earthquakes--Type } 3 \text { event) } \\
& =1 \text { (if deep-soll site) } \\
S_{D} & =\text { (otherwise) } \\
S_{R} & =1 \text { (if rock site) } \\
& =0 \text { (otherwise) } \\
a_{1}(f) \ldots & \text { (f) = Regression coefficients at frequency f }
\end{aligned}
$$


TABLE 5-2. OUTLIERS FROM REGRESSION ANALYSES OF SPECTRAL AMPLITUDES AT FREQUENCIES OF $0.067 \mathrm{~Hz}, 1.18 \mathrm{~Hz}$, AND $25.0 \mathrm{~Hz}$

\begin{tabular}{|c|c|c|c|c|c|c|c|c|c|}
\hline \multirow[b]{2}{*}{$\begin{array}{l}\text { Frequency of } \\
\text { Pseudovelocity, } \\
\text { Sv }(f), \mathrm{Hz}\end{array}$} & \multicolumn{2}{|c|}{ Accelerograph Station } & \multicolumn{3}{|c|}{ Earthquake Event } & \multirow[b]{2}{*}{$\begin{array}{c}\text { Site } \\
\text { Classification }\end{array}$} & \multirow[b]{2}{*}{$\begin{array}{l}\text { Direction-- } \\
\text { Horizontal }(H) \\
\text { or } \\
\text { Vertical }(V)\end{array}$} & \multirow[b]{2}{*}{$\begin{array}{c}\text { Value of } \\
\text { Pseudovelocity, } \\
\text { ips }\end{array}$} & \multirow[b]{2}{*}{$\begin{array}{l}\text { Deviation } \\
\text { of } \ln \operatorname{Sv}(f)\end{array}$} \\
\hline & Location & $\begin{array}{l}\text { Epl central } \\
\text { Distance, } \\
\text { km }\end{array}$ & Location & Date & Magn I tude & & & & \\
\hline 0.067 & $\begin{array}{l}\text { Long Beach, Callfornia } \\
\text { Public Utlilties Bidg. } \\
\text { San Antonlo Dam, } \\
\text { Upland, Call fornia }\end{array}$ & $\begin{array}{l}27.2 \\
72.1\end{array}$ & $\begin{array}{l}\text { Long Beach, } \\
\text { California } \\
\text { San Fernando, } \\
\text { Call fornia }\end{array}$ & $\begin{array}{l}3-10-33 \\
2-9-71\end{array}$ & $\begin{array}{l}6.3 \\
6.4\end{array}$ & $\begin{array}{l}\text { Undefined } \\
\text { UndefIned }\end{array}$ & $\begin{array}{l}\text { V } \\
\text { H }\end{array}$ & $\begin{array}{l}8.60 \\
0.139\end{array}$ & $\begin{array}{l}+3.70 \\
-3.10\end{array}$ \\
\hline \multirow[t]{5}{*}{.1 .18} & $\begin{array}{l}\text { Ft. Tejon, } \\
\text { Tejon, Cali fornia }\end{array}$ & 68.5 & $\begin{array}{l}\text { San Fornando, } \\
\text { Call fornla }\end{array}$ & $2-9-71$ & 6.4 & Intermediate & $H$ & 0.418 & -3.70 \\
\hline & $\begin{array}{l}\text { Tehachapi Pumping } \\
\text { Plant, Grapevine, } \\
\text { Call fornia }\end{array}$ & 70.7 & $\begin{array}{l}\text { San Fernando, } \\
\text { Callfornia }\end{array}$ & $2-9-71$ & 6.4 & Undefined & H & 0.436 & -3.60 \\
\hline & $\begin{array}{l}\text { Ft. Tejon, } \\
\text { Tejon, Cail fornla }\end{array}$ & & $\begin{array}{l}\text { San Fernando, } \\
\text { Call fornia }\end{array}$ & $2-9-71$ & 6.4 & Intermediate & $H$ & 0.484 & -3.40 \\
\hline & $\begin{array}{l}\text { El Centro, Callfornla } \\
\text { Terminal Substation }\end{array}$ & 23.6 & $\begin{array}{l}\text { Imperial Valley, } \\
\text { Callfornia }\end{array}$ & $1-13-53$ & 5.5 & Deep Soll & H & 0.514 & $-3.4 \sigma$ \\
\hline & $\begin{array}{l}\text { Tehachapi Pumping } \\
\text { Plant, Grapevine, } \\
\text { Call fornia }\end{array}$ & 70.7 & $\begin{array}{l}\text { San Fernando, } \\
\text { Callfornla }\end{array}$ & $2-9-71$ & 6.4 & Undeflned & H & 0.494 & -3.30 \\
\hline \multirow[t]{5}{*}{25.0} & $\begin{array}{l}\text { Long Beach, Callfornla } \\
\text { Public Utilities Bldg. }\end{array}$ & 6.2 & $\begin{array}{l}\text { Torrance-Gardena, } \\
\text { Call fornia }\end{array}$ & $11-14-41$ & 5.4 & Undefined & $v$ & 0.024 & -4.30 \\
\hline & $\begin{array}{l}\text { El Centro, Callfornla } \\
\text { Terminal Substation }\end{array}$ & 23.6 & $\begin{array}{l}\text { Imperial Valley, } \\
\text { Californla }\end{array}$ & $1-13-53$ & 5.5 & Deep Soll & $H$ & 0.019 & -4.00 \\
\hline & $\begin{array}{l}\text { Long Beach, Callfornia } \\
\text { Public Utilities BIdg. }\end{array}$ & 27.2 & $\begin{array}{l}\text { Long Beach, } \\
\text { Callfornia }\end{array}$ & $3-10-33$ & 6.3 & Undefined & $v$ & 1.370 & +3.70 \\
\hline & $\begin{array}{l}\text { Vernon, Call fornia } \\
\text { CMO Bldg. }\end{array}$ & 47.8 & $\begin{array}{l}\text { Long Beach, } \\
\text { Callfornia }\end{array}$ & $3-10-33$ & 6.3 & Undefined & $v$ & 0.530 & +3.10 \\
\hline & $\begin{array}{l}\text { Hollister, Callfornia } \\
\text { Public Library }\end{array}$ & 40.0 & Central Callfornia & $4-8-61$ & 5.7 & Undefined & H & 0.676 & +3.00 \\
\hline
\end{tabular}

Note:
(i) $\sigma=$ standard devlation of $\ln S v(f)$, where $\operatorname{Sv}(f)$ is the pseudovelocity (see Table 5-3). 
TABLE 5-3. DATA-FIT PARAMETERS--SPECTRAL AMPLITUDES AT

FREQUENCIES OF $0.067 \mathrm{~Hz}, 1.18 \mathrm{~Hz}$, AND $25.0 \mathrm{~Hz}$

\begin{tabular}{|c|c|c|c|}
\hline $\begin{array}{c}\text { Frequency of } \\
\text { Pseudovelocity, } \\
\text { Sv(f), Hz }\end{array}$ & $\begin{array}{c}\text { Standard } \\
\text { Deviation of } \\
\text { ln Sv(f) }\end{array}$ & $\begin{array}{c}\text { Coefficient of } \\
\text { Variation of } \\
\text { ln Sv(f) }\end{array}$ & $\begin{array}{c}\text { Correlation } \\
\text { Coefficient } \\
\text { for } \text { ln Sv(f) }\end{array}$ \\
\hline 0.067 & 0.610 & 0.671 & 0.641 \\
1.18 & 0.579 & 0.631 & 0.846 \\
25.0 & 0.577 & 0.629 & 0.834 \\
\hline
\end{tabular}




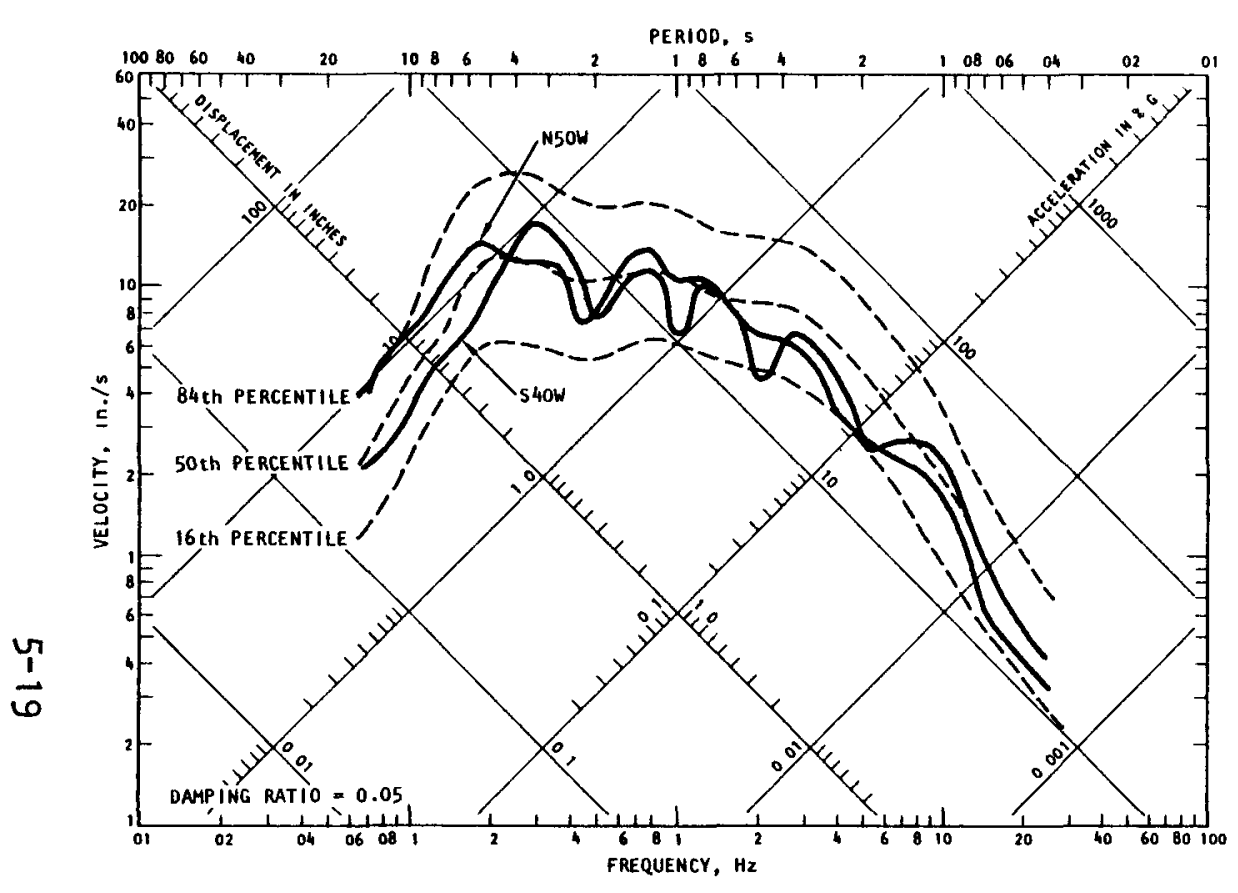

(a) Horizontal

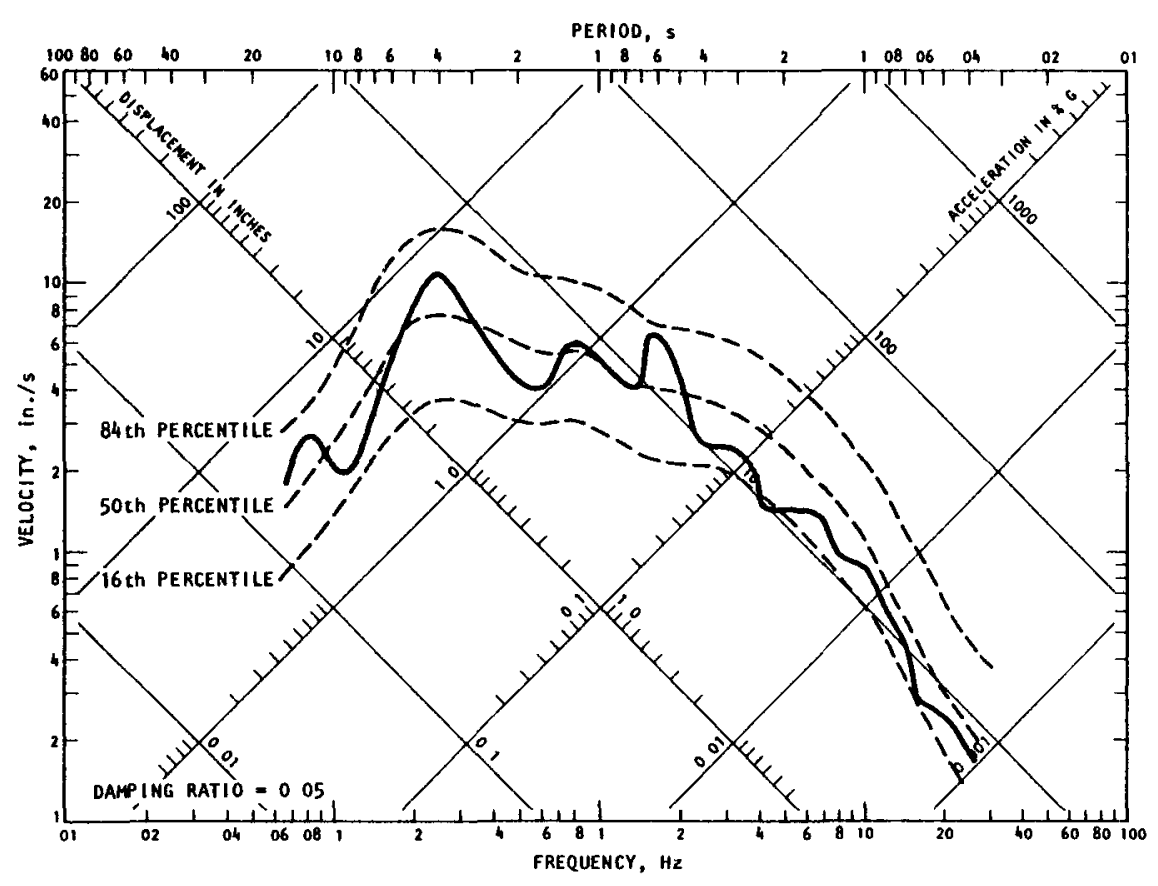

(b) Vertical

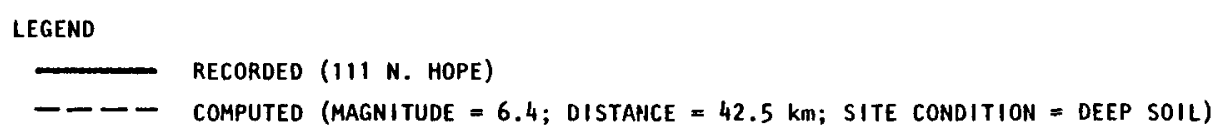

FIGURE 5-1. COMPARISON BETWEEN COMPUTED AND RECORDED GROUND RESPONSE SPECTRA FOR TYPE 1 EARTHQUAKE EVENT (111 N. Hope, 1971) 


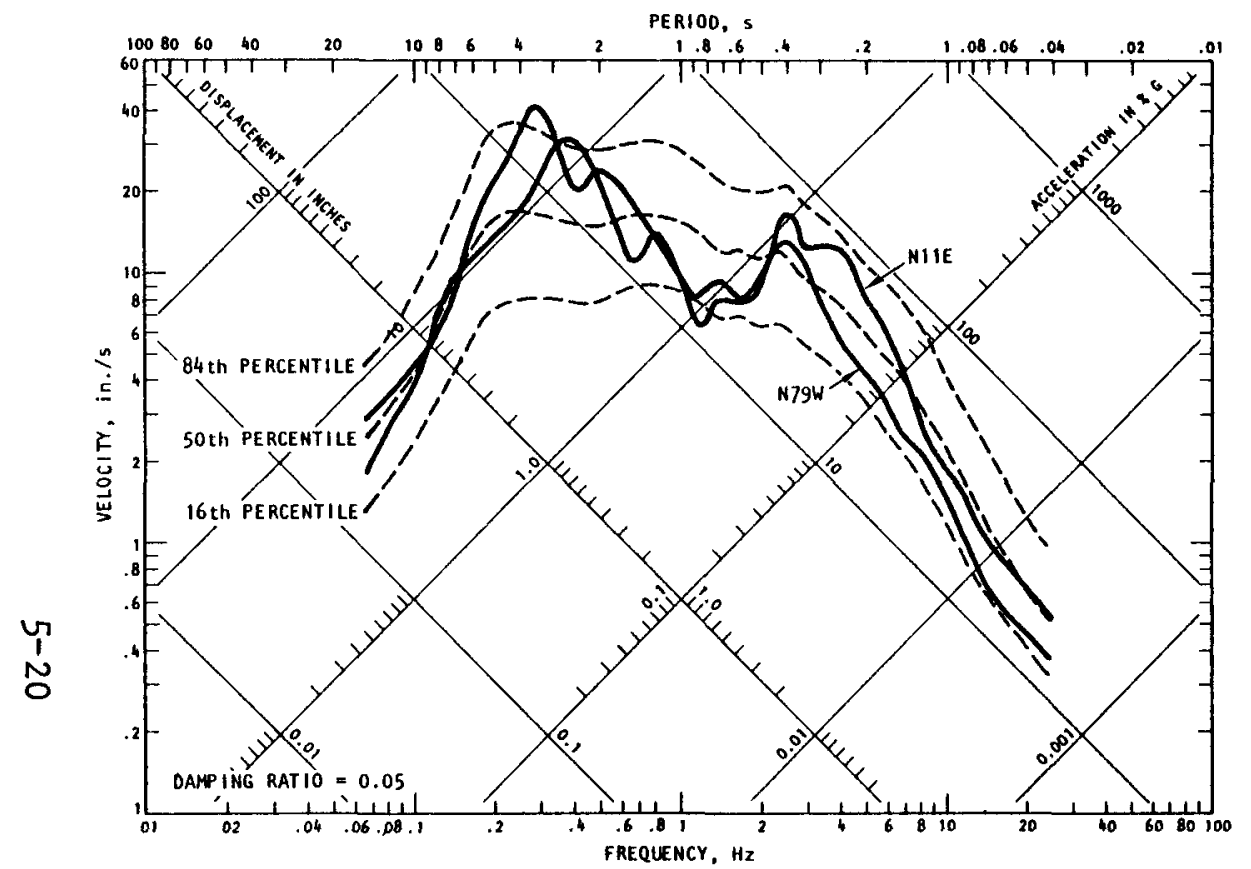

(a) Horizontal

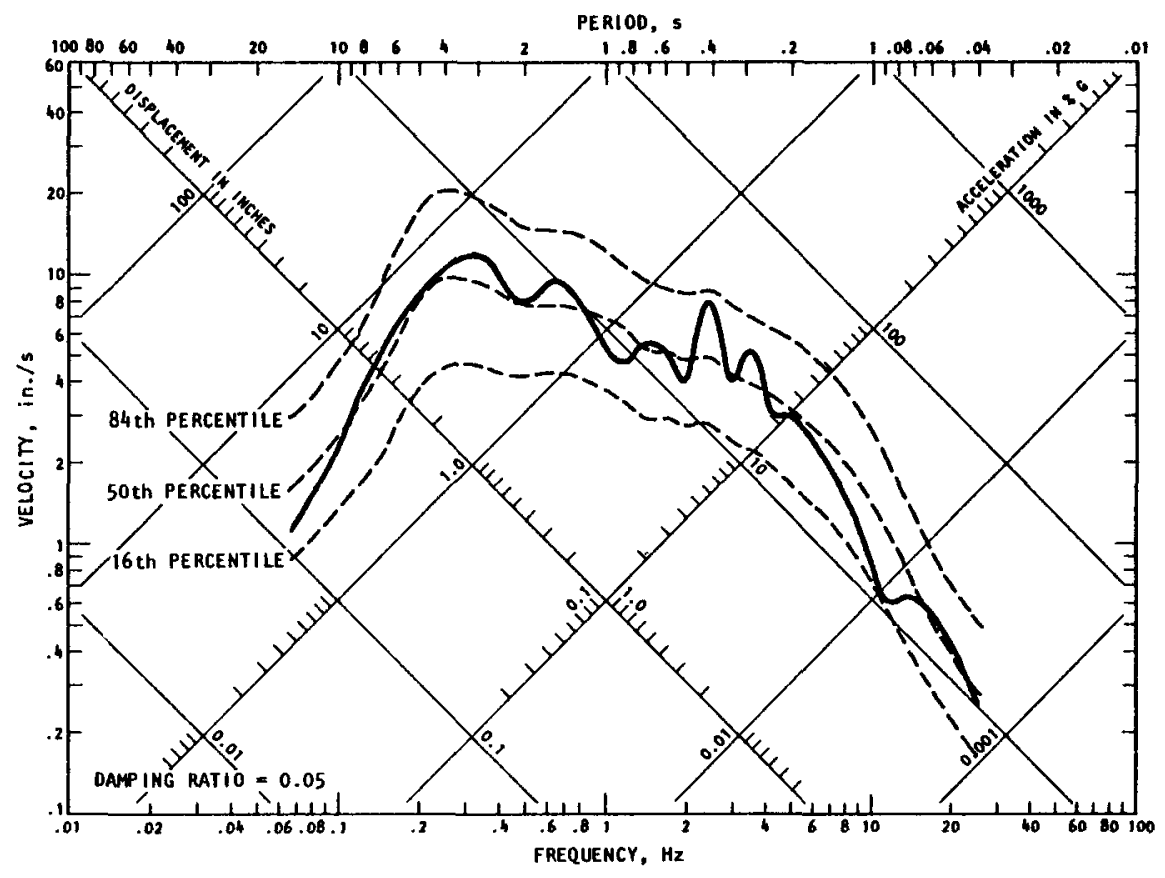

(b) Vertical

LEGEND

FIGURE 5-2. COMPARISON BETWEEN COMPUTED AND RECORDED GROUND RESPONSE SPECTRA FOR TYPE 1 EARTHQUAKE EVENT (15250 Ventura Blvd, 1971) 


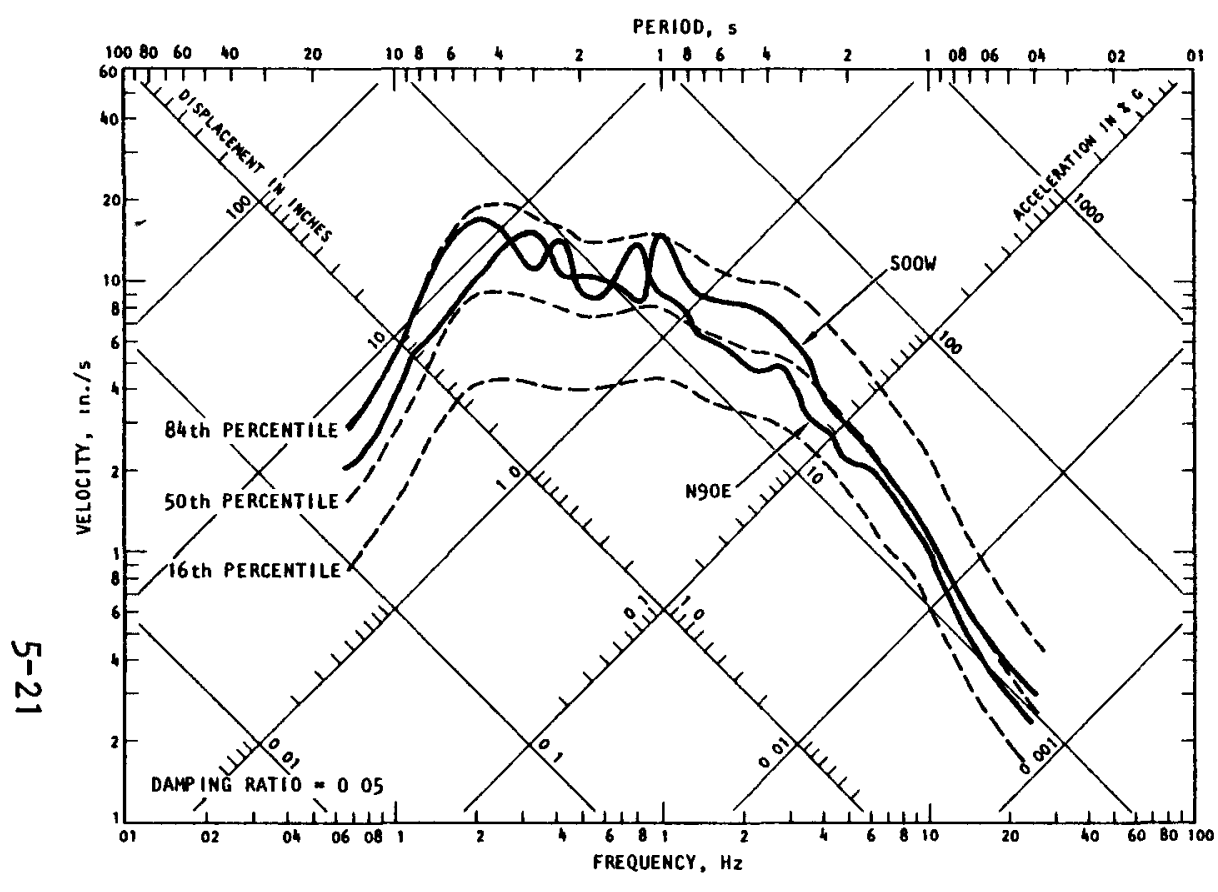

(a) Horizontal

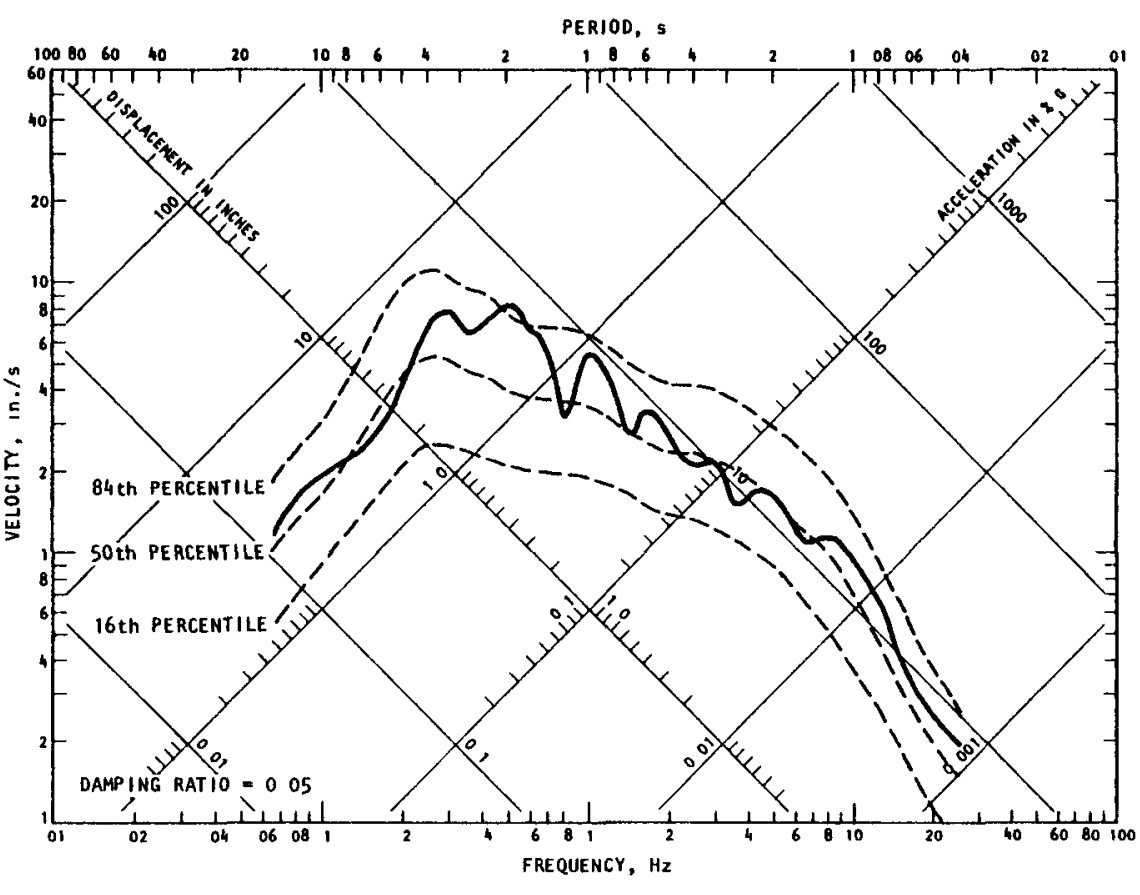

(b) Vertical

LEGEND

--- COMPUTED (MAGNITUDE $=6.4 ;$ DISTANCE $=40.0 \mathrm{~km}$, SITE CONDITION $=$ INTERMEDIATE)

FIGURE 5-3. COMPARISON BETWEEN COMPUTED AND RECORDED GROUND RESPONSE SPECTRA FOR TYPE 1 EARTHQUAKE EVENT (3345 Wilshire Blvd, 1971) 


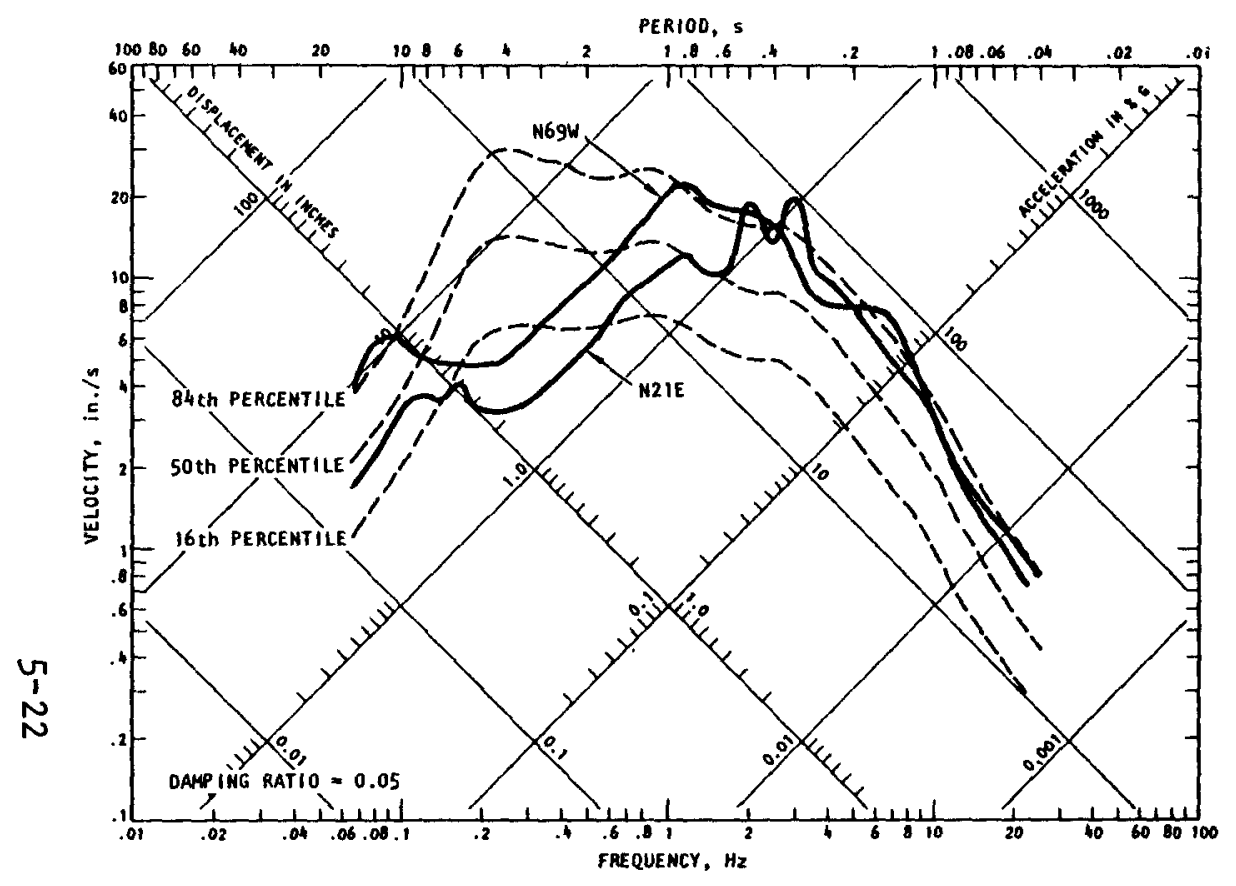

(a) Horizontal

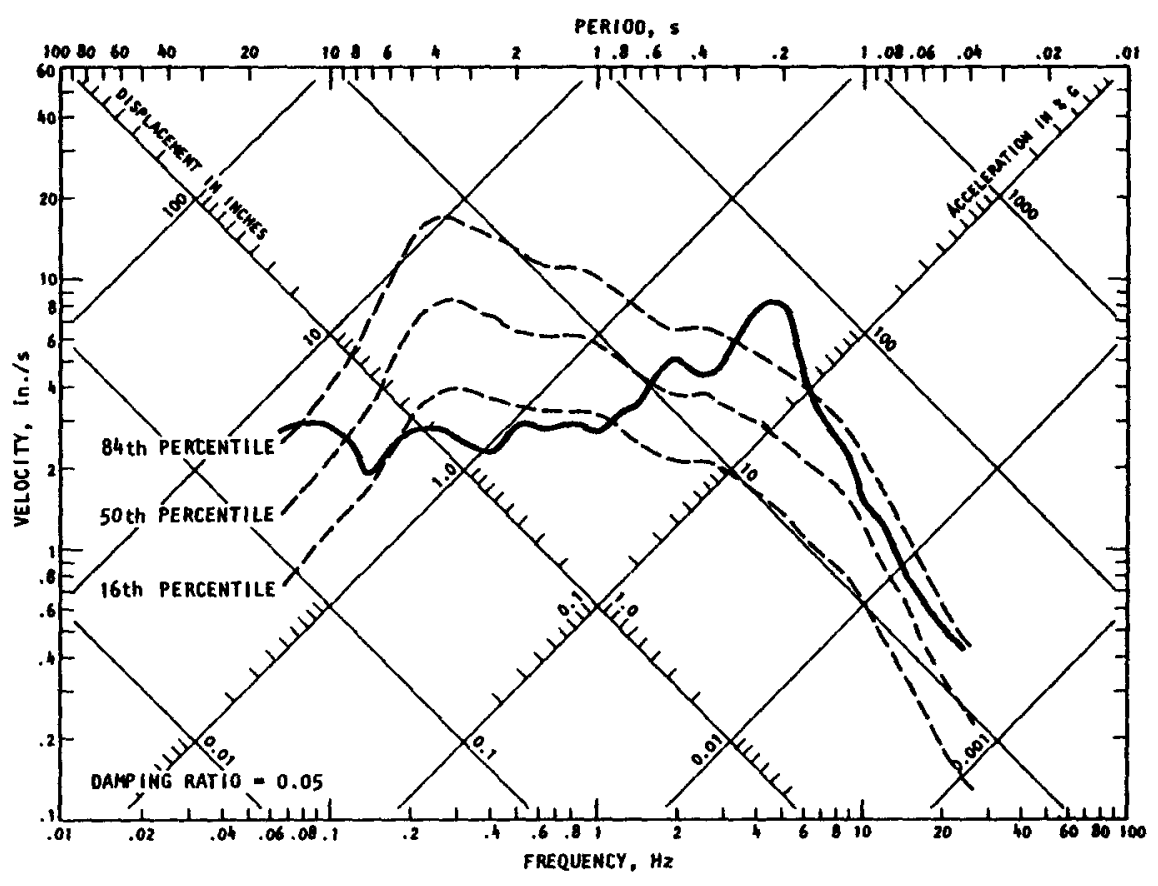

(b) Vertical

LEGEND

RECORDED (CASTAIC, 1971)

--- COMPUTEO (MAGNITUDE $=6.4 ;$ OISTANCE $=28.6 \mathrm{~km} ;$ SITE CONDITION $=$ (NTERMEDIATE)

FIGURE 5-4. COMPARISON BETWEEN COMPUTED AND RECORDED GROUND RESPONSE SPECTRA FOR TYPE 1 EARTHQUAKE EVENT (Castaic, 1971) 


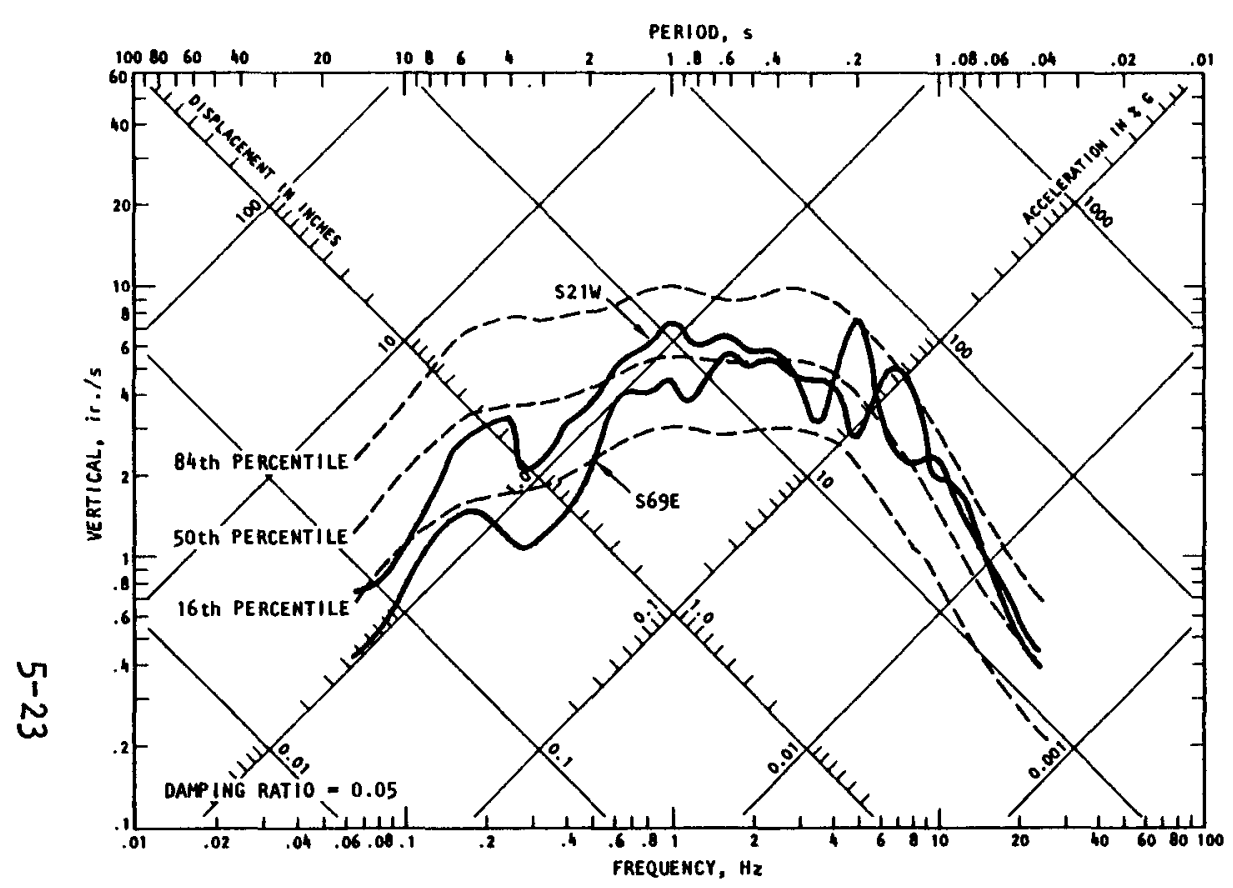

(a) Horizontal

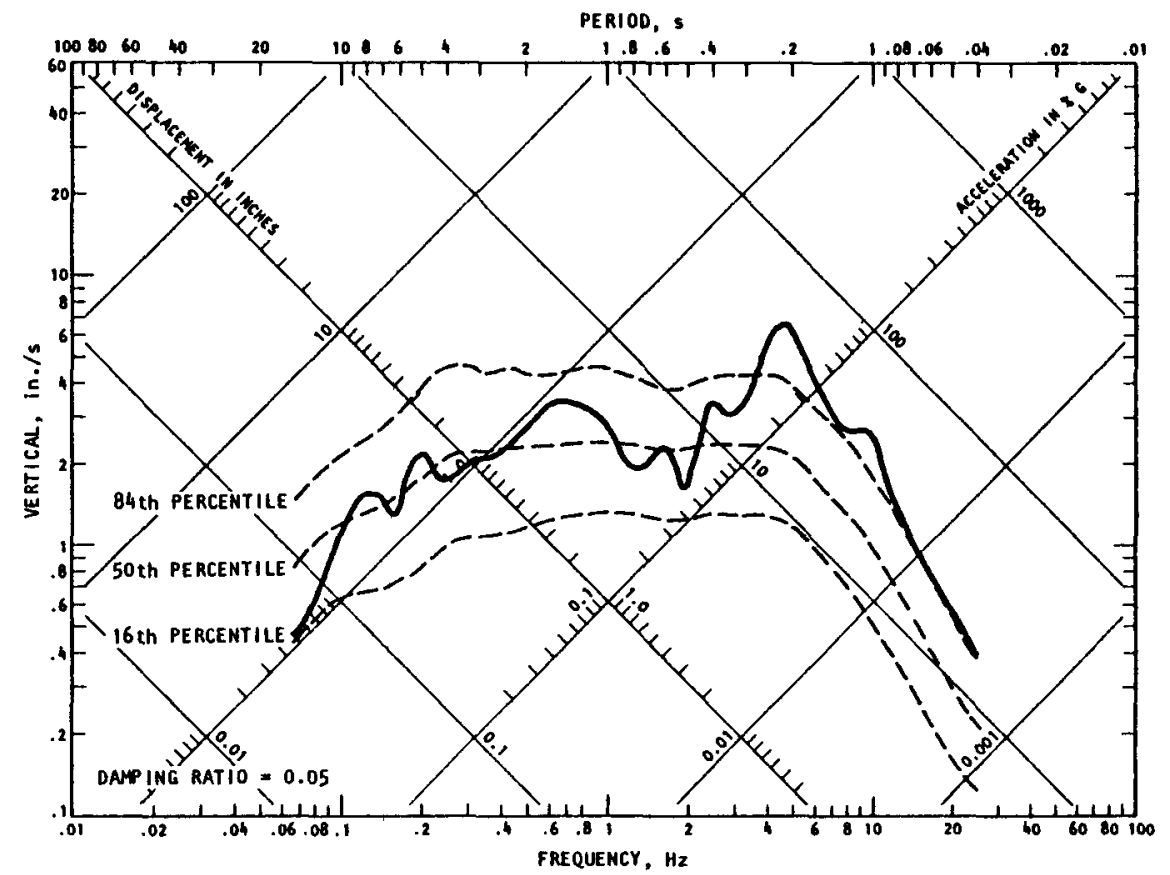

(b) Vertical

LEGEND 


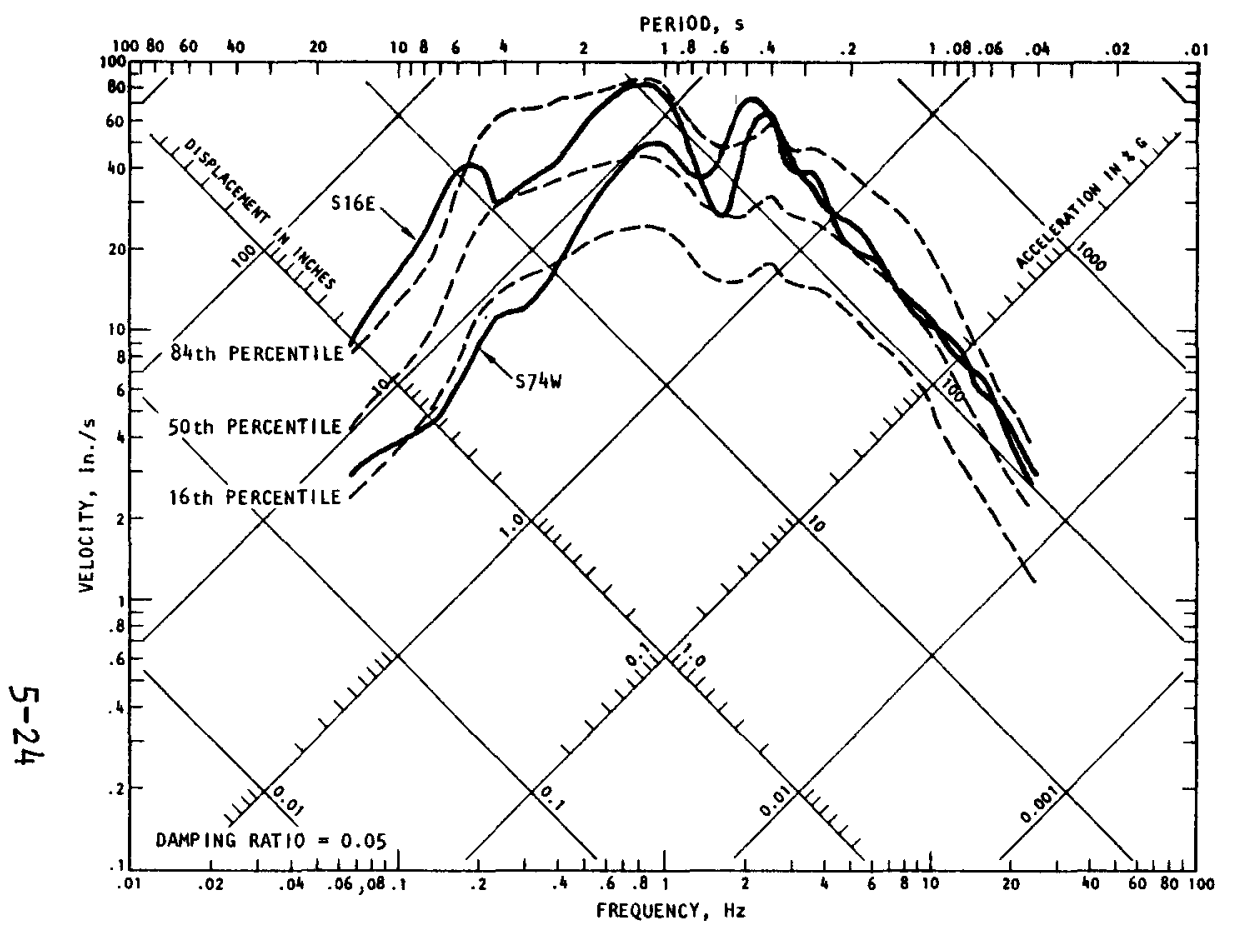

(a) Horizontal

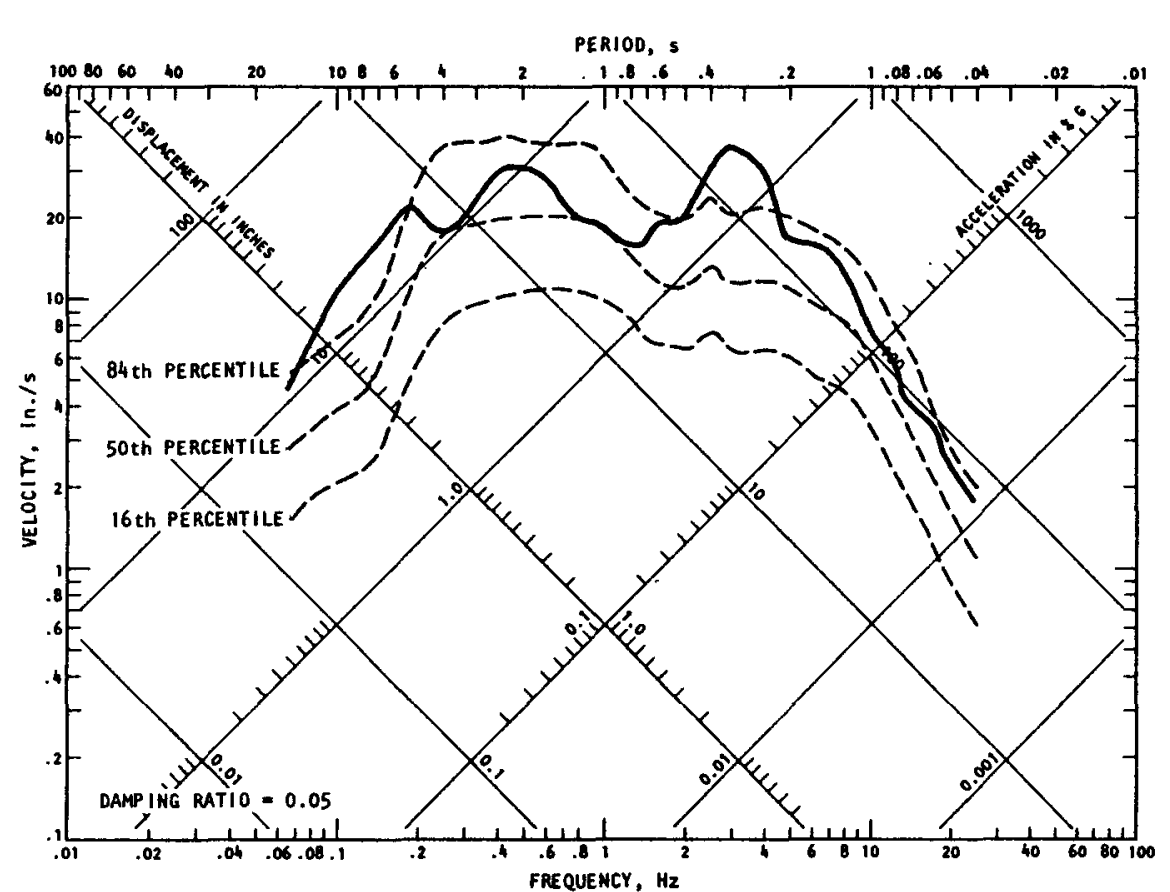

(b) Vertical

LEGEND

FIGURE 5-6. COMPARISON BETWEEN COMPUTED AND RECORDED GROUND RESPONSE SPECTRA FOR TYPE 1 EARTHQUAKE EVENT (Pacoima Dam, 1971) 


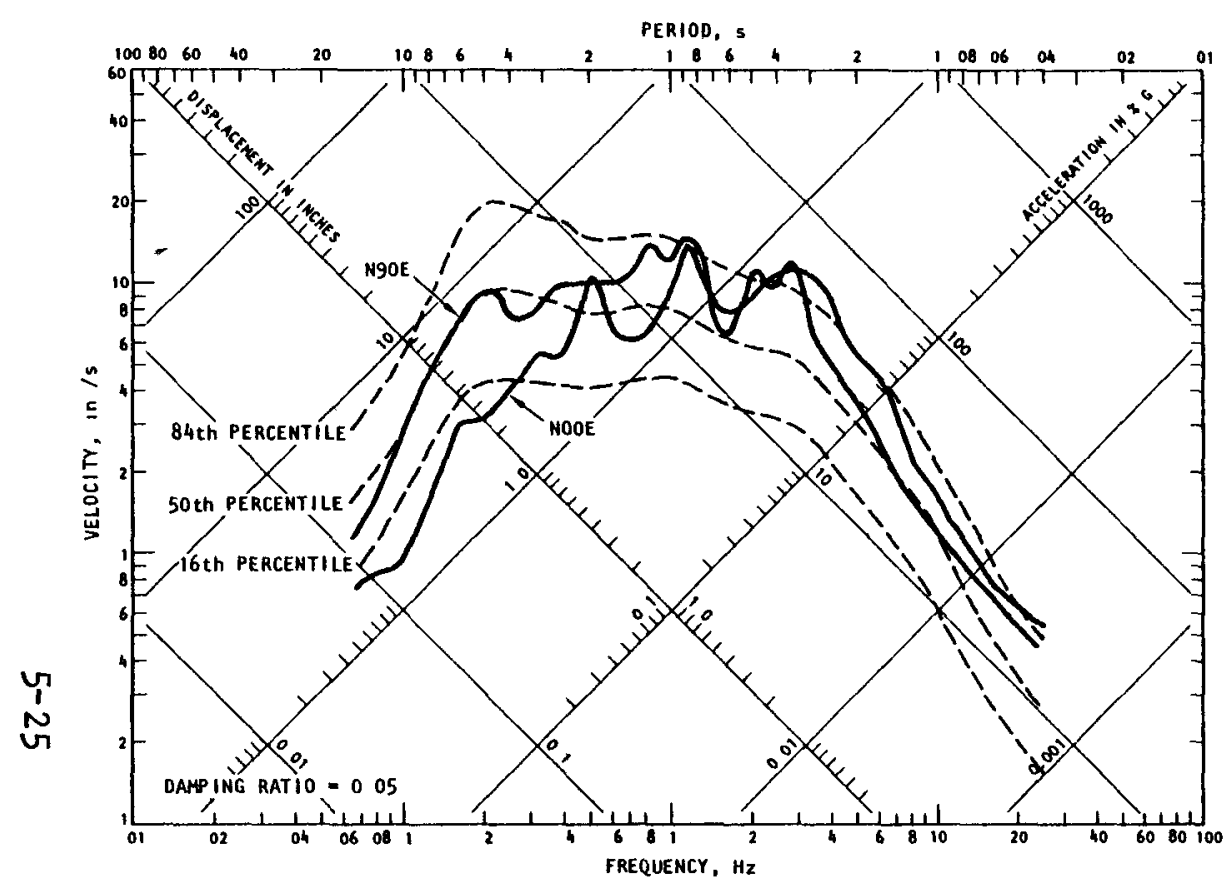

(a) Horizontal

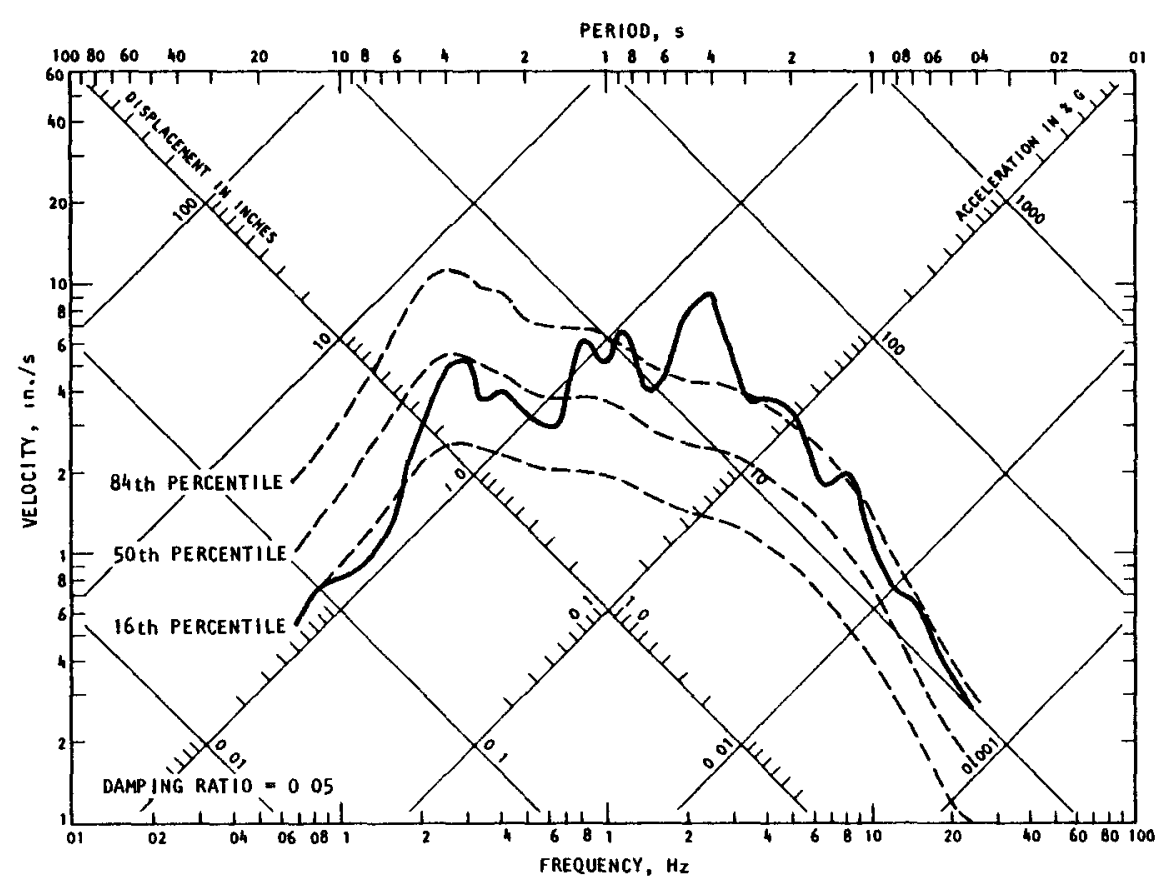

(b) Vertical

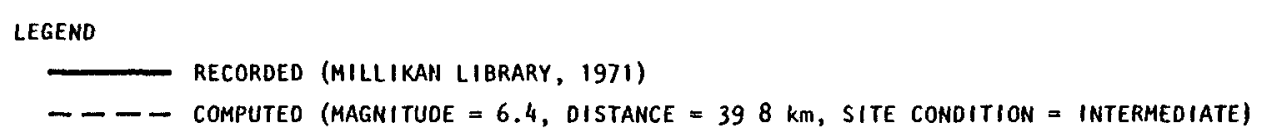

FIGURE 5-7. COMPARISON BETWEEN COMPUTED AND RECORDED GROUND RESPONSE SPECTRA FOR TYPE 1 EARTHQUAKE EVENT (Millikan Library, 1971) 


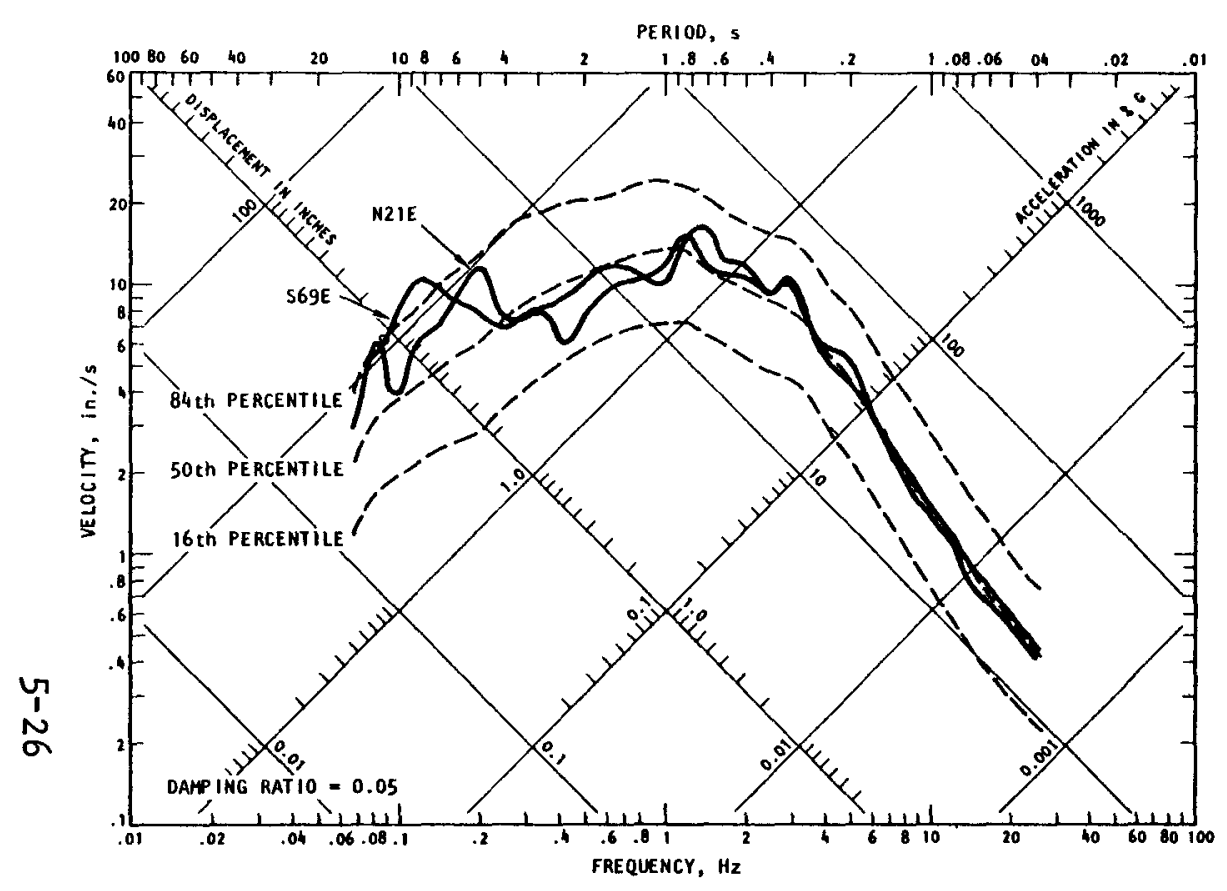

(a) Horizontal

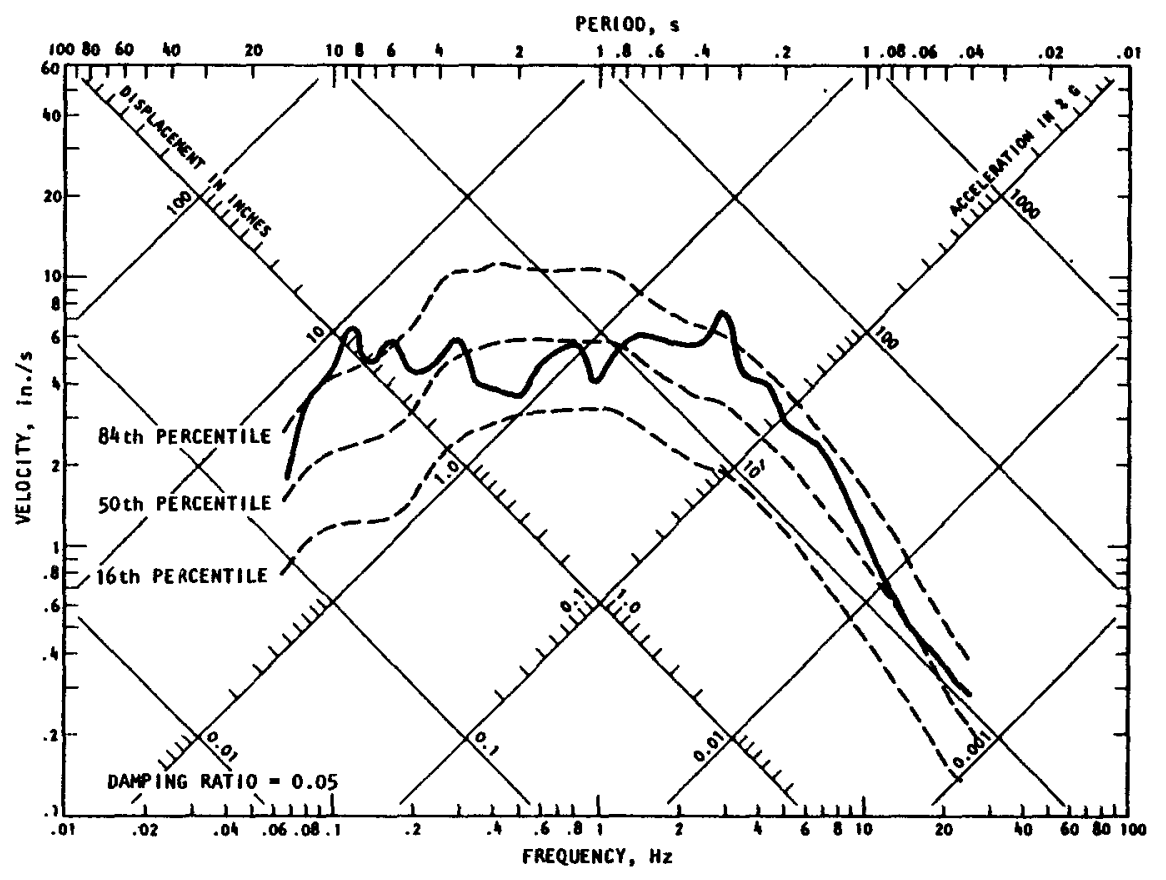

(b) Vertical

LEGEND

- RECORDED (TAFT LINCOLN SCHOOL, 1952)

- - - COMPUTEd (MAGNITUde $=7.7 ;$ DISTANCE $=43.0 \mathrm{~km} ;$ SITE CONDITION = INTERMEDIATE)

FIGURE 5-8. COMPARISON BETWEEN COMPUTED AND RECORDED GROUND RESPONSE SPECTRA FOR TYPE 2 EARTHQUAKE EVENT (Taft Lincoln School, 1952) 


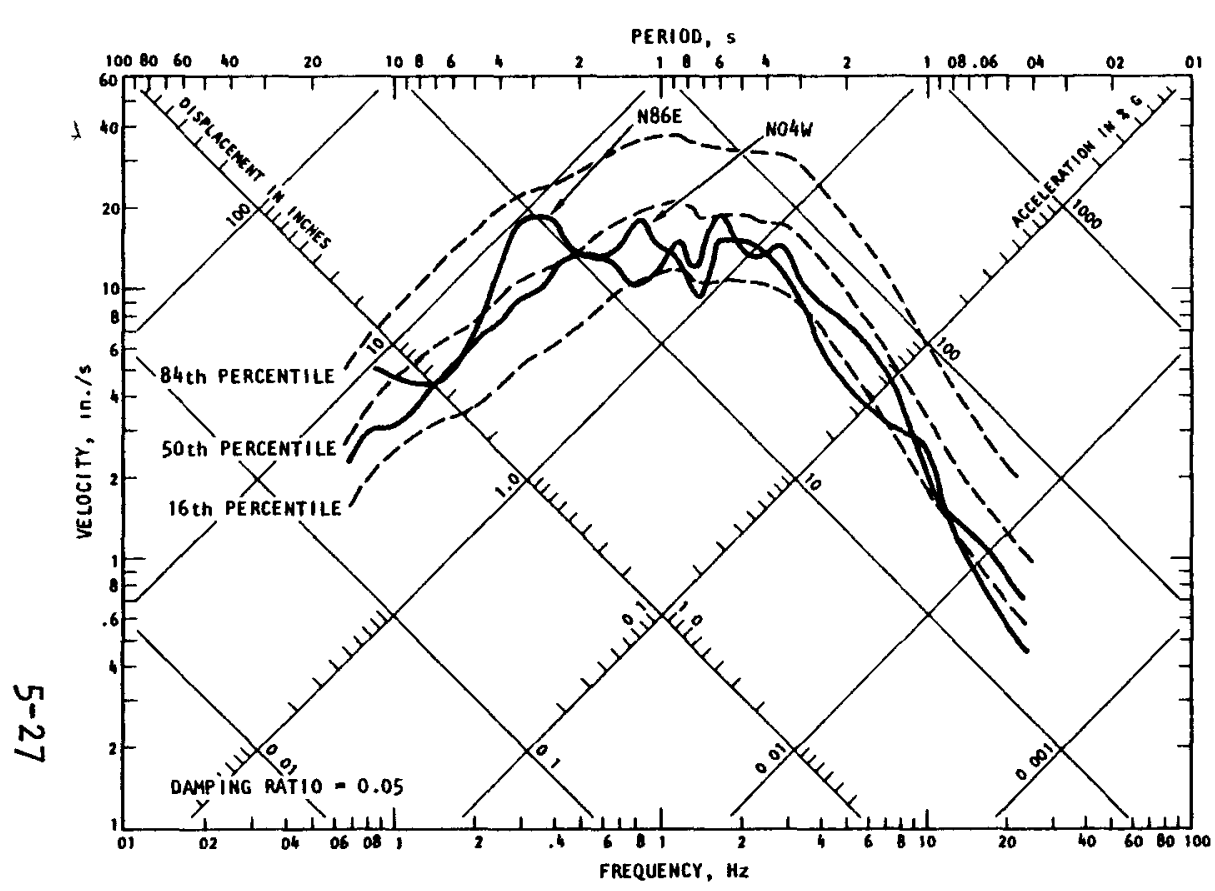

(a) Horizontal

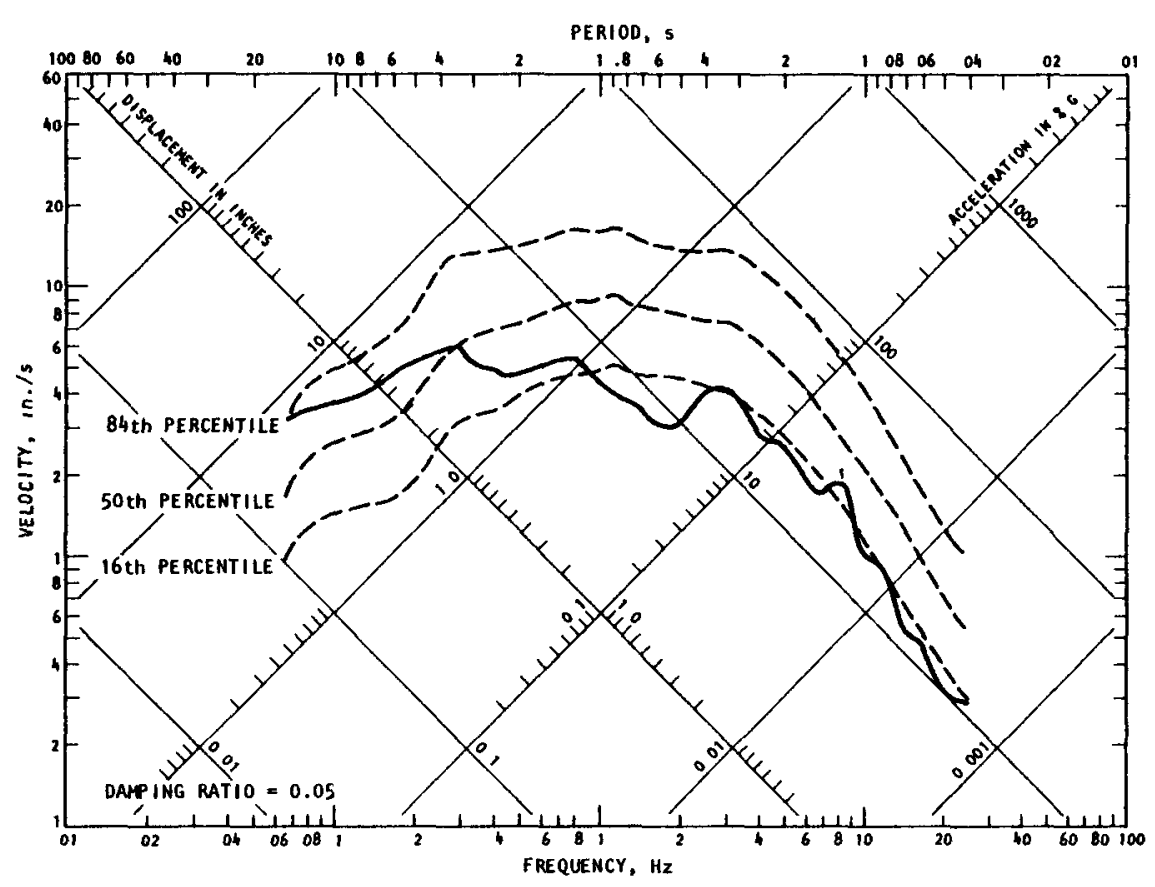

(b) Vertical

\section{LEGEND}

- RECORDED (OLYMPIA HIGHWAY TEST LABORATORY, 1949)

- - COMPUTED (MAGNITUDE $=7.1$; DISTANCE $=16.8 \mathrm{~km} ;$ SITE CONDITION - DEEP SOIL)

FIGURE 5-9. COMPARISON BETWEEN COMPUTED AND RECORDED GROUND RESPONSE SPECTRA FOR TYPE 2 EARTHQUAKE EVENT (Olympia Highway Test Laboratory, 1949) 


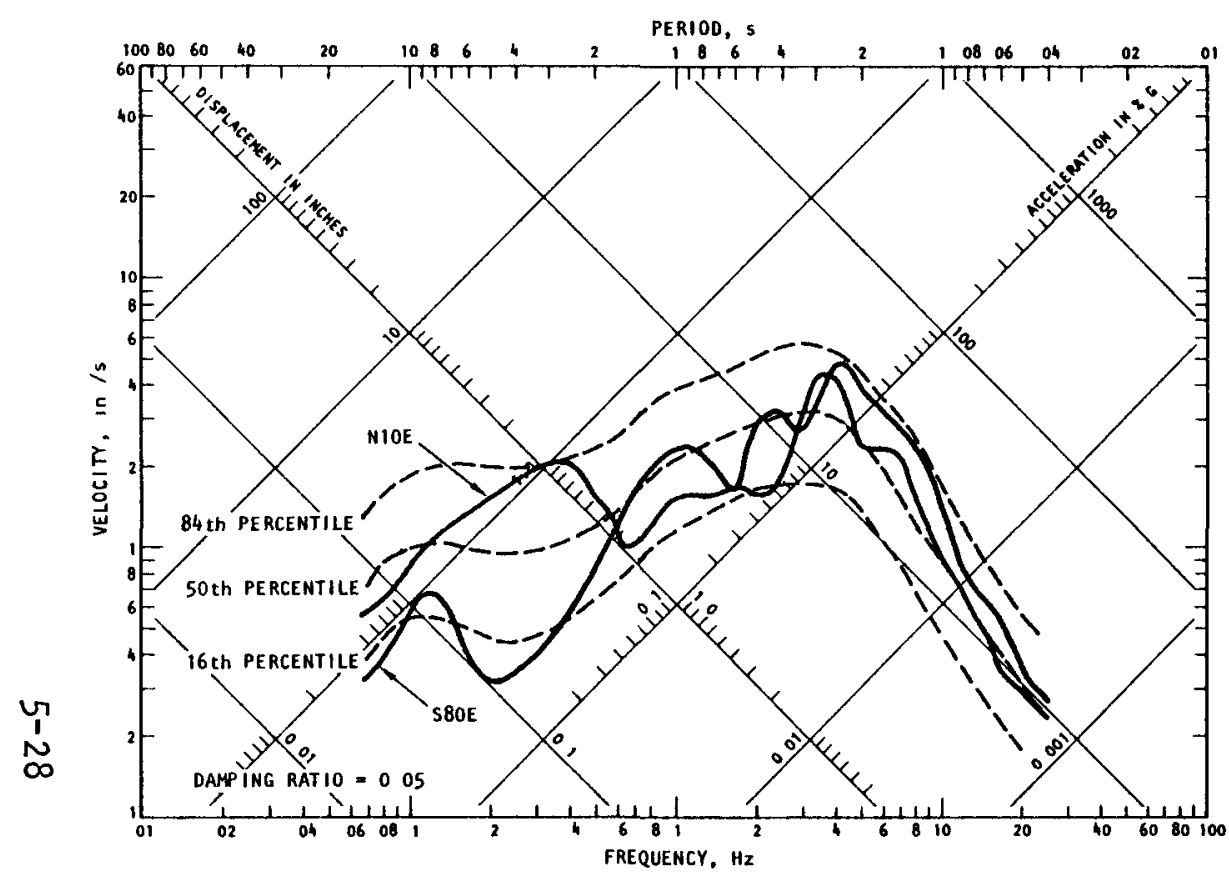

(a) Horizontal

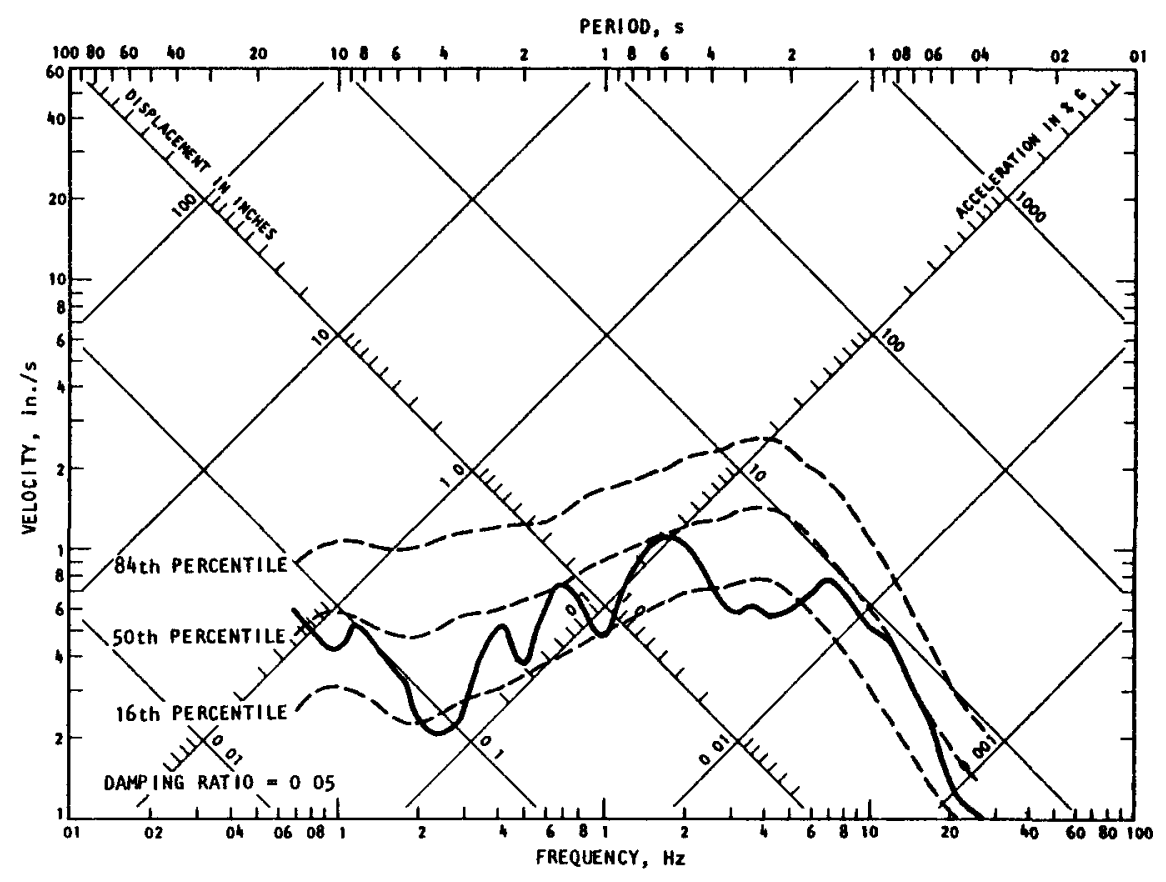

(b) Vertical

LEGEND

RECORDED (GOLDEN GATE PARK, 1957)

- - COMPUTED (MAGNITUDE $=5.3 ;$ DISTANCE $=11.8 \mathrm{~km}$; SITE CONDITION $=$ ROCK)

FIGURE 5-10. COMPARISON BETWEEN COMPUTED AND RECORDED GROUND RESPONSE SPECTRA FOR TYPE 2 EARTHQUAKE EVENT (Golden Gate Park, 1957) 


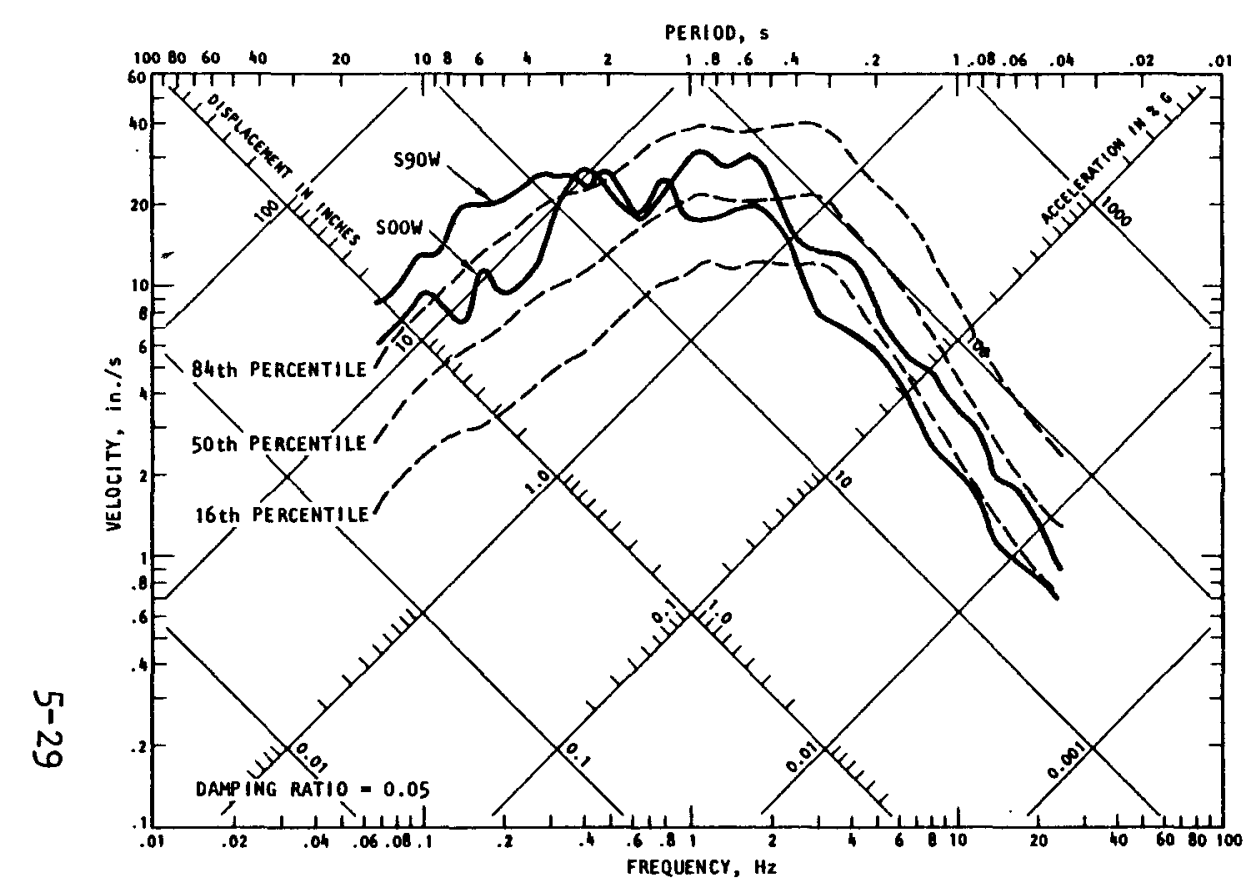

(a) Horizontal

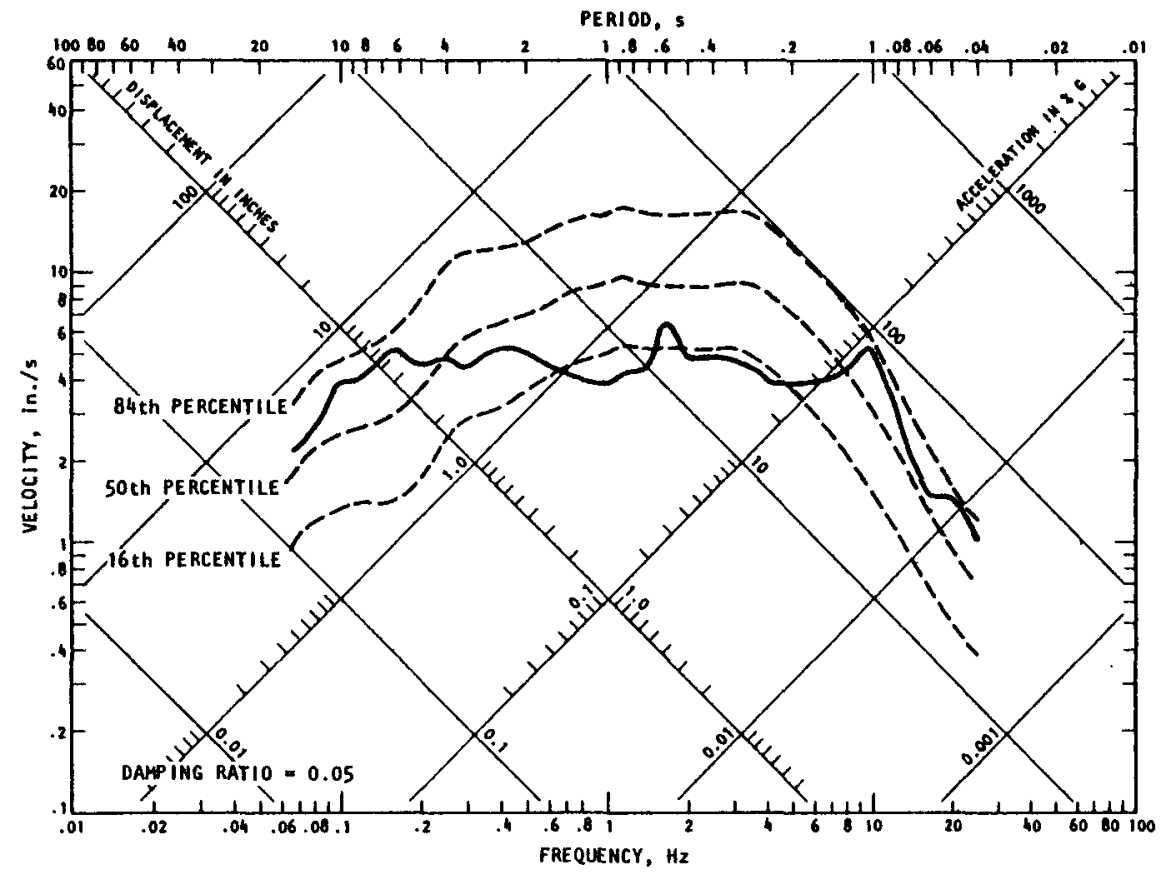

(b) Vertical

LEGEND

RECORDED (EL CENTRO TERMINAL SUBSTATION, 1940)

--- COMPUTED (MAGNITUDE $=6.4$; DISTANCE $=9.3 \mathrm{~km}$; SITE CONDITION $=$ DEEP, SOIL)

FIGURE 5-11. COMPARISON BETWEEN COMPUTED AND RECORDED GROUND RESPONSE SPECTRA FOR TYPE 2 EARTHQUAKE EVENT (El Centro Terminal Substation, 1940) 


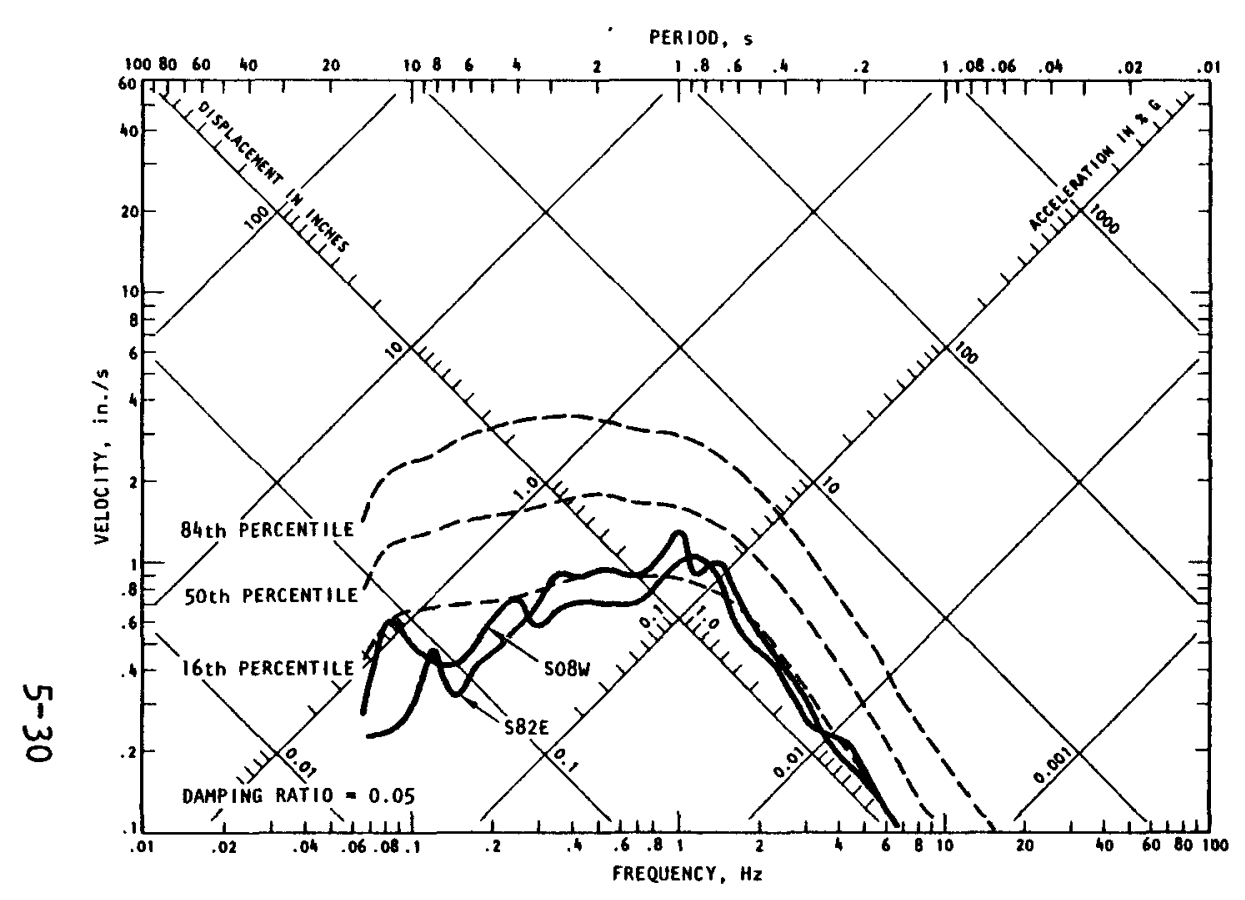

(a) Horizontal

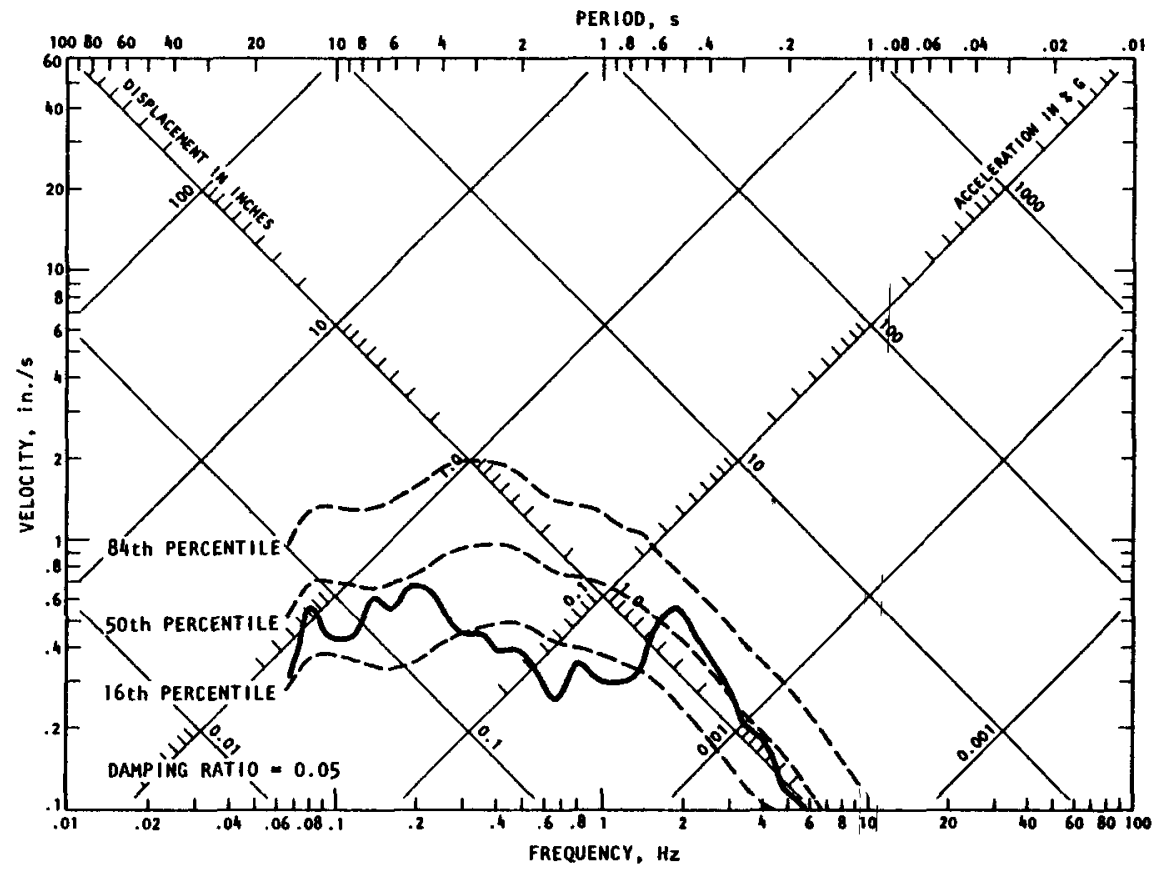

(b) Vertical

LEGEND

RECORDED (JET PROPULSION LABORATORY, 1968)

- - COMPUTED (MAGNITUDE $=6.4$; DISTANCE $=220.3 \mathrm{~km}$; SITE CONDITION $=$ INTERMEDIATE)

FIGURE 5-12. COMPARISON BETWEEN COMPUTED AND RECORDED GROUND RESPONSE SPECTRA FOR TYPE 2 EARTHQUAKE EVENT (Jet Propulsion Laboratory, 1968) 


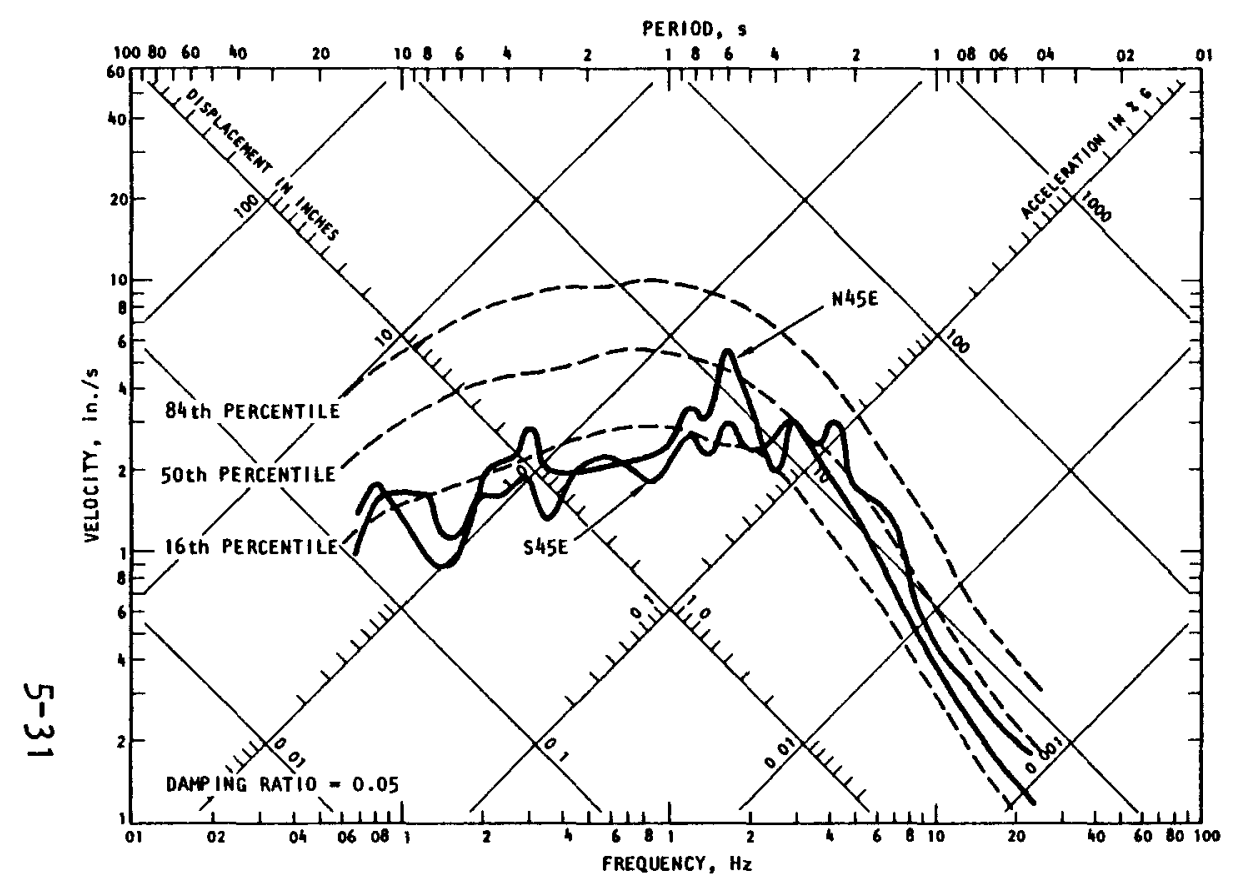

(a) Horizontal

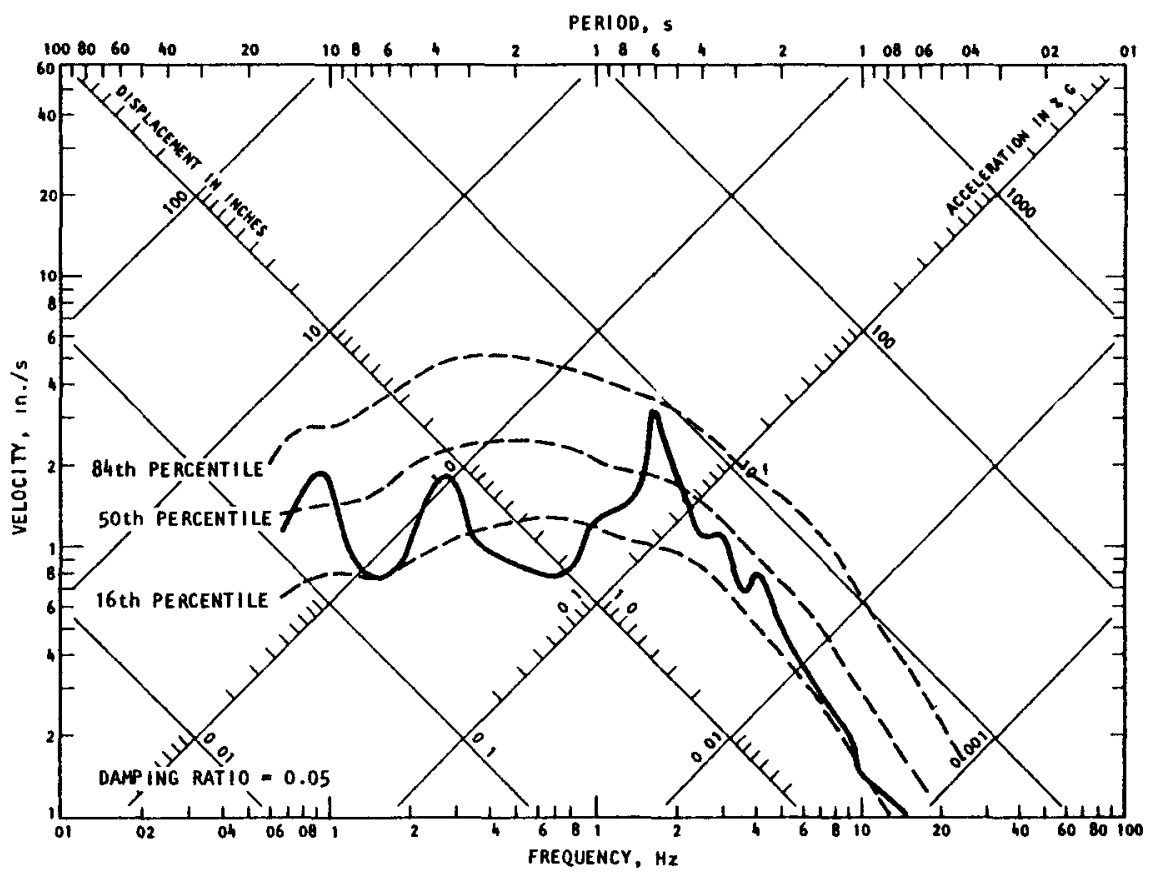

(b) Vertical

\section{LEGEND}

RECORDED (FERNDALE, 1941)

- - COMPUTED (MAGNITUDE $=6.4 ;$ DISTANCE $=98.3 \mathrm{~km} ;$ SITE CONDITION $=$ DEEP SOIL)

FIGURE 5-13. COMPARISON BETWEEN COMPUTED AND RECORDED GROUND RESPONSE SPECTRA FOR TYPE 2 EARTHQUAKE EVENT (Ferndale, 1941) 


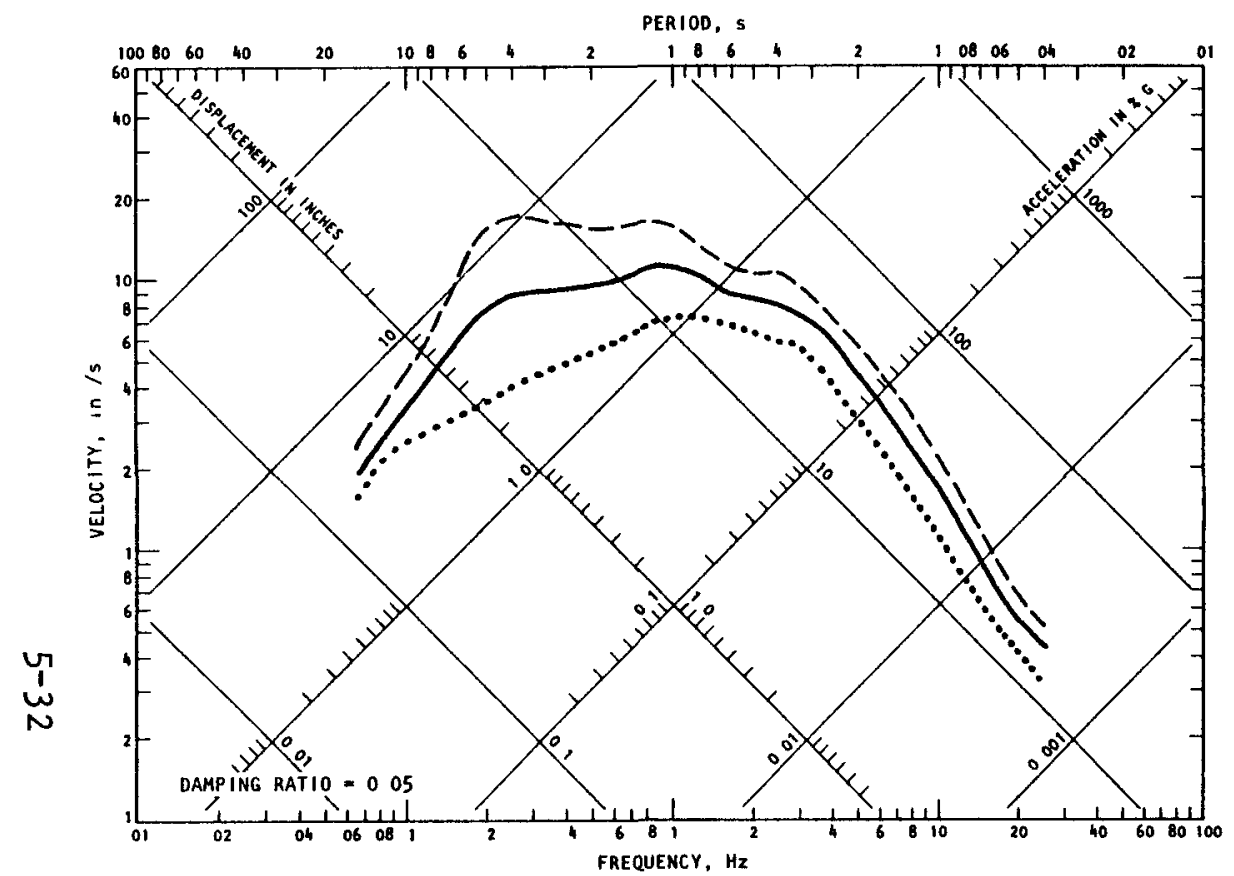

(a) Distance $=25 \mathrm{~km}$

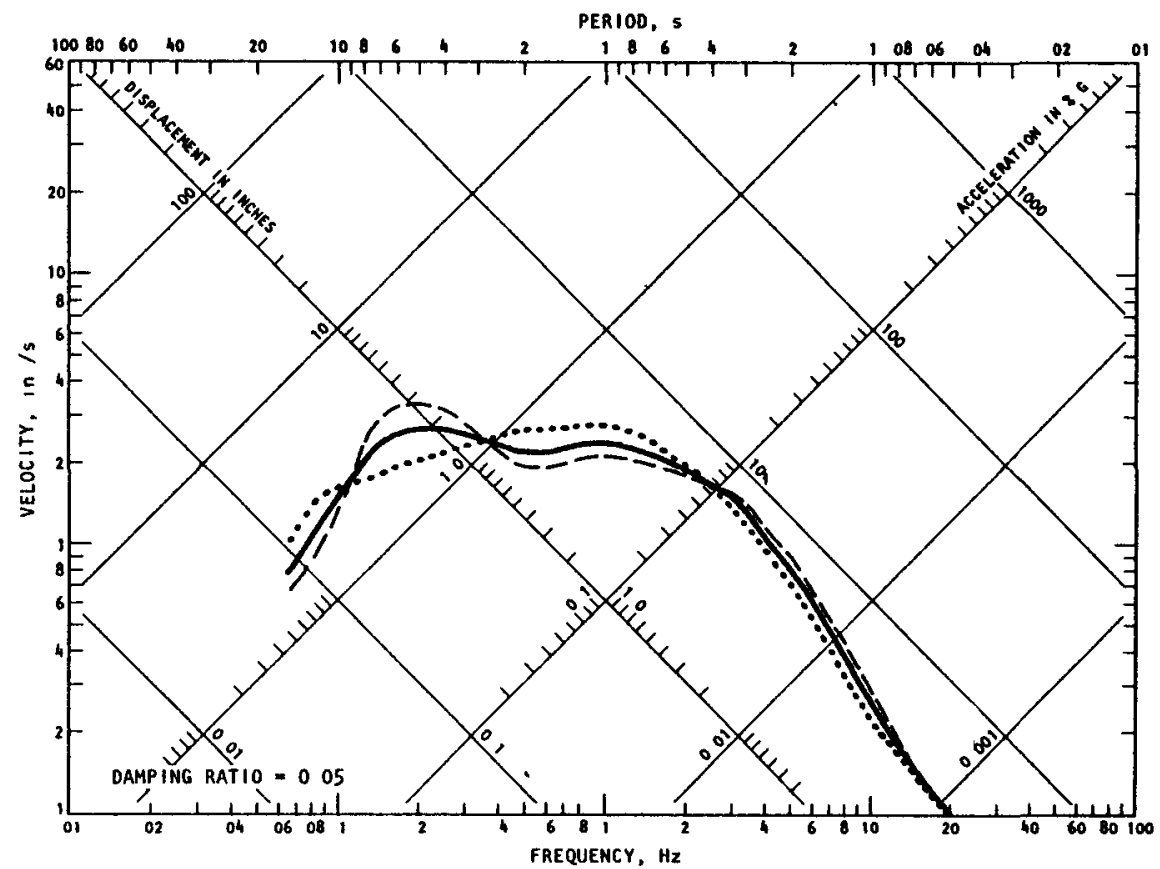

(b) Distance $=100 \mathrm{~km}$

LEGENO

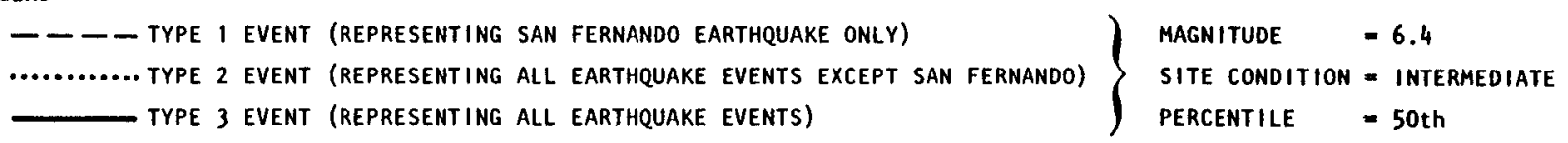

FIGURE 5-14. EFFECT OF EARTHQUAKE EVENT TYPE ON HORIZONTAL GROUND RESPONSE SPECTRA 


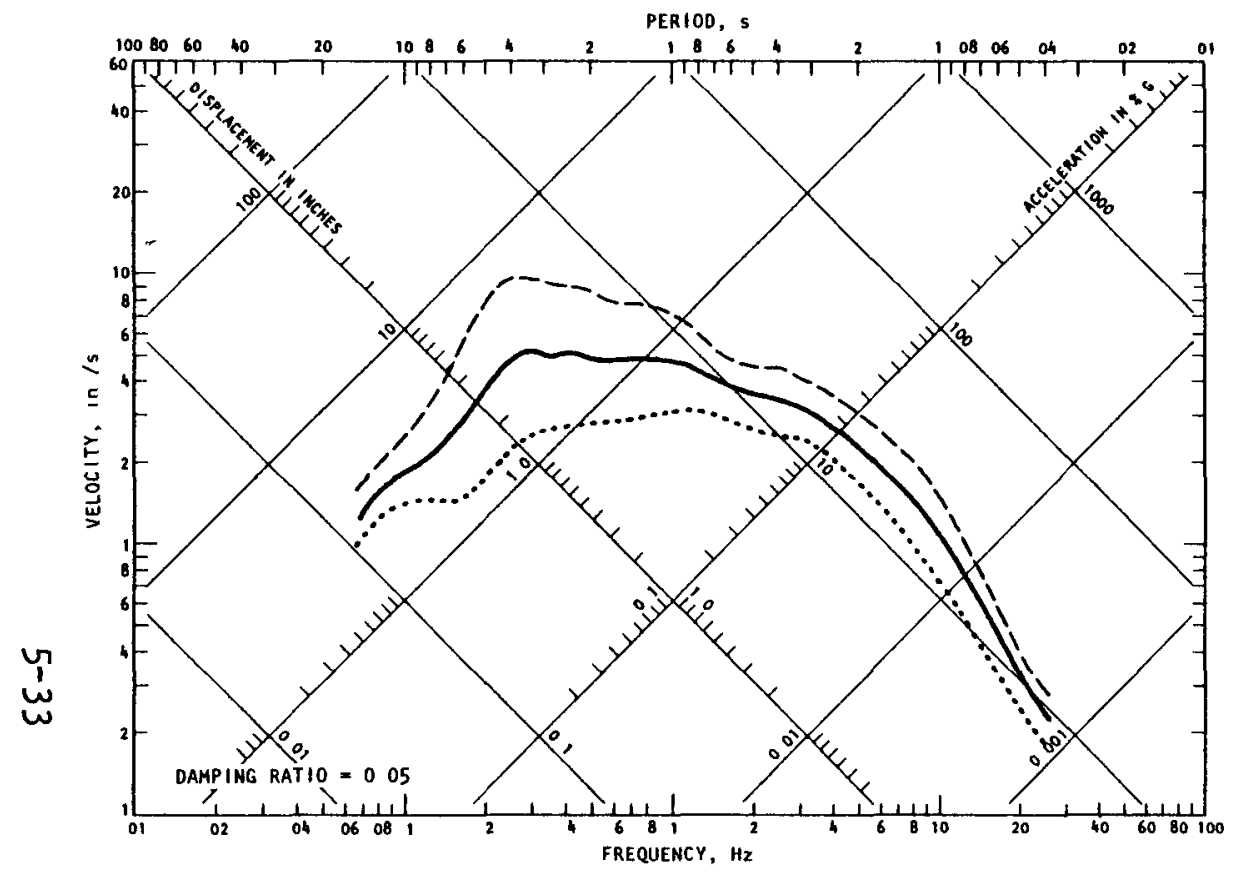

(a) Distance $=25 \mathrm{~km}$

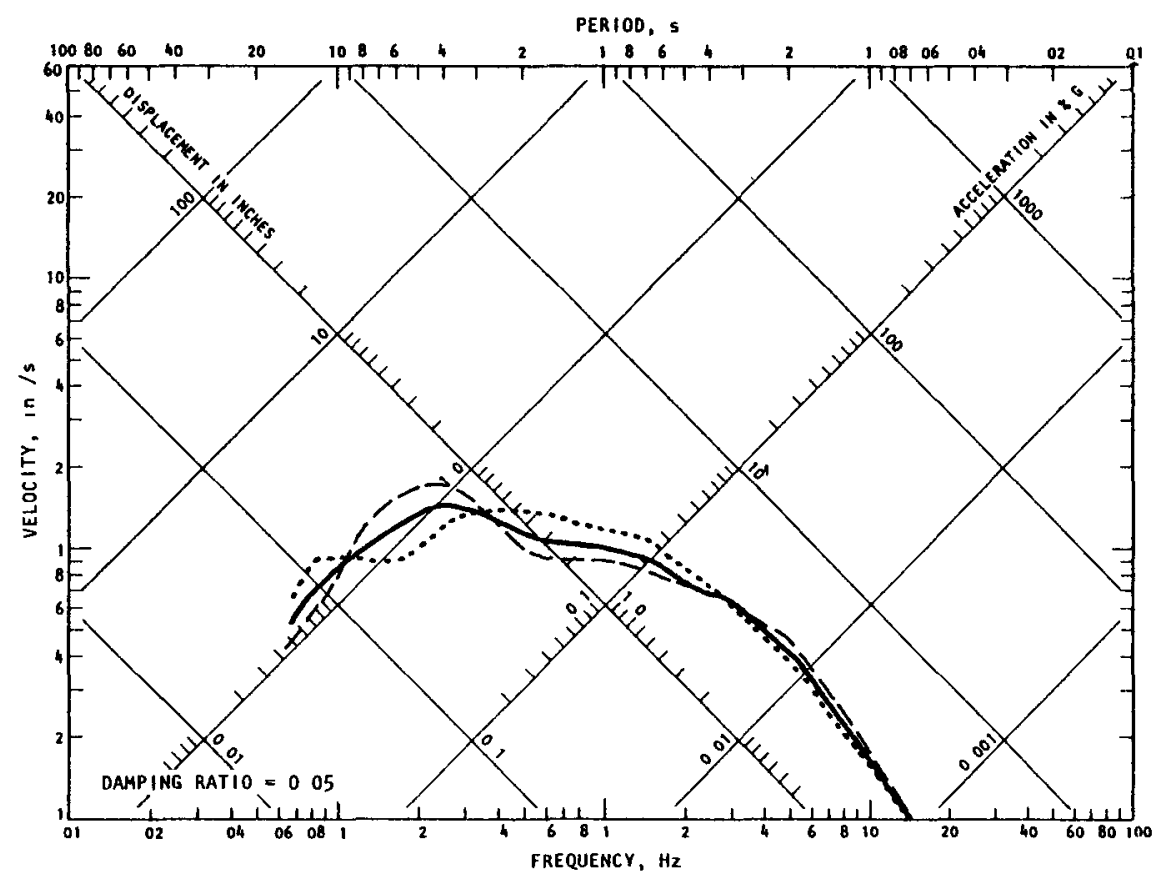

(b) Distance $=100 \mathrm{~km}$

LEGEND

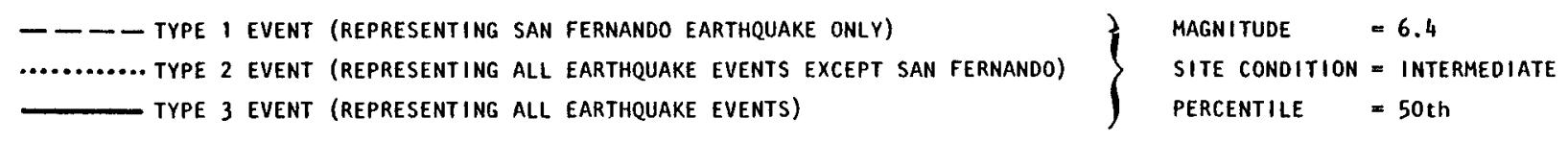

FIGURE 5-15. EFFECT OF EARTHQUAKE EVENT TYPE ON VERTICAL GROUND RESPONSE SPECTRA 


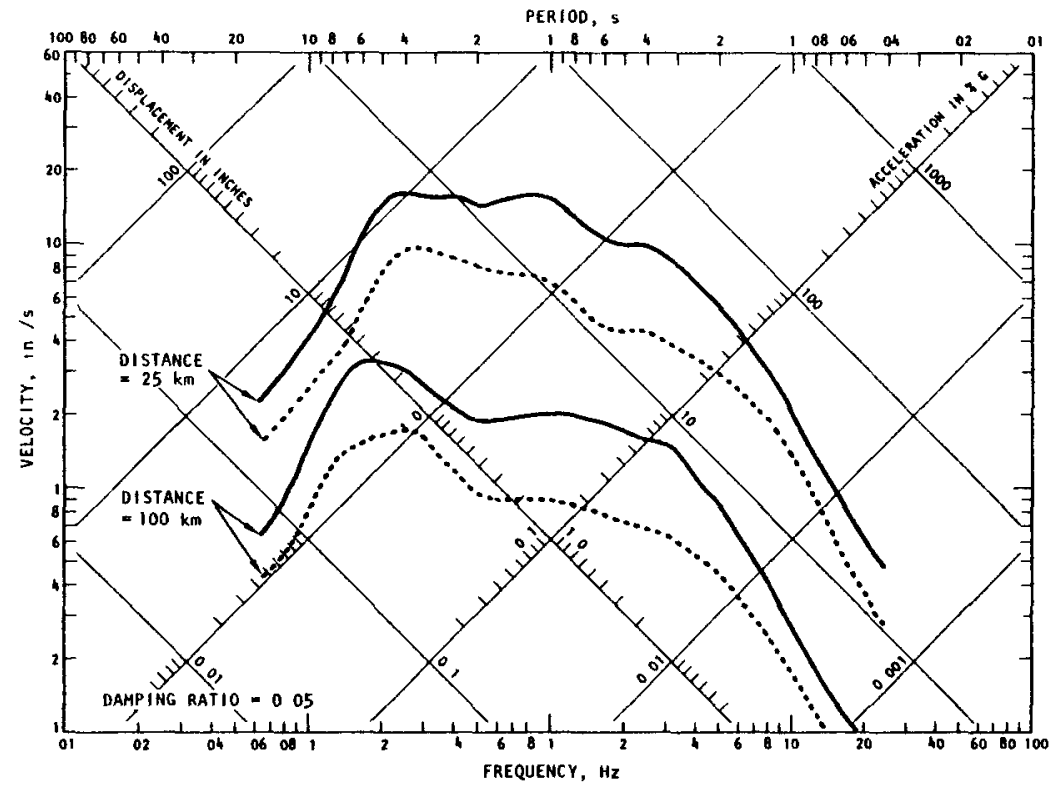

(a) Type 1 event

$\underset{w}{\underline{w}}$

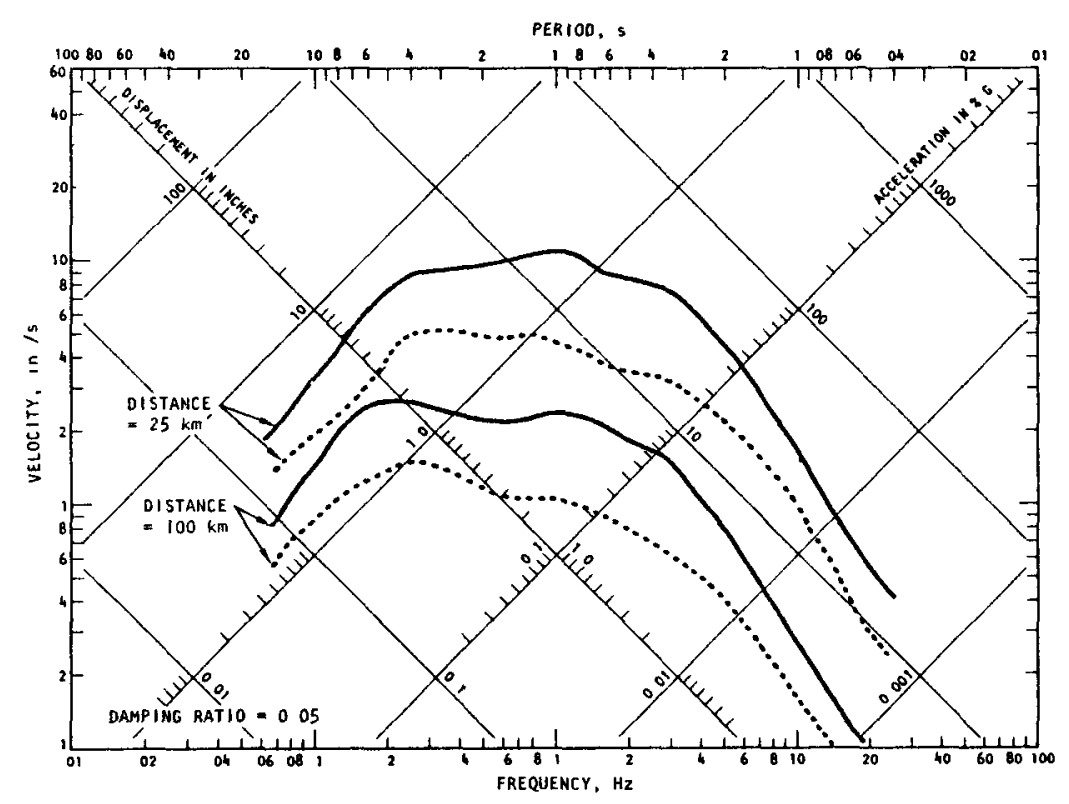

(c) Type 3 event

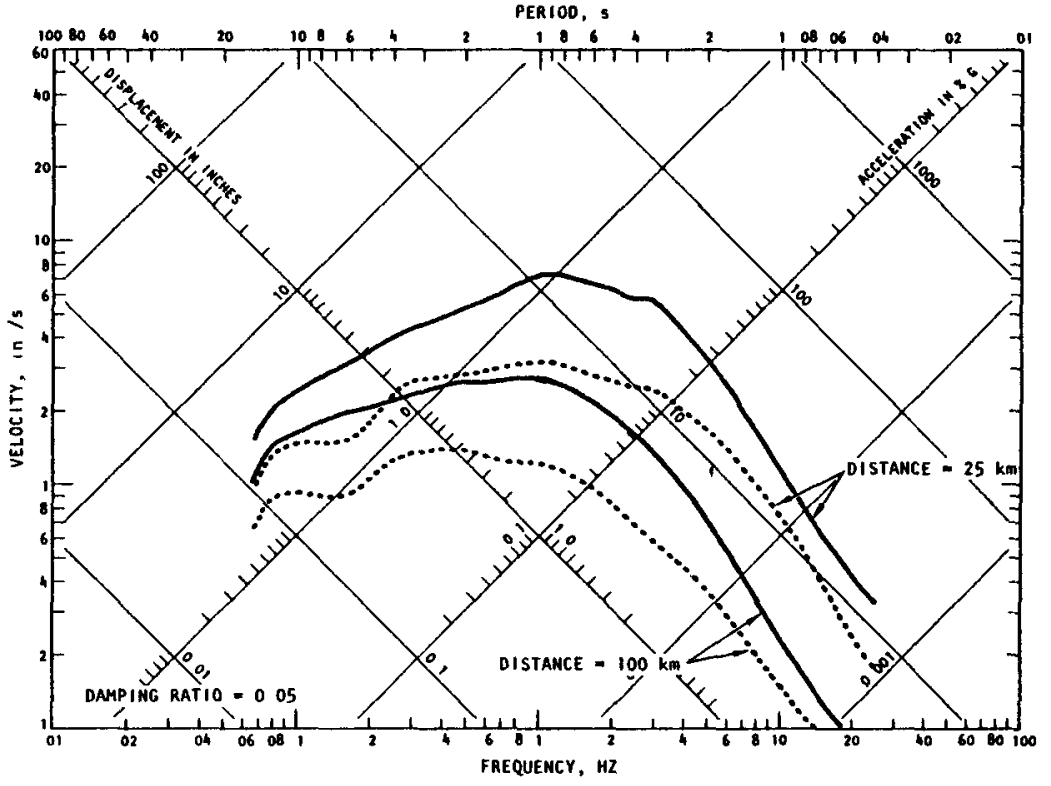

(b) Type 2 event

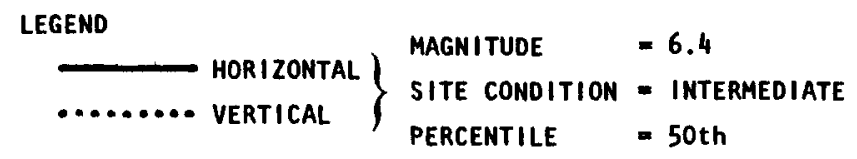

FIGURE 5-16. DISTANCE ATTENUATION OF HORIZONTAL AND VERTICAL GROUND RESPONSE SPECTRA FOR TYPES 1, 2, AND 3 EARTHQUAKE EVENTS. 


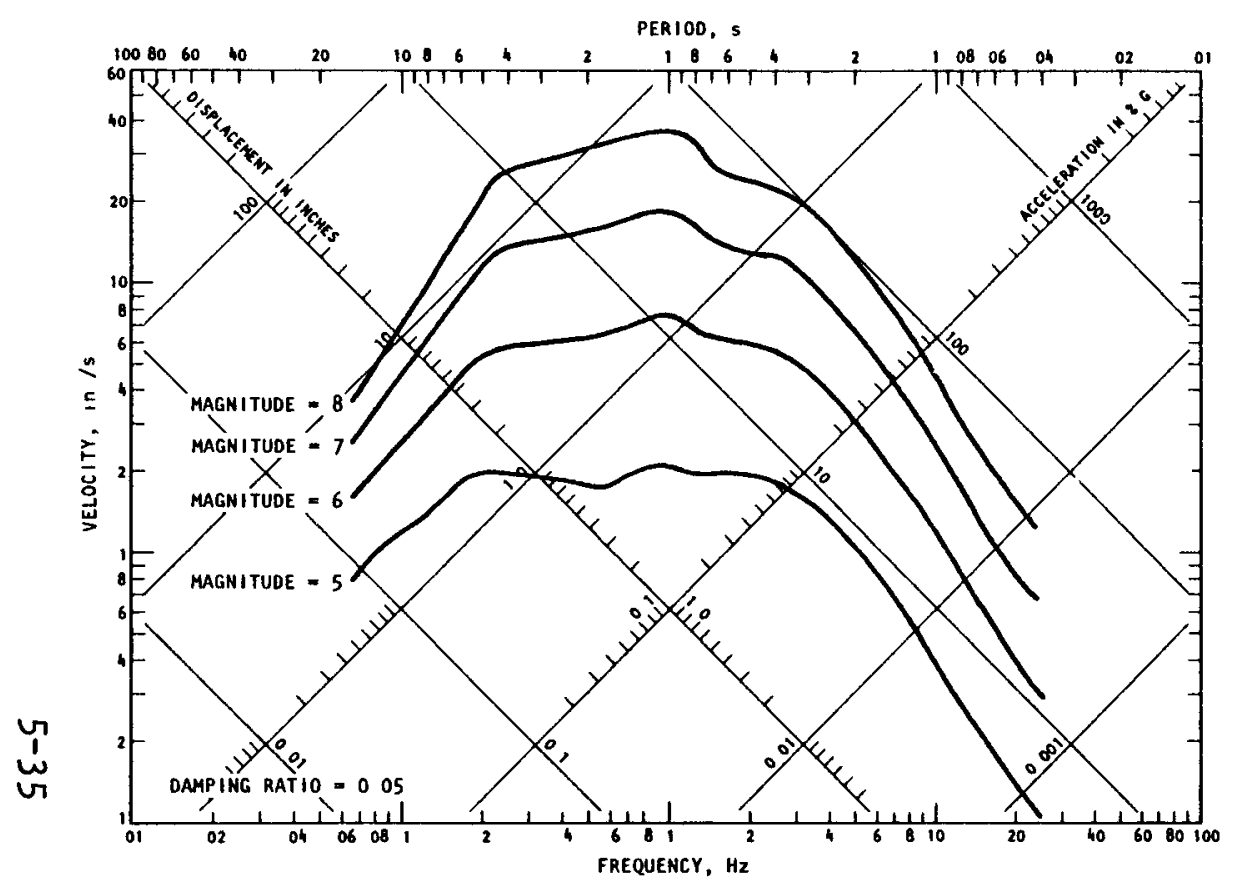

(a) Distance $=25 \mathrm{~km}$

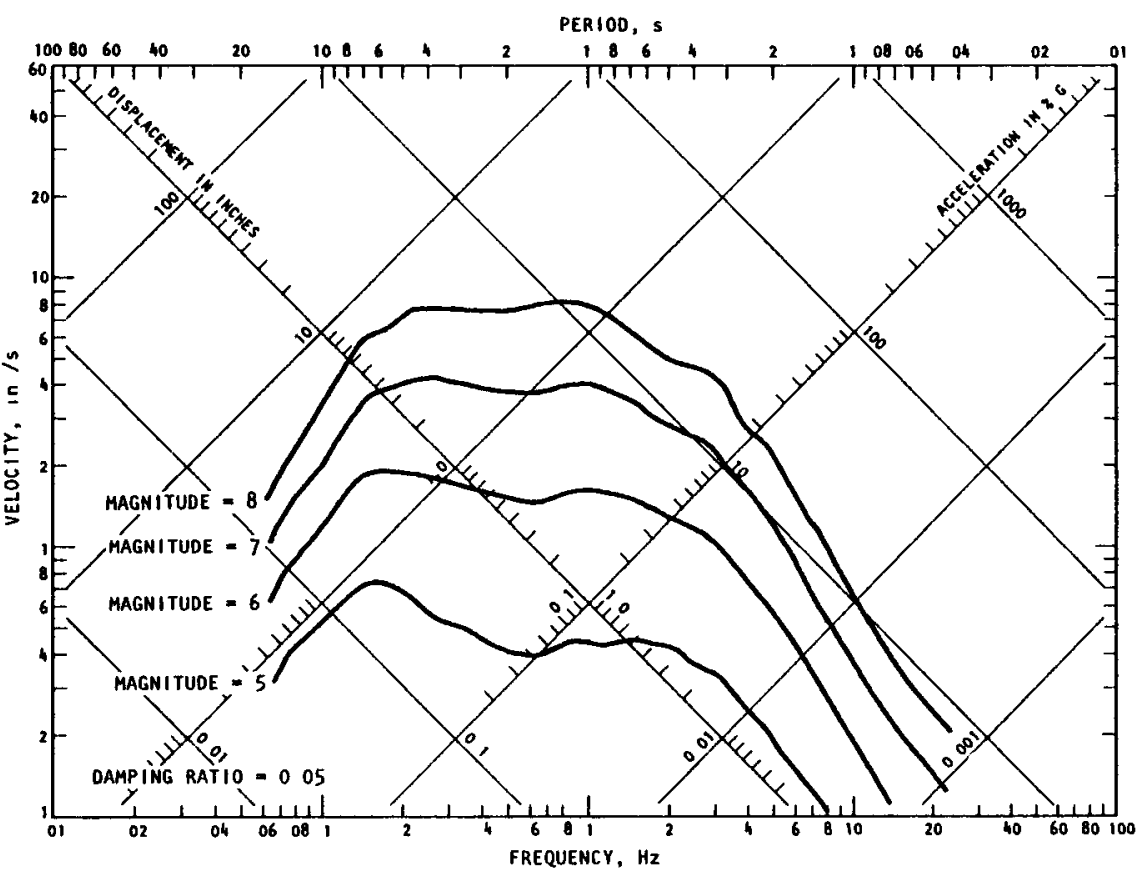

(b) Distance $=100 \mathrm{~km}$

NOTE

EARTHQUAKE EVENT $=$ TYPE 3

SITE CONDITION = INTERMEDIATE

PERCENTILE $=50$ th

FIGURE 5-17. EFFECT OF MAGNITUDE ON HORIZONTAL GROUND RESPONSE SPECTRA 


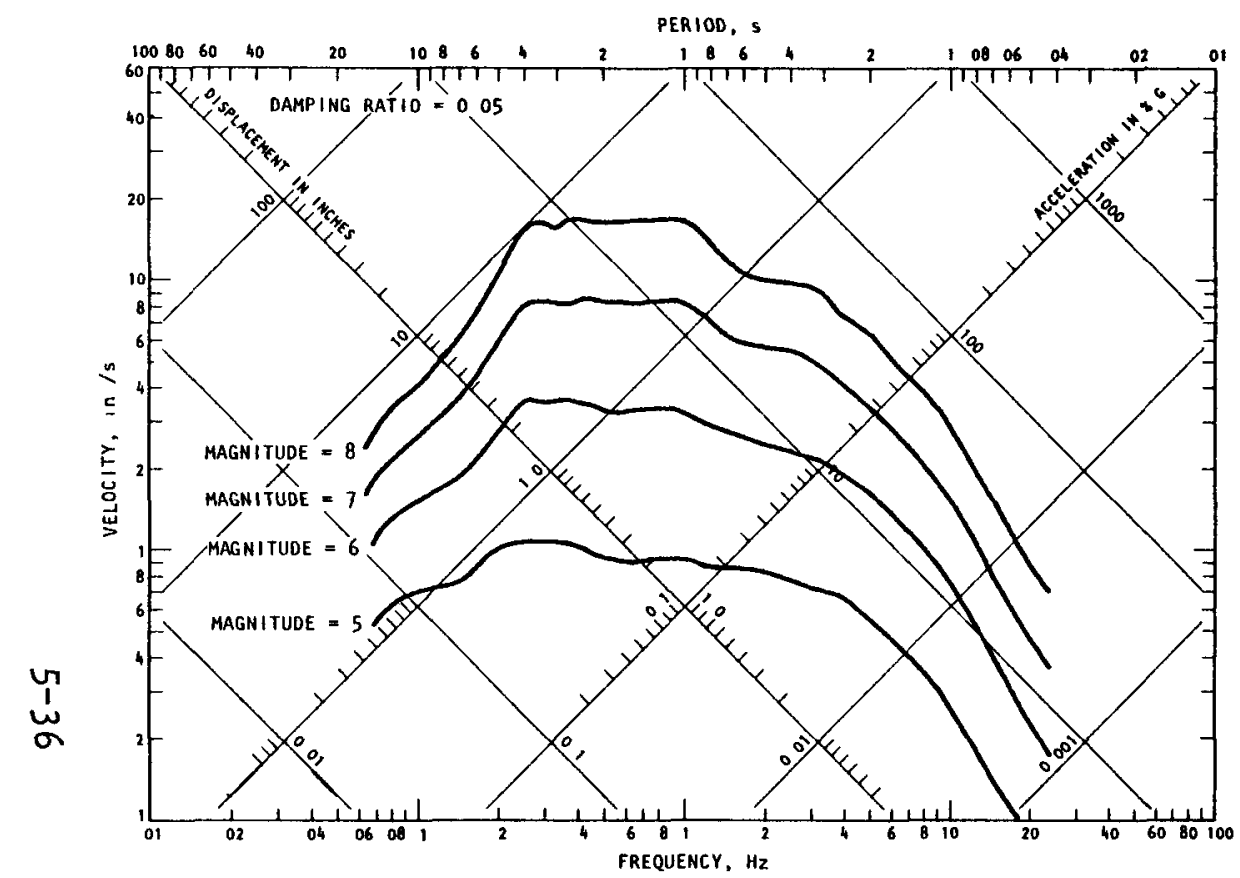

(a) Distance $=25 \mathrm{~km}$

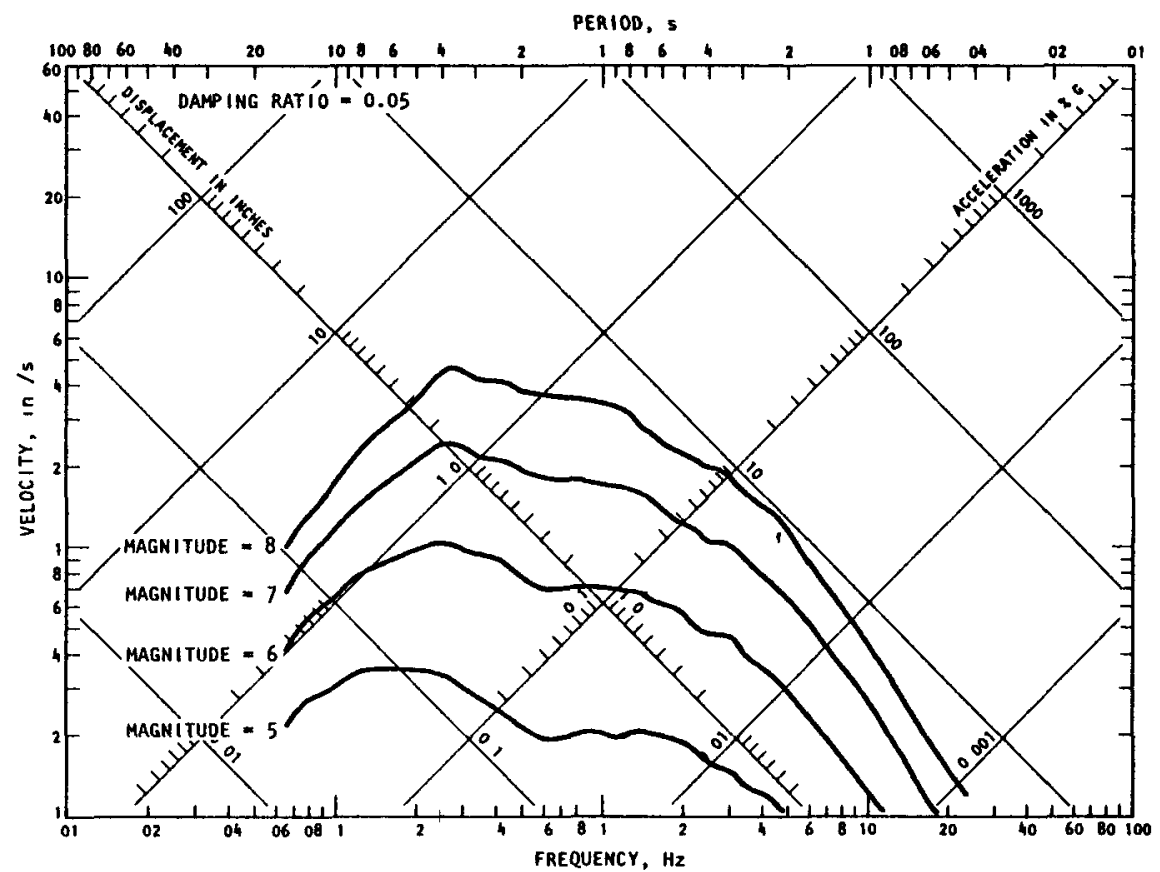

(b) Distance $=100 \mathrm{~km}$

NOTE

\author{
EARTHQUAKE EVENT = TYPE 3 \\ SITE CONDITIONS = INTERMEDIATE \\ PERCENTILE $=50 \mathrm{th}$
}

FIGURE 5-18. EFFECT OF MAGNITUDE ON VERTICAL GROUND RESPONSE SPECTRA 


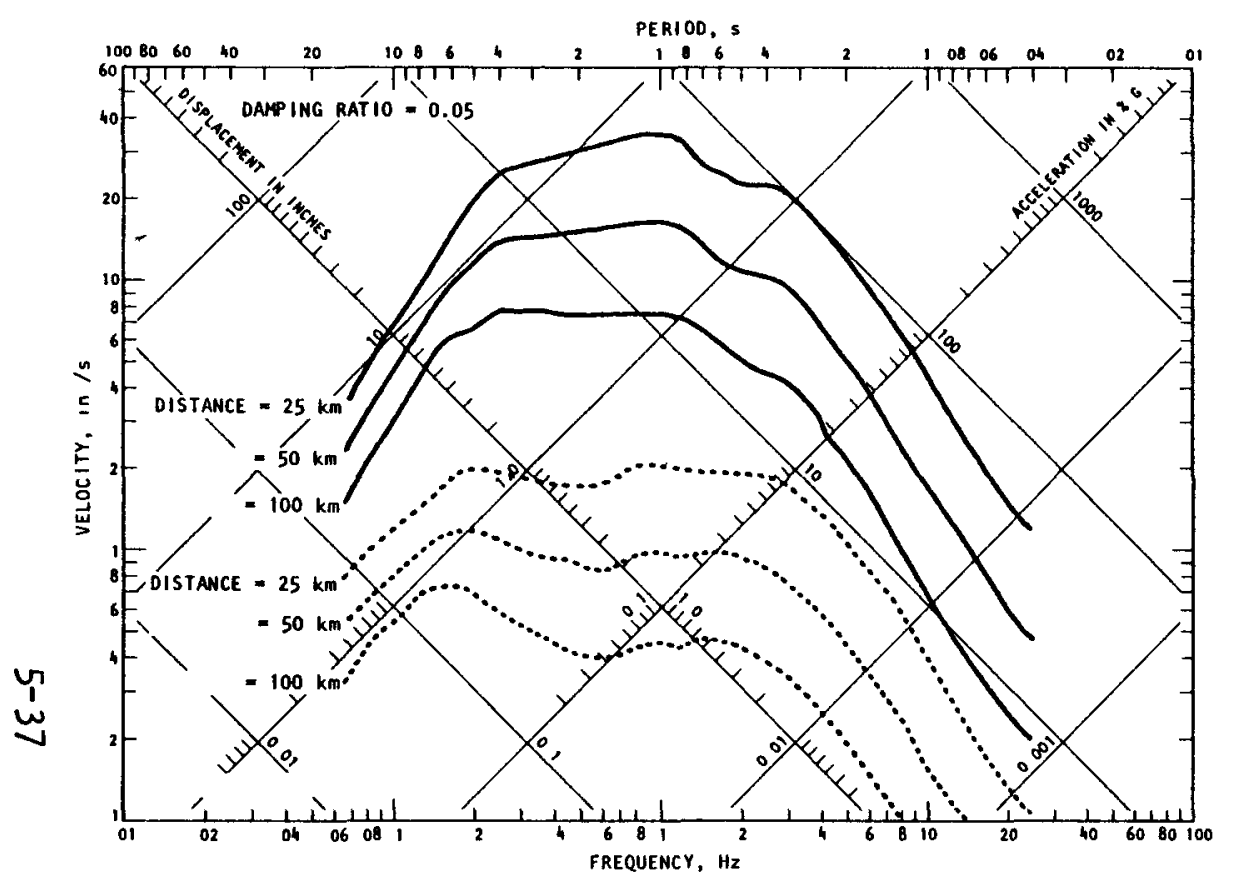

(a) Horizontal

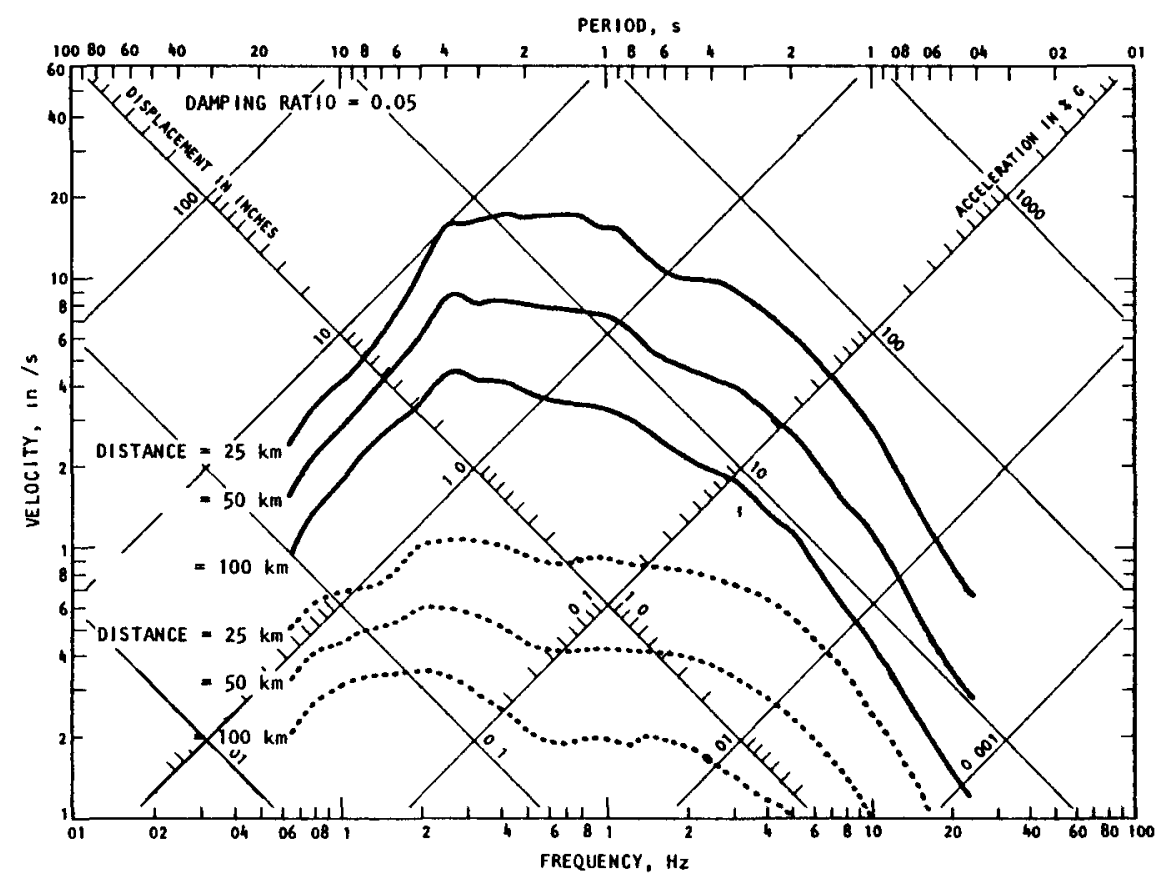

(b) Vertical

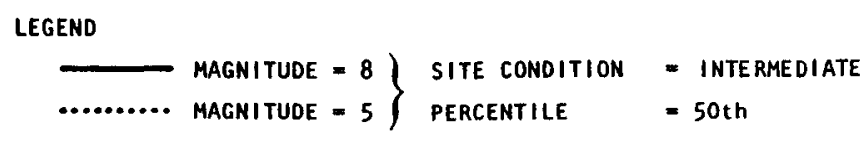

FIGURE 5-19. DISTANCE ATTENUATION OF HORIZONTAL AND VERTICAL GROUND RESPONSE SPECTRA FOR TYPE 3 EARTHQUAKES WITH VARIOUS MAGNITUDE LEVELS 


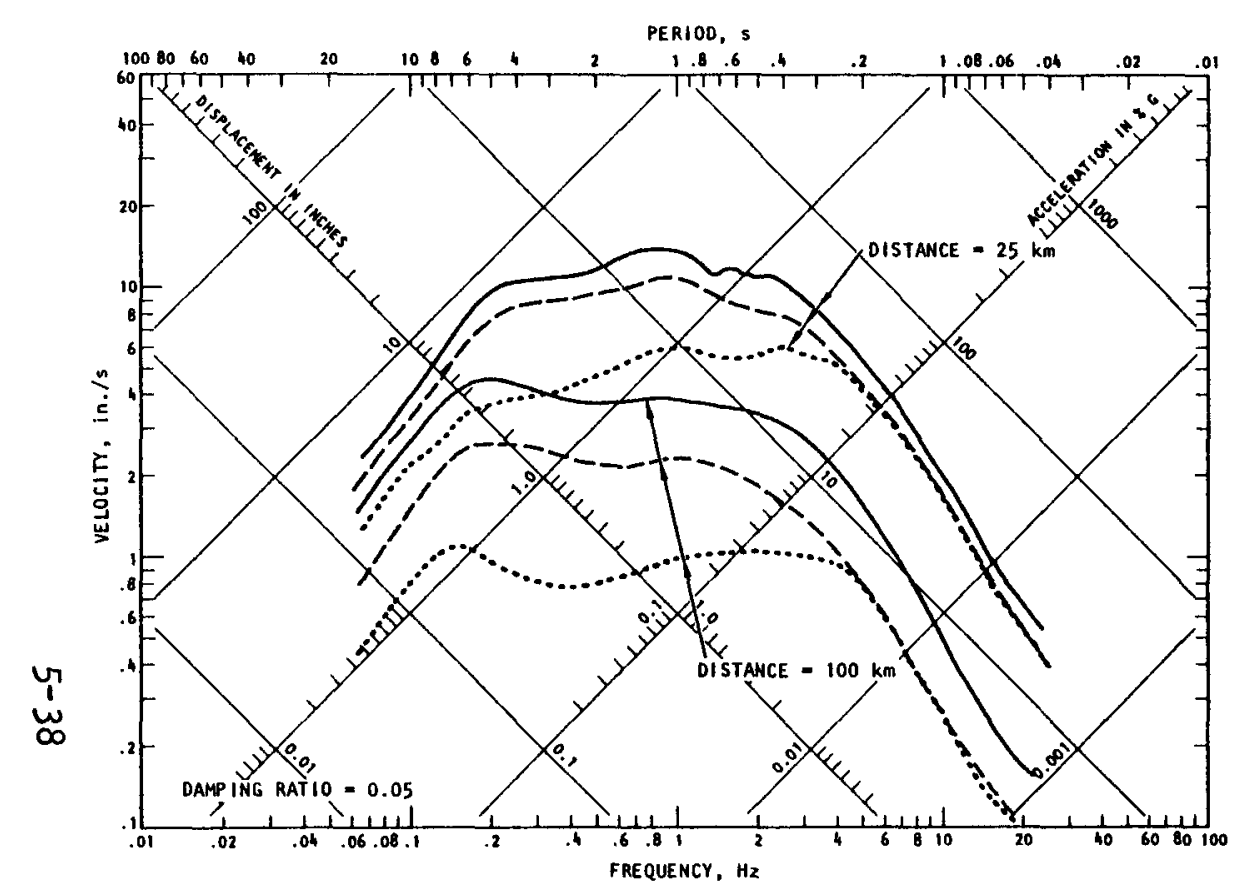

(a) Horizontal

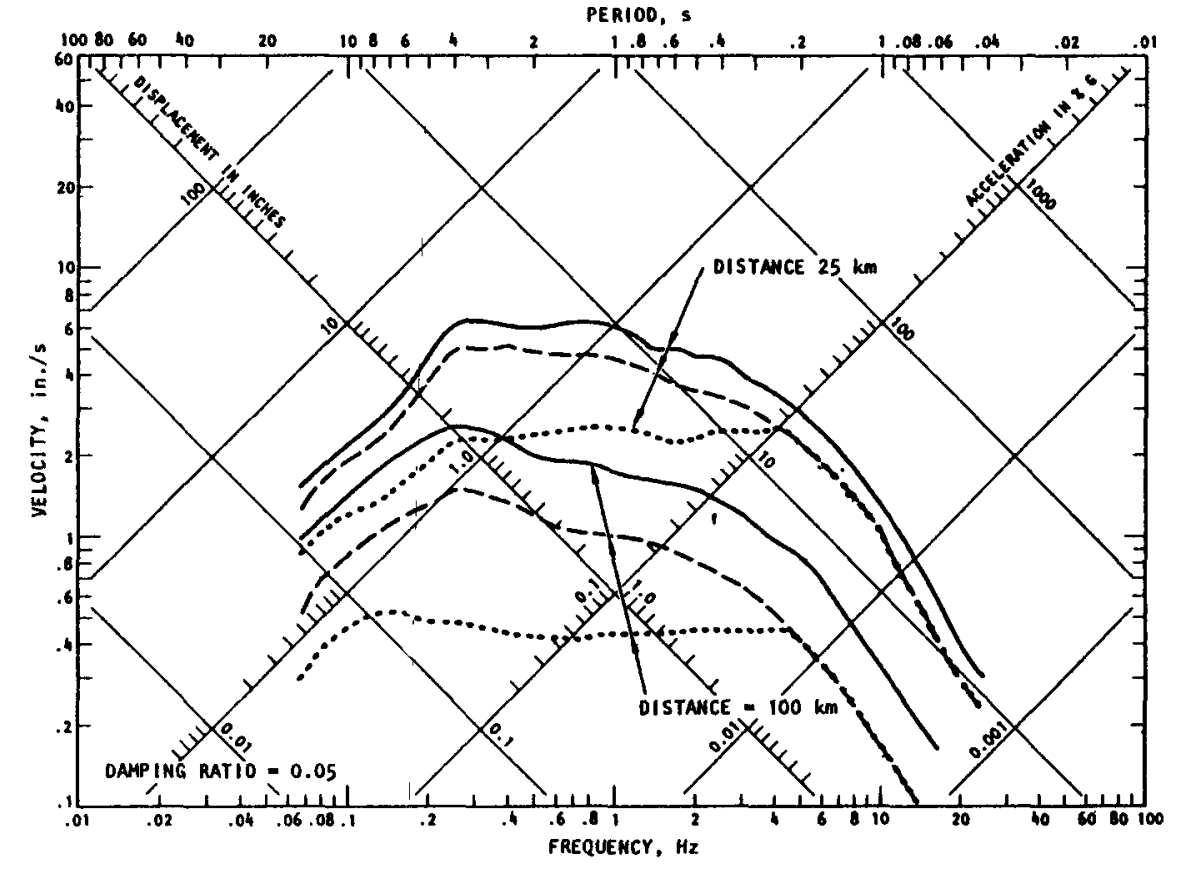

(b) Vertical

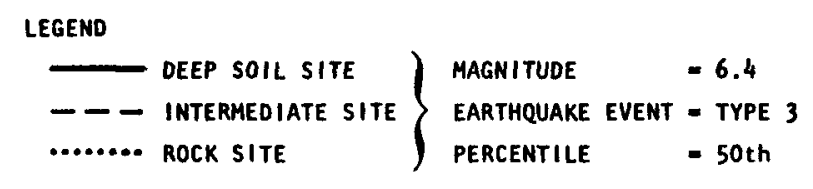

FIGURE 5-20. EFFECT OF SITE CONDITIONS ON GROUND RESPONSE SPECTRA 


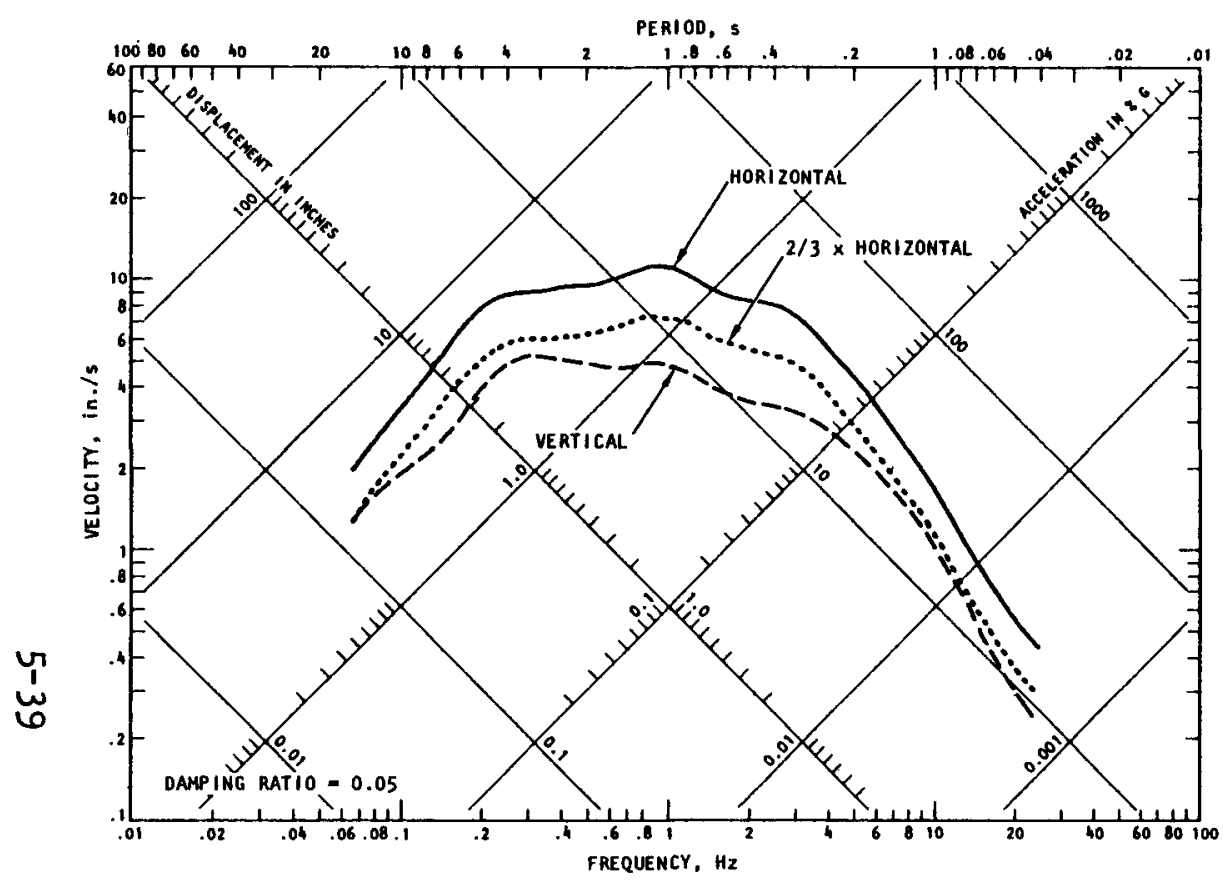

(a) Distance $=25 \mathrm{~km}$

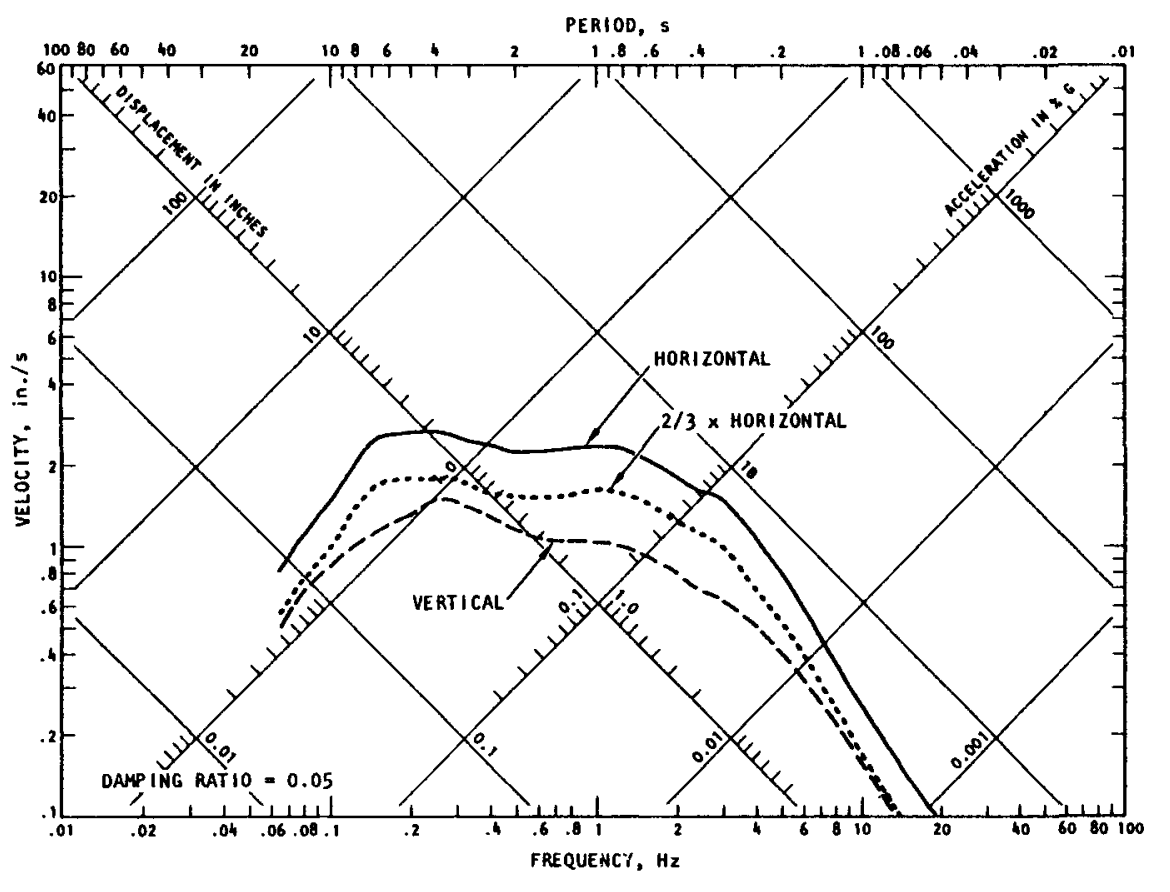

(b) Distance $=100 \mathrm{~km}$

NOTE:

$\begin{array}{ll}\text { EARTHQUAKE } & =\text { TYPE } 3 \\ \text { SITE CONDITION } & =\text { INTERMEDIATE } \\ \text { MAGNITUDE } & =6.4 \\ \text { PERCENTILE } & =50 \text { th }\end{array}$

FIGURE 5-21. COMPARISON BETWEEN HORIZONTAL AND VERTICAL GROUND RESPONSE SPECTRA 


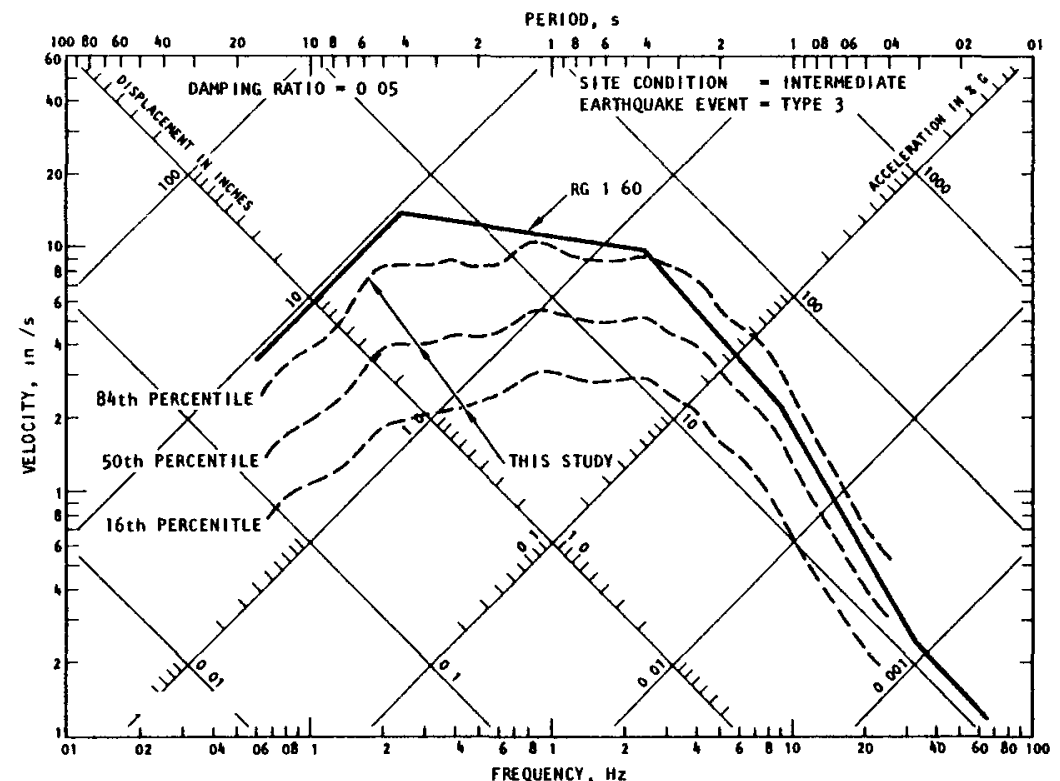

(a) Distance $=10 \mathrm{~km}$, horizontal motion

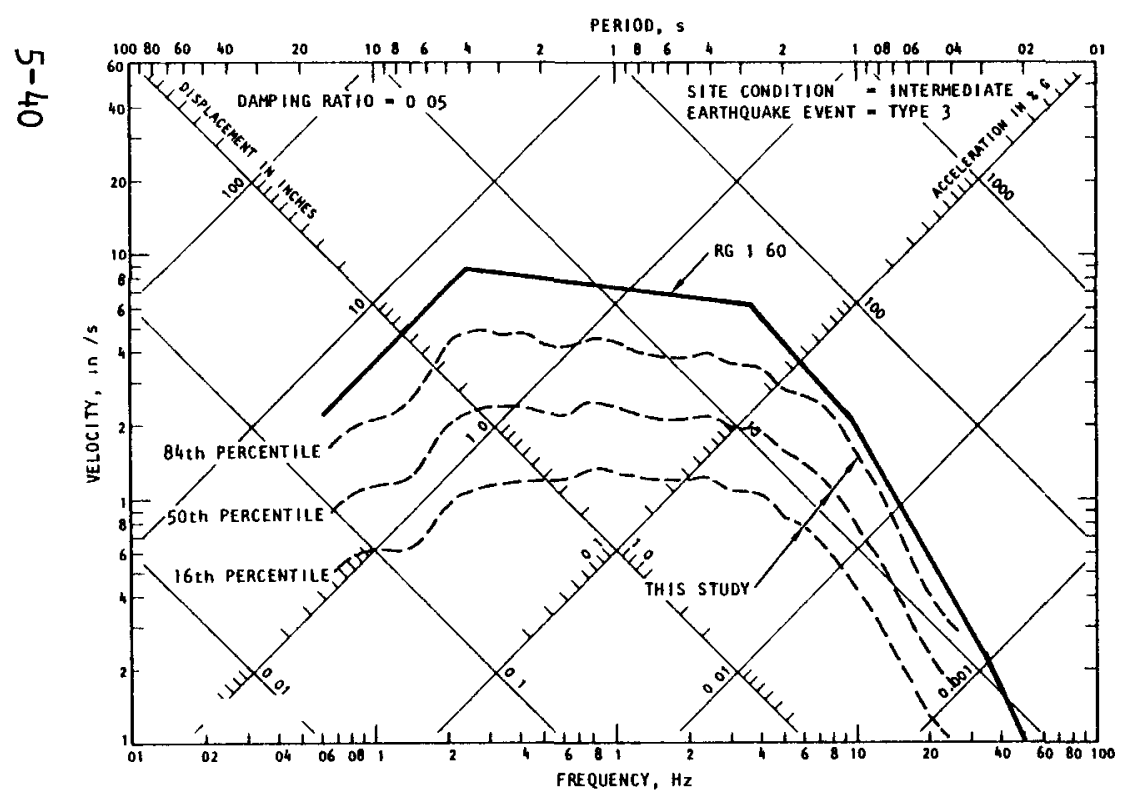

(c) Distance $=10 \mathrm{~km}$, vertical motion

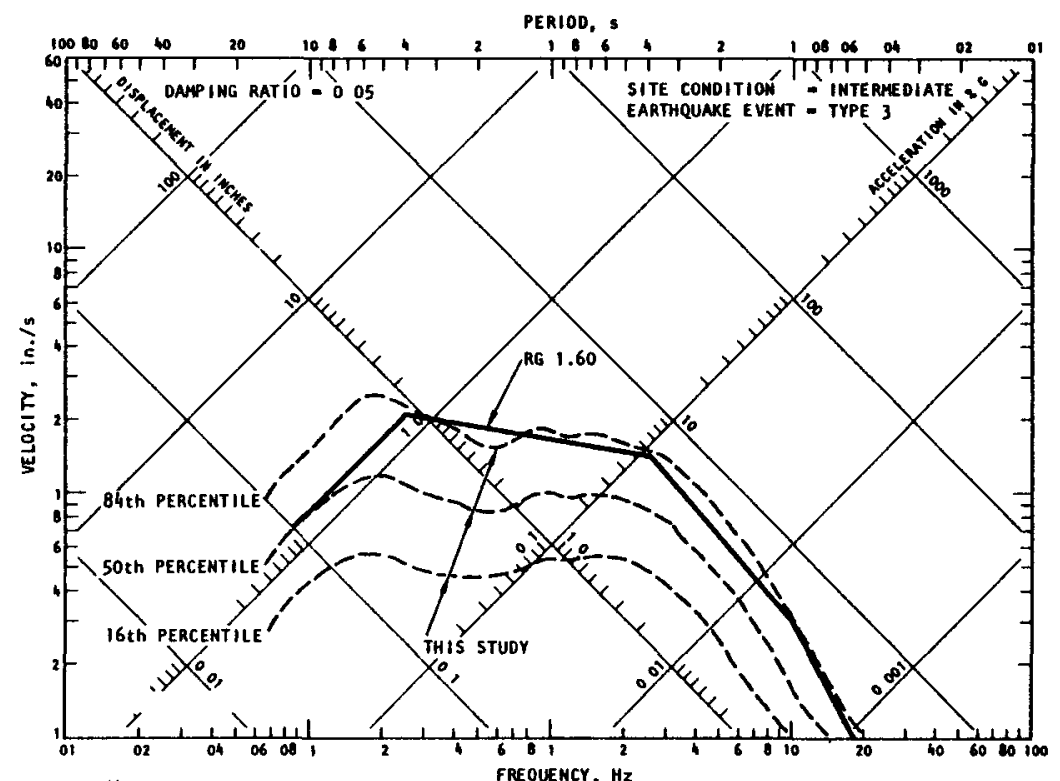

(b) Distance $=50 \mathrm{~km}$, horizontal motion

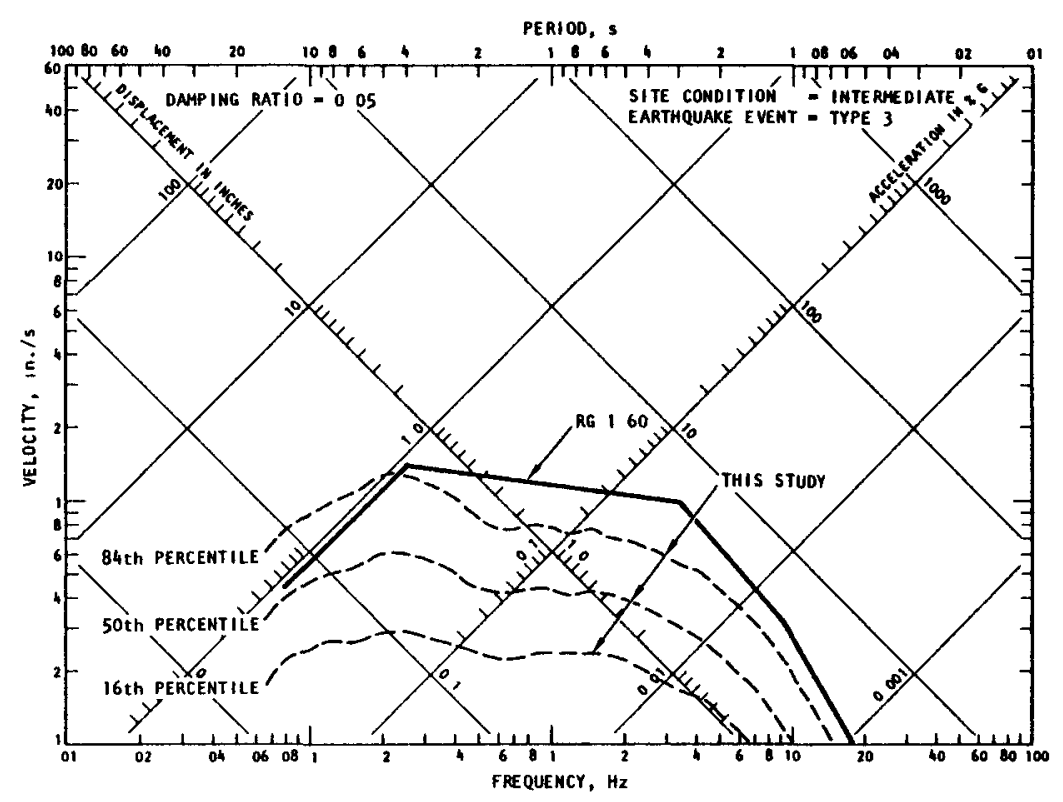

(d) Distance $=50 \mathrm{~km}$, vertical motion

FIGURE 5-22. COMPARISON OF SPECTRA FROM RG 1.60 AND FROM THIS STUDY FOR MAGNITUDE 5.0 EARTHQUAKES 


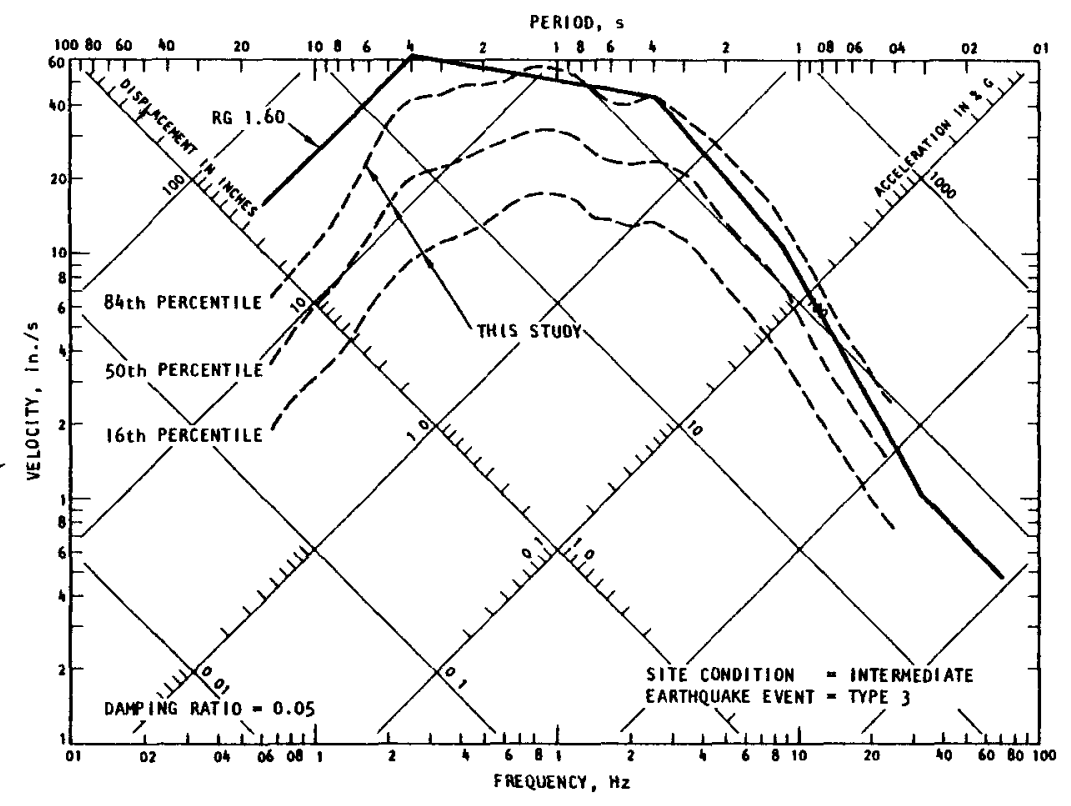

(a) Distance $=10 \mathrm{~km}$, horizontal motion

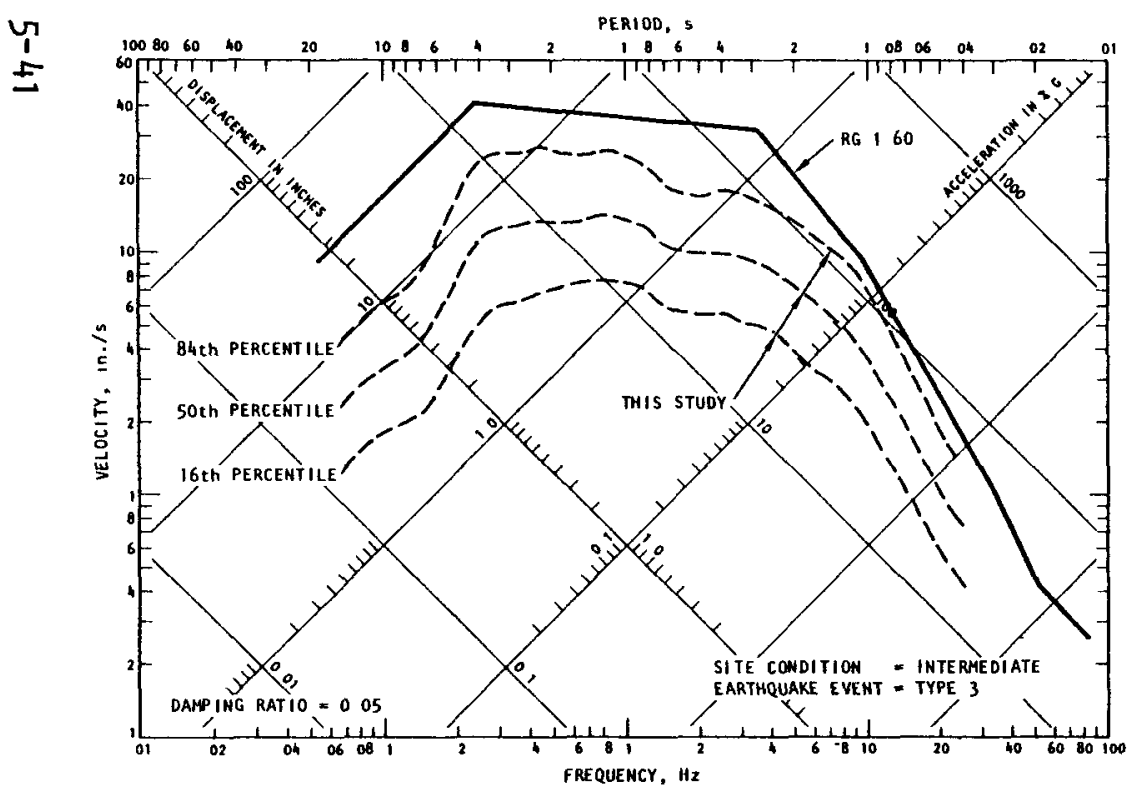

(c) Distance $=10 \mathrm{~km}$, vertical motion

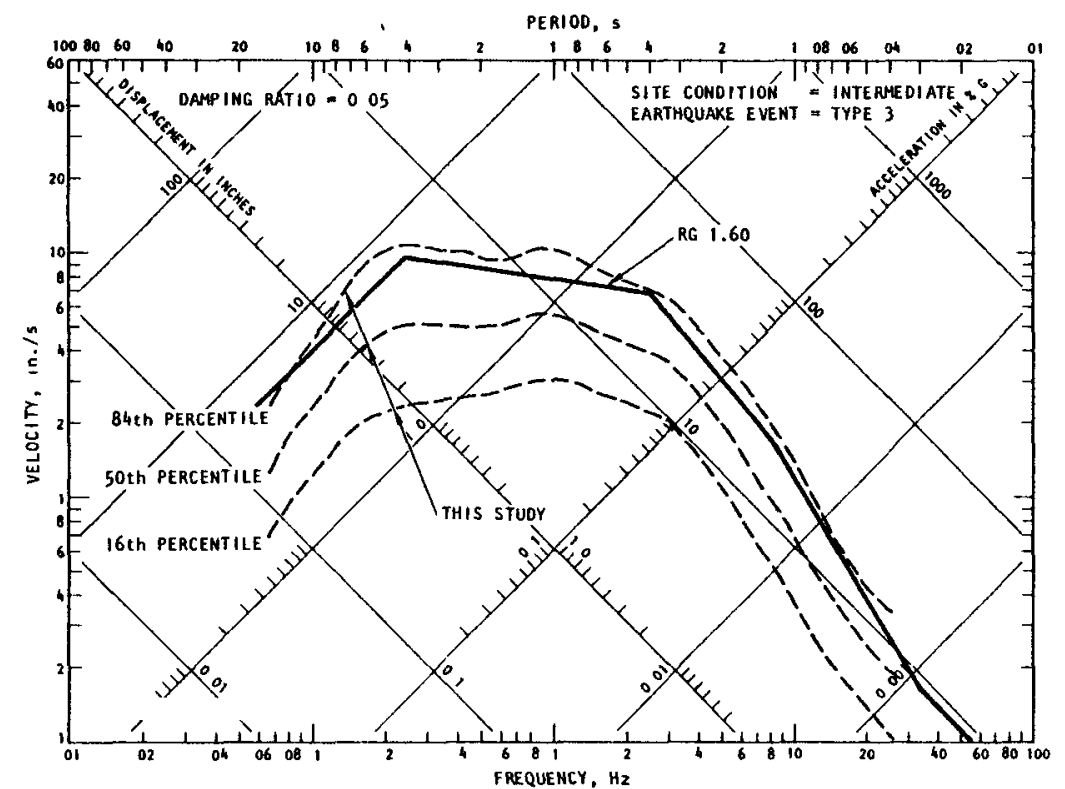

(b) Distance $=50 \mathrm{~km}$, horizontal motion

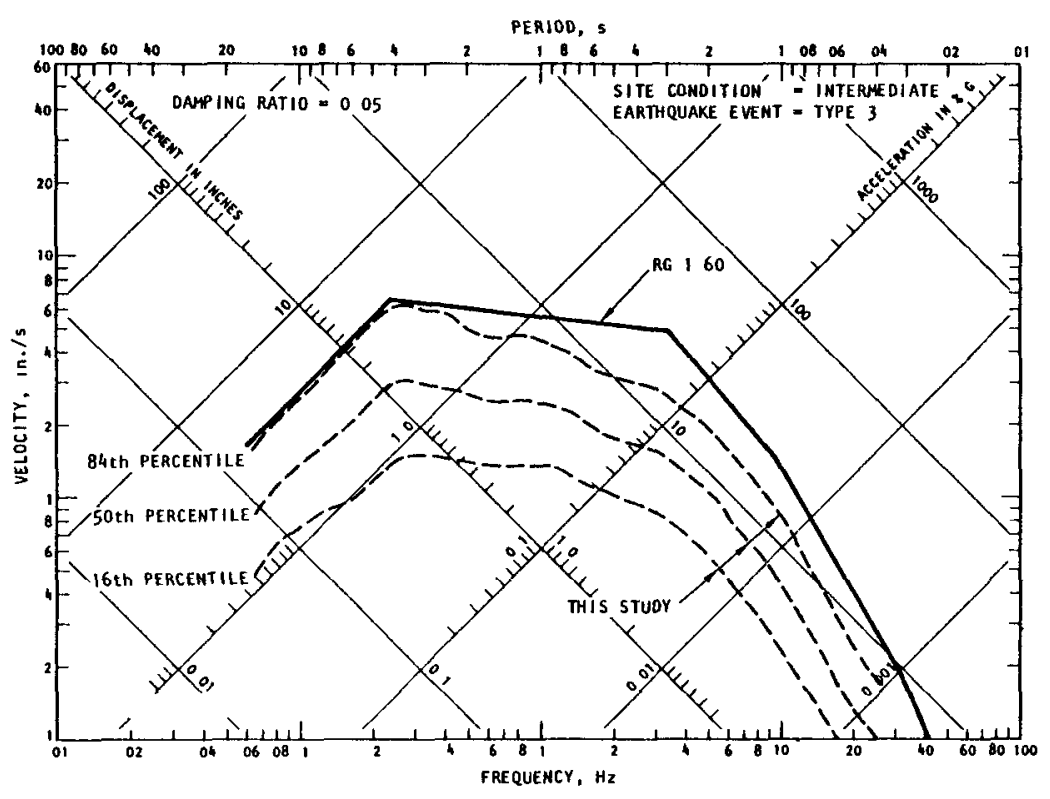

(d) Distance $=50 \mathrm{~km}$, vertical motion

FIGURE 5-23. COMPARISON OF SPECTRA FROM RG 1.60 AND FROM THIS STUDY FOR MAGNITUDE 6.5 EARTHQUAKES 


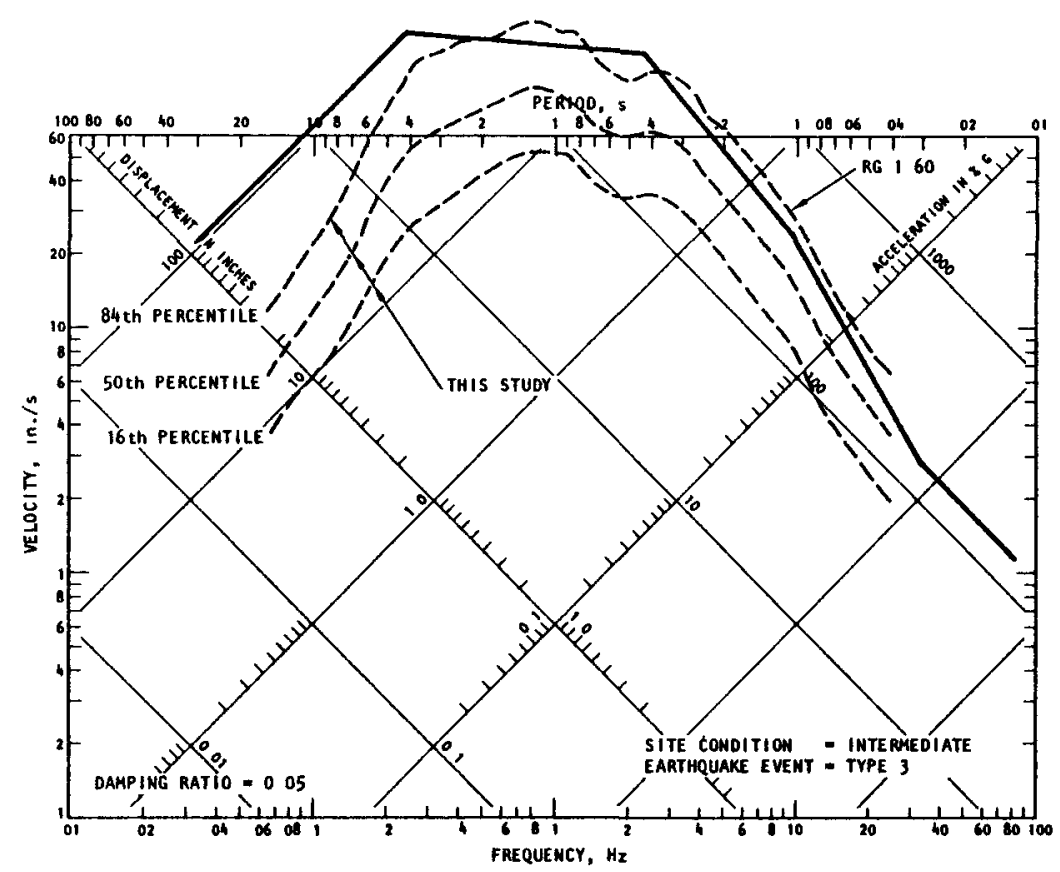

(a) Distance $=10 \mathrm{~km}$, horizontal motion

$\underset{1}{1}$

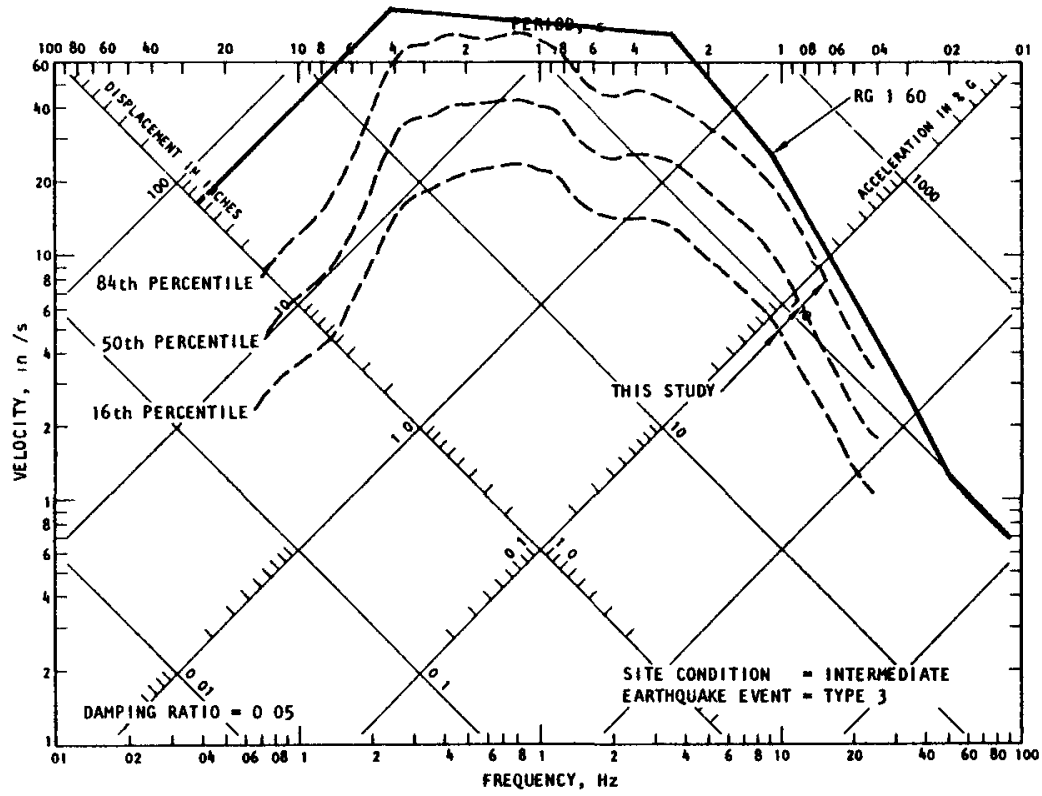

(c) Distance $=10 \mathrm{~km}$, vertical motion

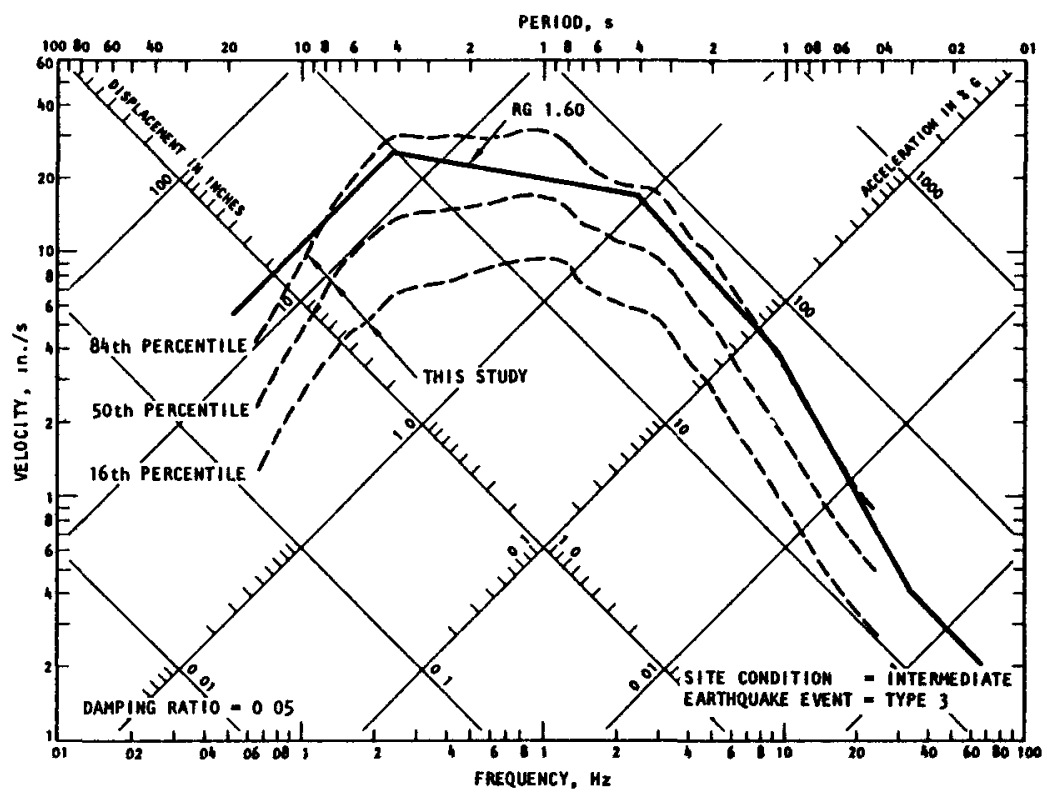

(b) Distance $=50 \mathrm{~km}$, horizontal motion

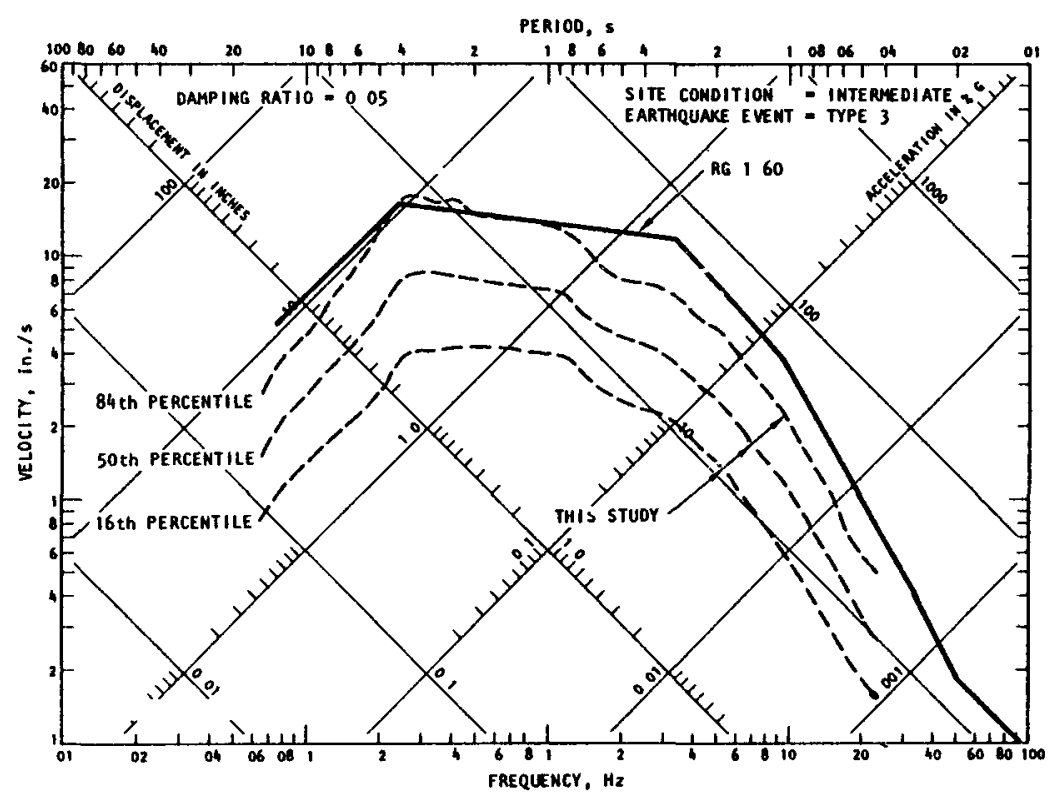

(d) Distance $=50 \mathrm{~km}$, vertical motion

FIGURE 5-24. COMPARISON OF SPECTRA FROM RG 1.60 AND FROM THIS STUDY FOR MAGNITUDE 8.0 EARTHQUAKES 


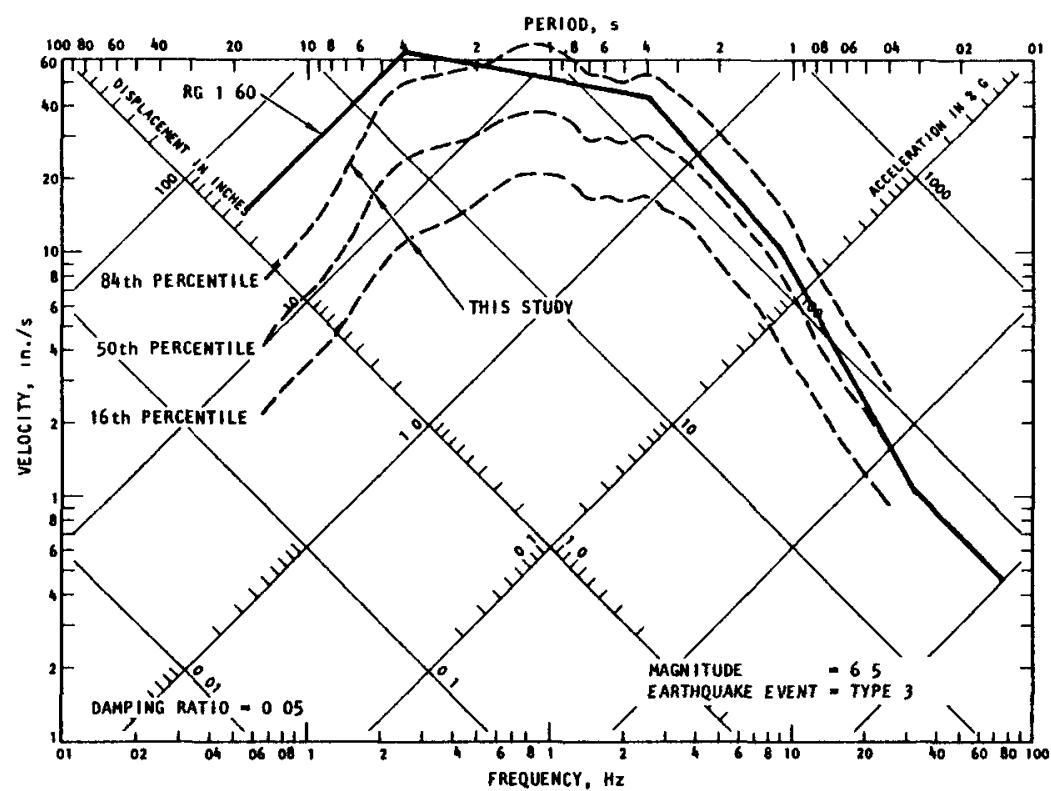

(a) Distance $=10 \mathrm{~km}$, deep soil sites

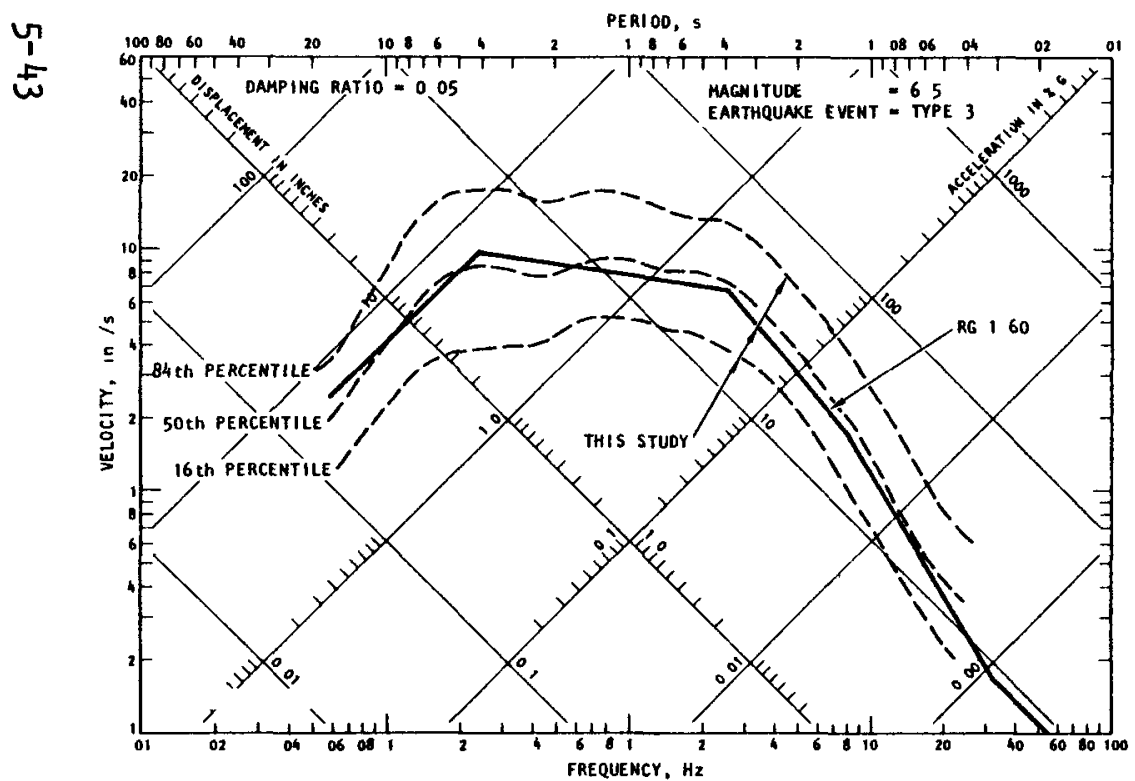

(c) Distance $=50 \mathrm{~km}$, deep soil sites

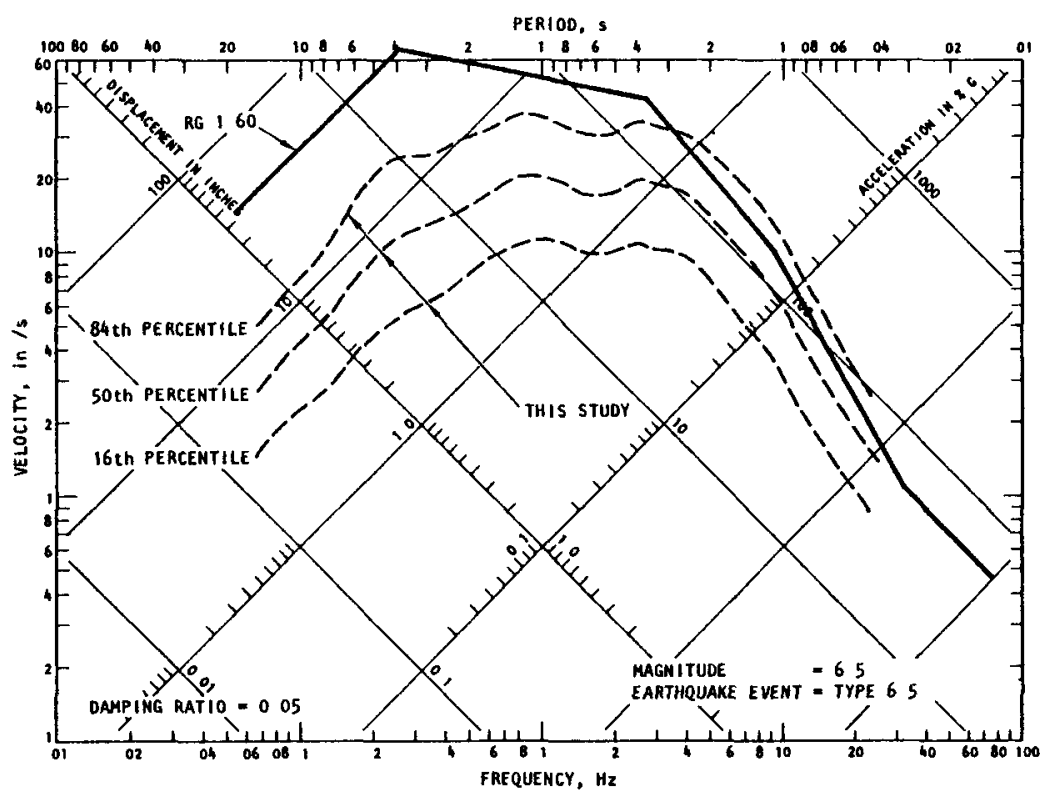

(b) Distance $=10 \mathrm{~km}$, rock sites

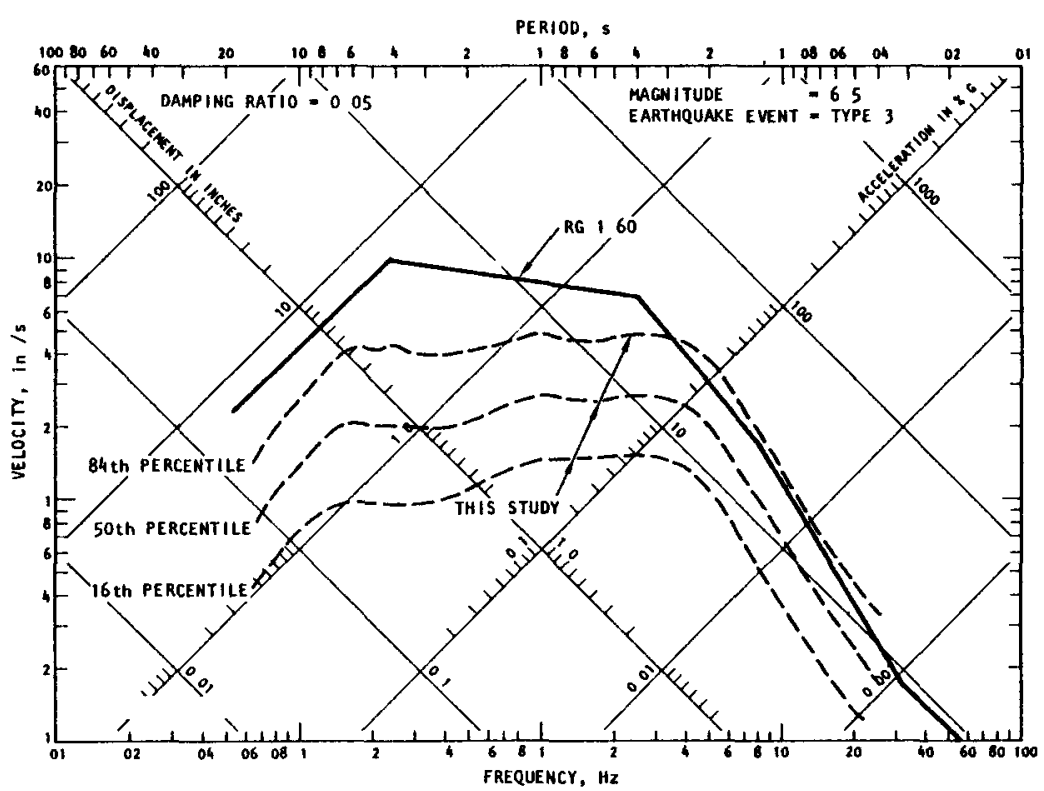

(d) Distance $=50 \mathrm{~km}$, rock sites

FIGURE 5-25. COMPARISON OF SPECTRA FROM RG 1.60 AND FROM THIS STUDY FOR VARIOUS SITE CONDITIONS--HORIZONTAL MOTIONS 


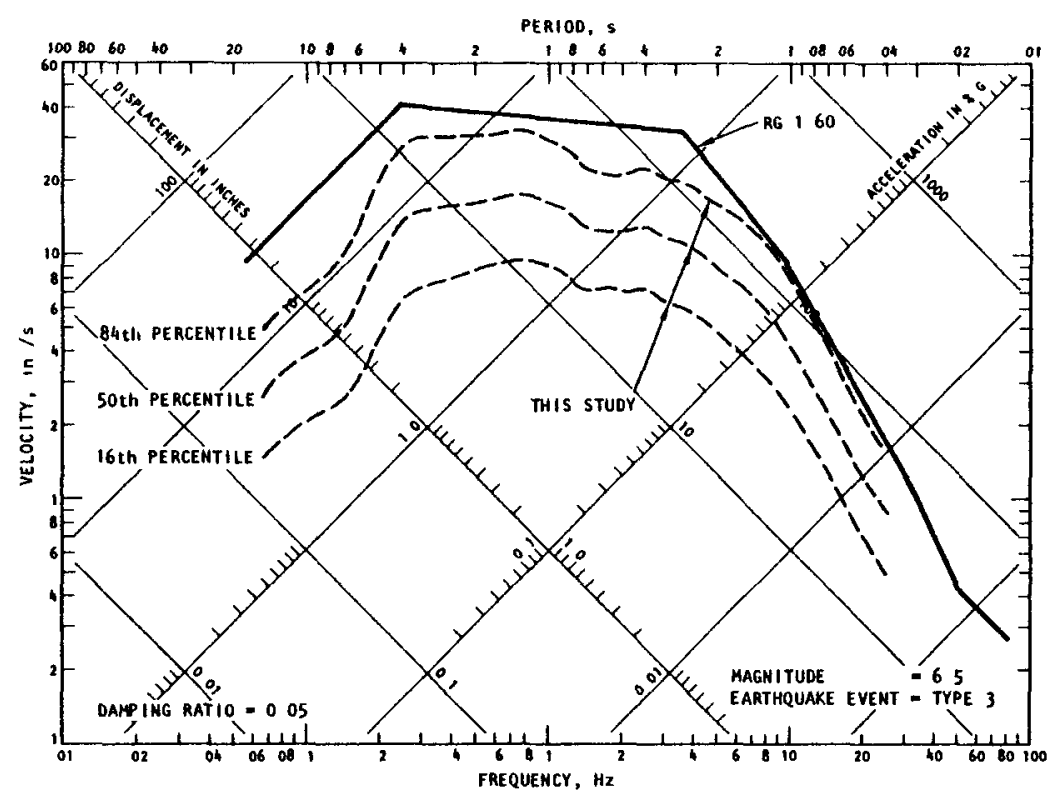

(a) Distance $=10 \mathrm{~km}$, deep soil sites

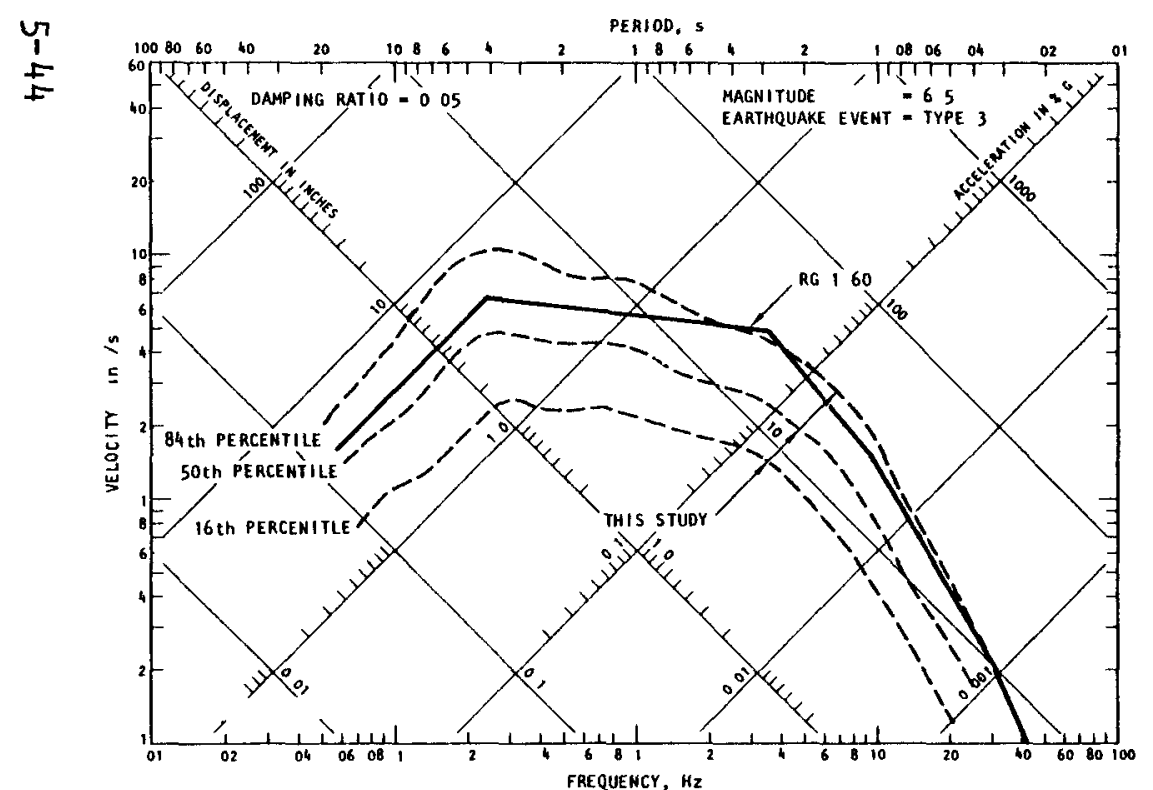

(c) Distance $=50 \mathrm{~km}$, deep soil sites

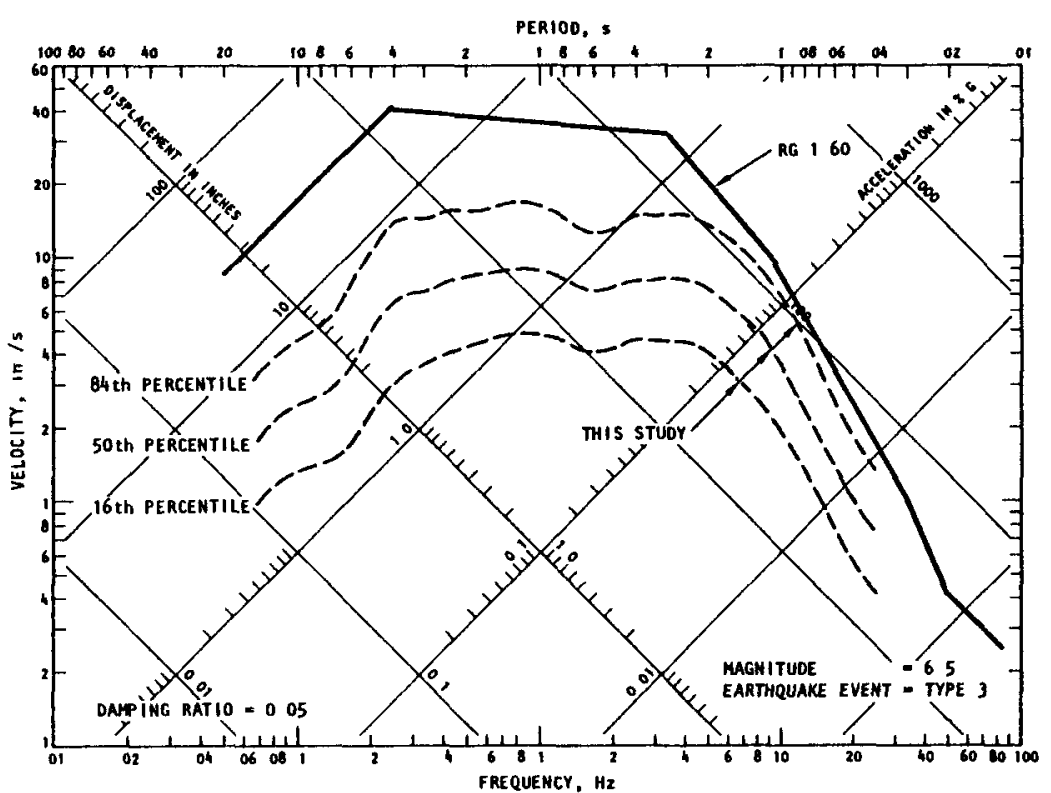

(b) Distance $=10 \mathrm{~km}$, rock sites

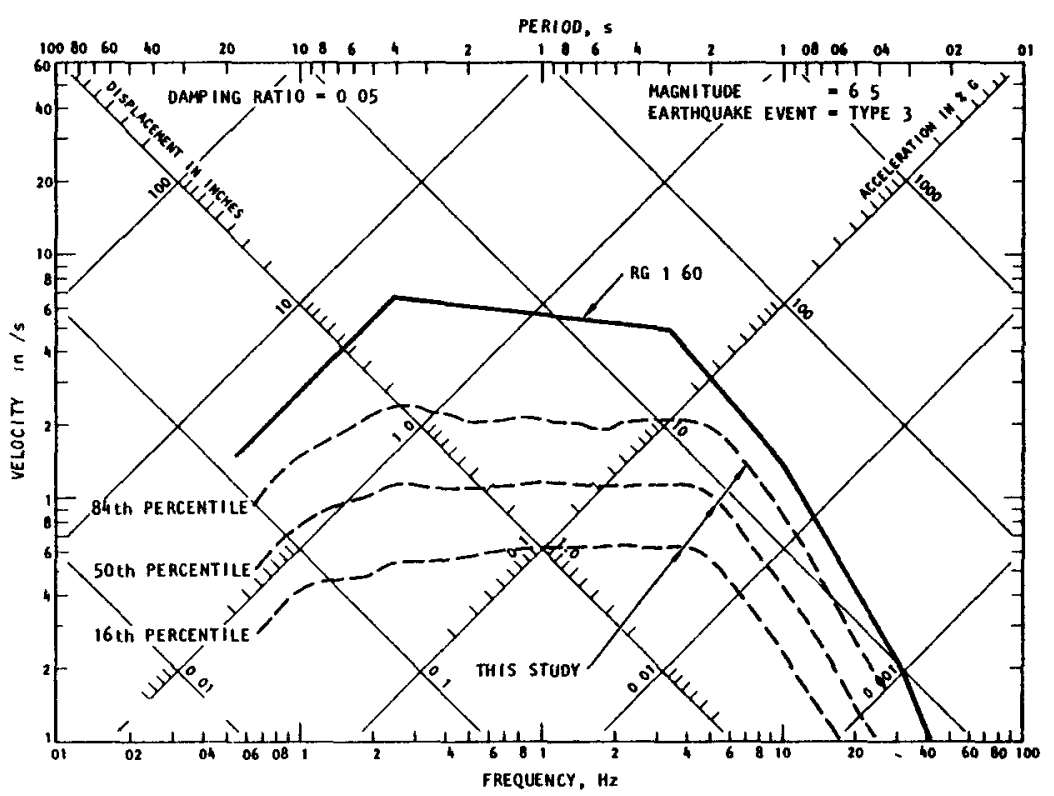

(d) Distance $=50 \mathrm{~km}$, rock sites

FIGURE 5-26. COMPARISON OF SPECTRA FROM RG 1.60 AND FROM THIS STUDY FOR VARIOUS SITE CONDITIONS--VERTICAL MOTIONS 


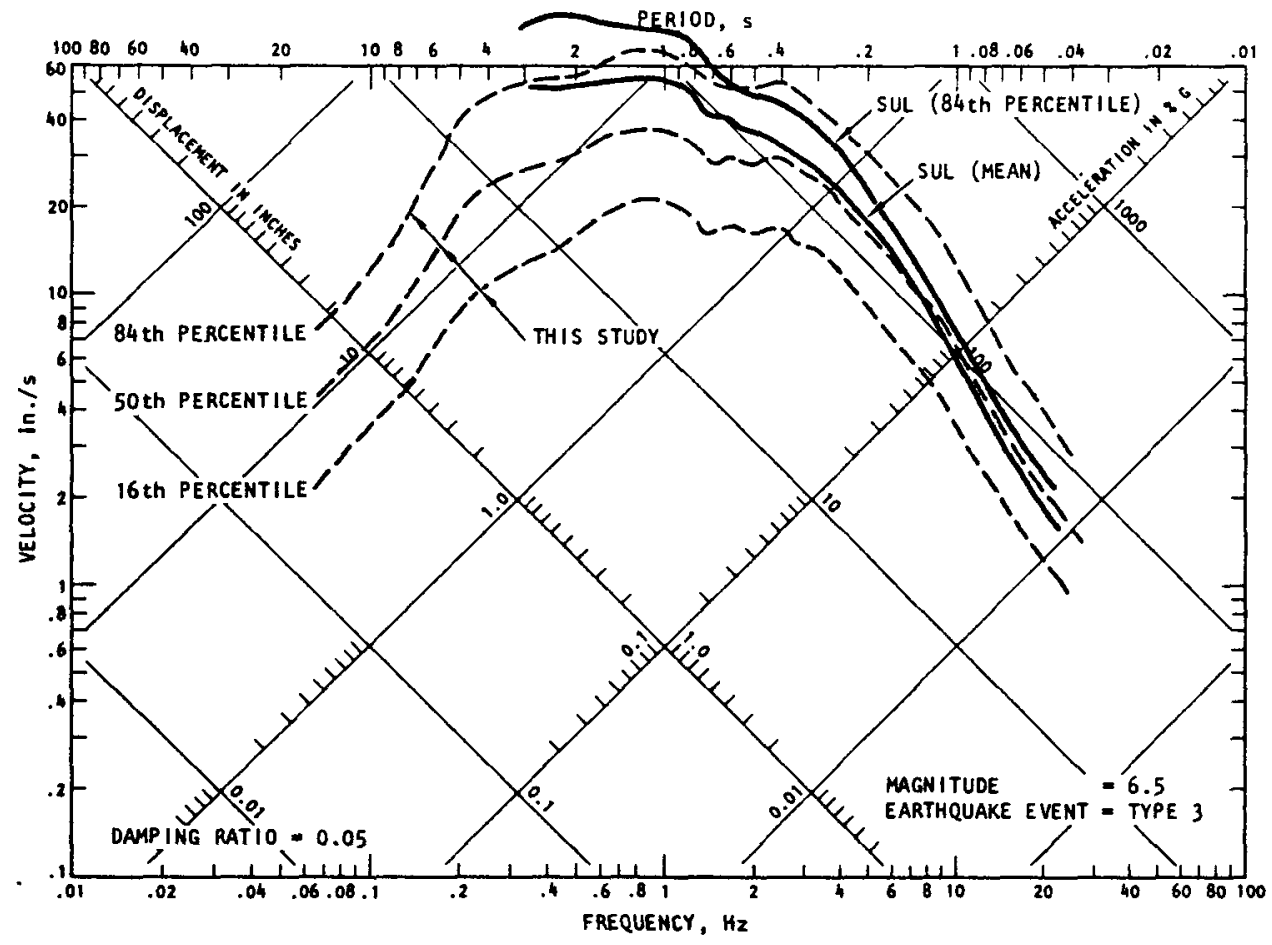

(a) Distance $=10 \mathrm{~km}$

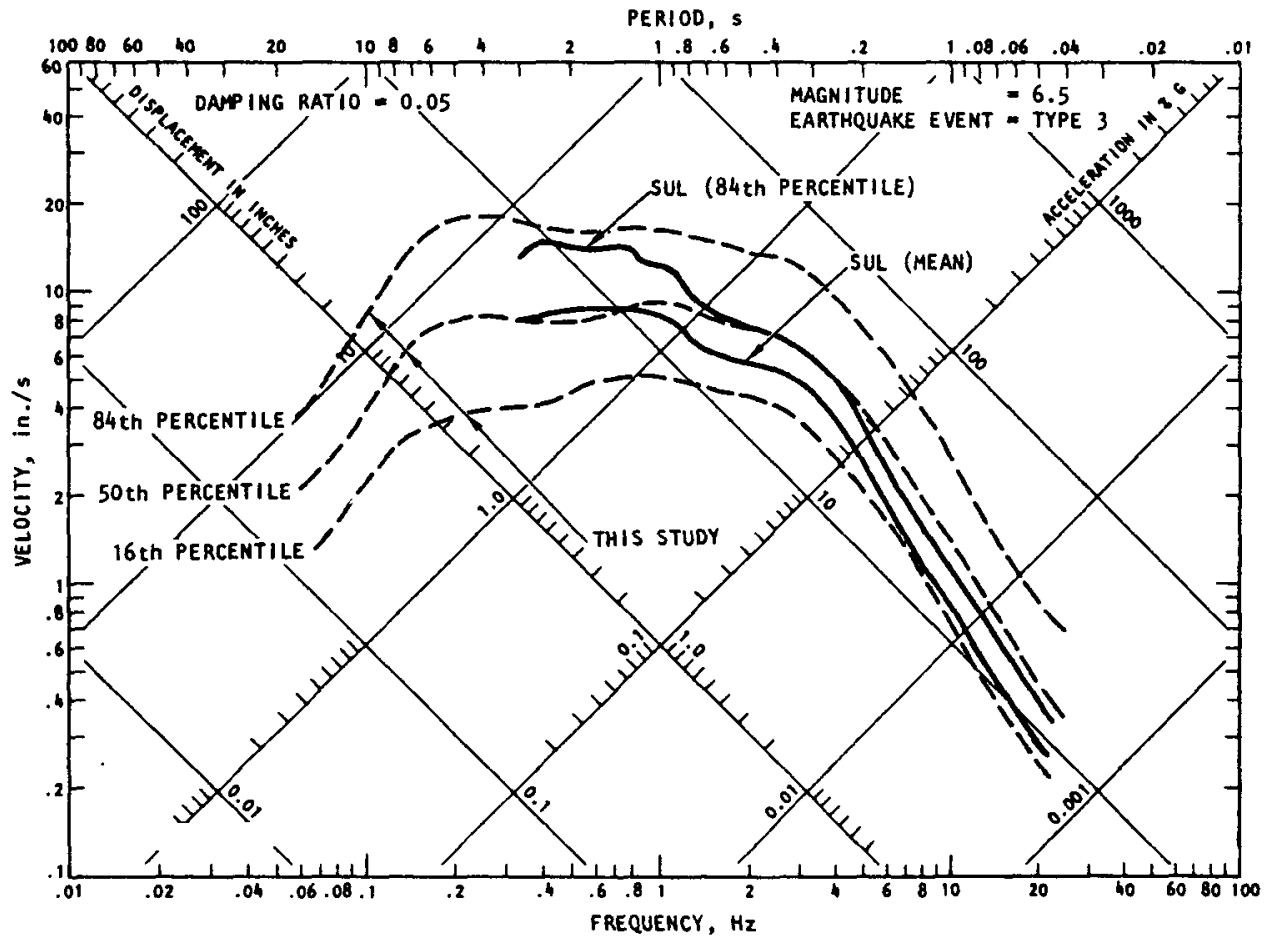

(b) Distance $=50 \mathrm{~km}$

FIGURE 5-27. COMPARISON OF SEED-UGAS-LYSMER (SUL) SPECTRA TO SPECTRA - FROM THIS STUDY--DEEP SOIL SITES 


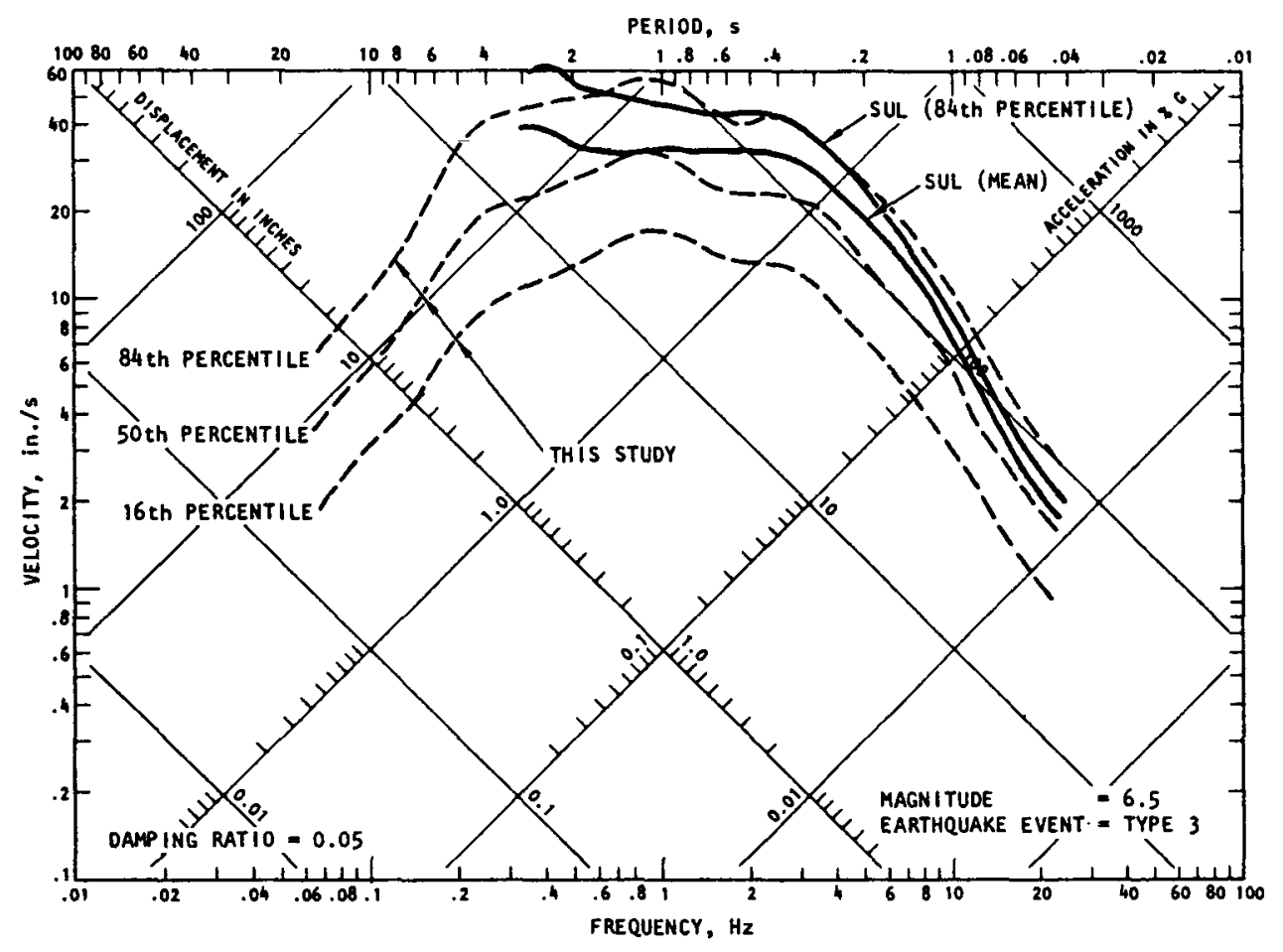

(a) Distance $=10 \mathrm{~km}$

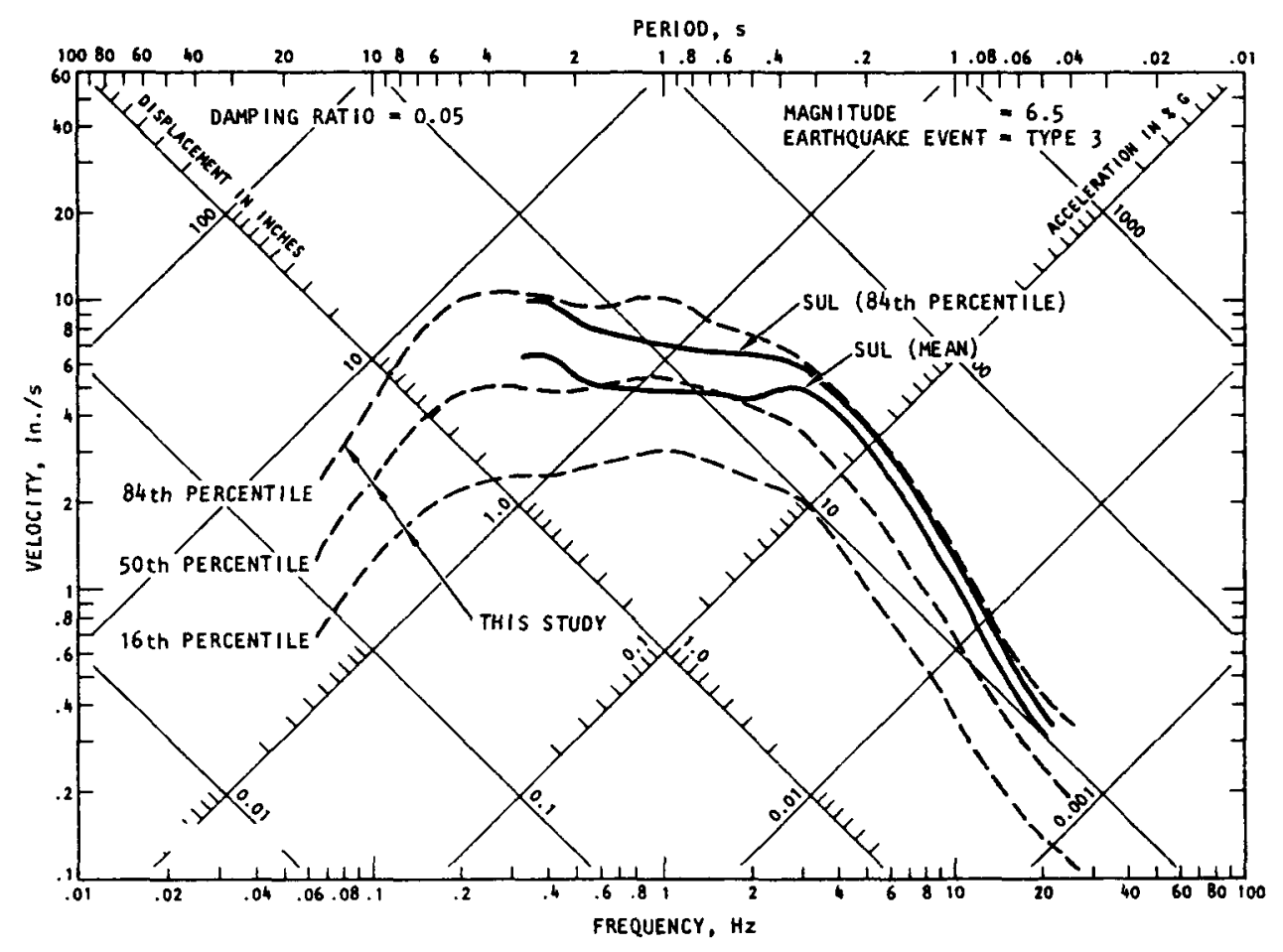

(b) Distance $=50 \mathrm{~km}$

FIGURE 5-28. COMPARISON OF SEED-UGAS-LYSMER (SUL) SPECTRA TO SPECTRA FROM THIS STUDY--INTERMEDIATE SITES 


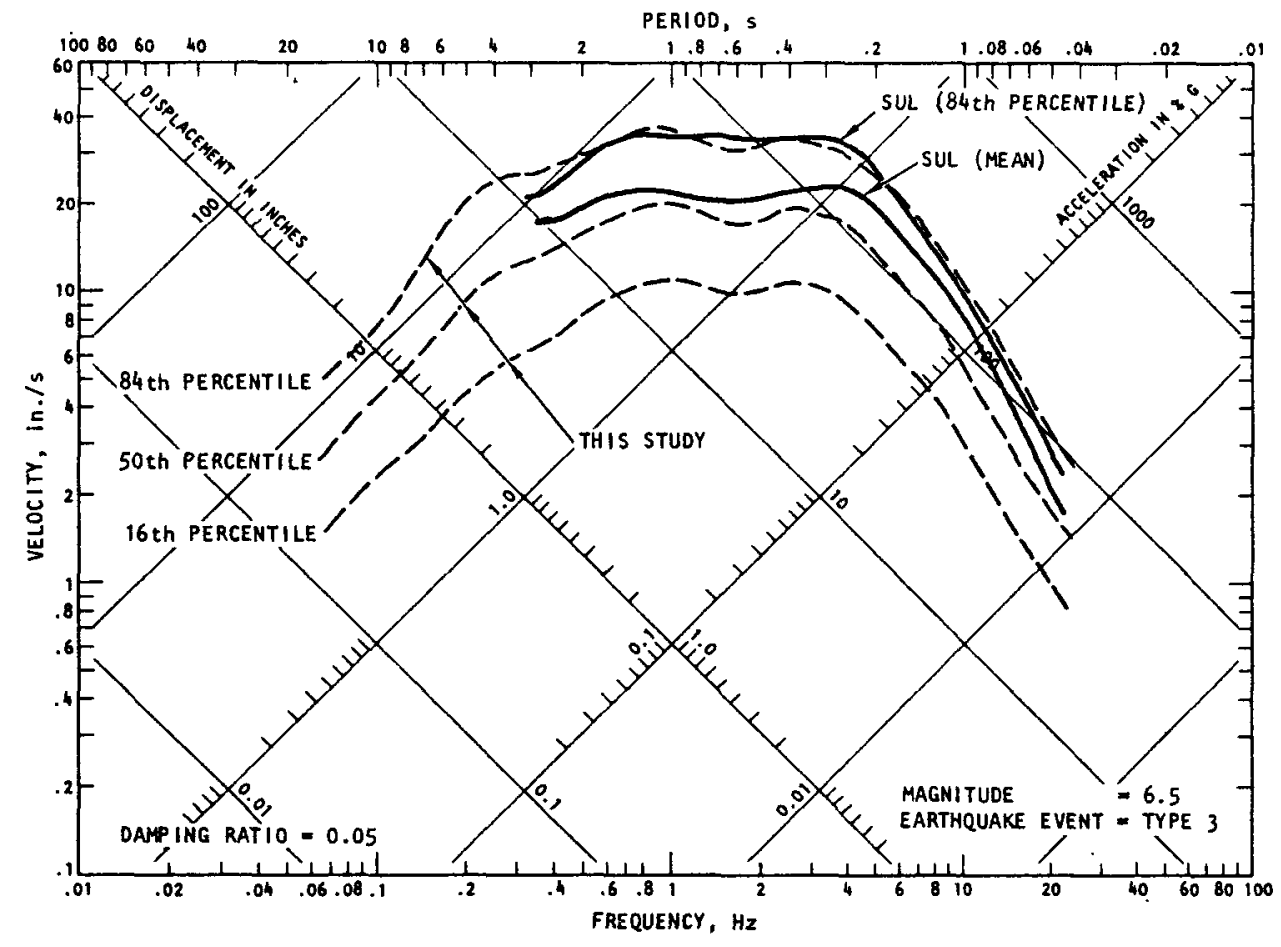

(a) Distance $=10 \mathrm{~km}$

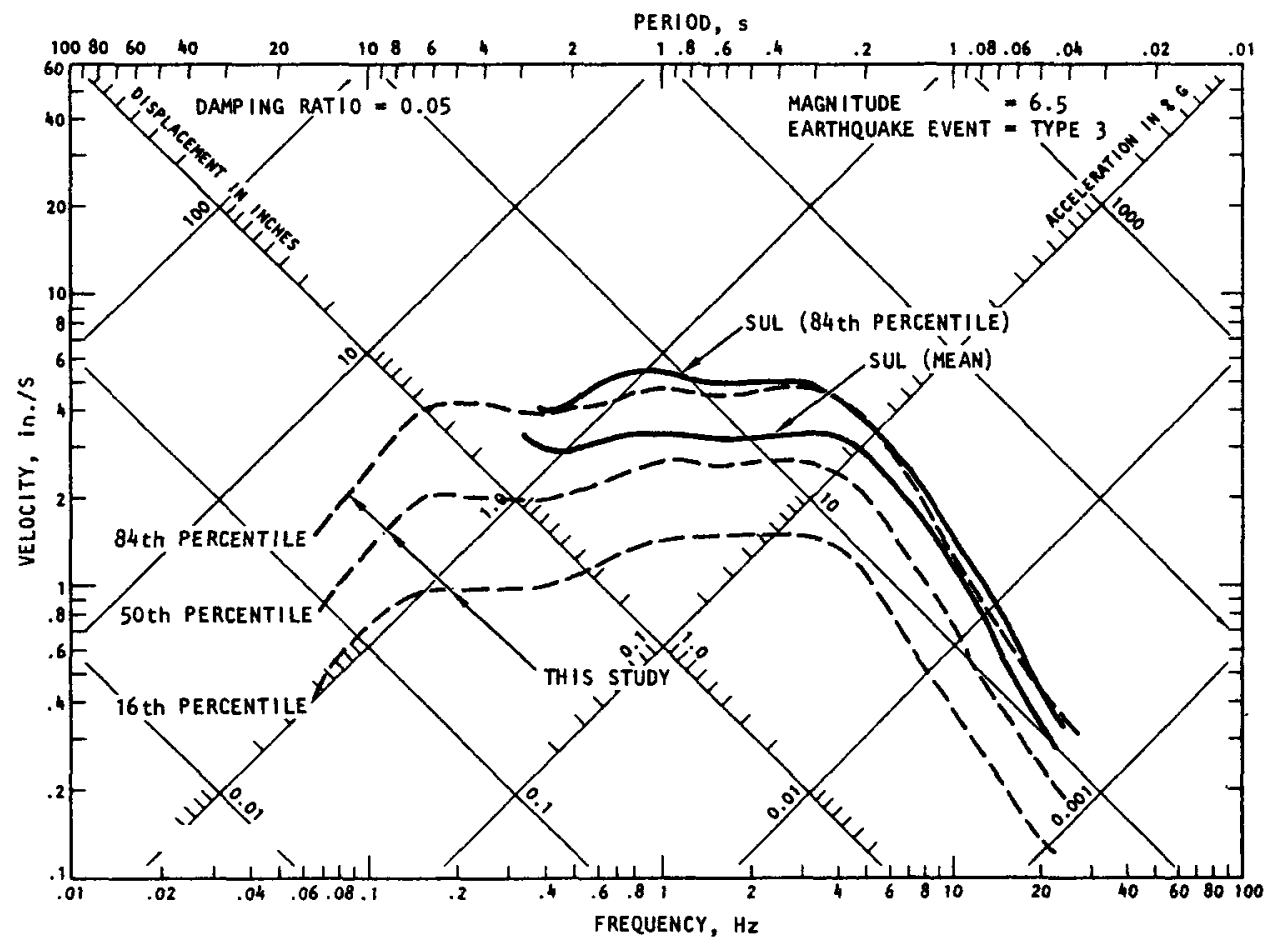

(b) Distance $=50 \mathrm{~km}$

FIGURE 5-29. COMPARISON OF SEED-UGAS-LYSMER (SUL) SPECTRA TO SPECTRA FROM THIS STUDY--ROCK SITES 
CHAPTER 6

REFERENCES

Arias, A.B. (1970) "A Measure of Earthquake Intensity," in Seismic Design for Nuclear Power Plants edited by R.J. Hansen. Cambridge, MA: Mass. Inst. of Tech. Press.

Benioff, H. (1934) "The Physical Evaluation of Destructiveness," in BuZZ. Seismoz. Soc. of Amer. 24:4, Oct, pp 398-403.

Bolt, B.A. (1973) "Duration of Strong Ground Motion," Proc. 5th Wortd Conf. on Earthquake Eng. Rome, Italy, Jun 1973, Paper No. 292.

Brady, A.G. (1975) "Estimating Response Spectra from Peak Values of Ground Motion," paper presented at the 70th Annual Meeting of the Seismological Society of America, Calif. State Univ. Los Angeles, Mar 25-27.

Brune, J.N. (1970) "Tectonic Stress and the Spectra of Seismic Shear Waves from Earthquakes," JnZ of Geophys. Res. Vol. 75, pp 4997-5009.

Calif. Inst. of Tech. (CIT). (1969-1975) Strong Motion Earthquake AcceZerogroms, Volumes I-IV, Parts A-Y. Pasadena: CIT Earthquake Eng. Res. Lab.

Crow, E.L.; Davis, F.A.; and Maxfield, M.W. (1960) Statistical Manual. New York: Dover Publications Inc.

Dobry, R.; Idriss, I.M.; and Ng, E. (1978) "Duration Characteristics of Horizontal Components of Strong Motion Earthquake Records," BuZZ. Seismoz. Soc. of Amer. 68:4, Oct, pp 1487-1520.

Donovan, N.C. (1973) "Earthquake Hazards for Buildings," in Building Practices for Disaster Mitigation, NBS Science Series 46. Washington, DC: USGPO.

Duke, C.M.et al. (1976) Effects of Site on Ground Motion in the San Eemando Earthquake, UCLA-ENG-7688. Los Angeles, CA: Univ. of Calif., Aug.

Esteva, L. (1970) "Seismic Risk and Seismic Design Decisions," in Seismic Design for Nuclear Power Plants edited by R.J. Hansen, Cambridge, MA: MIT Press, pp 142-182.

Guzman, R.A. and Jennings, P.C. (1976) "Design Spectra for Nuclear Power Plants," Proc. ASCE Power Div. 102:P02, Nov, pp 165-178.

Hall, W.J.; Mohraz, B.; and Newmark, N.M. (1976) Statistical Studies of Vertical and Horizontal Earthquake Spectra, NUREG-0003. Urbana, IL: Nathan M. Newmark Consulting Eng. Services, Jan (PB 248 232) 
Housner, G.W. (1952) "Spectrum Intensities of Strong Motion Earthquakes," Proc. of Symp. on Eartinquake and Blast Effects on Structures, Oakland, CA: Earthquake Eng. Res. Inst.

-.-. (1959) "Behavior of Structures during Earthquakes," Proc. ASCE Eng. Mech. Div. 85:EM4, Oct, pp 109-129.

-.-. (1975) "Measures of Severity of Earthquake Ground Shaking," Proc. U.S. Nat'l Conf. on Earthquake Eng. Ann Arbor, MI, Jun 1975.

Hudson, D.E. (1972) "Strong Motion Seismology," in Proc. Int. Conf. on Microzonation for Safer Construction Res. and Appl. Seattle, Nov 1972, Vol. 1, PP 29-60.

---. (1974 "Destructive Earthquake Ground Motions," in Applied Mechanics in Earthquake Engineering edited by W.D. Iwan. New York: Amer. Soc. of Civil Eng. (AMD Vol. 8)

McCann, M.W. and Shah, H.C. (1979) "RMS Acceleration for Seismic Risk Analysis: An Overview," Proc. of the 2nd US Nat' $Z$ Conf. On Earthquake Eng. Stanford, CA, Aug 22-24, 1979, pp 883-897.

McGuire, R.K. (1978) "Seismic Ground Motion Parameter Relations," in Proc. ASCE Geotech. Div. 104:GT4, Apr, pp 481-492.

McGuire, R.K. and Barnhard, T.P. (1979) "The Usefulness of Ground Motion Duration in Predicting the Severity of Ground Shaking, "Proc. of the 2nd US Nat'Z Conf. on Earthquake Eng. Stanford, CA, Aug 22-24, 1979, pp 713-722.

Mohraz, B (1976) "A Study of Earthquake Response Spectra for Different Geological Conditions," Buzz. Seismol. Soc. Amer. 66:3, Jun, pp 915-936.

Newmark, N.M.; Blume, J.A.; and Kapur, K.K. (1973) "Seismic Design Spectra for Nuclear Power Plants," Proc. ASCE Power Div. 99:P02, Nov, pp 288-303.

Newmark, N.M. and Hall, W.J. (1969) "Seismic Design Criteria for Nuclear Reactor Facilities," Proc. 4th World Conf. on Earthquake Eng. Santiago, Chile, Feb 1969.

Perez, V. (1974) Time Dependent Spectral Analysis of Thirty-One Strong Motion Earthquake Records, Open File Report 74-48. Reston, VA: U.S. Geological Survey, Nov.

Schnabel, P.B. et al. (1972) Modification of Seismograph Records for Effects of Local Soil Conditions," Bulz. Seismol. Soc. Amer. 62:6, Dec, pp 1649-1664.

Seed, H.B., et al. (1976) "Relationships of Maximum Accelerations, Maximum Velocity, Distance from Source, and Local Site Conditions for Moderately Strong Earthquakes," Buzz. Seismoz. Soc. Amer. 66:4, Aug, pp 1323-1342. 
Seed, H.B.; Ugas, C; and Lysmer, J. (1976) "Site Dependent Spectra for Earthquake Resistant Design," Bulz. Seismol. Soc. Amer. 66:1, Feb. pp 221-244.

Shannon \& Wilson/Agbabian Associates (SW/AA). (1975) Procedures for Evaluation of Vibratory Ground Motions of Soil Deposits at Nuclear Power Plant Sites, NUREG-75/072. Seattle, WA: SW \& El Segundo, CA: AA, Jun.

-..-. (1976) Geotechnical and Strong Motion Earthquake Data from U.S. Accelerograph Stations: Ferndale, Cholame, and El Centro, Califoria. NUREG-0029, Vol. 1. Seattle, WA: SW \& El Segundo, CA: AA, Sep. (PB 257 234)

---. (1977a) Geotechnical and Strong Motion Earthquake Data from U.S. AcceZerograph Stations: Gavilan College, Gilroy, California; Utah State University, Logan, Utah; Montana State University, Bozeman, Montana; County-City Building, Tacoma, Washington; Federal Building, Helena, Montana; Carroll College, Helena, Montana, Vol. 3. Seattle, WA: SW \& El Segundo, CA: AA, Mar. (draft)

---. (1977b) Verification of Subsurface Conditions at Selected "Rock" Accelerograph Stations in Califormia, Vol. 2. Seattle, WA: SW E El Segundo, CA: AA, Mar. (draft)

-.-. (1978a) Verification of Subsurface Conditions at Selected "Rock" Accelerograph Stations in California, NUREG/CR-0055, Vol. 1. Seattle, WA: SW \& El Segundo, CA: AA, May. (PB 282 205)

---. (1978b) Data from Selected Accelerograph Stations at Wilshire Boulevard, Century City, and Ventura Boulevard, Los Angeles, Califormia, NUREG/CR-0074. Seattle, WA: SW E El Segundo, CA: AA, Jun. (PB 283 029)

---. (1978c) Geotechnical and Strong Motion Earthquake Data from U.S. Accelerograph Station: Pasadena (CIT Millikan Library), Santa Barbara County Court House, Taft (Lincoln School Tunnel), and Hollister (Melendy Ranch Barm), Califormia, NUREG-0029, Vol. 2. Seattle, WA: SW E El Segundo, CA: AA, Jun.

-.-. (1979) Site-Dependent Response at EL Centro, California Accelerogroph Station Including Soil/Stmucture Interaction Effects, Seattle, WA: SW E El Segundo, CA: AA, May (draft)

Thatcher, W. and Hanks, T.C. (1973) "Source Parameters of Southern California Earthquakes," Inl of Geophys. Res. Vol. 78, pp 8547-8576.

Trifunac, M.D. (1971) "Zero Baseline Correction of Strong-Motion Accelerograms," Buzz. Seismol. Soc. Amer. 61:5, Oct, po 1201-1212.

---. (1972a) "A Note on Correction of Strong-Motion Accelerograms for Instrument Response,"BuZz. Seismol. Soc. Amer. 62:1, Feb, pp 401-410.

----. (1972b) "Stress Estimates for San Fernando California Earthquake of February 9, 1971: Main Event and Thirteen Aftershocks,"Buzz. Seismoz. Soc. Amer. 62:3, pp 721-750. 
-.-. (1972c) "Tectonic Stress and Source Mechanism of the Imperial Valley California Earthquake of 1940," Buzz. Seismoz. Soc. Amer. 61:5, Oct, pp 1283-1302.

----. (1976) "Preliminary Analys is of the Peaks of Strong Earthquake Ground Motion--Dependence of Peaks on Earthquake Magnitude, Epicentral Distance, and Recording Site Conditions,"BuZZ. Seismol. Soc. Amer. $66: 1$, Feb, pp 189-220.

-.--. (1977) "Forecasting the Spectral Amplitudes of Strong Earthquake Ground Motion," Proc. 6th World Conf. on Earthquake Eng. New Delhi, India, Jan 1977.

Trifunac, M.D. and Brady, A.G. (1975a) "On the Correlation of Seismic Intensity Scales with the Peaks of Recorded Strong Ground Motion," BuZZ. Seismoz. Soc. Amer. 65:1, Feb, pp 139-162.

---. (1975b) "A Study on the Duration of Strong Earthquake Ground Motion," Buzz. Seismoz. Soc. Amer. 65:3, Jun, pp 581-626.

Trifunac, M.D. and Westermo, B. (1977) "A Note on the Correlation of FrequencyDependent Duration of Strong Earthquake Ground Motion with the Modified Mercalli Intensity and the Geologic Conditions at the Recording Stations," Bul2. Seismol. Soc. Amer. 67:3, Jun, pp 917-927.

Trifunac, M.D.; Udwadia, F.E.; and Brady, A.G. (1973) "Recent Developments in Data Processing and Accuracy Evaluations of Strong Motion Acceleration Measurements," Proc. 5th World Conf. on Earthquake Eng. Rome, Italy, Jun 1973, Paper No. 79.

University Software Sys. (USS). (1971) MAC/STAT Statistical Data Analysis System-User Reference Manual. El Segundo, CA: USS, Jun.

U.S. Atomic Energy Comm. (USAEC). (1973) "Design Response Spectra for Seismic Design of Nuclear Power Plants," Regulatory Guide 1.60, Rev. 1. Washington, DC: USAEC, Dec.

Vanmarke, E.H. and Lai, S.P. (1977) Strong Motion Duration of Earthquakes, Report R77-16. Cambridge, MA: Mass. Inst. of Tech.

Werner, S.D. (1976) "Engineering Characteristics of Earthquake Ground Motions," Nuc. Eng. \& Des. 36:3, Mar, pp 367-396.

Werner, S.D. and Ts'ao, H.S. (1977) "Development of Ground Response Spectra from Site Mercalli Intensities," Paper K 1/4. Proc. 4th Int. Conf. on Struct. Mech. in Reactor Tech. San Francisco, CA, Aug 15-19, 1977.

---. (1978) "Effect of Local Site Conditions on Spectral Amplification Factors," Proc. 2nd Int. Conf. on Microzonation for Safer Construction--Res. and App 2. San Francisco, Nov 26-Dec 1, 1978, Vol. 2, pp 1077-1088. 
APPENDIX A

MULTIPLE LINEAR REGRESSION ANALYSIS

This appendix contains five sections that describe aspects of the multiple linear regression analysis carried out in this study. The first section of the appendix describes the assumptions inherent in the regression analysis procedure, and the second section describes how the regression coefficients are computed. In the third section, the step-down algorithm used in this procedure is described, and the fourth section provides procedures for computing data-fit parameters, once the regression analysis is completed. The final section briefly describes the MAC/STAT program used to carry out the regression analyses.

\section{A. 1 ASSUMPTIONS}

The main assumptions associated with the regression analysis are as follows:

1. Additivity and Linearity. The regression equation is comprised of the sum of terms linear in $m$ unknown regression coefficients, $a_{i}(i=1, \ldots m)$ i.e.,

$$
y=a_{1} x_{1}+a_{2} x_{2}+\ldots+a_{m} x_{m}+\varepsilon
$$

where $y$ is the dependent valuable, $x_{i}(i=1, \ldots m)$ are functions of the independent variables, and $\varepsilon$ is the residual. It is noted that terms nonlinear in $a_{i}$ may be used in a regression analysis; however, such terms unnecessarily complicate the regression analysis, particularly in view of the uncertain knowledge of the nature of the earthquake ground motion process. They can often be avoided by careful use of transformations.

"Y may also be a transformation of the dependent variable. For example, in the regression analyses carried out in this study for the strength parameters and the response spectral amplitudes, $y=\ln Y$ where $Y$ is the dependent variable. 
2. Independence. The residual for any given data point is completely uncorrelated with and unrelated to the residual for any other data.

3. Unbiasedness. Many measurements of ground shaking recorded under identical conditions average out to $\varepsilon=0$.

4. Homoscedasticity. The variance of the residual $\varepsilon$ is a constant value, $\sigma^{2}$, that is independent of any independent variable; i.e., $\sigma^{2}$ is independent of the variables that define the particular conditions under which any one ground motion measurement was recorded.

5. Normality. The residual, $\varepsilon$, of the ensemble of ground motion data is assumed to follow a normal distribution.

\section{A. 2 DETERMINATION OF REGRESSION COEFFICIENTS}

In a multiple linear regression analysis, we consider that a dependent variable $y$ (e.g., peak acceleration) is expressed as the following function of $m$ independent variables $x_{1}, x_{2}, \ldots x_{m}$ that are, in turn, functions of such quantities as magnitude, distance, etc. Rewriting Equation $A-1$, we have

$$
y=f\left(x_{1}, x_{2}, \ldots x_{m}\right)=a_{1} x_{1}+a_{2} x_{2}+\ldots+a_{m} x_{m}+\varepsilon
$$

where $a_{i}(i=1, \ldots m)$ are the unknown regression coefficients to be determined. The least squares technique for fitting this relationship to a given set of data involves determining the $a_{i}{ }^{\prime} s$ such that

$$
\Phi=\sum_{j=1}^{n}\left[y_{j}-f\left(x_{i j}, x_{2 j}, \ldots x_{m j}\right)\right]^{2}=\text { minimum }
$$

where $y_{j}$ and $x_{i j}, x_{2 j}, \ldots x_{m j}$ are the $j$ th set of $n$ observations of $x$ and $y$. Equation A-2 is mathematically equivalent to solving the following system of $m$ simultaneous equations

$$
\frac{\partial \Phi}{\partial a_{i}}=0 \quad(i=1,2, \ldots m)
$$


To illustrate how this is carried out in MAC/STAT we first define the following quantities:

Means:

$\mu_{y}=E(y)=\frac{\sum_{j=1}^{n} y_{j}}{n}$
$\mu_{x_{i}}=E\left(x_{i}\right)=\frac{\sum_{j=1}^{n} x_{i, j}}{n}$

Variances:

$\sigma_{y}^{2}=E\left[\left(y-\mu_{y}\right)^{2}\right]=\frac{\sum_{j=1}^{n}\left(y_{j}-\mu_{y}\right)^{2}}{n-1}$
$\sigma_{x_{i}}^{2}=E\left[\left(x_{i}-\mu_{x_{i}}\right)^{2}\right]=\frac{\sum_{j=1}^{n}\left(x_{i, j}-\mu_{x_{i}}\right)^{2}}{n-1}$

7

Correlation Coefficients:

$$
\begin{aligned}
\rho_{y x_{i}} & =\frac{E\left[\left(y-\mu_{y}\right)\left(x_{i}-\mu_{x_{i}}\right)\right]}{\sigma_{y} \sigma_{x_{i}}} \\
\rho_{x_{i} x_{k}} & =\frac{E\left[\left(x_{i}-\mu_{x_{i}}\right)\left(x_{k}-\mu_{x_{k}}\right)\right]}{\sigma_{x_{i}}{ }^{\sigma} x_{k}}
\end{aligned}
$$

\footnotetext{
*Note that if the variable $x_{1}$ is a constant (unity, for example) then $\mu_{x_{i}}=1, \quad \sigma_{x_{i}}=0$, and $\rho_{x_{1} x_{i}}=0$.
} 
Then, substituting Equations $A-2$ into $A-3$ and using the quantities defined in Equation $\mathrm{A}-4$, the following set of $m$ linear simultaneous equations are obtained:

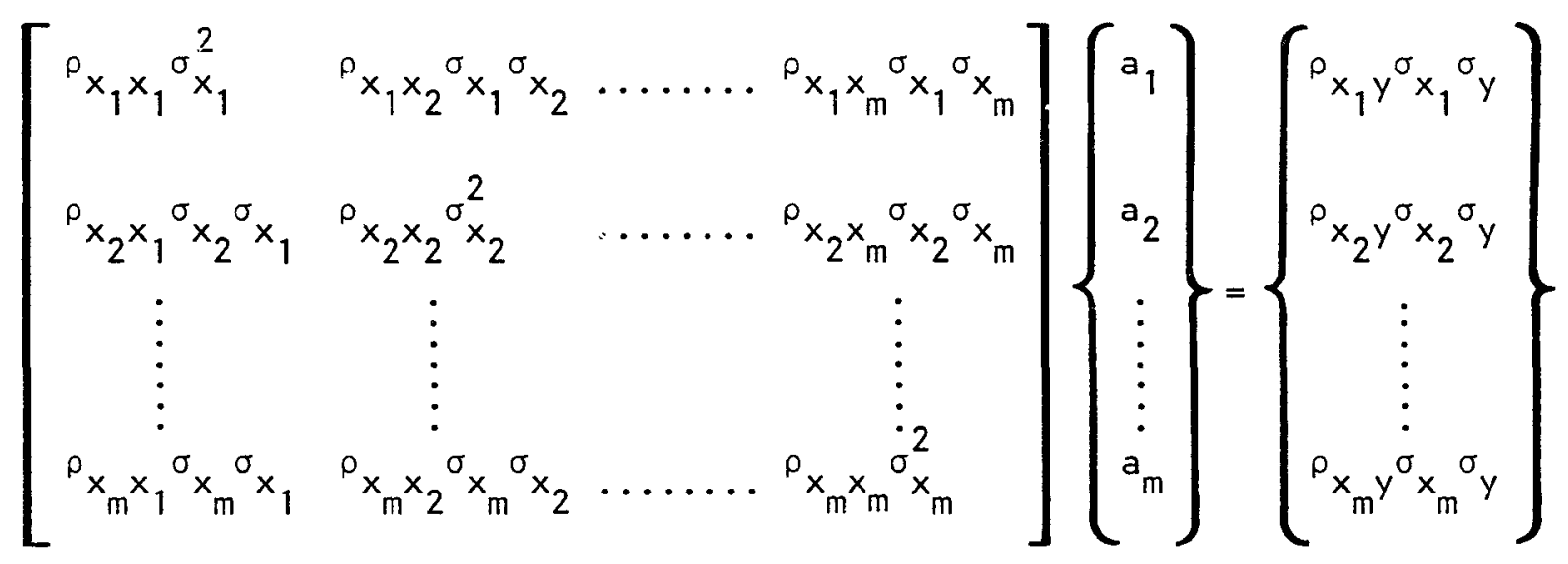

To solve for $\left\{a_{i}\right\}$, we define the quantity

$$
\beta_{i}=\frac{\sigma_{x_{i}}}{\sigma_{y}} a_{i} \quad(i=1, \ldots m)
$$

Substituting Equation A-6 into A-5, results in simultaneous equations of the form

$$
\left[\begin{array}{c}
\rho_{\beta} \\
\beta_{1} \\
\beta_{2} \\
\vdots \\
\vdots \\
\beta_{m}
\end{array}\right\}=\left\{\begin{array}{c}
\rho_{x_{1} y} \\
\rho_{x_{2} y} \\
\vdots \\
\vdots \\
\rho_{x_{m}}
\end{array}\right\}
$$


where

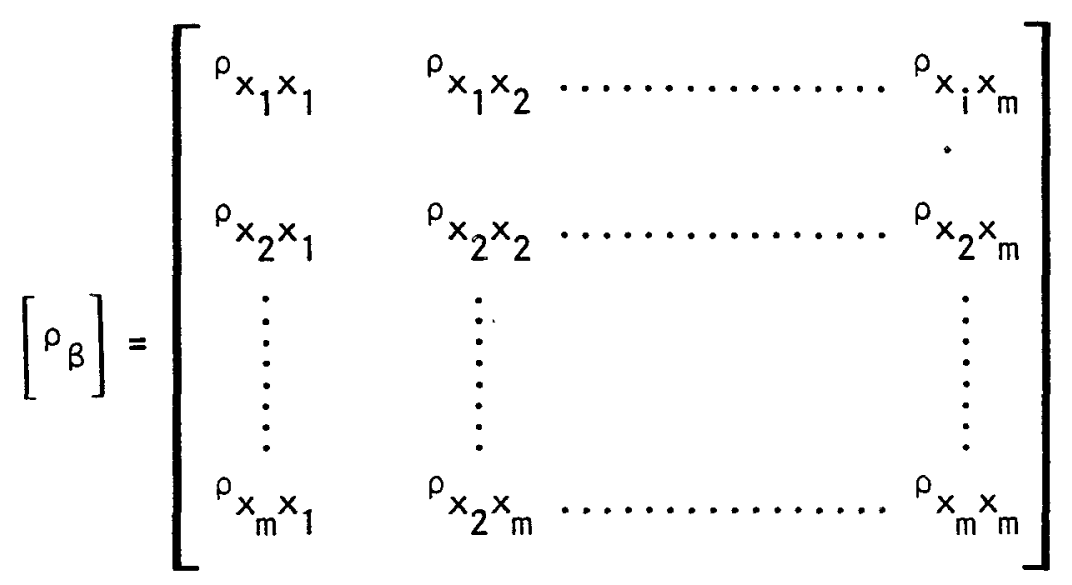

Note that $\left[\rho_{\beta}\right]$ is a symmetric matrix, since $\rho_{x_{i}} x_{j}=\rho_{x_{j} x_{i}}$. Moreover, the elements in the main diagonal are all equal to 1 , since $\rho_{x_{i}} x_{i}$ is the correlation coefficient of two identical variables. If $\operatorname{Det}[\rho \beta] \neq 0$, then Equation $A-7$ can be solved to obtain a unique solution for $\left\{\beta_{i}\right\}$, expressed

$$
\left\{\beta_{i}\right\}=\left\{\begin{array}{c}
\beta_{1} \\
\beta_{2} \\
\vdots \\
\vdots \\
\beta_{m}
\end{array}\right\}=\left[\rho_{\beta}\right]^{-1}\left\{\begin{array}{c}
\rho_{x_{1} y} \\
\rho_{x_{2} y} \\
\vdots \\
\vdots \\
\vdots \\
\rho_{x_{m} y}
\end{array}\right\}
$$

where the above matrix inversion operation is performed in MAC/STAT using a Gauss elimination technique. Once $\left\{\beta_{i}\right\}$ are determined, the regression 
coefficients $a_{i}$ are obtained from Equation $A-6$ as follows:

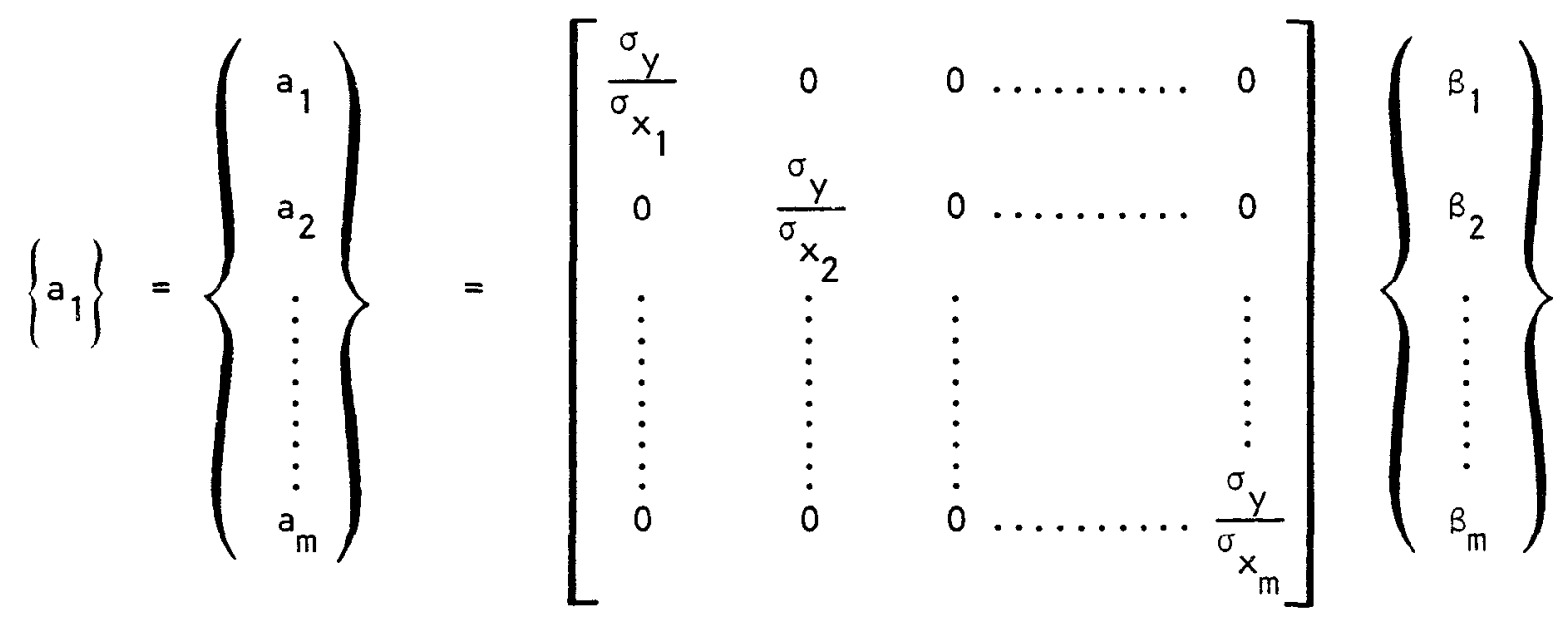

$(A-10)$

\section{A. 3 STEP-DOWN ALGORITHM}

Once the regression coefficients are computed as described in the previous section, the significance of the various terms on the right-hand side of Equation $A-1$ is then determined using a step-down regression analysis procedure. This procedure consists of the following steps.

1. Based on $m$ terms on the right side of Equation $A-1$, compute the sum of the squares of the residuals as

$$
S S D_{m}=\sum_{j=1}^{n} \varepsilon_{j}^{2}
$$

where $\varepsilon_{j}$, the residual corresponding to the $j \underline{\text { th }}$ of $n$ total observations, is

$$
\varepsilon_{j}=y_{j}-\sum_{i=1}^{m} a_{i} x_{i}
$$


2. Carry out the first step in the procedure to determine if the kth term $a_{k} x_{k}$ is statistically insignificant and can be neglected. To do this, we set $a_{k}=0$ (herein termed the null hypothesis) and use Equations A-11 and A-12 to recompute the SSD with the kth term eliminated. This new quantity is termed $S S D_{m-1, k}$ and must be greater than $S S D_{m}$, since one less term is now being used to fit the data.

3. Compute the quantity $F_{k}$ where

$$
F_{k}=\frac{\left(S S D_{m-1, k}-S S D_{m}\right)(n-m+1)}{S S D_{m-1}, k}
$$

4. Carry out an F-test to statistically evaluate $F_{k}$. In this, if the null hypothesis is valid, then $F_{k}$ is F-distributed with $1, n-m+1$ degrees of freedom, and the term $a_{k} x_{k}$ should not have a significant effect on SSD; i.e., the quantity $S_{m-1, k}$ should not be excessively larger than $S S D_{m}$. This assumption is checked statistically by seeing where the quantity $F_{k}$ falls on an F-distribution with $1, n-m+1$ degrees of freedom. If the difference between $S S D_{m-1, k}$ and $S S D_{m}$ is so large that $F_{k}$ exceeds, say, the 95 th percentile, then the $x_{k}$ term has a statistically significant effect and cannot be eliminated (i.e., we reject the null hypothesis). However, if $F_{k}$ corresponds to a smaller percentile, then the null hypothesis is conditionally accepted, and the $x_{k}$ term is considered to be statistically insignificant. ( $1 \mathrm{t}$ is noted that the 95 th percentile cutoff has been arbitrarily selected for use in this study in determining statistical significance. Somewhat higher or lower percentiles have been used in prior investigations).

\footnotetext{
"Percentiles of the F-distribution are tabulated in many statistics textbooks and manuals (e.g., Crow, Davis, and Maxfield, 1960).
} 
5. Repeat Steps 2 to 4 as follows:

a. Compute the $F_{k}$ corresponding to all terms on the right side of Equation $A-1$.

b. Examine the F-distribution percentiles for each $F_{k}$. If the smallest percentile falls below the 95 th percentile, eliminate that term as being statistically insignificant.

c. Carry out a new regression analysis with one fewer term in Equation A-1, determining a new set of regression coefficients. Repeat Steps $5 a$ and $5 b$ eliminating the one term whose $F_{k}$ corresponds to the smallest percentile, if that percentile falls below the 95 th percentile on the F-distribution.

d. Repeat this process until all remaining terms have an $F_{k}$ whose percentile exceeds the 95 th percentile.

6. Repeat Steps 1 to 5 trying cross products and higher powers of the independent variables found to be most significant upon completion of step 5 .

\section{A. 4 DATA-FIT PARAMETERS}

For each ground motion parameter studied in the course of this investigation, various parameters are given that indicate how well the regression equation fits the ensemble of data or, alternately, the degree of scatter of the data about the regression equation. The procedures for calculating these parameters are described in this section. 


\section{A.4.1 CORRELATION MATRIX}

To compute these data-fit parameters, the correlation matrix must first be defined as

$$
[p]=\left[\begin{array}{ccccc}
\rho_{y y} & \rho_{y x_{1}} & \rho_{y x_{2}} & \ldots \ldots \ldots & \rho_{y x_{m}} \\
\rho_{x_{1} y} & \rho_{x_{1} x_{1}} & \rho_{x_{1} x_{2}} & \ldots \ldots \ldots & \rho_{x_{1} x_{m}} \\
\vdots & \vdots & \vdots & & \vdots \\
\vdots & \vdots & \vdots & & \vdots \\
\vdots & \vdots & \vdots & & \vdots \\
\rho_{x_{m} y} & \rho_{x_{m} x_{1}} & \rho_{x_{m} x_{2}} & \ldots \ldots . & \rho_{x_{m}} x_{m}
\end{array}\right]
$$

where, as previously noted for $\left[p_{\beta}\right]$ (Eq. A-3), $[P]$ is symmetric and has unit diagonal elements. From $[P]$, its determinant (det $[P]$ ) can be obtained, along with the cofactor of any element $\left(\operatorname{Co}\left(\rho_{x_{i}} x_{j}\right)\right)$. By comparing $[P]$ and $\left[\rho_{\beta}\right]$ (Eq. $A-8)$, it is noted that $\operatorname{Co}\left(p_{y y}\right)$ is equal to $\operatorname{Det}\left[\rho_{\beta}\right]$.

\section{A.4.2 RESIDUAL VARIANCE AND STANDARD DEVIATION}

By substituting the regression coefficients (Eq. A-10) into Equation A-2 and taking the expectation, the residual variance is expressed as

$$
\sigma_{R}^{2}=E(\Phi)=\sigma_{y}^{2} \frac{\operatorname{Det}[P]}{\operatorname{Co}\left(\rho_{y y}\right)}=\frac{{ }_{S S D_{f}}}{n-m_{f}}
$$

where $n$ is the total number of data points, $m_{f}$ is the total number of terms on the right side of Equation $A-1$ after the regression analysis is completed, and $S S D_{m_{f}}$ is the sum of the square of the residuals corresponding to these $m_{f}$ terms (see Eq. A-11 and A-12). The square root of $\sigma_{R}^{2}$ is the standard deviation $\sigma_{R}$. 


\section{A.4.3 RESIDUAL COEFFICIENT OF VARIATION}

The residual coefficient of variation is defined as

$$
\operatorname{cov}=\frac{\sigma_{R}}{\mu_{y}}
$$

where $\mu_{y}$ is defined in Equation $\mathrm{A}-4$.

For several of the dependent variables considered in this study, the left side of Equation $A-1$ had the form

$$
y=\ln Y
$$

where $Y$ is the actual dependent variable. For this case, the coefficient of variation of $Y$ is

$$
\operatorname{cov}(Y)=\sqrt{\exp \left(\sigma_{R}^{2}(Y=\ln Y)\right)-1} \approx \sigma_{R}(y=\ln Y)
$$

where $\sigma_{R}(y=\ln Y)$ is computed directly from Equation A-15.

\section{A.4.4 MULTIPLE CORRELATION COEFFICIENT}

To define the multiple correlation coefficient, we consider the best estimate of $y$ as $y^{*}$ where

$$
y^{*}=a_{1} x_{1}+a_{2} x_{2}+\ldots+a_{m_{f}} x_{m_{f}}
$$

The multiple correlation coefficient between $y$ and $y^{*}$ can be shown to be

$$
\rho_{y y} *= \pm \sqrt{1-\frac{\operatorname{Det}[P]}{\operatorname{Co}\left(\rho_{y y}\right)}}= \pm \sqrt{1-\frac{S S D_{m_{F}}}{S S D_{1}}}
$$


where $S_{m_{f}}$ has been defined under Equation A-15 and $\mathrm{SSD}_{1}$ corresponds to the sum of the square of the residuals when only a constant term is included on the right side of Equation A-1 ( $i . e$. , only the term $a_{1} x_{1}$ where $x_{1}=1$ ). Note that

$$
0 \leq\left|\rho_{y y} *\right| \leq 1
$$

where $\rho_{y y} *= \pm 1$ corresponds to data that is perfectly correlated with the regression equation, and $\rho_{y y}{ }^{*}=0$ corresponds to perfectly uncorrelated data.

\section{A. 5 MAC/STAT SYSTEM}

\section{A.5.1 GENERAL DESCRIPTION}

MAC/STAT, a comprehensive system of digital computer programs for performing statistical computations and data analysis, was used to carry out the regression analyses for this study (USS, 1971). This system provides for easy, multilevel usage and consists of the following computational modules (Table A-1).

- UNistat Monitor

- Random Variate Generation

- Data Preparation

- Plotting and Tabulation

- Correlation

- Linear Regression

- Univariate Variance Analysis Module

- Matrix Operations

- Multivariate Statistical Analysis

- Multivariate Variance Analysis Module

The two modules used for the analyses carried out in this study are Data Preparation and Linear Regression. These are described below.

'MAC/STAT is a trademark of University Software Systems, a subsidiary of Agbabian Associates. 


\section{A.5.2 DATA PREPARATION MODULE}

The first step in the use of MAC/STAT is the determination of the independent and dependent parameters in their basic forms. Once this is done, the Data Preparation Module transforms the parameters into more appropriate forms. (For example, in this study, the peak motion $y$ was transformed into $\ln y$, the distance $R$ was transformed into $\ln (R+\Delta)$, etc.). There are 63 different types of transformations that can be performed in this module.

\section{A.5.3 LINEAR REGRESSION MODULE}

Once the data are prepared as described above, the regression analyses are carried out in this module. Basically, the regression coefficients are determined according to the procedures described in Section A.2, the stepdown algorithm is implemented as indicated in Section A.3, and the data-fit parameters are provided according to Section A.4. Several regression analyses can be performed for one basic set of independent parameters, by supplying a group of dependent parameters. This option allows calculations of different regression formulae without having to set up new input data for each dependent variable. 
TABLE A-1. MAC/STAT MODULE PROCEDURES

\begin{tabular}{|c|c|c|}
\hline $\begin{array}{l}\text { 1. Random Variable Generation } \\
\text { Uniform } \\
\text { Normal } \\
\text { Chi-Square } \\
\text { Exponential } \\
\text { Orthonormal } \\
\text { 2. Data Preparation } \\
\text { Select Variables } \\
\text { Select Observations } \\
\text { Single Transformations } \\
\text { Multiple Trnasofrmations } \\
\text { Data Screening/Replacement } \\
\text { Missing Data Replacement } \\
\text { Plotting and Tabulation } \\
\text { One-Way Tabulation } \\
\text { General Cross Tabulation } \\
\text { Cross Tabulations with } \\
\text { Stacking } \\
\text { Conditional Cross } \\
\text { Tabulation } \\
\text { Histogram and Chi-Square } \\
\text { Test } \\
\text { Two-Way Histogram } \\
\text { Sequential Printer Plot } \\
\text { Two-Way Histogram with } \\
\text { Plotting } \\
\text { Digital Sequential Plot }\end{array}$ & $\begin{array}{l}\text { 4. Correlation Analysis } \\
\text { Product Moment } \\
\text { Correlation } \\
\text { Point Biserial } \\
\text { Correlation } \\
\text { Phi Coefficient } \\
\text { Multiple Correlation } \\
\text { Partial Correlation } \\
\text { 5. Linear Regression Analysis } \\
\text { Basic Multiple Regression } \\
\text { Stepwise Multiple } \\
\text { Regression } \\
\text { Polynomial Regression } \\
\text { Periodic Regression } \\
\text { Univariate Analysis of } \\
\text { Variance } \\
\text { One-Way } \\
\text { Two-Way } \\
\text { Multiple Factor } \\
\text { One-Way Covariance } \\
\text { Two-Way Covariance } \\
\text { Multiple Factor Covariance }\end{array}$ & $\begin{array}{l}\text { 7. Matrix Operations } \\
\text { Determinant } \\
\text { Inverse } \\
\text { Eigenvalues/Eigenvectors } \\
\text { Linear Equations Solution } \\
\text { Orthogonalization } \\
\text { 8. Multivariate Statistics } \\
\text { Discriminant Analysis } \\
\text { Canonical Correlations } \\
\text { 9. Multivariate Analysis of } \\
\text { Variance } \\
\text { One-Way } \\
\text { Two-Way } \\
\text { Multiple Factor } \\
\text { One-Way Covariance } \\
\text { Two-Way Covariance } \\
\text { Multiple Factor Covariance }\end{array}$ \\
\hline
\end{tabular}




\section{APPENDIX B}

\section{USE OF THEORETICAL SOURCE MECHANISM \\ STUDIES IN DEFINING DISTANCE-ATTENUATION RELATIONSHIPS}

\section{B.1 DESCRIPTION OF APPROACH}

In the regression equations for the ground motion strength parameters and response spectral amplitudes, the attenuation with distance of these parameters is defined using a series of terms involving $\ln (R+\Delta)$, where $R$ is the epicentral distance and $\Delta$ is a constant to be determined. It is noted that the quantity $\Delta$ only affects the ground motion parameters at small values of $R$; its influence decreases rapidly as $R$ increases. Also, at the small values of $R$ where $\Delta$ has the greatest influence, there are no strong motion data on which to base the determination of $\Delta$. Therefore, the most feasible approach for defining $\Delta$ is through the use of theoretical source mechanism solutions that describe the amplitudes of ground shaking at the epicenter.

This appendix describes such an application of theoretical solutions. The particular solutions used were outlined by Trifunac (1976); these interrelate the peak ground displacement at the epicenter to the static dislocation amplitude and seismic moment, and the epicentral peak velocity and acceleration to the stress drop. The value of $\Delta$ is chosen using a trial-and-error approach in which a single value is determined that results in the peak displacement, velocity, and acceleration that best matches the results from the theoretical solutions. This value of $\Delta$ is then used to define the attenuation rate for the strength parameters and response spectral amplitudes for which regression analyses have been carried out in the course of this study.

\section{B.2 PEAK EPICENTRAL DISPLACEMENT}

Trifunac (1976) has shown that the maximum dynamic displacement at the epicenter, $d_{\max }$, can be approximately interrelated with the overall average static dislocation amplitude, $\bar{u}$, through the expression

$$
\overline{\mathrm{u}} \approx \frac{3}{2} \mathrm{~d}_{\max }
$$


This dislocation amplitude is, in turn, used to compute the seismic moment at the source through the expression

$$
M_{0}=\mu \overline{u A}
$$

where $M_{0}$ is the seismic moment, $\mu$ is the rigidity constant for the source region, $\vec{u}$ is the average dislocation amplitude, and $A$ is the area of the fault. Assuming that $A$ can be represented by a disk of radius $R$, the average dislocation can be approximated from known values of $M_{0}$ and $R$ as

$$
\bar{u}=\frac{M_{0}}{\mu \pi R^{2}}
$$

Figure $B-1$ shows results of the calculations of $\bar{u}$ vs. the local magnitude $M$ using Equation B-3 with $\mu=3 \times 10 \mathrm{in}$. dynes $/ \mathrm{cm}$. These results, as presented by Trifunac (1976), were developed by Thatcher and Hanks (1973) and by Trifunac $(1972 b, 1972 \mathrm{c})$. They are seen to exhibit considerable scatter, and there is a general tendency for $\bar{u}$ to increase with increasing magnitude.

To compare results from the present investigation and from the source mechanism solutions in Figure B-1, the following approach is used:

a. Assume $\Delta$ (several different values of $\Delta$ ranging from 25.0 to 0.25 were considered).

b. For each assumed value of $\Delta$, carry out the following:

1. Use the peak displacement regression equations from this study (see Eq. 3-4 and Table 3-1) to compute $d_{\max }$ vs. local magnitude $M$ for $R=0$, intermediate site conditions, and Type 3 earthquake events.

2. Use Equation B-1 to express the results from (1) in terms of the average dislocation, $\bar{u}$.

3. Plot the resulting relationship between $\bar{u}$ and $M$ onto Figure $B-1$. 
c. Determine which value of $\Delta$ results in a $\vec{u}$ vs. M relationship that best agrees with the theoretical results.

The resulting comparisons of the epicentral displacement results from the present study and from the theoretical source mechanism studies are shown in Figure B-1. These comparisons show that, for those magnitudes of interest for design purposes (magnitudes 25 ), the curves corresponding to $\Delta=5,1$, and 0.5 were generally closest to the theoretical displacement results.

\section{B.3 PEAK EPICENTRAL VELOCITY}

To determine the peak epicentral velocity (i.e., the peak velocity at $R=0$ ), the stress drop $\sigma$ can be used. Brune (1970) has shown that the peak particle velocity at the epicenter $V_{\text {max' }}$ the stress drop $\sigma$, the shear wave velocity $V_{s}$, and the material rigidity in the source region $\mu$, can be interrelated through the expression

$$
\sigma \approx V_{\max } \frac{\mu}{V_{s}}
$$

Trifunac (1976) presents theoretical data points by Trifunac (1972b, 1972c) and Thatcher and Hanks (1973) who used Equation B-4 to define $\sigma$ in terms of the local magnitude $M$; these are shown in Figure B-2. These data points, like those of Figure $B-1$, exhibit considerable scatter and a tendency for $\sigma$ to increase with increasing magnitude.

To superimpose results from the present investigation onto Figure B-2, a procedure similar to that described in Section B-2 is used. In this, for different values of $\Delta$, the regression analysis is first used to compute $V_{\max } v s$. $M$ for $R=0$, intermediate soil conditions, and Type 3 earthquake events $(\mathrm{Eq} \cdot 3-1)$. These values of $V_{\max }$ are then converted to stress drop, using Equation B-4; these stress drops, in turn, are plotted in Figure $8-2$. Such results, developed for $\Delta=25,5,1,0.5$, and 0.25 , show that for magnitudes exceeding 5.0, the curve for $\Delta=5$ best matches the Thatcher and Hanks results, whereas the curve for $\Delta=1$ best matches the Trifunac (1972b, 1972c) results. 


\section{B. 4 PEAK EPICENTRAL ACCELERATION}

Trifunac (1976) has shown that the peak ground acceleration at the epicenter is related to the stress drop at the source through the following expression

$$
13 \alpha \leq \frac{a_{\max }}{\sigma} \leq 33 \alpha \quad\left(\frac{\mathrm{cm}}{\mathrm{sec}^{2} / \text { bar }}\right)
$$

where $a_{\max }$ is the expected value of the epicentral peak acceleration, $\sigma$ is the stress drop, and $\alpha$ is a parameter related to the duration of strong shaking. For a Trifunac-Brady (1975b) epicentral duration of about 7 to $10 \mathrm{sec}$ (typical for reasonably strong shaking, regardless of magnitude), Trifunac (1976) shows that $\alpha$ is about 1.6. Therefore, Equation B-5 becomes

$$
20.6<\frac{a_{\max }}{\sigma}<52.3\left(\frac{\mathrm{cm}}{\mathrm{sec}^{2} / b_{b a r}}\right)
$$

or

$$
\frac{a_{\max }}{52.3} \leq \sigma \leq \frac{a_{\max }}{10.6}
$$

To assess different values of $\Delta$ for epicentral peak acceleration, the same data points as shown in Figure B-2 (interrelating $\sigma$ vs. $M$ ) are used as a basis for comparison. The development of corresponding results from the regression analyses follows a procedure similar to that described in Section B-3. In this, for each assumed value of $\Delta$ the regression equations are used to compute $a_{\max } v s$. magnitude for $R=0$, intermediate soil conditions, and Type 3 earthquake events. Then Equation B-6 is used to obtain corresponding ranges of the stress drop $\sigma$, and this value, in turn, is plotted vs. magnitude in Figure $B-3$. 
Three different stress-drop ranges are plotted vs. $M$ in Figure B-3, corresponding to $\Delta=25.0,1.0$, and 0.25 . This plot shows that the intermediate value, $\Delta=1.0$, appears to have the best correlation with the theoretical data points for moderate-to-high magnitudes ( $M \geq 5$ ).

\section{B.5 SELECTION OF $\triangle$}

From the various results presented in Figures $B-1$ to $B-3$, it is seen that values of $\Delta$ ranging from about 1.0 to 5.0 provide the best fits to the theoretical data points from the source mechanism studies. Within this range, $\Delta=1.0$ is selected for use in all regression analyses of strength parameters and response spectral amplitudes described in Chapters 3 and 5 of this report.

The approach described in this appendix, while approximate, provides the best means known at this time for selecting $\Delta$. This is particularly true in view of the fact that, as noted previously, $\Delta$ affects only the near-field ground response for which essentially no data exist. The approach should be refined in the future when near-field measurements of strong ground shaking are obtained. 


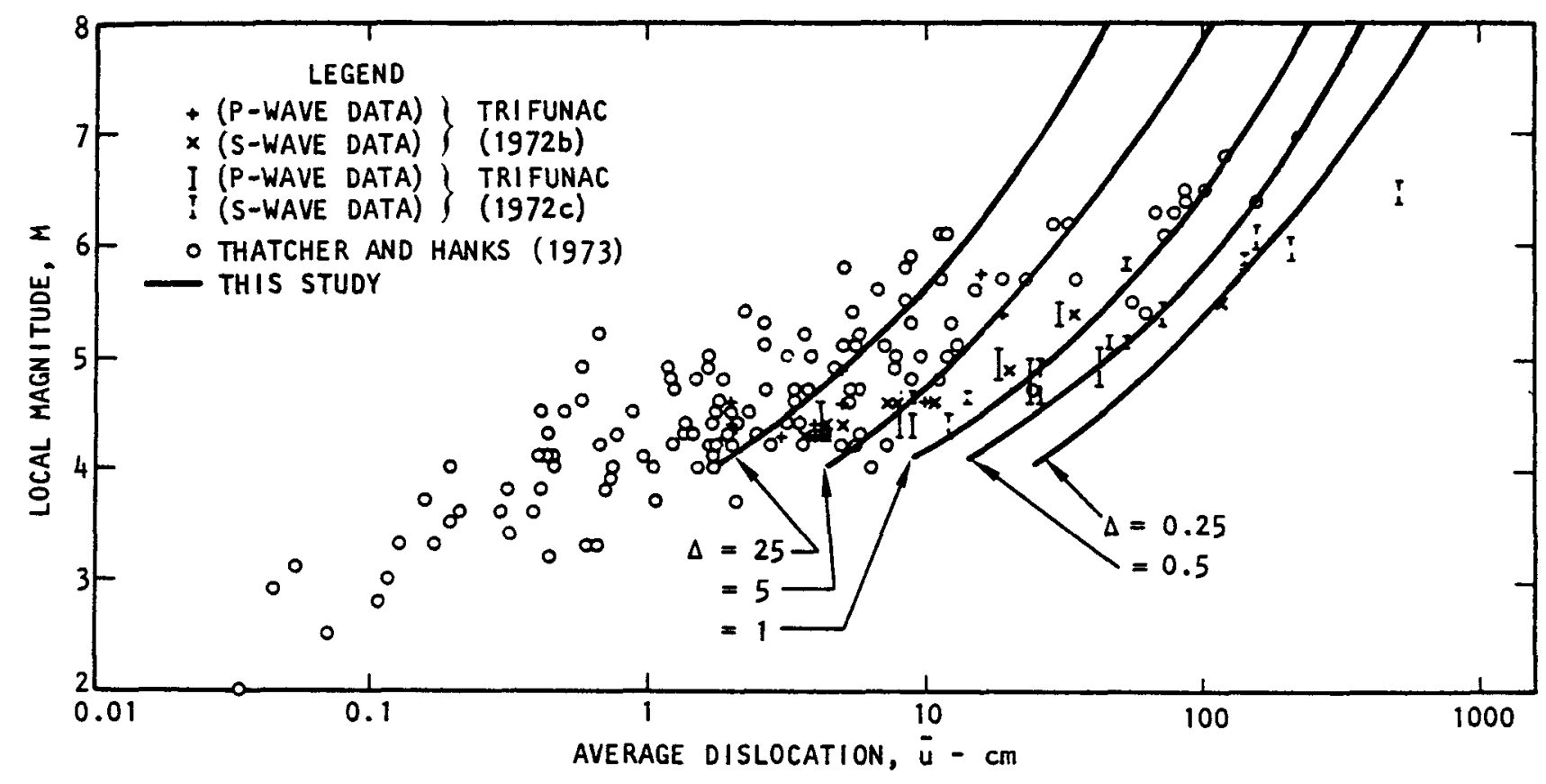

FIGURE B-1. COMPARISON OF AVERAGE DISLOCATION FROM COMPUTED PEAK DISPLACEMENTS WITH THEORETICAL RESULTS FROM SOURCE MECHANISM STUDIES (Modified from Trifunac, 1976) 


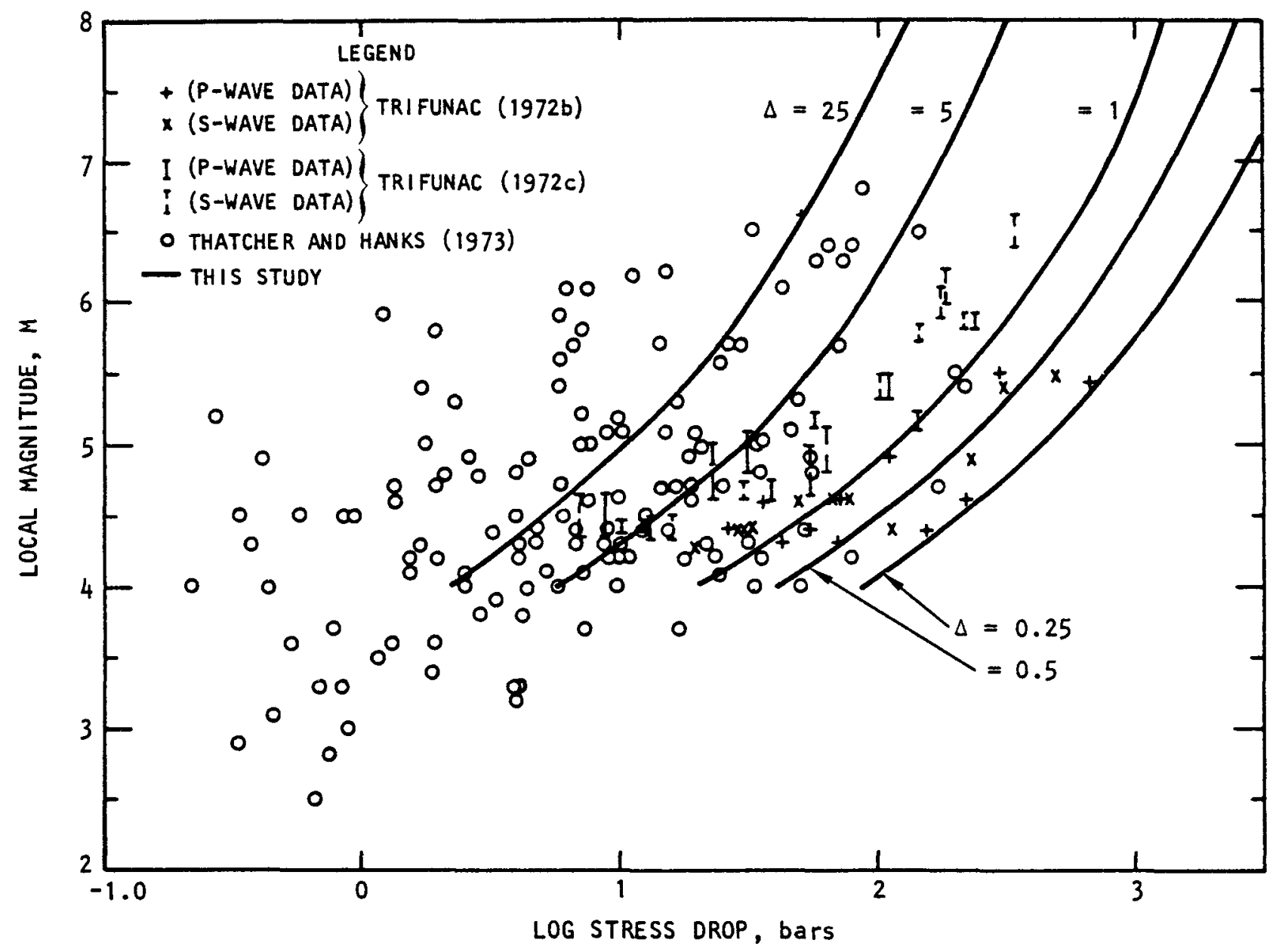

FIGURE B-2. COMPARISON OF STRESS DROPS FROM COMPUTED PEAK VELOCITIES WITH THEORETICAL RESULTS FROM SOURCE MECHANISM STUDIES (Modified from Trifunac, 1976) 


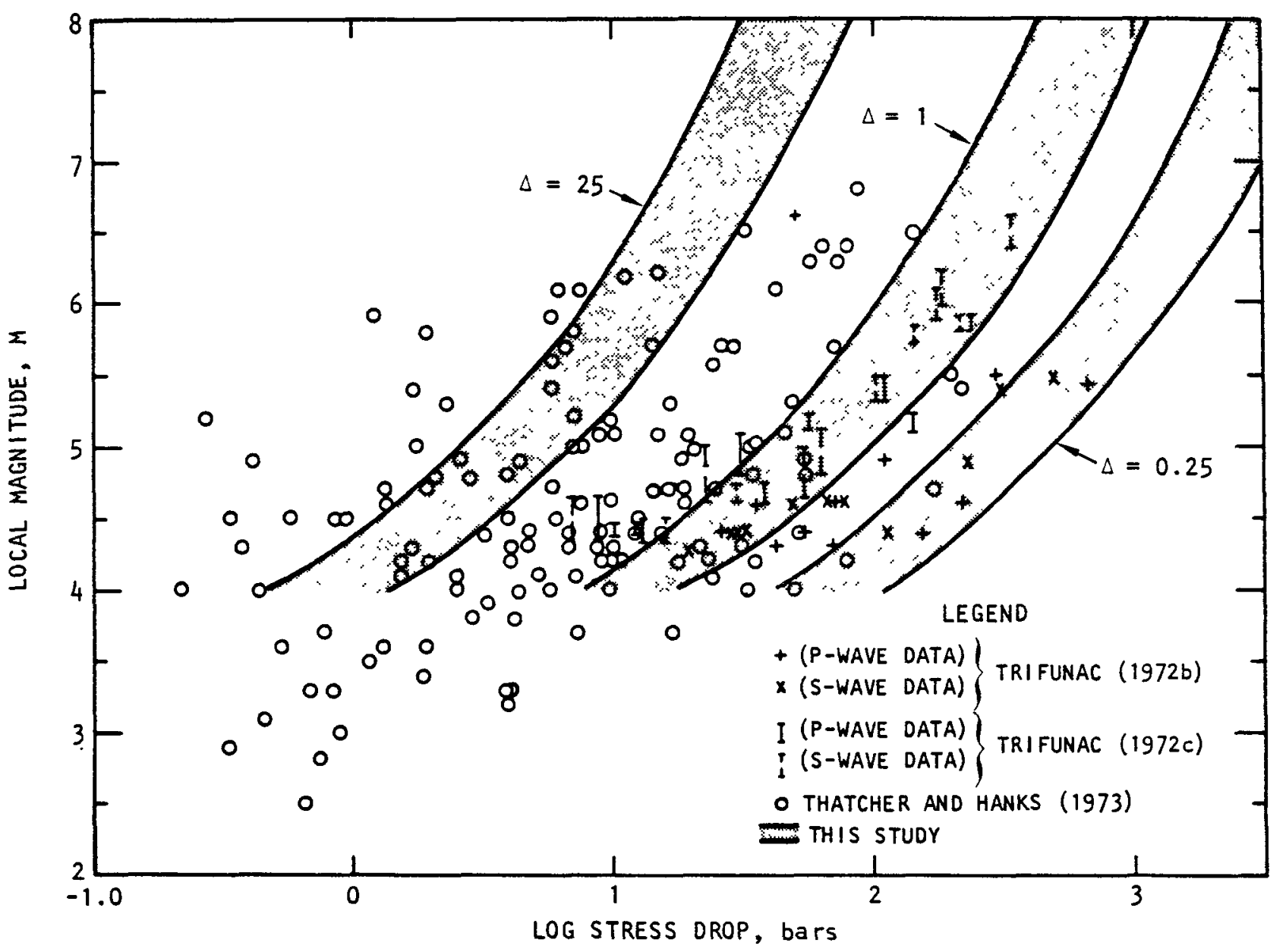

FIGURE B-3. COMPARISON OF STRESS DROPS FROM COMPUTED PEAK ACCELERATIONS WITH THEORETICAL RESULTS FROM SOURCE MECHANISM STUDIES (Modified from Trifunac, 1976) 


\section{NRC FOAM 335 \\ (7-77) \\ U.S. NUCLEAR REGULATORY COMMISSION \\ BIBLIOGRAPHIC DATA SHEET}

4. TITLE AND SUBTITLE (AddVolume No., if appropriate)

Statistical Analys is of Earthquake Ground Motion Parameters

7. AUTHOR(S)

Shannon \& Wilson, Inc. and Agbabian Associates

9. PERFORMING ORGANIZATION NAME AND MAILING ADDRESS (Include $Z$ ip Code)

Shannon \& Wilson, Inc. and Agbabian Associates

1105 North 38th Street

Seattle, Washington 98103

12. SPONSORING ORGANIZATION NAME AND MAILING ADDRESS (Include $Z$ ip Code)

Site Safety Research Branch

Office of Nuclear Regulatory Research

U.S. Nuclear Regulatory Commission

Washington, D.C. 20555

13. TYPE OF REPORT

Technical report

PERIOD COVERED (/nclusive dates)

15. SUPPLEMENTARY NOTES

14. (Leave b/ank)

16. ABSTRACT (200 words or less)

Several earthquake ground response parameters that define the strength, duration, and frequency content of the motions are investigated using regression analyses techniques; these techniques incorporate statistical significance testing to establish the terms in the regression equations. The parameters investigated are the peak acceleration, velocity, and displacement; Arias intensity; spectrum intensity; bracketed duration; Trifunac-Brady duration; and response spectral amplitudes. The study provides insight into how these parameters are affected by magnitude, epicentral distance, local site conditions, direction of motion (i.e., whether horizontal or vertical), and earthquake event type. The results are presented in a form so as to facilitate their use in the development of seismic input criteria for nuclear plants and other major structures. They are also compared with results from prior investigations that have been used in the past in the criteria development for such facilities.

\begin{tabular}{|l|l|}
\hline 19. SE GURLTYCLASS (Th's report) & 21. NO. OF PAGES \\
\hline 20. SECURITY CLASS (This page) & $\begin{array}{c}22 \text { PRICE } \\
\text { S }\end{array}$ \\
\hline
\end{tabular}

